Title:

\title{
The molecular structure of plant sporopollenin
}

Authors:

Fu-Shuang $\mathrm{Li}^{1}$, Pyae Phyo ${ }^{2}$, Joseph Jacobowitz ${ }^{1,3}$, Mei Hong ${ }^{2}$, Jing-Ke Weng ${ }^{1,3 *}$

${ }^{1}$ Whitehead Institute for Biomedical Research, Cambridge, Massachusetts 02142, United States.

${ }^{2}$ Department of Chemistry, Massachusetts Institute of Technology, Cambridge, Massachusetts 02139, United States.

${ }^{3}$ Department of Biology, Massachusetts Institute of Technology, Cambridge, Massachusetts 02139, United States.

${ }^{*}$ Corresponding Author:

Jing-Ke Weng, Whitehead Institute for Biomedical Research, 455 Main Street, Cambridge, MA, 02142, USA

Email: wengi@wi.mit.edu, Tel.: +1 6173244921 
Sporopollenin is a ubiquitous and extremely chemically inert biopolymer that constitutes the outer wall of all land-plant spores and pollen grains. Sporopollenin protects the vulnerable plant gametes against a wide range of environmental assaults, and is considered as a prerequisite for the migration of early plants onto land. Despite its importance, the chemical structure of plant sporopollenin has remained elusive. Using a newly developed thioacidolysis degradative method together with state-of-the-art solid-state NMR techniques, we determined the detailed molecular structure of pine sporopollenin. We show that pine sporopollenin is primarily composed of aliphatic-polyketide-derived polyvinyl alcohol units and 7-O-p-coumaroylated C16 aliphatic units, crosslinked through a distinctive m-dioxane moiety featuring an acetal. Naringenin was also identified as a minor component of pine sporopollenin. This discovery answers the long-standing question about the chemical makeup of plant sporopollenin, laying the foundation for future investigations of sporopollenin biosynthesis and for design of new biomimetic polymers with desirable inert properties.

Early land plants arose approximately 450 million years ago. To cope with a multitude of abiotic and biotic stresses associated with the terrestrial environments, plants evolved the ability to synthesize numerous specialized biopolymers, including lignin, condensed tannin, cutin, suberin, natural rubber, and sporopollenin. Each of these biopolymers possesses a unique set of physicochemical properties pertinent to their biological functions ${ }^{1}$. Whereas the chemical structures of most plant biopolymers have been elucidated, sporopollenin stands as one of the last and least-understood biopolymers regarding its structural composition ${ }^{2}$. While enabling plant spores and 
pollen to travel long distances and survive hostile conditions, the extreme chemical inertness of sporopollenin has presented a major technical challenge to its full structure elucidation.

Using relatively harsh chemical degradation methods and whole-polymer spectroscopic methods, previous studies have suggested that sporopollenin contains hydroxylated aliphatic and aromatic units (Supplementary Note 1). Extensive genetic studies of plant mutants defective in pollen exine formation have also identified a series of metabolic enzymes that are highly conserved among land plants and apparently involved in sporopollenin biosynthesis ${ }^{2}$. Many of these enzymes exhibit in vitro biochemical specificities that suggest their functions in fatty acid and polyketide metabolism ${ }^{2}$. However, the exact monomer composition and inter-monomer linkages of sporopollenin are unknown. Consequently, the precise sporopollenin biosynthetic pathway has not been established, even though many of the participating enzymes have been identified.

In this study, we interrogated sporopollenin polymer structure by exploring new chemical and biophysical methodologies. Unlike most of the other plant biopolymers, sporopollenin is challenging to obtain in large quantities from model plants that are commonly used for lab research. We therefore chose to study sporopollenin of the pitch pine Pinus rigida, from which kilogram quantities of pollen can be collected for analysis (Fig. 1A). Inspired by the recent adoption of high-energy ball milling to increase lignin solubility in organic solvents ${ }^{3}$, we incorporated ball milling in an improved protocol ${ }^{4}$ for preparing pine sporopollenin (Figs. 1A, B). Ball milling of whole pollen grains produced a fine powder, which was hydrolyzed enzymatically by cellulase cocktails, and washed 
excessively with a series of solvents with increasing polarity. The remaining insoluble residue was lyophilized to yield the total pine sporopollenin.

Structure elucidation of polymers benefits from the development of suitable enzymatic and chemical degradation methods that can provide information about polymer fragments, from which the whole molecular structure can be deduced. To establish a degradative method for sporopollenin, we surveyed a variety of chemical reagents known to depolymerize other biopolymers (Supplementary Note 2). From this survey, several thioacidolysis reagents ${ }^{5}$, namely benzyl mercaptan, $\mathrm{n}$-dodecyl mercaptan and ethyl mercaptan, were found to partially degrade pine sporopollenin under acidic conditions and to yield a number of small-molecular-weight compounds readily detectable by high-performance liquid chromatography coupled in tandem with UV detector and mass spectrometer (HPLC-UV-MS) (Supplementary Figs. 5, 40, 41). We further optimized an ethyl-mercaptan-based thioacidolysis protocol, and observed that $55 \pm 3 \%(\mathrm{w} / \mathrm{w})$ of the starting pine sporopollenin can be degraded under this condition. HPLC-UV-MS analysis of the soluble fraction of the reaction products gave three major and several minor UV-detectable degradation products (Figs. 1B, C and Supplementary Fig. 6). These compounds were purified chromatographically, and their structures were determined by a combination of $M S / M S$ and ${ }^{1} \mathrm{H},{ }^{13} \mathrm{C}, \mathrm{HSQC}, \mathrm{HMBC}$ NMR analyses (Fig. 1D and Supplementary Figs. 11, 12, 20-23).

Compound I is the most abundant thioacidolysis product from the soluble fraction, and features a p-coumaroylated $7-\mathrm{OH}-\mathrm{C} 16$ aliphatic core flanked by two diethylsulfanyl groups on both ends (Fig. 1D). Compounds $\mathbf{I I}_{\mathbf{a}}$ and $\mathbf{I}_{\mathbf{b}}$ are chromatographically inseparable and were therefore co-purified as one fraction. Upon 
detailed NMR analysis of the mixture (Supplementary Fig. 12), $\boldsymbol{I}_{\mathbf{a}}$ and $\mathbf{I}_{\mathbf{b}}$ were identified to be related to I, with either the 1- or 16-diethylsulfanyl group of I substituted by a free hydroxy group (Fig. 1D). We also identified p-coumaric acid (III) and naringenin (VI) as minor thioacidolysis products, suggesting that they exist as covalently linked structural units in pine sporopollenin, although III could be solely derived from I and $\mathbf{I I}_{(\mathbf{a}+\mathbf{b})}$ through extensive acid hydrolysis (Figs. 1C, D and Supplementary Fig. 20). Compounds IV and V are additional minor products, which were verified to be derived from III and I respectively through nucleophilic addition of an ethylsulfanyl group to the $p$-coumaroyl olefin during the thioacidolysis reaction (Figs. 1C, D and Supplementary Figs. 21, 22). Based on peak area integration of the HPLC-UV chromatogram, the molar ratio of I to $\mathrm{II}_{(\mathrm{a}+\mathrm{b})}$ is estimated to be approximately 6 7:1 (Supplementary Fig. 6).

To probe the origin of various free hydroxy groups observed in I and $\mathbf{I I}_{(\mathbf{a}+\mathbf{b})}$ prior to thioacidolysis, we prepared methylated and acetylated total pine sporopollenin samples, respectively, to methylate or acetylate any free hydroxy and carboxy groups that may be present in the sporopollenin polymer. Subsequent thioacidolysis experiments starting with methylated or acetylated sporopollenin produced the corresponding methylated or acetylated $\mathbf{I}$ and $\mathbf{I}_{(\mathbf{a}+\mathbf{b})}$ respectively (Fig. 2A and Supplementary Figs. 1, 2, 7, 8, 13-19), suggesting that the $p-\mathrm{OH}$ group of the $p$-coumaroyl moiety of $\mathbf{I}$ and $\mathrm{II}_{(\mathbf{a}+\mathbf{b})}$ and the $\omega$-OH group of $\mathrm{II}_{(\mathbf{a}+\mathbf{b})}$ exist as free hydroxy groups not engaged in inter-unit coupling in sporopollenin polymer.

The $p$-coumaroyl moiety of $\mathbf{I}$ and $\mathbf{I}_{(\mathrm{a}+\mathrm{b})}$ is linked to the $\mathrm{C} 16$ aliphatic core through a chiral carbon at the $\mathrm{C}_{7}$ position. Chiral HPLC analysis of I suggests a predominant enantiomeric configuration (>97\%) (Supplementary Fig. 33). However, the very similar 
alkyl neighborhoods flanking each side of this chiral center makes it difficult to determine the absolute configuration of this chiral center using the conventional Mosher's method ${ }^{6,7}$. Moreover, circular dichroism (CD) measurement of I gave only baseline spectrum (Supplementary Fig. 42), while the oily nature of I also precludes structural elucidation by conventional X-ray crystallography. We therefore turned to a pair of recently reported chiral labeling reagents, $(1 R, 2 R)-(-)-2-(2,3-$ anthracenedicarboximide) cyclohexane carboxylic acid and (1S,2S)-(+)-2-(2,3anthracenedicarboximide) cyclohexane carboxylic acid ${ }^{8,9}$, and used them as modified Mosher's reagents capable of engaging in long-distance spatial interactions. By reacting $I_{a}$ (de-esterified I, Supplementary Figs. S34 and S35) with these two chiral labeling reagents, we generated two corresponding diastereomers ( $\mathbf{l}_{\mathrm{a}}-\boldsymbol{R} \boldsymbol{R}$ and $\left.\mathbf{I}_{\mathrm{a}}-\mathbf{S S}\right)$ (Supplementary Figs. 32, 36, 37). Comparison of their ${ }^{1} \mathrm{H}-\mathrm{NMR}$ spectra led us to unequivocally assign the absolute configuration of $C_{7}$ to be $S$ (Supplementary Fig. 38).

Thioacidolysis of $\beta-O-4-$ linked lignin using ethyl mercaptan results in monoethylsulfanyl substitutions at $\alpha, \beta$ and $\gamma$ positions of the cleaved monolignols via a well-characterized ether-cleavage mechanism ${ }^{5}$ (Supplementary Fig. 43). However, the diethylsulfanyl moiety observed at either or both ends of the main sporopollenin thioacidolysis products indicates a different linkage prior to cleavage. Previous studies of thioacidolysis chemistry using a panel of model compounds showed that reacting aldehyde or acetal with ethyl mercaptan gives diethylsulfanyl derivatives ${ }^{5}$. We then tested whether the diethylsulfanyl moiety of the sporopollenin thioacidolysis products could be derived from aldehyde and/or acetal functional groups present in sporopollenin polymer. We first performed sporopollenin pretreatment with sodium borohydride 
$\left(\mathrm{NaBH}_{4}\right)$, a reagent that reduces aldehydes to the corresponding alcohols and therefore renders them non-reactive to ethyl mercaptan. However, subsequent thioacidolysis was not impacted by $\mathrm{NaBH}_{4}$ pretreatment (Fig. 2A), suggesting that the diethylsulfanyl moiety is unlikely derived from free aldehyde. We then employed a newly reported reagent, TMDS/Cu(OTf)2, which was shown to selectively cleave acetals to yield the corresponding ethers ${ }^{10,11}$ (Supplementary Fig. 44). Interestingly, sporopollenin pretreated with $\mathrm{TMDS} / \mathrm{Cu}(\mathrm{OTf})_{2}$ becomes completely inert to ethyl mercaptan degradation (Fig. 2A), consistent with the hypothesis that sporopollenin contains prevalent thioacidolysis-liable acetals, which are converted to ethers by TMDS/Cu(OTf $)_{2}$ pretreatment. To further validate this hypothesis, we conducted thioacidolysis experiments on two acetal-containing model compounds, 1,1-dimethoxydodecane (XIII) and polyvinyl butyral (PVB). Both experiments produced degradation products featuring diethylsulfanyl moieties exactly as predicted, reminiscent of those derived from sporopollenin thioacidolysis (Supplementary Figs. 4, 30, 31).

Thioacidolysis of pine sporopollenin consistently yields a residue (R), accounting for $45 \pm 3 \%(w / w)$ of the starting sporopollenin material. Like sporopollenin, $\mathbf{R}$ is recalcitrant to chemical modification, degradation, and dissolution by a wide variety of reagents (Supplementary Note 3 ). Nonetheless, refluxing $\mathbf{R}$ with acetic anhydride over 72 hours yielded acetylated $\mathbf{R}$ (R-Ac), which could be dissolved in DMSO at appreciable concentration. We surmise that thioacidolysis cleavage of sporopollenin yields free hydroxy groups in $\mathbf{R}$, which are acylated by acetic anhydride to produce $\mathbf{R}$-Ac with higher solubility in DMSO than $\mathbf{R}$, allowing a set of ${ }^{1} \mathrm{H}, \mathrm{HSQC}$ and HMBC spectra to be recorded and analyzed (Supplementary Fig. 39). R-Ac resembles polyvinyl acetate 
(PVAc), and is composed of polyhydroxylated aliphatic units interlinked through ester bonds, although the exact length of each individual polyhydroxylated aliphatic unit of $\mathbf{R}$ could not be determined due to its non-degradable nature.

Magic-angle-spinning (MAS) solid-state NMR (SSNMR) spectroscopy is well suited to the structure determination of insoluble biopolymers such as plant cell walls ${ }^{12-}$ ${ }^{15}$, sporopollenin ${ }^{16}$, and other biomaterials ${ }^{17,18}$. We measured the ${ }^{13} \mathrm{C}$ NMR spectra of pine sporopollenin using the multi-cross-polarization $(C P)$ experiment ${ }^{19}$, which not only enhances the sensitivity of ${ }^{13} \mathrm{C}$ in natural abundance $(1.1 \%)$ but also gives quantitative intensities that reflect the relative number of different types of carbons (Supplementary Fig. 45 and Table S1). At a high magnetic field of 18.8 Tesla, where spectral resolution is optimal, pine sporopollenin exhibits a $103-p p m{ }^{13} \mathrm{C}$ signal indicative of acetal carbons (Fig. 3A) and no intensities in the 200-210-ppm range that is expected for aldehydes, supporting the hypothesis that $\mathbf{I}$ and $\mathbf{I}_{(\mathbf{a}+\mathbf{b})}$ are derived from thioacidolysis cleavage of acetal linkages but not aldehydes. SSNMR spectrum of $\mathbf{R}$ (Supplementary Fig. 46) shows that thioacidolysis suppresses the $103-p p m$ acetal ${ }^{13} \mathrm{C}$ peak, further supporting acetal as the major thioacidolysis-labile linkage in sporopollenin. Consistently, $\mathrm{NaBH}_{4}$ treatment has no impact on the SSNMR spectrum, while TMDS/Cu(OTf) 2 treatment greatly reduces the 103-ppm peak intensity, confirming acetal as a major inter-unit linkage in pine sporopollenin.

Since carbonyl and aromatic carbons have large chemical shift anisotropies, which spread their intensities over multiple sidebands at high magnetic fields, we measured the ${ }^{13} \mathrm{C}$ spectrum of the untreated pine sporopollenin at 9.4 Tesla and $13-\mathrm{kHz}$ MAS to obtain more quantitative intensities for these carbons. The spectrum (Fig. 3B) 
shows two carboxyl signals at 173 and 168 ppm, six p-coumaric acid peaks between 160 and 110 ppm (Table S2), a 103-ppm acetal peak, a strong 74-ppm peak of oxygenbearing carbons, and three strong aliphatic peaks between 44 and 30 ppm, respectively. The carboxyl signals can be assigned to ester linkages in the major

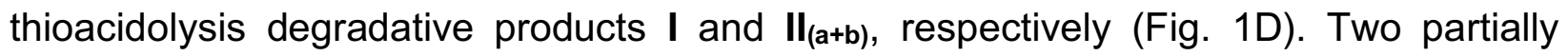
resolved signals at 87 and 96 ppm are assigned to $\alpha$-pyrone, which have been reported to be products of the conserved type III polyketide synthases involved in sporopollenin biosynthesis (e.g. LAP5 and LAP6 in Arabidopsis) ${ }^{20,21}$. To determine whether the 103ppm, 87-ppm and 60-75 ppm ${ }^{13} \mathrm{C}$ peaks result from polysaccharides, we conducted a modified phenol-sulfuric acid reaction ${ }^{22}$ and found no polysaccharide degradative products released (Supplementary Fig. 10). To verify the ${ }^{13} \mathrm{C}$ peak assignment, we conducted additional spectral-editing experiments that selectively detect methyl and quaternary ${ }^{13} \mathrm{C}$ signals ${ }^{23}$ or $\mathrm{CH}_{2}$ signals (Supplementary Fig. 47) ${ }^{24}$. The former confirmed the assignment of the 173-ppm, 168-ppm, 160-ppm, and 126-ppm signals to quaternary carbons in $p$-coumaric acid and $\alpha$-pyrone, while the latter showed that a significant fraction of the $75-26$ ppm intensities and the 44-36 ppm intensites are from $\mathrm{CH}_{2}$ groups. We deconvoluted the whole pine sporopollenin spectrum to determine the relative number of carbons for the different functional groups. Assuming the resolved 160-ppm peak to represent two carbons from two p-coumaric acids, we obtained 98 carbons per repeat unit, among which 18 carbons result from the two $p$-coumaric acid moieties, 5 are acetal carbons, 5 are ester and pyrone carbons, 26 are oxygen-bearing carbons, and 42 are aliphatic carbons (Tables S2 and S3). The remaining carbons for the 153-ppm and 53-ppm chemical shifts are unassigned. 
To probe the structure of residue $\mathbf{R}$ after thioacidolysis, we measured the quantitative ${ }^{13} \mathrm{C}$ multi-CP SSNMR spectrum of $\mathbf{R}$ (Supplementary Fig. 46). The spectrum shows much reduced $p$-coumaroyl ${ }^{13} \mathrm{C}$ intensities and the appearance of a new 131-ppm peak attributable to alkenes. Below 80 ppm, the spectrum contains three dominant peaks at 70,40 , and $30 \mathrm{ppm}$. This pattern resembles the polyvinyl alcohol (PVA) spectrum, which also exhibits dominant signals at 70 and 40 ppm. The 30-ppm peak and the 103-ppm acetal peak suggest that half of the acetal-linked C16 backbones (i and $\mathbf{i i )}$ are retained in $\mathbf{R}$ but without the $p$-coumaroyl sidechain. The presence of the 88-ppm, 99-ppm, and 160-175 ppm peaks indicate that the a-pyrone moiety also remains after thioacidolysis. The two methyl carbons may result from the substitution of glycerol-like moieties by two diethylsulfanyl groups. The deconvoluted spectrum of $\mathbf{R}$ indicates 71 carbons per repeat unit (Tables S4 and S5), among which 35 are aliphatic, 19 are oxygen-bearing, 6 are ester and pyrone carbons, 4 are olefinic, and 2 are acetals. The remaining five carbons were not assigned (Tables S4).

These degradation product analyses and quantitative ${ }^{13} \mathrm{C}$ SSNMR spectra (Supplementary Fig. 48) indicate an average pine sporopollenin structure that consists of two fatty acid-derived PVA-like units (r), each flanked at two ends by an $a$-pyrone moiety and an ester group (Fig. 3C and 4). The two PVA-like units are crosslinked by a series of $7-0-p$-coumaroylated $\mathrm{C} 16$ aliphatic units (i/ii) through a distinctive $m$-dioxane moiety featuring an acetal. A fraction $(\sim 15 \%)$ of these $\mathrm{C} 16$ aliphatic units (ii $\mathbf{a} / \mathbf{b})$ are crosslinked only on one end, with the other end existing as free hydroxy group (Supplementary Fig. 6). The PVA-like units are likely linked through ether bonds with glycerol-like moieties (G), and small amount of naringenin (vi). The average structure is 
depicted with an approximate two-fold symmetry and a total of 200 carbons (Fig. 4), but the true structure of natural sporopollenin polymer is likely heterogeneous and involves higher-dimensional inter-unit crosslinking.

Our study indicates that pine sporopollenin is crosslinked through two major types of linkages: ester and acetal. Whereas ester is relatively stable under the acidic condition, acetal can withstand strong alkaline condition ${ }^{25}$. The involvement of both linkages likely accounts for the superior chemical inertness of sporopollenin relative to other plant biopolymers that are crosslinked predominantly via only one type of linkages, e.g. cutin (ester-linked), lignin (ether-linked), cellulose (glycosidic bond-linked) and synthetic polymers such as PVB (acetal-linked). The interweaving hydrophobic and hydrophilic elements stemming from various monomer units also contribute to the poor solubility of sporopollenin in most solvents. From an evolutionary perspective, the identification of $p$-coumaroyl and naringenin moieties as integral components of sporopollenin not only explains sporopollenin's essential function of protecting gametes against damaging UV light, but also suggests that phenylpropanoid and flavonoid metabolism might have first emerged as part of the evolutionary development towards constructing sporopollenin in early land plants ${ }^{26}$. In addition, the monomer composition and linkage heterogeneity in sporopollenin may render it resistant to enzymatic degradation by microbes and animals, which consequently contributed to the massive accumulation of plant spores from lycophytes during the Carboniferous period and the formation of maceral sporinite as a major component of many coals ${ }^{27}$.

Determining the chemical structure of sporopollenin paves the way towards understanding plant sporopollenin biosynthesis. For example, the identification of 
structural motifs $\mathbf{i}$ and ii corroborates that CYP703A2 and CYP704B1, two P450s required for pollen exine formation in Arabidopsis and possessing in vitro fatty acid inchain and $\omega$-hydroxylase activities respectively ${ }^{28,29}$, are involved in installing key hydroxyl groups on C16 fatty acid precursors of i and ii. In particular, the chiral-specific configuration of the 7-substituted C16 aliphatic units further suggests that the in-chain hydroxylation reaction catalyzed by CYP703A2 likely occurs on a bent C16 substrate with disparate functional groups at each end, presenting only one predominant conformation when entering the CYP703A2 active site. Moreover, the ester-linked $p$ coumaroyl moiety predicts the involvement of an hydroxycinnamoyl transferase yet to be identified. On the other hand, the PVA-like units (r) are most likely extended from fatty acid precursors through a type III polyketide biosynthetic mechanism unique to plants $^{30}$. A number of sporopollenin biosynthetic enzymes, including an acyl-CoA ligase, ACOS5 ${ }^{31}$, type III polyketide synthases LAP5 and LAP6 ${ }^{20}$, and two NAD(P)Hdependent reductases, DRL1 and DRL2 ${ }^{21}$, previously identified through genetic studies, likely catalyze sequential steps to produce PVA-like monomers of r. From an application perspective, knowledge gained from this study on the detailed structure and the biosynthetic logic of sporopollenin natural polymer will also inspire new biomimetic polymer design. 


\section{Acknowledgement}

This work was supported by the Pew Scholar Program in the Biomedical Sciences (J.K.W.) and the Searle Scholars Program (J.K.W.). The solid-state NMR part of this work (by P.P. and M.H.) was supported by the Center for Lignocellulose Structure and Formation, an Energy Frontier Research Center funded by the U.S. Department of Energy, Office of Science, Basic Energy Sciences under Award \# DE-SC0001090.

\section{Author Contributions}

F.S.L. and J.K.W. designed the research. F.S.L. developed thioacidolysis and pretreatment methods for studying sporopollenin, and carried out structural elucidation of all degradative products. P.P. performed SSNMR experiments. J.J. performed EM imaging. F.S.L, P.P., M.H. and J.K.W. interpreted the results and wrote the paper. 


\section{Figures}

A

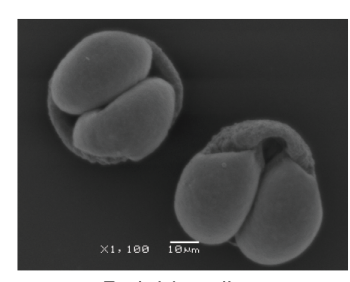

$P$. rigida pollen

C

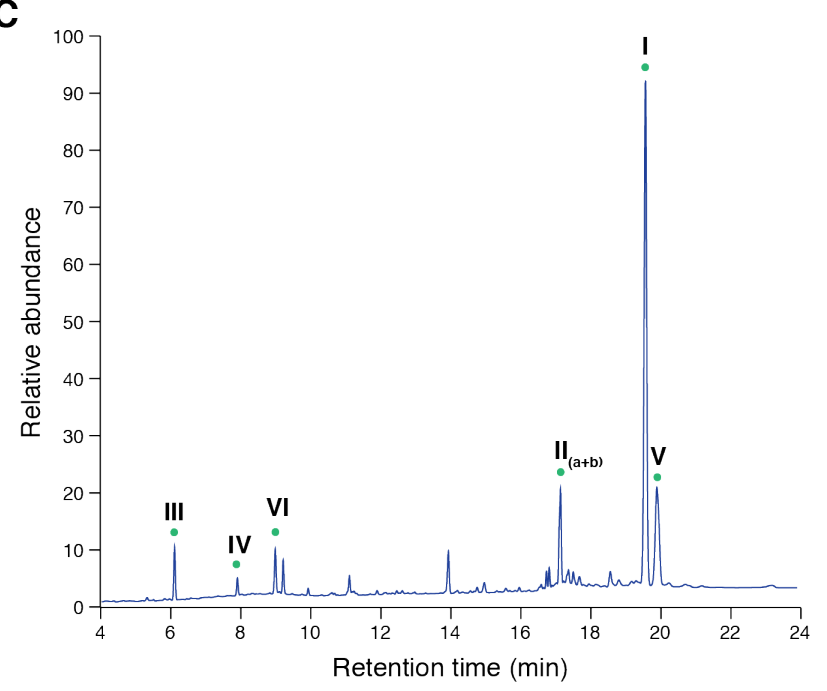

B

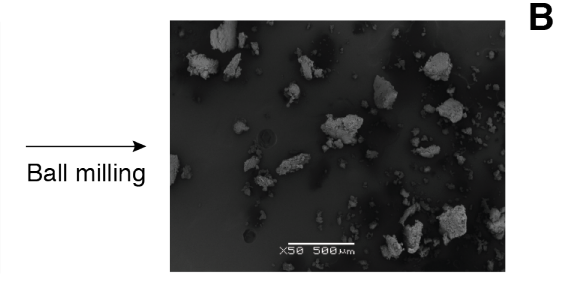

P. rigida pollen
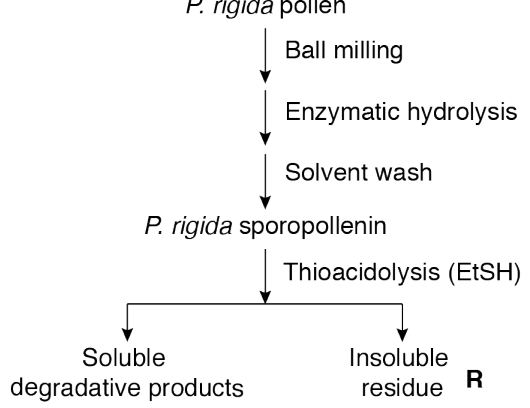

D
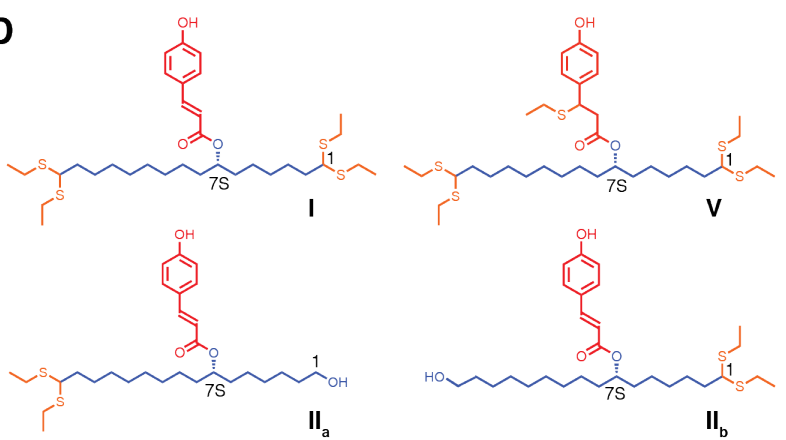

$\mathrm{II}_{\mathrm{a}}$

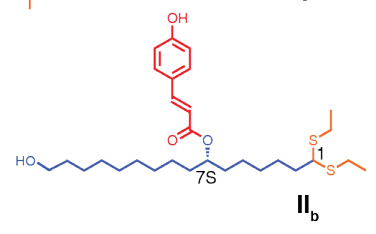

IIII
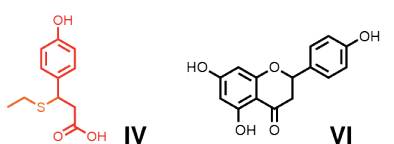

Fig. 1. Pine sporopollenin preparation and degradative analysis by thioacidolysis.

A, Electron micrographs of $P$. rigida pollen grains and the fine powder derived from them after ball milling. B, The optimized protocol for pine sporopollenin preparation and thioacidolysis degradation using ethyl mercaptan (EtSH). C, Thioacidolysis of pine sporopollenin gave three major $\left(\mathbf{I}, \mathbf{I I}_{\mathbf{a}}, \mathbf{I I}_{\mathbf{b}}\right)$ and several minor (III-VI) UV-detectable degradative products under HPLC-UV-MS analysis. D, Structural elucidation of the major thioacidolysis products of pine sporopollenin. The Roman numerals correspond to HPLC peaks as shown in C. 

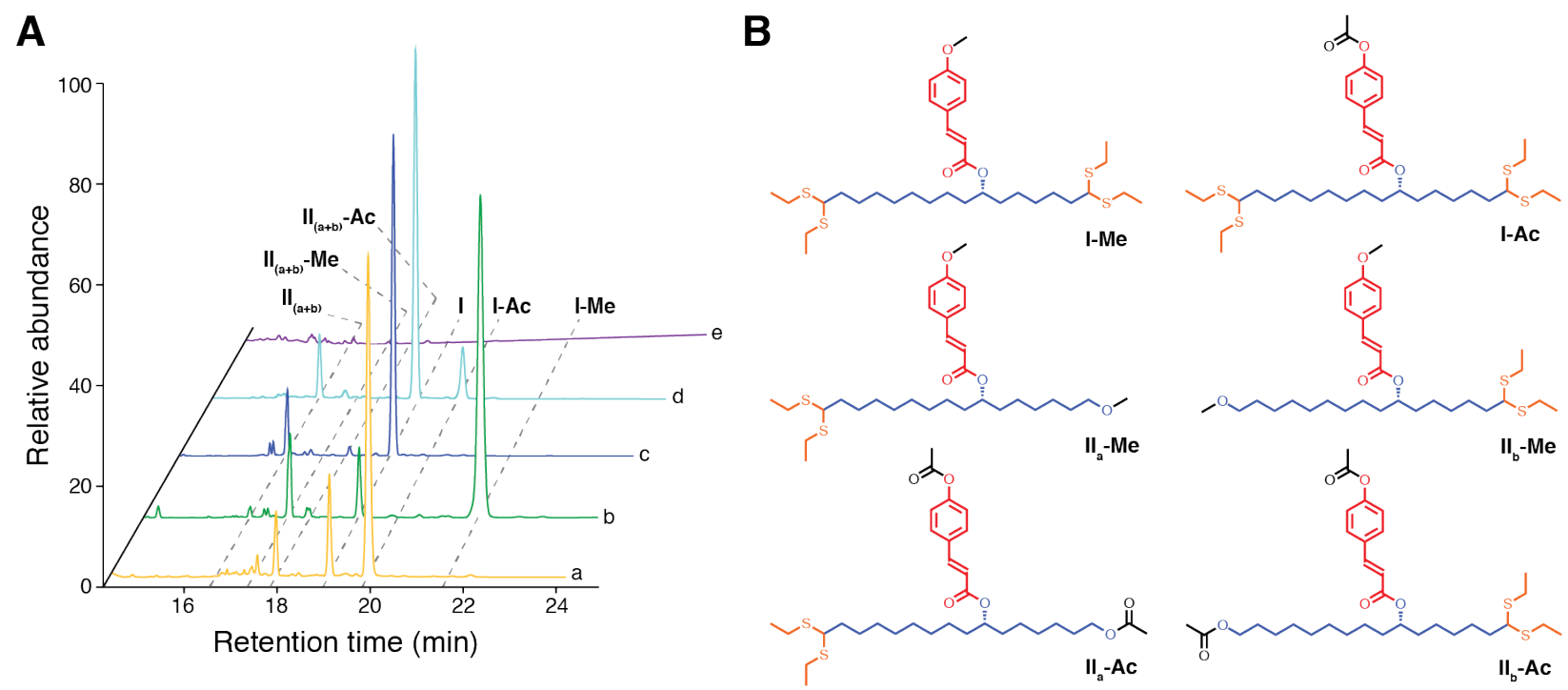

Fig. 2. Structural characterization of pine sporopollenin by whole-polymer derivatization followed by thioacidolysis. A, HPLC-UV chromatograms of thioacidolysis products after various pretreatments. The five traces are: (a), Acetylated pine sporopollenin; (b), Methylated pine sporopollenin; (c), Untreated pine sporopollenin; (d), Acetylated pine sporopollenin subsequently treated with $\mathrm{NaBH}_{4}$, and (e), Acetylated pine sporopollenin subsequently treated with $\mathrm{TMDS} / \mathrm{Cu}(\mathrm{OTf})_{2}$. B, Structural elucidation of thioacidolysis products from methylated or acetylated whole sporopollenin polymer. These results show that the $p$-OH group of the $p$-coumaroyl moiety of I and $\mathrm{II}_{(\mathrm{a}+\mathrm{b})}$ as well as the $\omega-\mathrm{OH}$ of $\mathrm{II}_{(\mathrm{a}+\mathrm{b})}$ exist as free hydroxy groups not engaged in interunit coupling in sporopollenin polymer. 
A

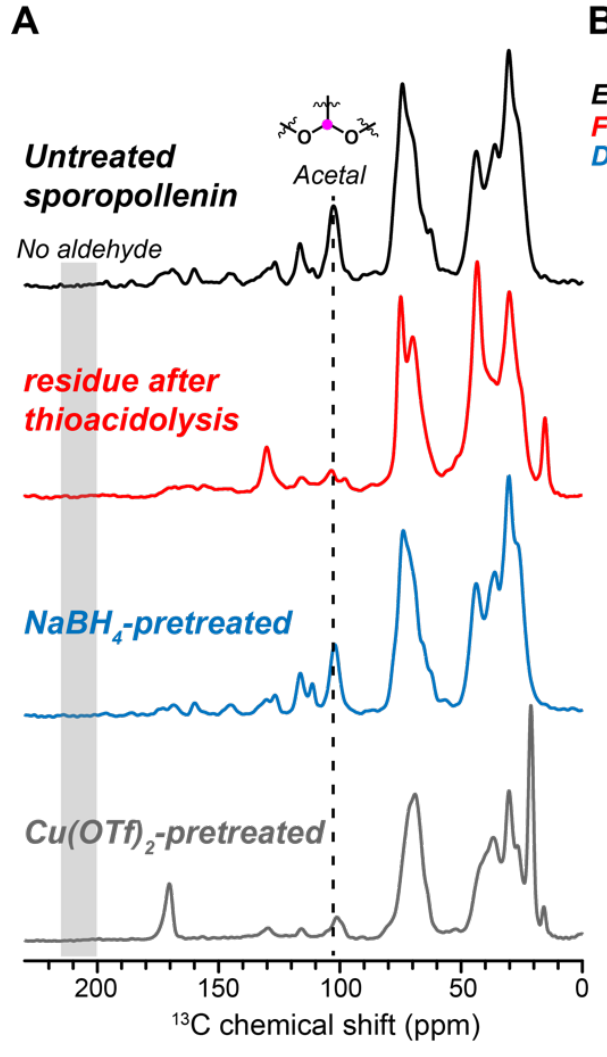

B

Experimental spectrum Fitted sum

Deconvoluted peaks
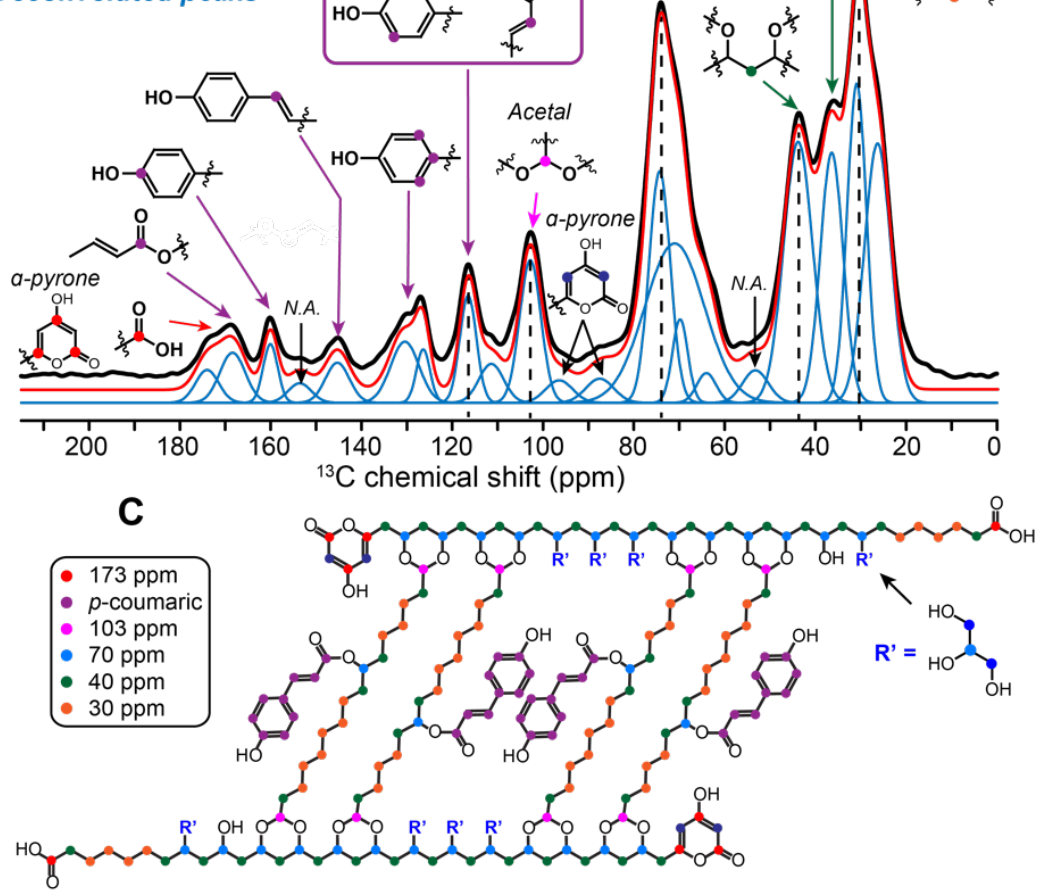

Fig. $3 .{ }^{13} \mathrm{C}$ solid-state NMR spectra of untreated and treated pine sporopollenin for structure determination. A, ${ }^{13} \mathrm{C}$ multi-CP spectra of untreated sporopollenin, residue (R) after thioacidolysis, residue after $\mathrm{NaBH}_{4}$ treatment, and residue after $\mathrm{TMDS} / \mathrm{Cu}(\mathrm{OTf})_{2}$ treatment. All spectra except for $\mathbf{R}$ were measured on an $800 \mathrm{MHz}$ NMR spectrometer under $14 \mathrm{kHz}$ MAS. B, Multi-CP ${ }^{13} \mathrm{C}$ spectrum of untreated sporopollenin measured on the $400 \mathrm{MHz}$ NMR under $13 \mathrm{kHz}$ MAS. Spectral deconvolution yielded the relative number of carbons for each assigned peak. C, Average chemical structure of pine sporopollenin based on the quantitative ${ }^{13} \mathrm{C}$ NMR spectra. 


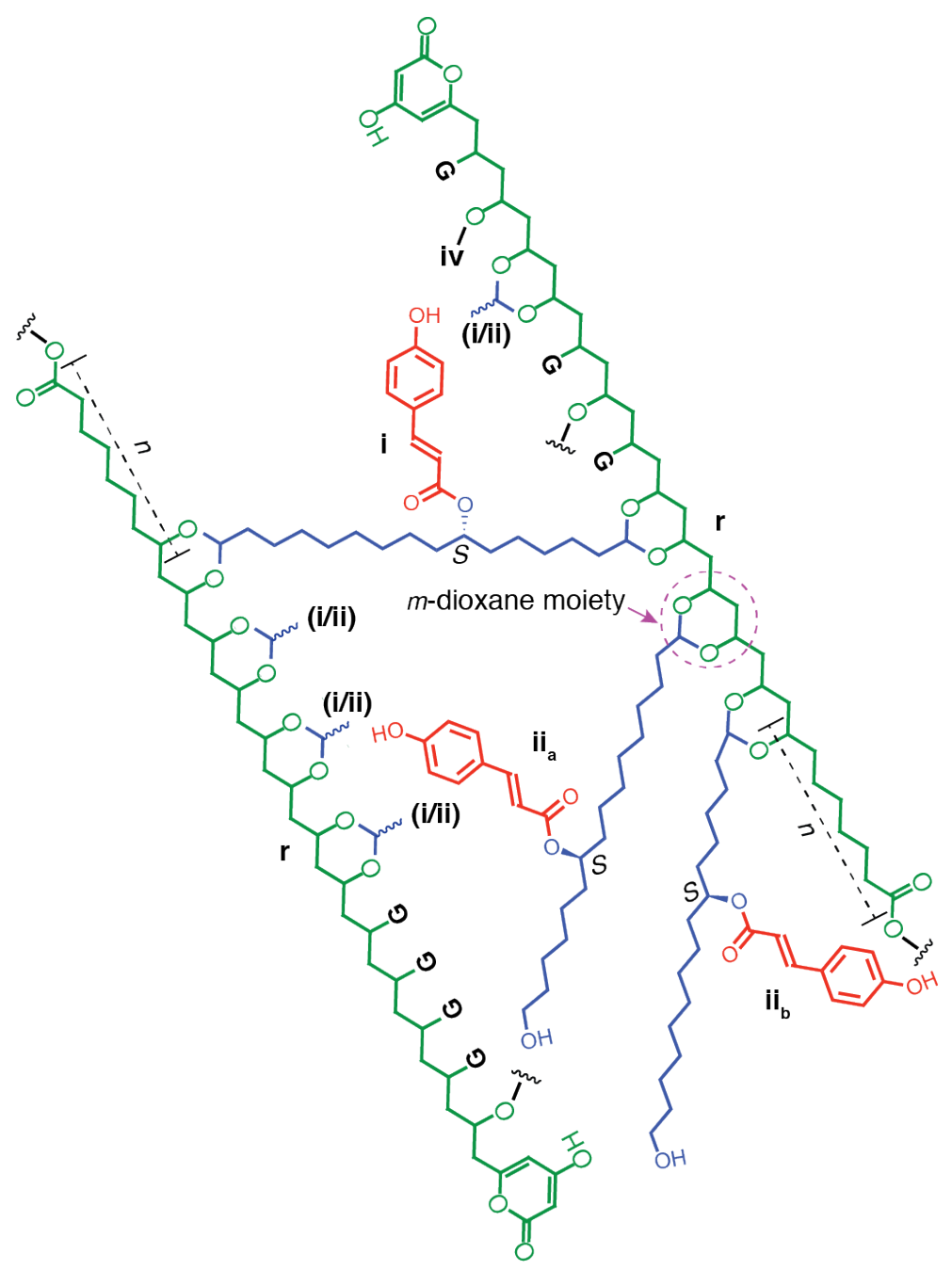

Fig. 4. Structural model of pine sporopollenin highlighting the major units and linkages elucidated through this study. In this "averaged" representation of pine sporopollenin, each polyketide-derived PVA-like unit (r) contains 38 carbons and is flanked at two ends by an a-pyrone and an ester, respectively. To reflect the "averaged" SSMNR quantitation of different carbon features, $\mathbf{r}$ is drawn as derived from a caprylic acid precursor $(n=8)$ with 15 cycles of polyketide chain extension, although in a heterogeneous sporopollenin polymer, $n$ could also be other even numbers representing other fatty acids employed as polyketide precursors for sporopollenin biosynthesis. The length of the PVA portion of $\mathbf{r}$ may also vary in a heterogenous 
sporopollenin polymer. A fraction of the a-pyrone moiety may be substituted by an ester moiety, as $a$-pyrone can be linearized through hydrolysis to give $\beta$-keto acid, capable of engaging in ester formation. Each $\mathbf{r}$ unit is drawn to form four $m$-dioxane moieties featuring an acetal to crosslink with the 7-O-p-coumaroylated $\mathrm{C} 16$ aliphatic units (i/ii). The ratio of i:ii is approximately 6 7:1. Glycerol-like moieties (G) and small amount of naringenin (vi) are ether-linked to the hydroxy groups of $\mathbf{r}$. Although the interunit crosslinking is drawn in two dimensions, higher-dimensional cross-linking is likely the case in natural sporopollenin polymer. 


\section{References}

1. Weng, J.-K., Philippe, R. N. \& Noel, J. P. The rise of chemodiversity in plants. Science 336, 1667-1670 (2012).

2. Kim, S. S. \& Douglas, C. J. Sporopollenin monomer biosynthesis in arabidopsis. J. Plant Biol. 56, 1-6 (2013).

3. Lu, F. \& Ralph, J. Non-degradative dissolution and acetylation of ball-milled plant cell walls: high-resolution solution-state NMR. Plant J. 35, 535-544 (2003).

4. Ahlers, F., Thom, I., Lambert, J., Kuckuk, R. \& Rolf Wiermann. 1H NMR analysis of sporopollenin from Typha Angustifolia. Phytochemistry 50, 1095-1098 (1999).

5. Rolando, C., Monties, B. \& Lapierre, C. Thioacidolysis. in Methods in Lignin Chemistry 334-349 (Springer, Berlin, Heidelberg, 1992).

6. Seco, J. M., Quiñoá, E. \& Riguera, R. The Assignment of Absolute Configuration by NMR. Chem. Rev. 104, 17-118 (2004).

7. Imaizumi, K., Terasima, H., Akasaka, K. \& Ohrui, H. Highly Potent Chiral Labeling Reagents for the Discrimination of Chiral Alcohols. Anal. Sci. 19, 1243-1249 (2003).

8. Ohrui, H. Development of highly potent chiral discrimination methods that solve the problems of diastereomer method. Anal. Sci. 24, 31-38 (2008).

9. Ohtaki, T., Akasaka, K., Kabuto, C. \& Ohrui, H. Chiral discrimination of secondary alcohols by both $1 \mathrm{H}-\mathrm{NMR}$ and HPLC after labeling with a chiral derivatization reagent, 2-(2, 3-anthracenedicarboximide)cyclohexane carboxylic acid. Chirality 17, $171-176$ (2005).

10. Zhang, Y.-J., Dayoub, W., Chen, G.-R. \& Lemaire, M. Environmentally benign 
metal triflate-catalyzed reductive cleavage of the $\mathrm{C}-\mathrm{O}$ bond of acetals to ethers.

Green Chem. 13, 2737-2742 (2011).

11. Zhang, Y. J., Dayoub, W. \& Chen, G. R. TMDS as a Dual-Purpose Reductant in the Regioselective Ring Cleavage of Hexopyranosyl Acetals to Ethers. European Journal of (2012).

12. Dick-Pérez, M. et al. Structure and Interactions of Plant Cell-Wall Polysaccharides by Two- and Three-Dimensional Magic-Angle-Spinning Solid-State NMR. Biochemistry 50, 989-1000 (2011).

13. Wang, T., Phyo, P. \& Hong, M. Multidimensional solid-state NMR spectroscopy of plant cell walls. Solid State Nucl. Magn. Reson. 78, 56-63 (2016).

14. Phyo, P., Wang, T., Yang, Y., O’Neill, H. \& Hong, M. Direct Determination of Hydroxymethyl Conformations of Plant Cell Wall Cellulose Using $1 \mathrm{H}$ Polarization Transfer Solid-State NMR. Biomacromolecules 19, 1485-1497 (2018).

15. Phyo, P. et al. Gradients in Wall Mechanics and Polysaccharides along Growing Inflorescence Stems. Plant Physiol. 175, 1593-1607 (2017).

16. Guilford, W. J., Schneider, D. M., Labovitz, J. \& Opella, S. J. High resolution solid state C NMR spectroscopy of sporopollenins from different plant taxa. Plant Physiol. 86, 134-136 (1988).

17. Mao, J., Cory, R. M., McKnight, D. M. \& Schmidt-Rohr, K. Characterization of a nitrogen-rich fulvic acid and its precursor algae from solid state NMR. Org. Geochem. 38, 1277-1292 (2007).

18. Mao, J.-D. et al. Abundant and Stable Char Residues in Soils: Implications for Soil Fertility and Carbon Sequestration. Environ. Sci. Technol. 46, 9571-9576 (2012). 
19. Johnson, R. L. \& Schmidt-Rohr, K. Quantitative solid-state 13C NMR with signal enhancement by multiple cross polarization. J. Magn. Reson. 239, 44-49 (2014).

20. Kim, S. S., Grienenberger, E. \& Lallemand, B. LAP6/POLYKETIDE SYNTHASE A and LAP5/POLYKETIDE SYNTHASE B encode hydroxyalkyl a-pyrone synthases required for pollen development and .... The Plant (2010).

21. Grienenberger, E. et al. Analysis of TETRAKETIDE a-PYRONE REDUCTASE function in Arabidopsis thaliana reveals a previously unknown, but conserved, biochemical pathway in sporopollenin monomer biosynthesis. Plant Cell 22, 40674083 (2010).

22. Rasouli, M., Ostovar-Ravari, A. \& Shokri-Afra, H. Characterization and improvement of phenol-sulfuric acid microassay for glucose-based glycogen. Eur. Rev. Med. Pharmacol. Sci. 18, 2020-2024 (2014).

23. Mao, J. D. \& Schmidt-Rohr, K. Accurate quantification of aromaticity and nonprotonated aromatic carbon fraction in natural organic matter by $13 \mathrm{C}$ solid-state nuclear magnetic resonance. Environ. Sci. Technol. 38, 2680-2684 (2004).

24. Mao, J.-D. \& Schmidt-Rohr, K. Methylene spectral editing in solid-state 13C NMR by three-spin coherence selection. J. Magn. Reson. 176, 1-6 (2005).

25. Liu, R., He, B. \& Chen, X. Degradation of poly(vinyl butyral) and its stabilization by bases. Polym. Degrad. Stab. 93, 846-853 (2008).

26. Weng, J.-K. \& Chapple, C. The origin and evolution of lignin biosynthesis. New Phytol. 187, 273-285 (2010).

27. Hayatsu, R., E. Botto, R., L. McBeth, R., G. Scott, R. \& Winans, R. Chemical structure of a sporinite from a lignite: Comparison with a synthetic sporinite 
transformed from sporopollenin. Prepr. Pap., Am. Chem. Soc., Div. Fuel Chem 32, 1-8 (1987)

28. Dobritsa, A. A. et al. CYP704B1 is a long-chain fatty acid omega-hydroxylase essential for sporopollenin synthesis in pollen of Arabidopsis. Plant Physiol. 151, $574-589$ (2009).

29. Morant, M. et al. CYP703 is an ancient cytochrome P450 in land plants catalyzing in-chain hydroxylation of lauric acid to provide building blocks for sporopollenin synthesis in pollen. Plant Cell 19, 1473-1487 (2007).

30. Austin, M. B. \& Noel, J. P. The Chalcone Synthase Superfamily of Type III Polyketide Synthases. ChemInform 34, (2003).

31. de Azevedo Souza, C. et al. A novel fatty Acyl-CoA Synthetase is required for pollen development and sporopollenin biosynthesis in Arabidopsis. Plant Cell 21, 507-525 (2009). 


\title{
Supplementary Information for
}

\section{The molecular structure of plant sporopollenin}

\author{
Fu-Shuang Li, Pyae Phyo, Joseph Jacobowitz, Mei Hong, Jing-Ke Weng* \\ *Corresponding author: wengj@wi.mit.edu
}

\section{This file includes}

Supplementary Notes

Methods

Figs. S1 to S48

Tables S1 to S5

NMR data

Supplementary References 


\section{Supplementary Notes}

\section{Supplementary Note 1}

\section{Prior knowledge regarding the chemical composition of plant sporopollenin}

Various attempts have been made to chemically degrade sporopollenin from different species in order to obtain monomers/oligomers. Unlike nucleic acids, proteins or polysaccharides, which contain uniform inter-unit linkages susceptible to enzymatic or chemical hydrolysis, sporopollenin is enriched with multiple, unknown carbon-carbon and ether/ester cross-links which partially explain its extremely resistant characteristics. Conventional techniques can only determine limited information of chemical composition while harsh protocols (ozonolysis, potash fusion, nitrobenzene oxidation, aluminium iodide attack, etc.) destroy linkage information and may produce artefacts. Shaw reported that $P$. silvestris sporopollenin gave 7-hydroxyhexadecanedioic acid and $p$-coumaric acid by alkaline hydrolysis ${ }^{1}$. The $p$-coumaric acid was also found as the main degradative product in Osthoff ${ }^{2}$ and Wehling's ${ }^{3}$ work when $P$. rigida sporopollenin was saponified and treated with aluminium iodide, respectively. In tracing experiments, the aromatic systems were quite well defined in sporopollenin structure. Gubatz ${ }^{4}$ discovered that the whole carbon skeleton of phenylalanine was incorporated at substantial rates into the sporopollenin of Tulipa and he assumed that the phenylpropane unit, such as $p$-coumaric acid, formed the actual monomer. Oleic and stearic acids were also observed to be significantly incorporated into sporopollenin, implicating aliphatic and fatty acid metabolism ${ }^{5,6}$. Hot 2-aminoethanol ${ }^{7}$ was claimed to "dissolve" sporopollenin of Typha Angustifolia which made whole-polymer spectroscopic 
analysis possible, but its poor solubility allowed only ${ }^{1} \mathrm{H}$ NMR with restriction to the aromatic region. Moreover, piperidine ${ }^{8}$ turned out to be a more suitable solvent for sporopollenin than hot 2-aminoethanol, as it allowed for higher solubility for 2D-NMR investigations. Unfortunately, the HETCOR and COSY spectra of silylated and acetylated Typha samples only evidenced the aliphatic polyhydroxy monomers as well as phenolics substituted by $-\mathrm{OH}$ groups. Altogether, these experiments yielded no information for the linkages between different units.

\section{Supplementary Note 2}

\section{Chemical degradation of pine sporopollenin by various reagents}

Before thioacidolysis, various chemical degradative methods were tested to break down pine sporopollenin. After vigorous stirring with $70 \%$ nitric acid for 24 hours, P. rigida sporopollenin dissolved/degraded and gave a series of aromatic nitro compounds (VIIX) which revealed $p$-coumaric acid as a possible main aromatic unit in $P$. rigida sporopollenin. By stirring P. rigida sporopollenin with methyl iodide in dry acetone ${ }^{9}$, methylated $P$. rigida sporopollenin produced the corresponding methylated degradative products (XI-XII) during nitric acid degradation, this observation undoubtedly suggested that free $p-\mathrm{OH}$ groups occurred on $p$-coumaroyl units in $P$. rigida sporopollenin (Supplementary Fig. 3, 9, 24-29). These results only provided limited structural information. Several degradative methods previously developed for analyzing plant polymers (ethyl mercaptan/n-dodecyl mercaptan thioacidolysis for lignin ${ }^{10,11}$, benzyl mercaptan thioacidolysis for tannins ${ }^{12}$ and methanolic base hydrolysis for cutins ${ }^{13}$ ) 
were tested, none of them reacted with $P$. rigida sporopollenin to a significant degree except ethyl mercaptan-based thioacidolysis. Ethyl mercaptan-based thioacidolysis degraded about $55 \pm 3 \%$ of $P$. rigida sporopollenin and HPLC-UV-MS analysis of the soluble fraction of the reaction gave three major and several minor UV-detectable degradation products (Figs. 1B, C and Supplementary Fig. 6).

\section{Supplementary Note 3}

\section{Methods been used for studying chemical structure of $\mathbf{R}$}

Many efforts (acetylation by acetic chloride, silylation by BSTFA, Hydrolysis by potassium hydroxide, etc) had been devoted to modify/degrade $\mathbf{R}$. None of them worked well. 


\section{Methods}

\section{Chemicals and instruments}

All chemicals were purchased from Sigma-Aldrich, unless otherwise specified. P. rigida pollen was collected in Cape Cod, MA, United States. Solvents for liquid chromatography high-resolution mass spectrometry were Optima ${ }^{\circledR}$ LC-MS grade (Fisher Scientific) or LiChrosolv ${ }^{\circledR}$ LC-MS grade (Millipore). High-resolution mass spectrometry analysis was performed on a Thermo ESI-Q-Exactive Orbitrap MS coupled to a Thermo Ultimate 3000 UHPLC system. Low-resolution mass spectrometry analysis was done on a Thermo ESI-QQQ MS coupled to a Thermo Ultimate 3000 UHPLC system. Prep-HPLC was performed on a Shimadzu Preparative HPLC with LC20AP pump and SPD-20A UV-VIS detector. Solution NMR spectra were recorded on a Bruker AVANCE-400 NMR spectrometer with a Spectro Spin superconducting magnet in the Massachusetts Institute of Technology, Department of Chemistry Instrumentation Facility (MIT DCIF) and Oxford $600 \mathrm{MHz}$ Magnet, Bruker AVANCE II Console system, equipped with $5 \mathrm{~mm}$ Prodigy HCN TXI cold probe in the Harvard Medical School, East Quad NMR facility. SSNMR spectra were measured on an $800 \mathrm{MHz}\left({ }^{1} \mathrm{H}\right.$ Larmor frequency) Bruker AVANCE II spectrometer at $18.8 \mathrm{~T}$ using a $3.2 \mathrm{~mm}$ MAS probe and a $400 \mathrm{MHz}$ (9.4 T) AVANCE III spectrometer using a $4 \mathrm{~mm}$ probe. Typical radiofrequency field strengths were $50-62.5 \mathrm{kHz}$ for ${ }^{13} \mathrm{C}$ and $50-80 \mathrm{kHz}$ for ${ }^{1} \mathrm{H}$. All ${ }^{13} \mathrm{C}$ chemical shifts were externally referenced to the adamantine $\mathrm{CH}_{2}$ peak at $38.48 \mathrm{ppm}$ on the tetramethylsilane (TMS) scale. Circular Dichroism (CD) spectrum was performed on a JASCO Model J-1500 Circular Dichroism Spectrometer equipped with a multi-cuvette holder. Ball milling was done on a high energy Retsch PM 100 Ball Mill. 


\section{$P$. rigida sporopollenin preparation}

The ball milling technique ${ }^{14}$ combined with a modified conventional protocol ${ }^{7}$ was used for $P$. rigida sporopollenin preparation. Briefly, $P$. rigida pollen was ball milled to a super fine powder using a high energy Retsch PM 100 Ball Mill and enzymatically hydrolyzed at $37^{\circ} \mathrm{C}$ for 16 hours using a mixture of Macerozym R10 and Cellulase Onozuka R10 (Yakult, Nishinomiya, Japan) (1\% of each in $0.1 \mathrm{M}$ sodium acetate buffer, $\mathrm{pH} 4.5)$. The resulting material was further extracted exhaustively using a series of solvents of increasing polarity, including hexane, chloroform, ethyl acetate, acetone, methanol, and water. After extraction, the remaining material was lyophilized to obtain $P$. rigida sporopollenin, which accounts for $\sim 33 \%$ of the starting pollen in dry weight.

\section{Acetylation and methylation of $\boldsymbol{P}$. rigida sporopollenin}

Acetylation of $P$. rigida sporopollenin . According to the method of $\mathrm{Lu}^{14}, P$. rigida sporopollenin $(0.1 \mathrm{~g})$ was suspended in dimethyl sulfoxide (DMSO, $10 \mathrm{ml}$ ) and $\mathrm{N}$ methylimidazole (NMI, $5 \mathrm{ml}$ ) was added. The solution was stirred for 2 hours, excess acetic anhydride ( $3 \mathrm{ml})$ was added, and the mixture was stirred for 2 hours. The brown solution was transferred into cold water $(500 \mathrm{ml})$, and the mixture was allowed to stand overnight in a $4{ }^{\circ} \mathrm{C}$ cold room. The precipitate was recovered by filtration and washed with water $(50 \mathrm{~mL})$. The final product was then lyophilized.

$P$. rigida sporopollenin methylation. According to the method of Kettley ${ }^{9}, P$. rigida sporopollenin $(0.1 \mathrm{~g})$ was stirred with acetone $(10 \mathrm{~mL})$ and anhydrous $\mathrm{K}_{2} \mathrm{CO}_{3}(0.68 \mathrm{~g}$, more than 3 equivalents relative to the loading of sporopollenin hydroxyls) at room temperature for 1 hour. Methyl iodide $(0.5 \mathrm{~mL}$, more than 3 equivalents $)$ was then added and the mixture was refluxed under nitrogen for 24 hours. The mixture was cooled and 
the sporopollenin was collected by filtration and washed with acetone $(3 \times 20 \mathrm{~mL})$, water $(3 \times 20 \mathrm{~mL})$, methanol $(\mathrm{MeOH}, 3 \times 20 \mathrm{~mL})$ and dichloromethane $(\mathrm{DCM}, 3 \times 20 \mathrm{~mL})$. The final product was then lyophilized.

Thioacidolysis of untreated/acetylated/methylated $\boldsymbol{P}$. rigida sporopollenin and model compound 1, 1-dimethoxydodecane, polyvinyl butyral

According to the method of Rolando $^{10}$, untreated/acetylated/methylated $P$. rigida sporopollenin $(0.1 \mathrm{~g})$ or model compound 1, 1-dimethoxydodecane $(20 \mathrm{mg}) /$ polyvinyl butyral $(0.1 \mathrm{~g})$ was reacted in a $100 \mathrm{~mL}$ solution containing ethyl mercaptan $(10 \%, \mathrm{v} / \mathrm{v})$ and $0.2 \mathrm{M}$ boron trifluoride etherate $\left(\mathrm{BF}_{3} \mathrm{OEt}_{2}\right)$ in dioxane at $100{ }^{\circ} \mathrm{C}$ for 4 hours with stirring in a Teflon-screw cap flask under an atmosphere of nitrogen. After the reaction mixture cooled, adjusted its $\mathrm{pH}$ to $3-4$ by $0.4 \mathrm{M} \mathrm{NaHCO}_{3}$ then extracted with $\mathrm{CHCl}_{3}(3 \times$ $100 \mathrm{~mL}$ ). The combined organic extracts were dried over anhydrous $\mathrm{Na}_{2} \mathrm{SO}_{4}$, evaporated under reduced pressure and analyzed by HPLC-UV-MS [Thermo ESI-QQQ MS coupled to a Thermo Ultimate 3000 UHPLC system, Phenomenex Kinetex® $2.6 \mu \mathrm{m}$ $\mathrm{C}_{18}$ reverse phase $100 \AA 150 \times 3 \mathrm{~mm}$ LC column, LC gradient: solvent $\mathrm{A}$-water $(0.1 \%$ formic acid), solvent B-acetonitrile (0.1\% formic acid), $0-1$ minutes $5 \% \mathrm{~B}, 1-15$ minutes $5-80 \% \mathrm{~B}, 15-25$ minutes $95 \% \mathrm{~B}, 25-30$ minutes $5 \% \mathrm{~B}, 0.7 \mathrm{~mL} / \mathrm{min})$. The residue after thioacidolysis was collected by filtration, washed by water and dried by lyophilization. Thioacidolysis consistently solubilized about $55 \pm 3 \%$ of $P$. rigida sporopollenin by dry weight. 


\section{Acetylation of $\boldsymbol{P}$. rigida sporopollenin thioacidolysis residue}

According to a modified method of $\mathrm{Kettley}^{9}$, P. rigida sporopollenin thioacidolysis residue $(10 \mathrm{mg})$ and acetic anhydride $(2 \mathrm{~mL})$ were refluxed with stirring for 72 hours, The cooled acetylated residue was then recovered by filtration and washed with water $(3 \times 30 \mathrm{~mL})$. The final product was then lyophilized.

\section{Untreated/methylated $P$. rigida sporopollenin reacted with $70 \%$ nitric acid}

Untreated or methylated $P$. rigida sporopollenin $(0.1 \mathrm{~g})$ vigorous stirred with $100 \mathrm{~mL}$ $70 \%$ nitric acid in room temperature for $24 \mathrm{~h}$. The reaction mixture was then slowly adjusted (in $0^{\circ} \mathrm{C}$ ) its $\mathrm{pH}$ to 7 by $10 \mathrm{M} \mathrm{NaOH}$, then extracted with ethyl acetate $(3 \times 100$ $\mathrm{mL}$ ). The combined organic extracts were dried over anhydrous $\mathrm{Na}_{2} \mathrm{SO}_{4}$, evaporated under reduced pressure and analyzed by HPLC-UV-MS [Thermo ESI-QQQ MS coupled to a Thermo Ultimate 3000 UHPLC system, Phenomenex Kinetex® $2.6 \mu \mathrm{m} \mathrm{C}_{18}$ reverse phase $100 \AA 150 \times 3$ mm LC column, LC gradient: solvent $A$-water $(0.1 \%$ formic acid), solvent $B$-acetonitrile $(0.1 \%$ formic acid), $0-1$ minutes $5 \%$ B, $1-15$ minutes $5-80 \%$, 15 25 minutes $95 \%$ B, 25-30 minutes $5 \%$ B, $0.7 \mathrm{~mL} / \mathrm{min})$. The degradative products were separated by Sephadex $\mathrm{LH} 20$ eluted with $\mathrm{CHCl}_{3} / \mathrm{MeOH}$ (1:1). Pure compounds were dried in vacuo, subjected to NMR analysis in DMSO-d6.

\section{$P$. rigida sporopollenin treated with modified phenol-sulfuric acid reaction}

According to a modified method of Rasouli ${ }^{15}, P$. rigida sporopollenin or cellulose $(0.1 \mathrm{~g})$ vigorous stirred with $100 \mathrm{~mL} 80 \%$ sulfuric acid in $100{ }^{\circ} \mathrm{C}$ for 30 minutes. The reaction mixture $\mathrm{pH}$ was then slowly adjusted $\left(\right.$ at $0^{\circ} \mathrm{C}$ ) to 7 by addition of $10 \mathrm{M} \mathrm{NaOH}$, then extracted with ethyl acetate $(3 \times 100 \mathrm{~mL})$. The combined organic extracts were dried over anhydrous $\mathrm{Na}_{2} \mathrm{SO}_{4}$, evaporated under reduced pressure and analyzed by HPLC- 
UV-MS [Thermo ESI-QQQ MS coupled to a Thermo Ultimate 3000 UHPLC system, Phenomenex Kinetex® $2.6 \mu \mathrm{m} \mathrm{C}_{18}$ reverse phase $100 \AA 150 \times 3$ mm LC column, LC gradient: solvent A-water ( $0.1 \%$ formic acid), solvent B-acetonitrile $(0.1 \%$ formic acid), 0-1 minutes $5 \%$ B, $1-15$ minutes $5-80 \%$ B, $15-25$ minutes $95 \%$ B, 25-30 minutes $5 \%$, $0.7 \mathrm{~mL} / \mathrm{min})$.

\section{$P$. rigida sporopollenin treated with $\mathrm{TMDS} / \mathrm{Cu}(\mathrm{OTf})_{2}$}

According to a modified method of Zhang $^{16}, \mathrm{Cu}(\mathrm{OTf})_{2}$ (74 mg) and 1,1,3,3tetramethyldisiloxane (TMDS; $1 \mathrm{~mL}$ ) were added to a suspension of $P$. rigida sporopollenin $(0.1 \mathrm{~g})$ in $\mathrm{CHCl}_{3}(15 \mathrm{~mL})$ at room temperature. After stirring overnight, the mixture was diluted with $\mathrm{CHCl}_{3}$, washed with $\mathrm{HCl}$ aq. and water. The residue (PM_Cu) was then recovered by filtration and lyophilization. In the subsequent thioacidolysis treatment of PM_Cu, compounds I, II were not detected in the HPLC-UV-MS chromatogram and it produced an almost undegraded residue (PM_Cu_Thio_Residue). If less $\mathrm{Cu}(\mathrm{OTf})_{2}(7.4 \mathrm{mg})$ and TMDS $(0.1 \mathrm{~mL})$ were added in the $\mathrm{TMDS} / \mathrm{Cu}(\mathrm{OTf})_{2}$ reaction, the corresponding residue PM_Cu_Less produced compound I, II in its HPLCUV-MS chromatogram in the subsequent thioacidolysis treatment. These results suggested that TMDS/Cu(OTf $)_{2}$ converted acetal to ether interlinkages and resulted in a modified sporopollenin that was unsusceptible to thioacidolysis.

\section{Purification and characterization of thioacidolysis degradative products from $P$. rigida sporopollenin}

The combined organic extracts after thioacidolysis treatment of untreated/acetylated/methylated $P$. rigida sporopollenin were separated by Sephadex LH2O eluted with $\mathrm{CHCl}_{3} / \mathrm{MeOH}$ (1:1). Fractions were collected and analyzed by HPLC- 
UV-MS [Thermo ESI-QQQ MS coupled to a Thermo Ultimate 3000 UHPLC system, Phenomenex Kinetex® $2.6 \mu \mathrm{m} \mathrm{C}_{18}$ reverse phase $100 \AA 150 \times 3 \mathrm{~mm}$ LC column, LC gradient: solvent A-water $(0.1 \%$ formic acid $)$, solvent B-acetonitrile $(0.1 \%$ formic acid $)$, 0-1 minutes $5 \%$ B, $1-15$ minutes $5-80 \%$ B, $15-25$ minutes $95 \%$ B, 25-30 minutes $5 \%$, $0.7 \mathrm{~mL} / \mathrm{min}$ ). Further purification was performed on Prep-HPLC (Kinetex $5 \mu \mathrm{C}_{18}$ 100A, $150 \times 21.2 \mathrm{~mm}$ column, solvent A-water, solvent B-acetonitrile, 0-30 minutes $40-80 \% \mathrm{~B}$, 30-35 minutes 80-95\% B, 35-65 minutes 95\% B, $10 \mathrm{~mL} / \mathrm{min})$. Pure compounds were dried in vacuo and subjected to NMR analysis in $\mathrm{CDCl}_{3}$.

Absolute configuration identification of compound I. Potassium hydroxide hydrolysis of compound I. Compound I (10 mg) was refluxed in $1 \mathrm{M} \mathrm{KOH}$ for $1 \mathrm{~h}$. After the reaction mixture cooled, its $\mathrm{pH}$ was adjusted to 7 by addition of $1 \mathrm{M} \mathrm{HCl}$ and then extracted with $\mathrm{CHCl}_{3}(3 \times 10 \mathrm{~mL})$. The combined organic extracts were dried over anhydrous $\mathrm{Na}_{2} \mathrm{SO}_{4}$ and then evaporated under reduced pressure at $40{ }^{\circ} \mathrm{C}$. Further purification was performed on Prep-HPLC (Kinetex $5 \mu \mathrm{C}_{18} 100 \mathrm{~A}, 150 \times 21.2 \mathrm{~mm}$ column, solvent A-water, solvent B-acetonitrile, 0-30 minutes $40-80 \%$ B, 30-35 minutes $80-95 \%$ B, 35-65 minutes 95\% B, $10 \mathrm{~mL} / \mathrm{min})$. Pure compound $\mathrm{I}_{\mathbf{a}}$ was dried in vacuo, subjected to NMR analysis in $\mathrm{CDCl}_{3}$. Compound I was analyzed by chiral HPLC-UV-MS [Thermo ESI-QQQ MS coupled to a Thermo Ultimate 3000 UHPLC system, Lux $3 \mu$ Cellulose-4, $250 \times 4.6 \mathrm{~mm}$ chiral column, LC gradient: solvent A-water $(0.1 \%$ formic acid), solvent B-acetonitrile (0.1\% formic acid), 0-30 minutes $50-95 \%$ B, 30-40 minutes $95 \% \mathrm{~B}, 40-42$ minutes $50 \% \mathrm{~B}, 0.7 \mathrm{~mL} / \mathrm{min})$.

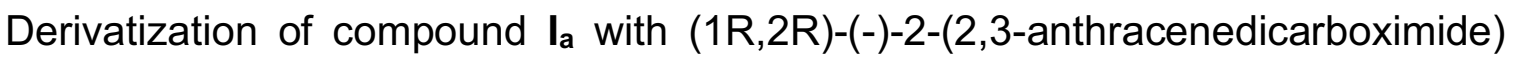
cyclohexane carboxylic acids and (1S,2S)-(+)-2-(2,3-anthracenedicarboximide) 
cyclohexane carboxylic acids. According to a modified method of Ohrui ${ }^{17}$, Compound $\mathbf{I}_{\mathbf{a}}$ was esterified with (1R,2R)-(-)-2-(2,3-anthracenedicarboximide) cyclohexane carboxylic acids or (1S,2S)-(+)-2-(2,3-anthracenedicarboximide) cyclohexane carboxylic acids by using 1-ethyl-3- (3-dimethylaminopropyl) carbodiimide hydrochloride (EDC) in the presence of 4-(dimethylamino)pyridine (DMAP) in a mixture of toluene and acetonitrile $(1: 1, v / v)$. The resultant mixture was stirred at $40{ }^{\circ} \mathrm{C}$ for overnight. The reaction mixture was analyzed by HPLC-UV-MS [Thermo ESI-QQQ MS coupled to a Thermo Ultimate 3000 UHPLC system, Phenomenex Kinetex® $2.6 \mu \mathrm{m} \mathrm{C}_{18}$ reverse phase $100 \AA 150 \times 3$ mm LC column, LC gradient: solvent A-water $(0.1 \%$ formic acid), solvent B-acetonitrile (0.1\% formic acid), 0-1 minutes $5 \%$ B, $1-15$ minutes $5-80 \%$ B, $15-25$ minutes $95 \%$ B, 25-30 minutes $98 \% \mathrm{~B}, 30-35$ minutes $5 \% \mathrm{~B}, 0.7 \mathrm{~mL} / \mathrm{min})$. Further purification was performed on Prep-HPLC (Kinetex $5 \mu \mathrm{C}_{18} 100 \mathrm{~A}, 150 \times 21.2 \mathrm{~mm}$ column, solvent Awater, solvent B-acetonitrile, 0-30 minutes $40-80 \%$ B, 30-35 minutes $80-95 \%$ B, 35-65 minutes $95 \% \mathrm{~B}, 10 \mathrm{~mL} / \mathrm{min})$. Pure $\mathrm{I}_{\mathbf{a}}-\boldsymbol{R} \boldsymbol{R}$ and $\mathrm{I}_{\mathbf{a}}-\mathrm{SS}$ were dried in vacuo, subjected to NMR analysis in $\mathrm{CDCl}_{3}$.

\section{Solid-state NMR experiments}

To obtain quantitative ${ }^{13} \mathrm{C}$ spectra that reflect the relative numbers of chemically distinct carbons in sporopollenin, we conducted the multiple cross-polarization (multi-CP) experiment ${ }^{18}$. Compared to direct polarization (DP) ${ }^{13} \mathrm{C}$ experiments with long recycle delays, which is the traditional method of quantitative ${ }^{13} \mathrm{C}$ NMR, multi-CP achieves twofold higher sensitivity by repeated polarization transfer from protons. Moreover, multi-CP gives uniform intensities for carbons with different numbers of attached protons by repolarizing the ${ }^{1} \mathrm{H}$ magnetization during the ${ }^{1} \mathrm{H}$ spin-lattice relaxation periods $\left(\mathrm{t}_{\mathrm{z}}\right)$ that 
alternate with the CP periods. The CP contact times and the $t_{z}$ periods were empirically optimized using the model tripeptide, formyl-MLF, by comparing the multi-CP spectrum with the quantitative DP spectrum measured with a $35 \mathrm{~s}$ recycle delay. For the untreated and treated sporopollenin samples, we used five cycles of CP periods where each cycle has a contact time of $330 \mu \mathrm{s}$ and a $\mathrm{t}_{\mathrm{z}}$ period of $0.4 \mathrm{~s}$ to $1 \mathrm{~s} .{ }^{13} \mathrm{C}$ multi-CP spectra with gated ${ }^{1} \mathrm{H}$ decoupling ${ }^{19,20}$ were measured on the $400 \mathrm{MHz} \mathrm{NMR}$ spectrometer under $13 \mathrm{kHz}$ MAS at $296 \mathrm{~K}$. The gate period was $36 \mu$ sefore and after the $180^{\circ}$ pulse, which suppresses the protonated ${ }^{13} \mathrm{C}$ signals due to their strong ${ }^{13} \mathrm{C}-{ }^{1} \mathrm{H}$ dipolar couplings. For the untreated pine sporopollenin sample, 7190 scans were acquired for the gated multi-CP spectrum while 10496 scans were acquired for the regular multi-CP spectrum. For the sample after thioacidolysis treatment, 8192 scans were acquired for the gated multi-CP spectrum and 6400 scans were acquired for the regular multi-CP spectrum. The $\mathrm{CH}_{2}$ selection experiment ${ }^{21}$ was conducted on the 800 MHz spectrometer under $6 \mathrm{kHz}$ MAS at $296 \mathrm{~K}$. A short CP contact time of 50 us was used to suppress the signals of methyl and non-protonated carbons. During the $\mathrm{CH}_{2}$ selection period, the ${ }^{1} \mathrm{H} 0^{\circ}$ and $90^{\circ}$ pulses were constructed from two phase-cycled $45^{\circ}$ pulses with an rf field strength of $73.5 \mathrm{kHz}$, while the ${ }^{13} \mathrm{C} 101^{\circ}$ pulse had an rf field strength of $67.5 \mathrm{kHz}$. The z-filter, which was designed to further suppress the methyl ${ }^{13} \mathrm{C}$ signals by fast $T_{1}$ relaxation, was set to $0.1 \mu \mathrm{s}$, since it was found to not affect the spectra of natural-abundance L-Leucine, which was used to optimize the experiment. For leucine, 512 scans were averaged for the $\mathrm{CH}_{2}$ selected single-CP spectrum while 8 scans were acquired for the non-selective single-CP spectrum. For the untreated 
sporopollenin sample, 68,608 scans were acquired for the $\mathrm{CH}_{2}$-selected single-CP spectrum and 6144 scans were acquired for the non-selective single-CP spectrum.

\section{Spectral assignment and deconvolution}

${ }^{13} \mathrm{C}$ chemical shifts in the MAS NMR spectra were assigned using ChemDraw Professional predictions and literature chemical shifts $20,22,23$. The multi-CP spectra were deconvoluted into Gaussian peaks using the DMFit software ${ }^{24}$ to extract the relative intensity of each peak. The model used for deconvolution was "Gaus/Lor", and adjustable parameters were chemical shift, peak amplitude, width, and type of line shape. Carbonyl and aromatic carbons with large chemical shift anisotropies (CSAs) lost part of their intensities to spinning sidebands even at $9.4 \mathrm{~T}$ (with a ${ }^{13} \mathrm{C}$ Larmor frequency of $100 \mathrm{MHz}$ ) under an MAS frequency of $13 \mathrm{kHz}$. We quantitatively accounted for the fraction of intensities lost to the sidebands by simulating the CSA sideband patterns for these groups using the "CSA mas" model in DMFit. The inputs for the simulations include the MAS frequency, the magnetic field strength, and chemical shift anisotropy parameter and asymmetry parameter, which are well known. This information is included in tables S1 and S3 as centerband to total intensity ratios, and is necessary for determining the accurate carbon counts. Finally, in determining the carbon counts, we also took into account imperfections in the multi-CP experiment, which is reflected by the slightly lower intensities of carbonyl and aromatic carbons (20$25 \%)$ relative to the quantitative direct polarization intensities measured on the model compound, formyl-MLF (Tables S1 and S3). 


\section{Supplementary Figures}
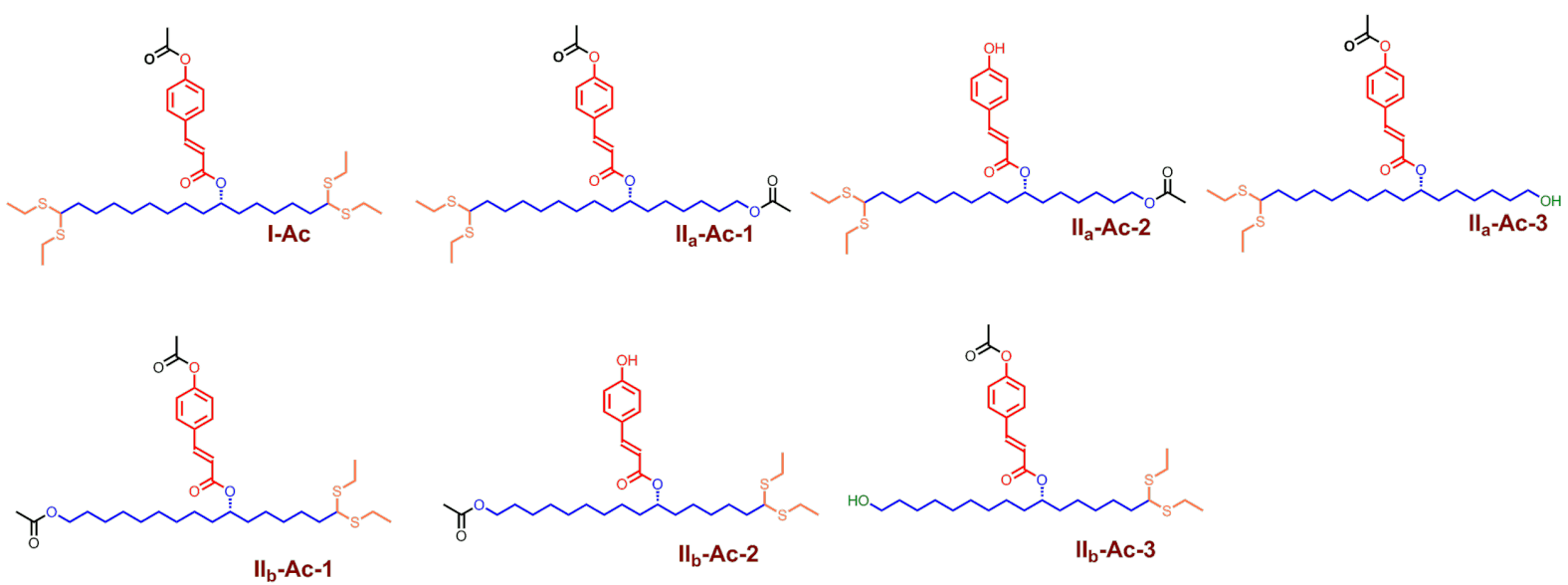

Fig. S1. Degradative products of acetylated $P$. rigida sporopollenin thioacidolysis 


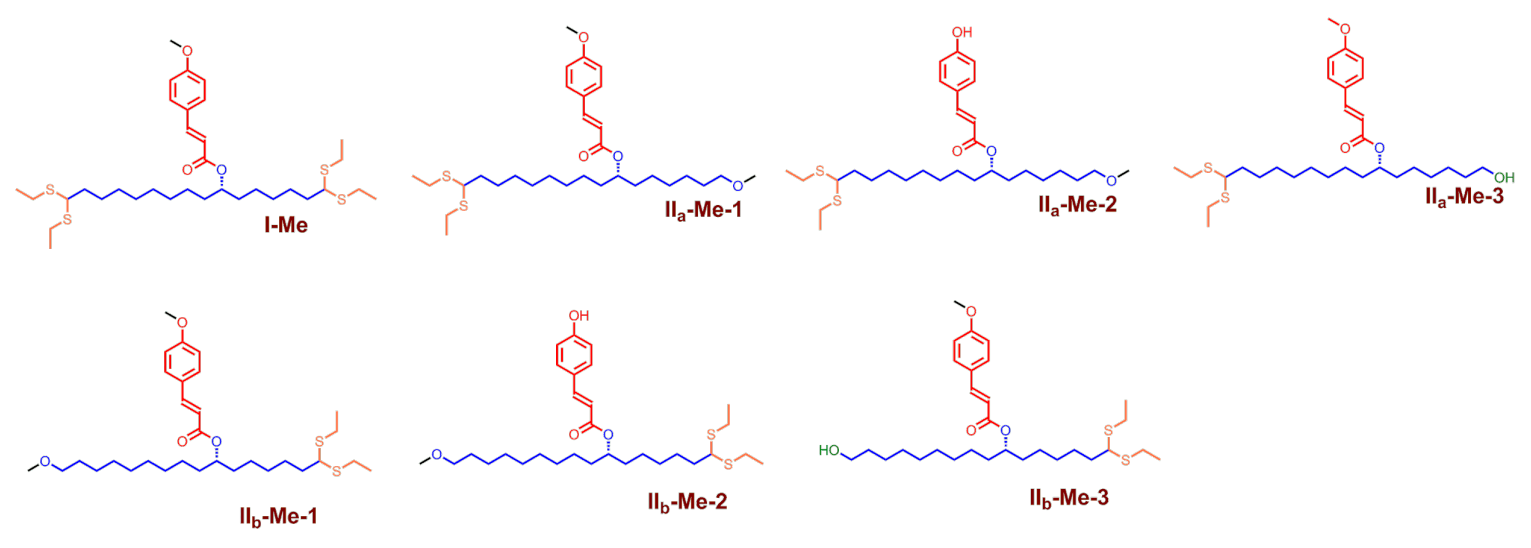

Fig. S2. Degradative products of methylated $P$. rigida sporopollenin thioacidolysis 
<smiles>O=Cc1cc([N+](=O)[O-])c(O)c([N+](=O)[O-])c1</smiles>

VII<smiles>COc1ccc(C=O)cc1[N+](=O)[O-]</smiles>

$\mathbf{X I}$<smiles>O=Cc1ccc(O)c([N+](=O)[O-])c1</smiles>

VIII<smiles>COc1ccc(/C=C/C(=O)O)cc1[N+](=O)[O-]</smiles>

XII<smiles>O=C(O)c1cc([N+](=O)[O-])c(O)c([N+](=O)[O-])c1</smiles>

IX<smiles>O=C(O)/C=C/c1ccc(O)c([N+](=O)[O-])c1</smiles>
$\mathbf{X}$

Fig. S3. Degradative products of $P$. rigida sporopollenin and methylated $P$. rigida sporopollenin treated with nitric acid 

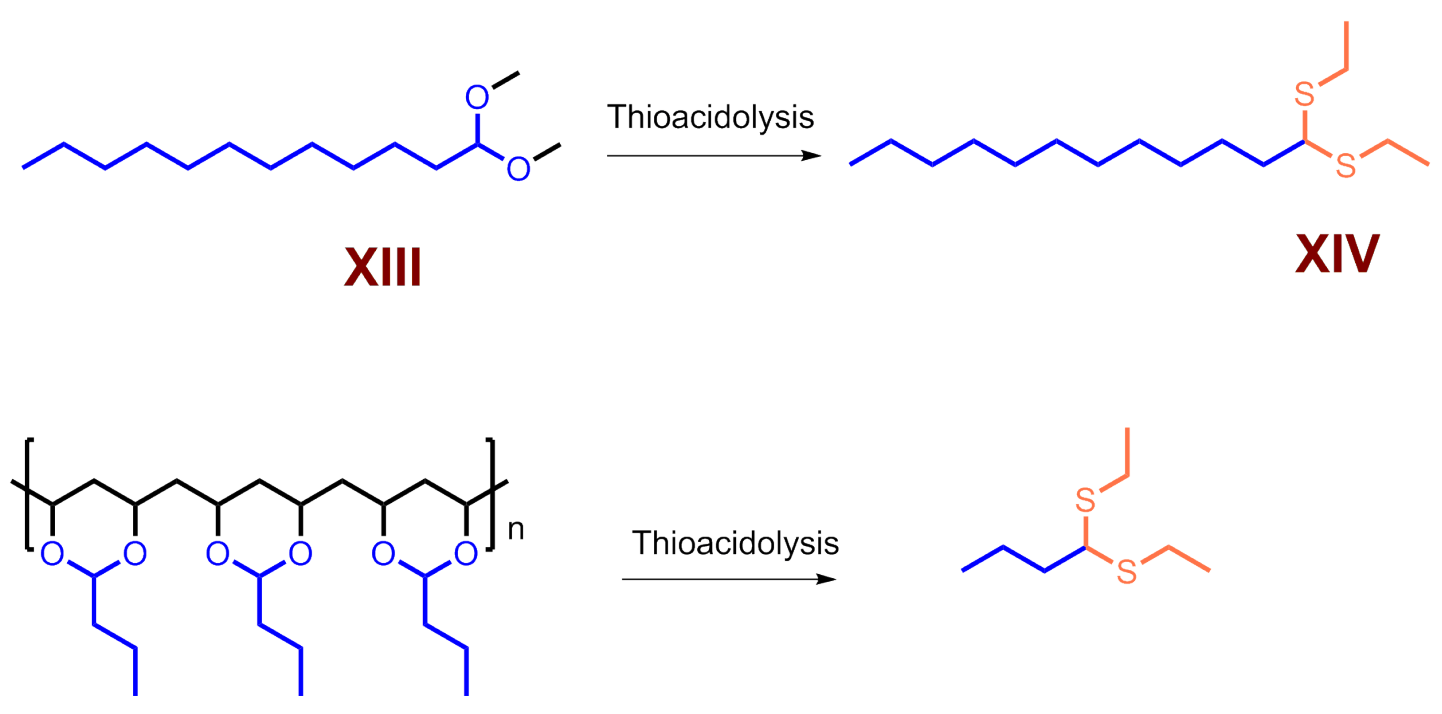

\section{Polyvinyl butyral}

XV

Fig. S4. Thioacidolysis of 1, 1-dimethoxydodecane (XIII) and Polyvinyl butyral produced $\mathbf{X I V}$ and $\mathbf{X V}$ respectively. 


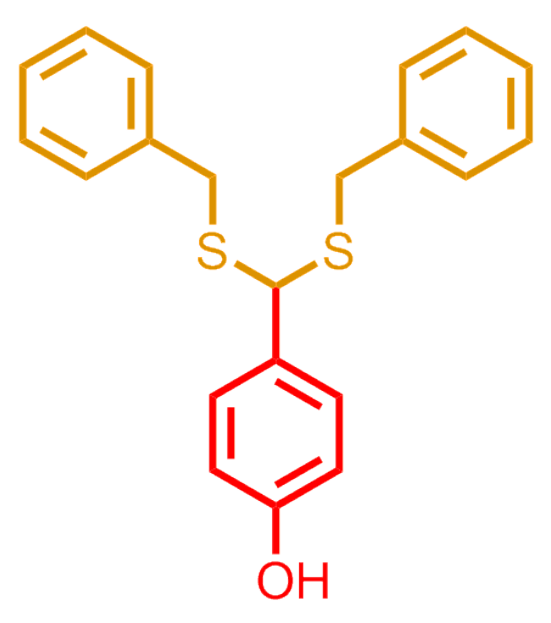

XVI

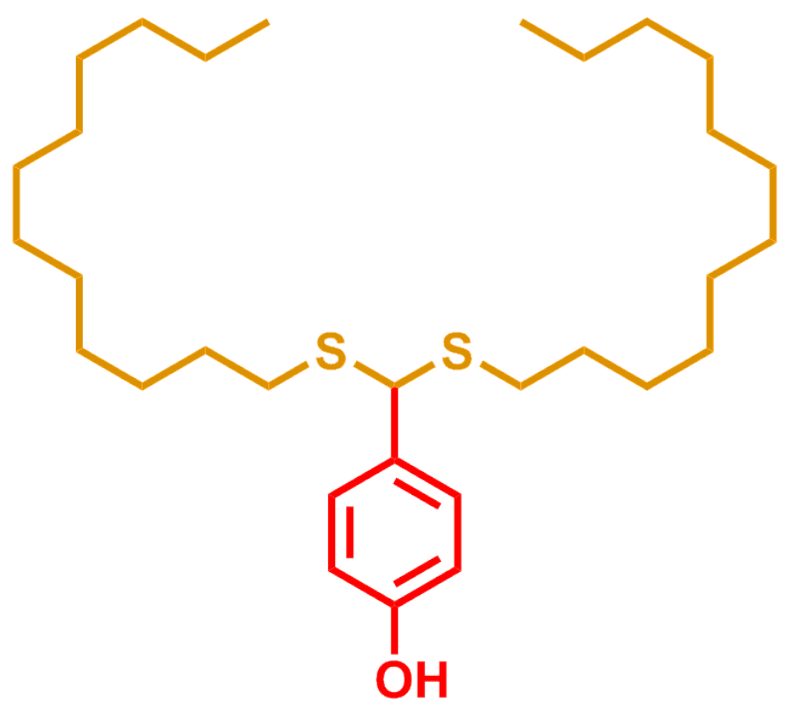

XVII

Fig. S5. Degradative products of $P$. rigida sporopollenin benzyl mercaptan thioacidolysis (XVI and n-dodecyl mercaptan thioacidolysis (XVII). 


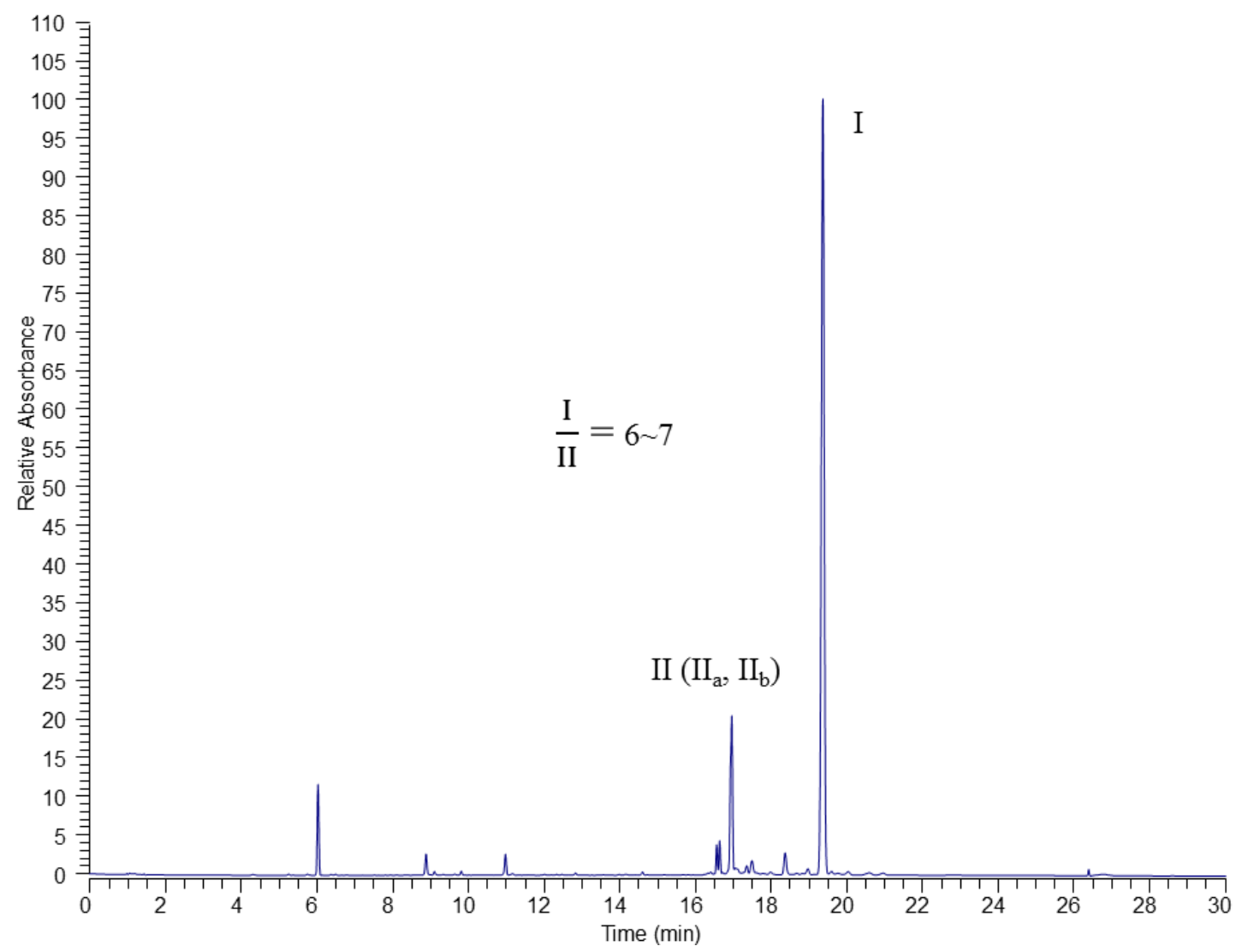

Fig. S6. HPLC-UV (310nm) chromatogram of $P$. rigida sporopollenin thioacidolysis, the ratio of peak areas of I and II is about 6 7. A subfraction ( 15\%) of the C16 aliphatic units (ii) are crosslinked only on one end, with the other end existing as free hydroxy group. 


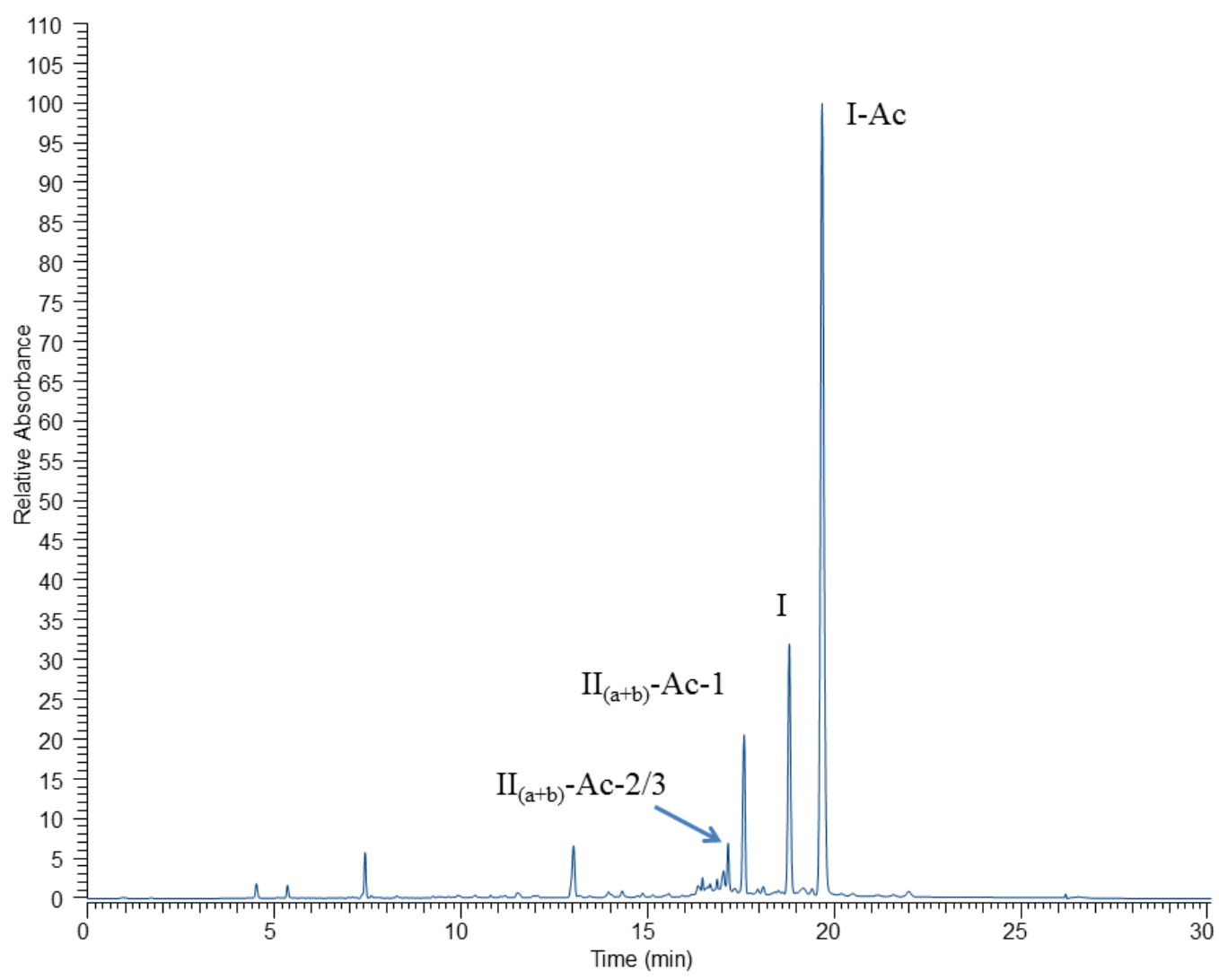

Fig. S7. HPLC-UV (280nm) chromatogram of acetylated P. rigida sporopollenin thioacidolysis 


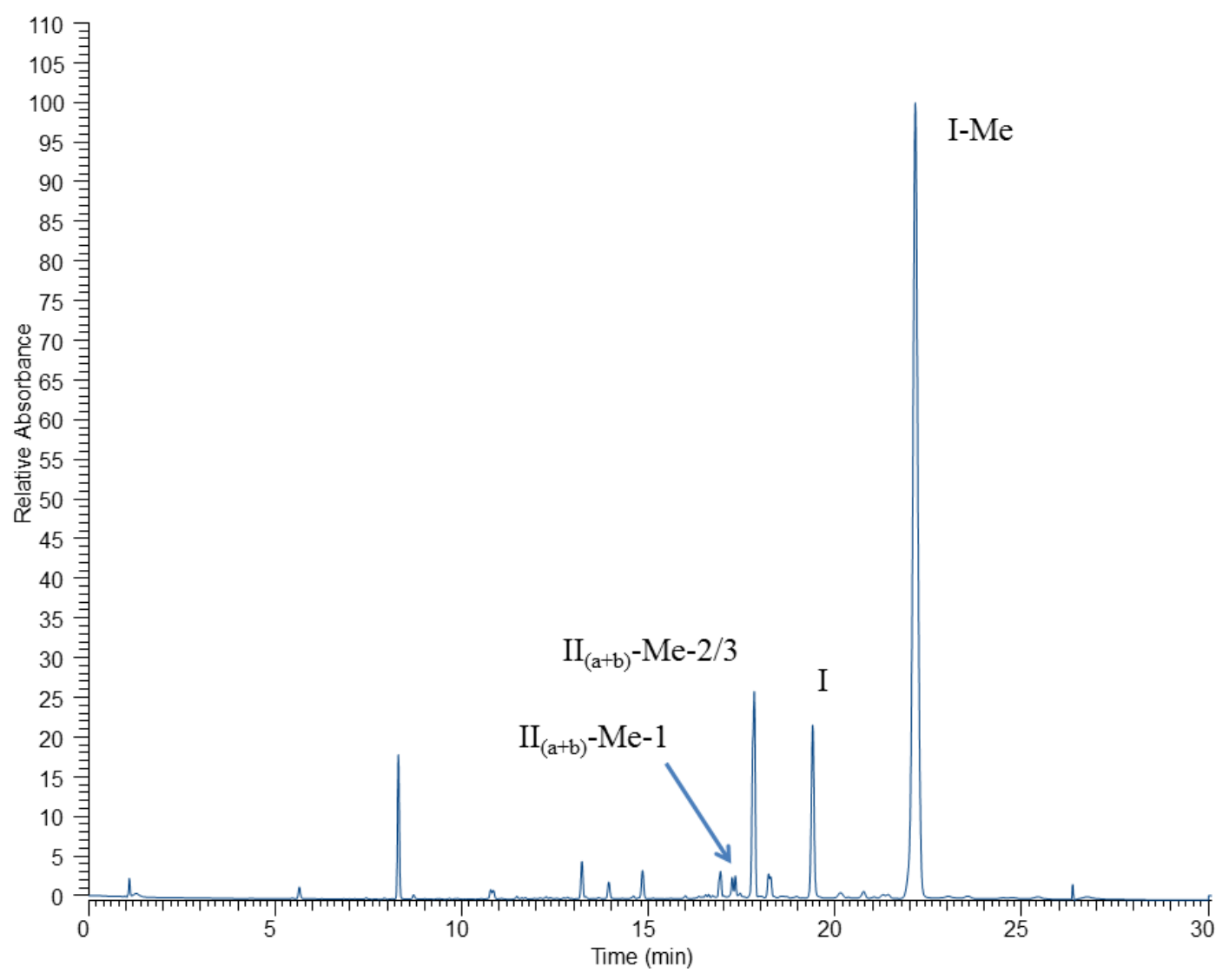

Fig. S8. HPLC-UV $(310 \mathrm{~nm})$ chromatogram of methylated $P$. rigida sporopollenin thioacidolysis 


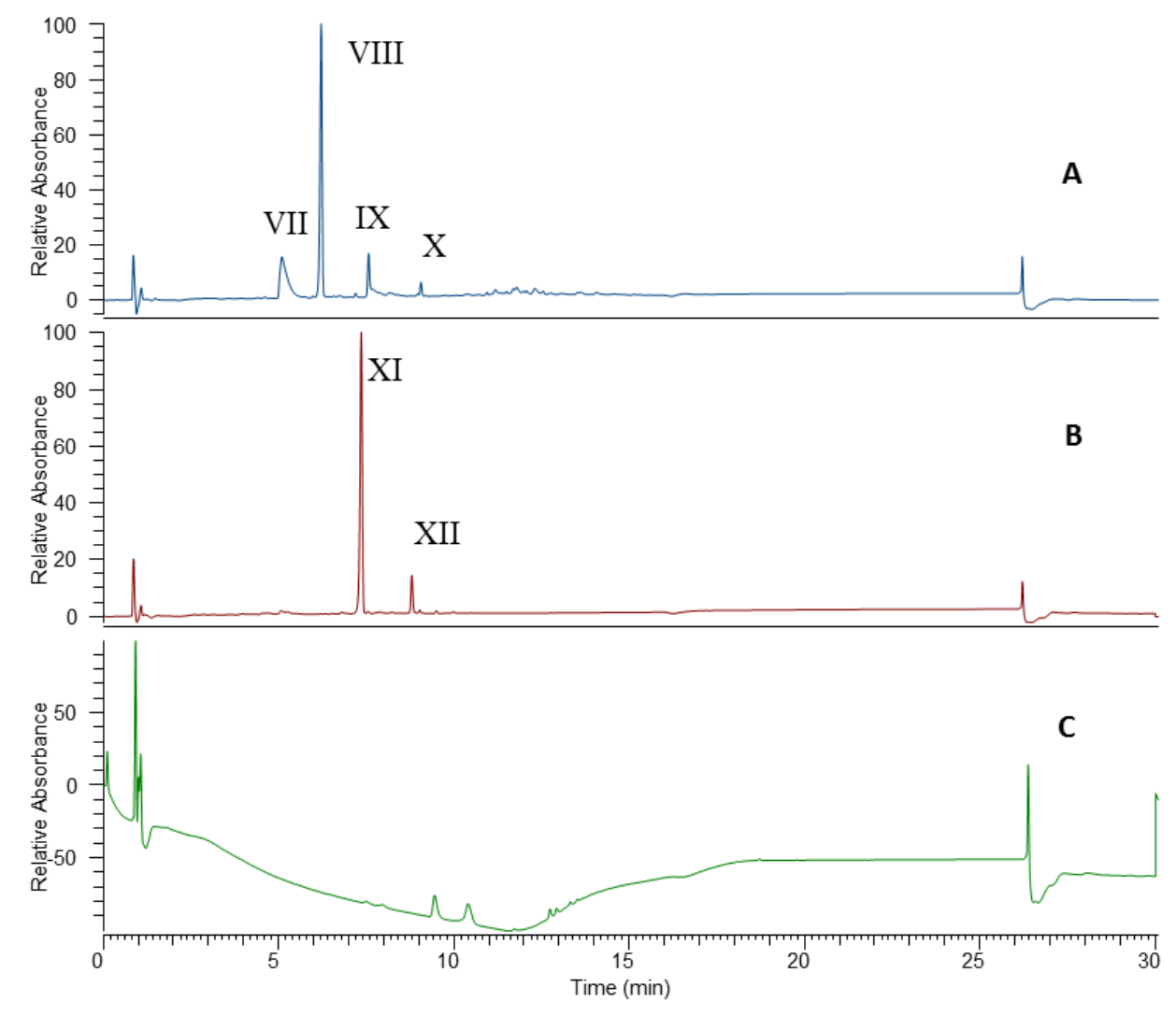

Fig. S9. HPLC-UV (PDA) chromatogram of $P$. rigida sporopollenin and methylated $P$. rigida sporopollenin treated with nitric acid. (A) Degradative products of $P$. rigida sporopollenin treated with nitric acid, (B) Degradative products of methylated $P$. rigida sporopollenin treated with nitric acid, (C) Nitric acid treatment of the residue from methylated $P$. rigida sporopollenin thioacidolysis did not produce detectable degradative products. 


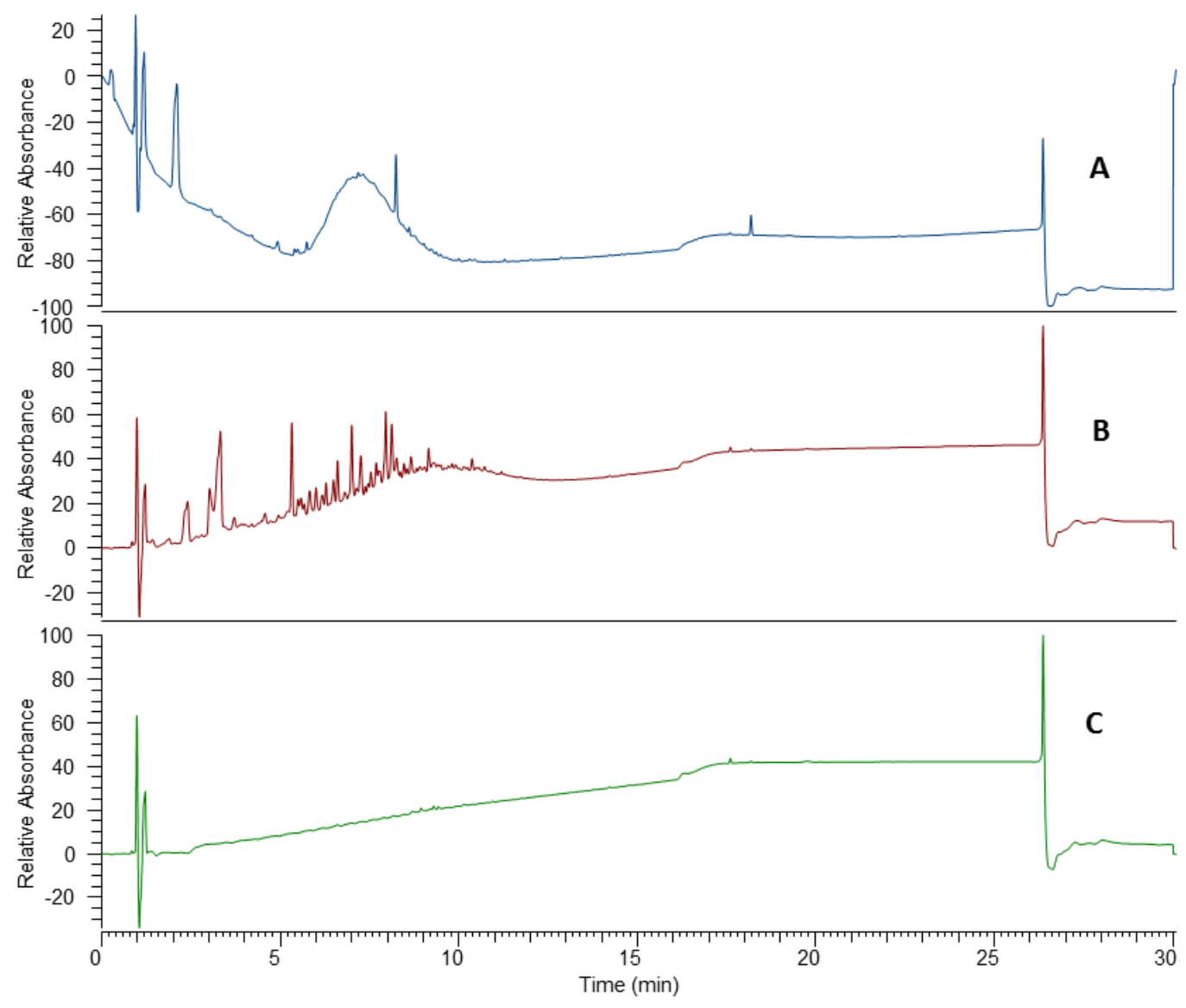

Fig. S10. HPLC-UV (PDA) chromatogram of $P$. rigida sporopollenin and cellulose treated with $\mathbf{8 0} \%$ sulfuric acid. (A) Degradative products of $P$. rigida sporopollenin treated with $80 \%$ sulfuric acid, (B) Degradative products of cellulose treated with $80 \%$ sulfuric acid (C) Blank control chromatogram of $80 \%$ sulfuric acid reaction. 


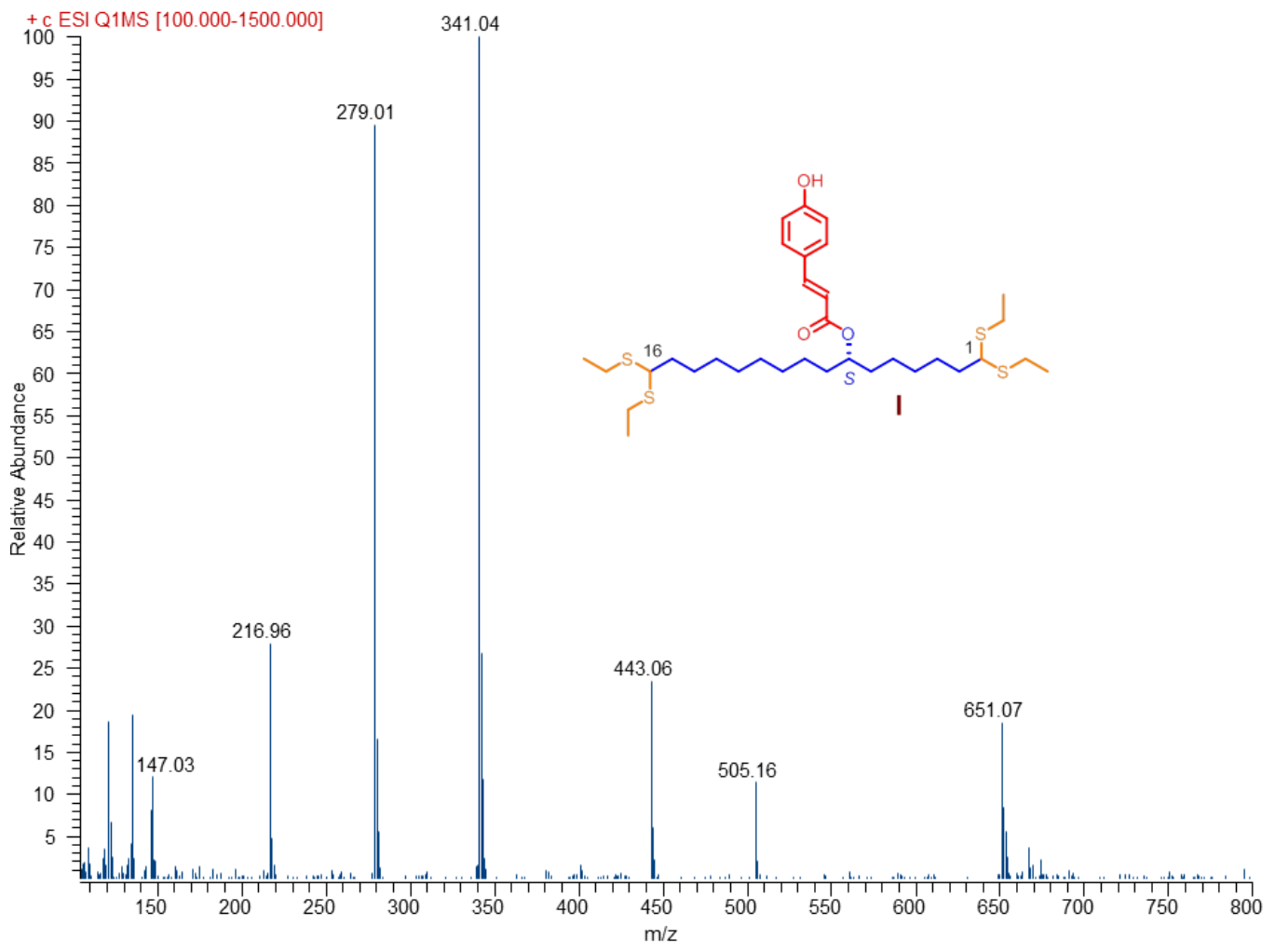

Fig. S11-A. Characterization of compound I, MS/MS spectrum of compound I. 


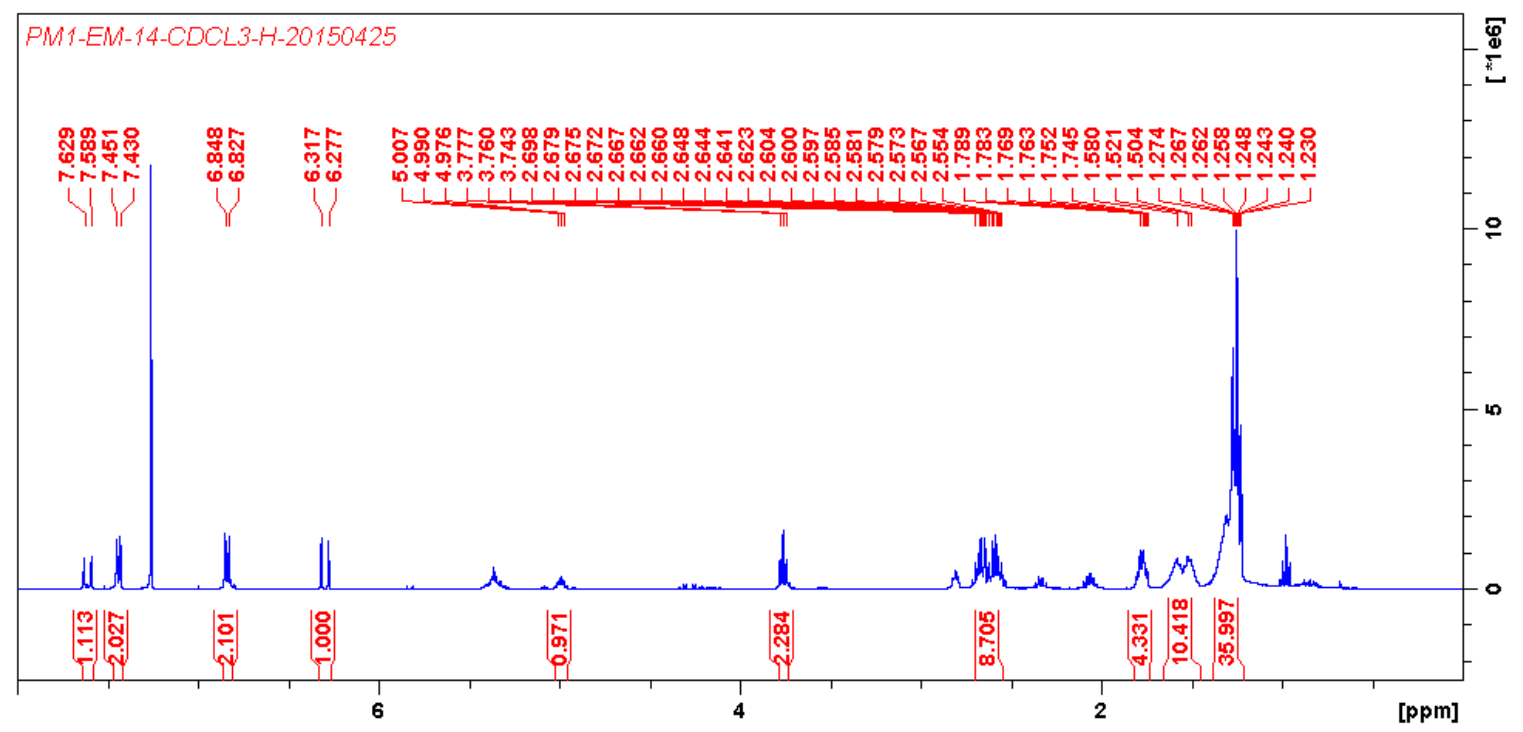

Fig. S11-B. Characterization of compound I, ${ }^{1} \mathrm{H}$ NMR $\left(400 \mathrm{MHz}, \mathrm{CDCl}_{3}\right)$ spectrum of compound $\mathrm{I}$. 


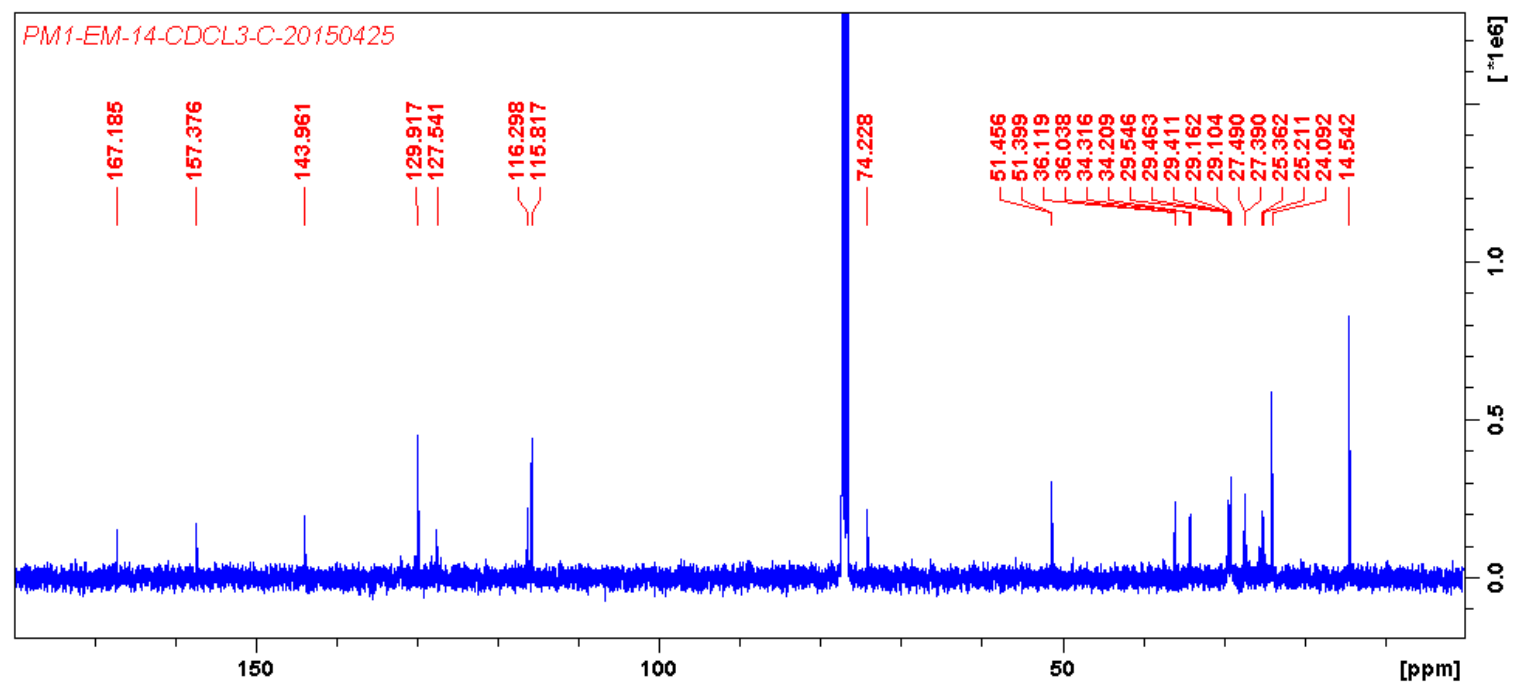

Fig. S11-C. Characterization of compound I, ${ }^{13} \mathrm{C}$ NMR $\left(100 \mathrm{MHz}, \mathrm{CDCl}_{3}\right)$ spectrum of compound I 


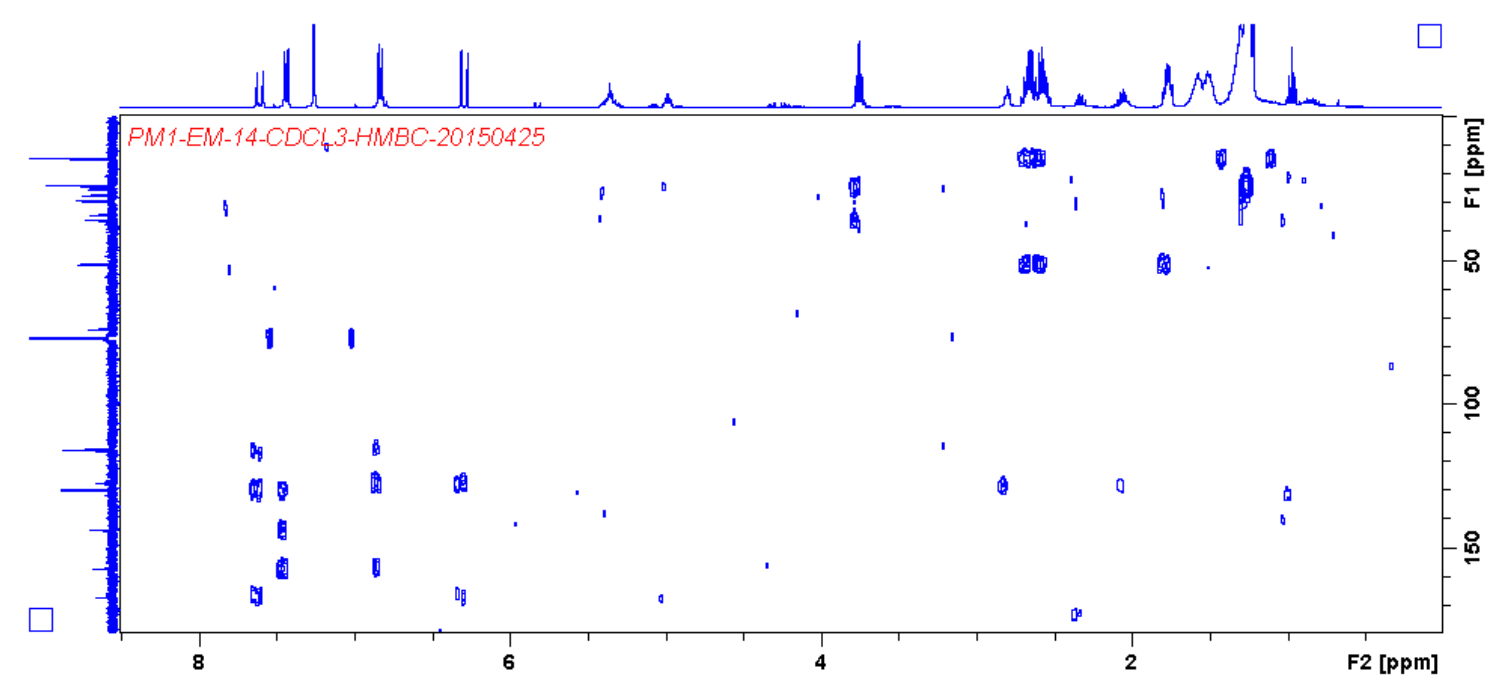

Fig. S11-D. Characterization of compound I, HMBC spectrum of compound I. 


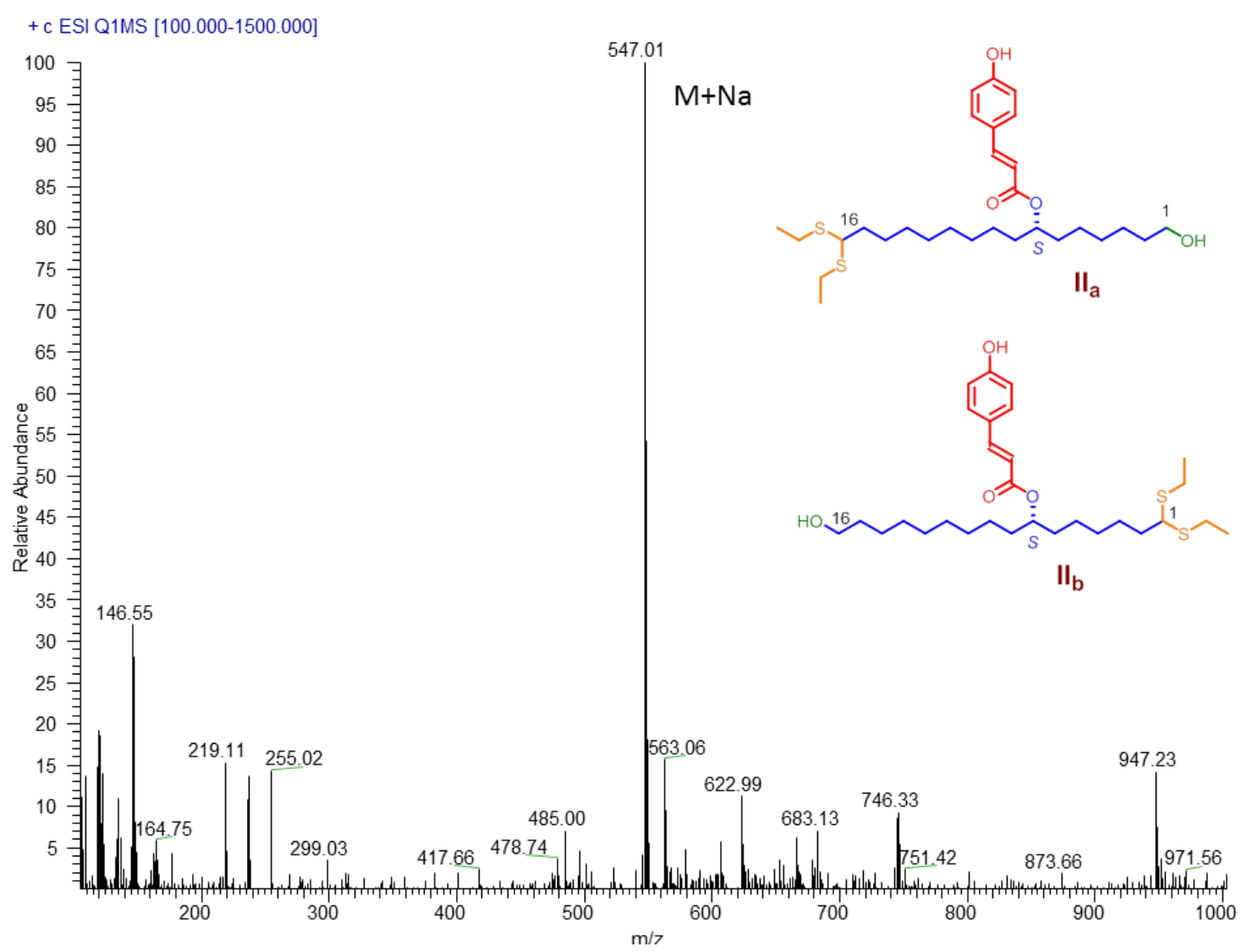

Fig. S12-A. Characterization of compound II, MS/MS spectrum of compound II. 


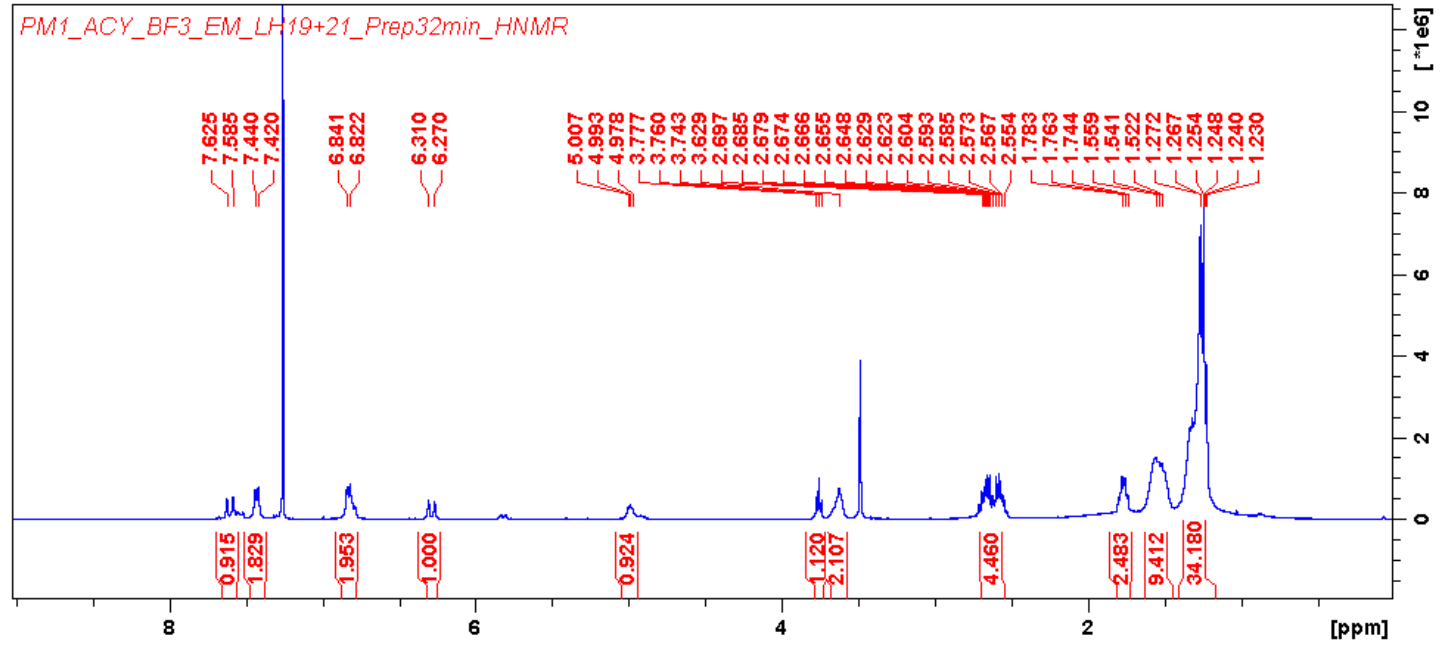

Fig. S12-B. Characterization of compound II, ${ }^{1} \mathrm{H}$ NMR $\left(400 \mathrm{MHz}, \mathrm{CDCl}_{3}\right)$ spectrum of compound II. 


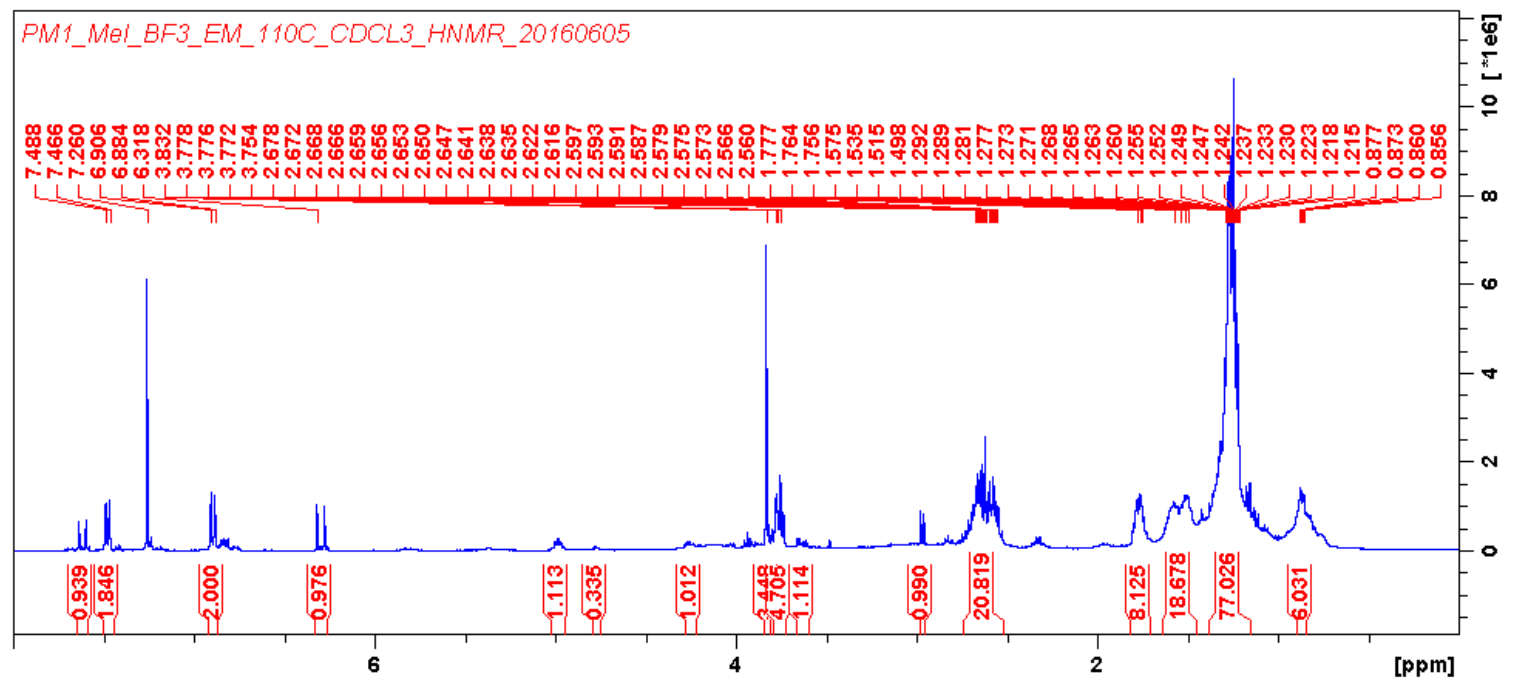

Fig. S13. ${ }^{1} \mathrm{H}$ NMR $\left(400 \mathrm{MHz}, \mathrm{CDCl}_{3}\right)$ spectrum of total soluble products of methylated $P$. rigida sporopollenin thioacidolysis. 


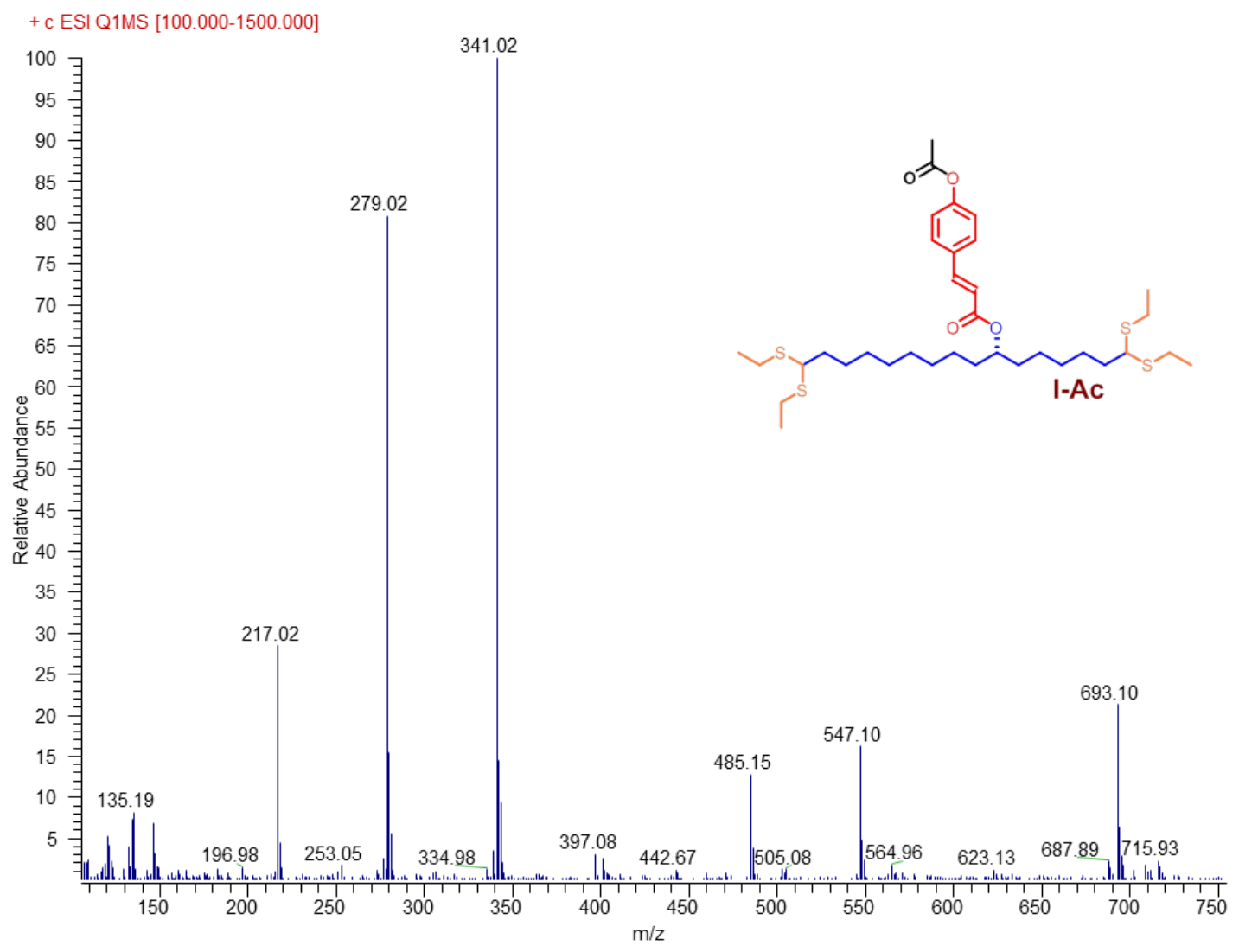

Fig. S14-A. Characterization of compound I-Ac, MS/MS spectrum of compound I-Ac. 


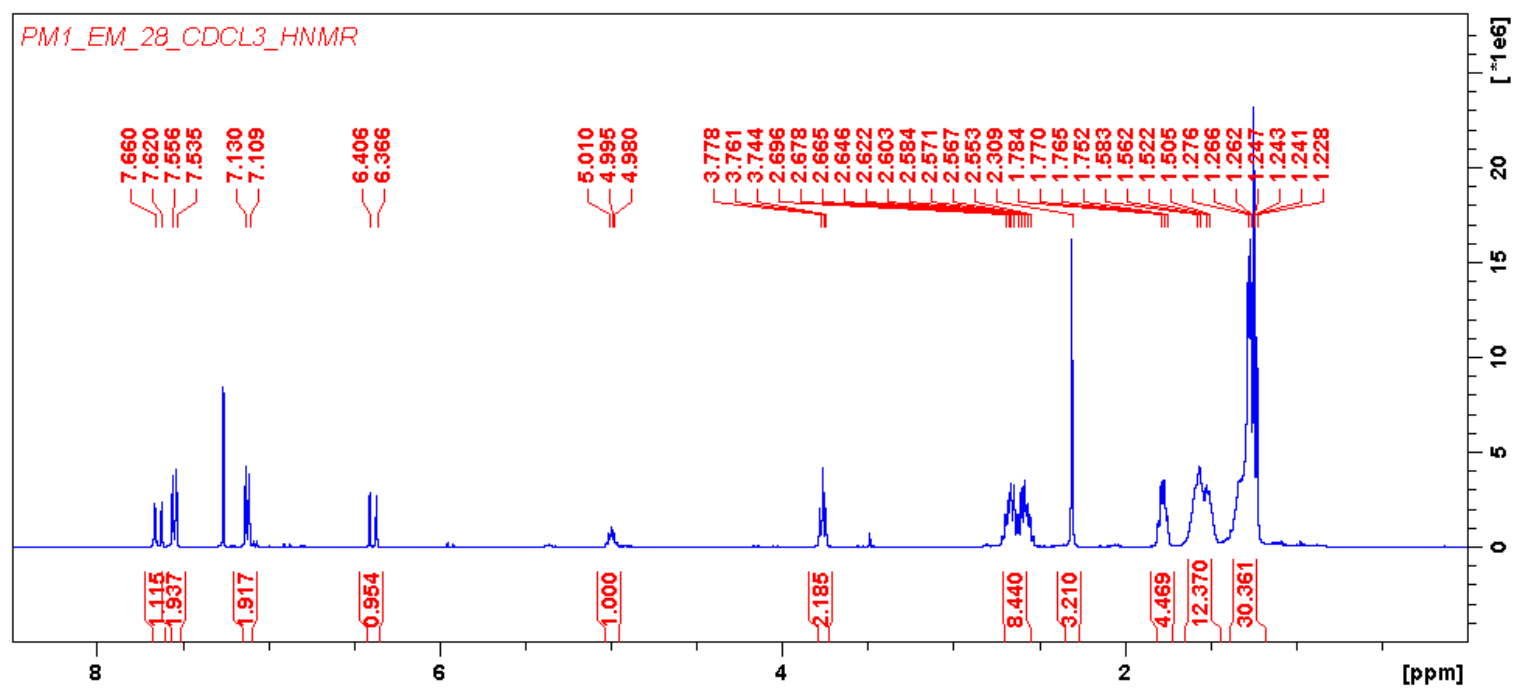

Fig. S14-B. Characterization of compound I-Ac, ${ }^{1} \mathrm{H}$ NMR $\left(400 \mathrm{MHz}, \mathrm{CDCl}_{3}\right)$ spectrum of compound I-Ac. 


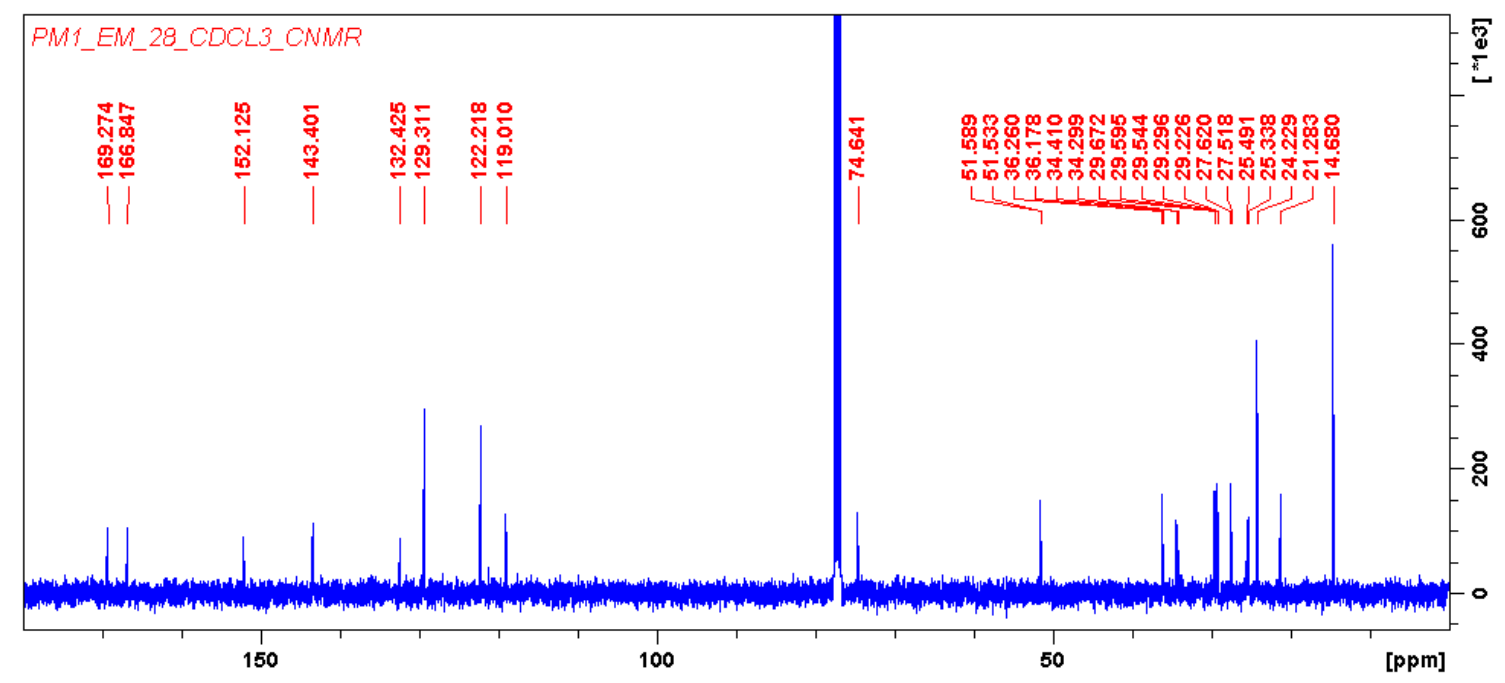

Fig. S14-C. Characterization of compound I-Ac, ${ }^{13} \mathrm{C} \mathrm{NMR}\left(100 \mathrm{MHz}, \mathrm{CDCl}_{3}\right)$ spectrum of compound I-Ac. 


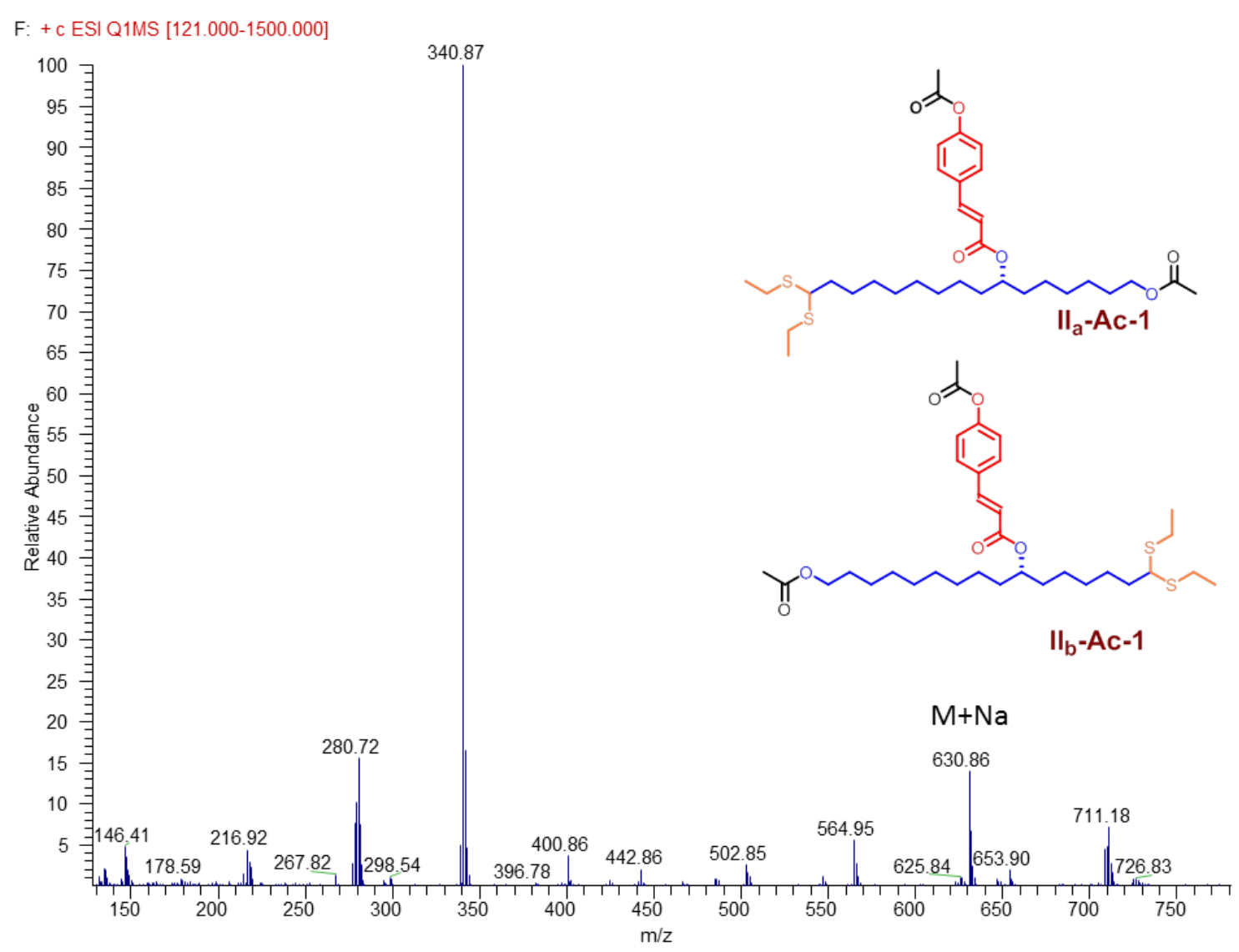

Fig. S15-A. Characterization of compound $\mathrm{II}_{(\mathrm{a}+\mathrm{b})}-\mathrm{Ac}-1, \mathrm{MS} / \mathrm{MS}$ spectrum of compound II $(\mathrm{a}+\mathrm{b})-\mathrm{Ac}-1$. 


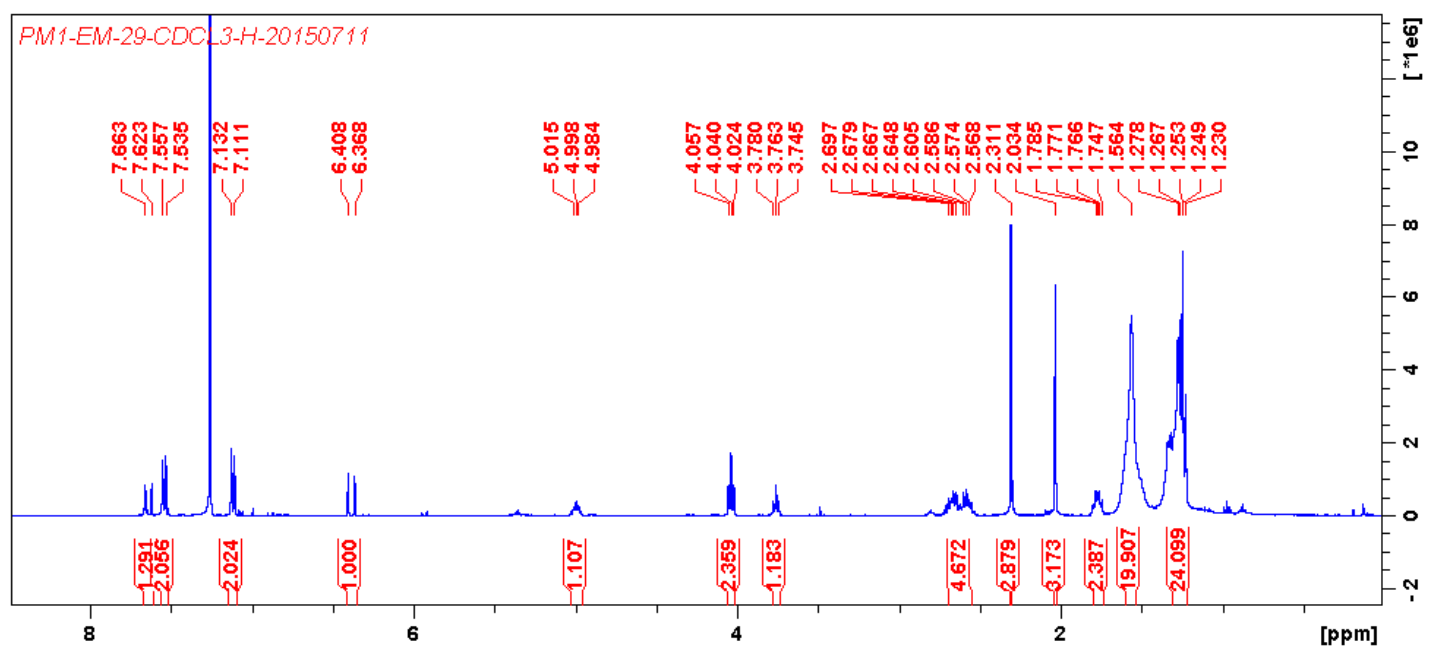

Fig. S15-B. Characterization of compound $\mathrm{II}_{(\mathrm{a}+\mathrm{b})}-\mathrm{Ac}-1,{ }^{1} \mathrm{H}$ NMR $\left(400 \mathrm{MHz}, \mathrm{CDCl}_{3}\right)$ spectrum of compound $\mathrm{II}_{(\mathrm{a}+\mathrm{b})}-\mathrm{Ac}-1$. 


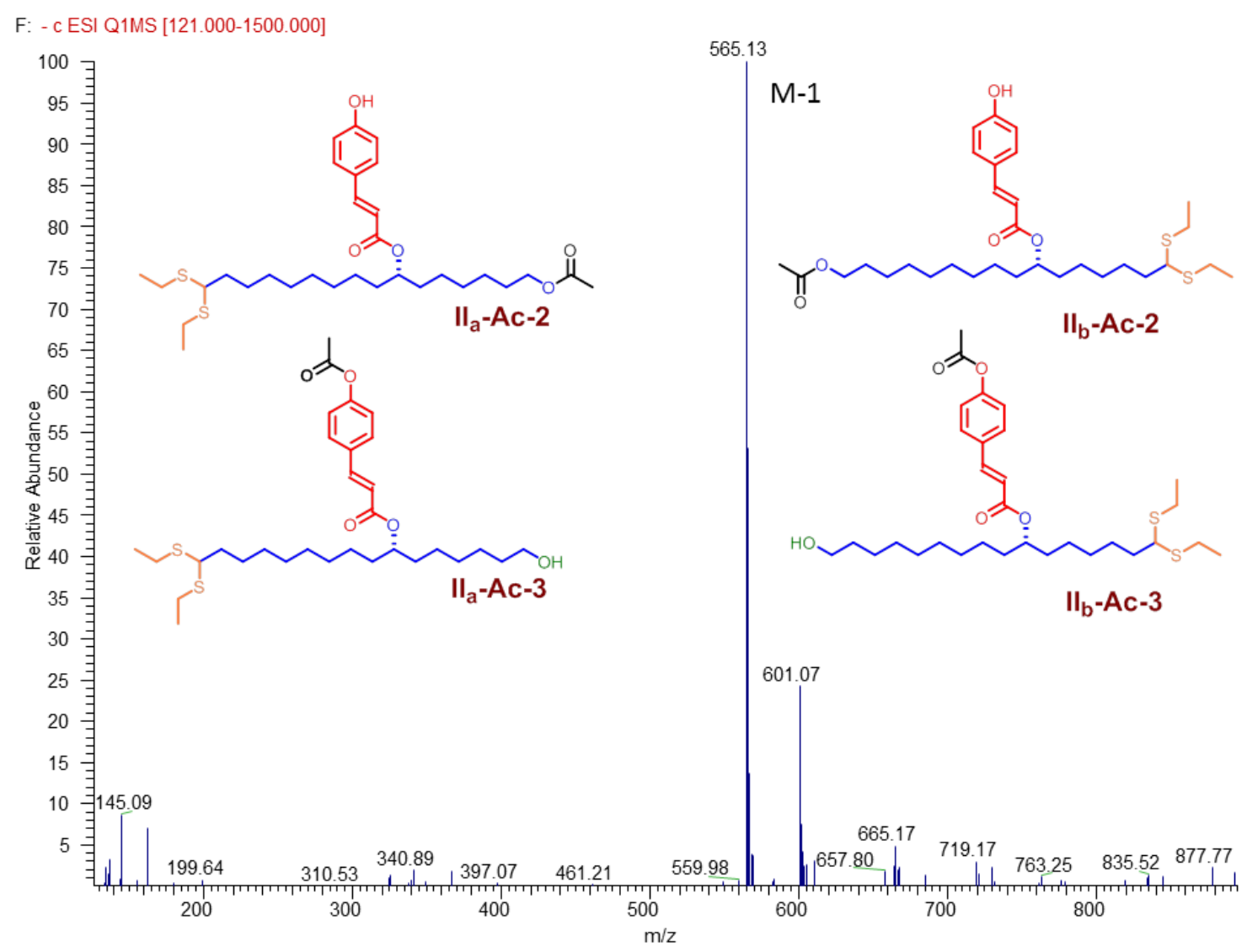

Fig. S16. Characterization of compound $\mathrm{II}_{(\mathrm{a}+\mathrm{b})}-\mathrm{Ac}-2$ and $\mathrm{II}_{(\mathrm{a}+\mathrm{b})}-\mathrm{Ac}-3, \mathrm{MS} / \mathrm{MS}$ spectrum of compound $\mathrm{II}_{(\mathrm{a}+\mathrm{b})}-\mathrm{Ac}-2$ and $\mathrm{II}_{(\mathrm{a}+\mathrm{b})}-\mathrm{Ac}-3$. 


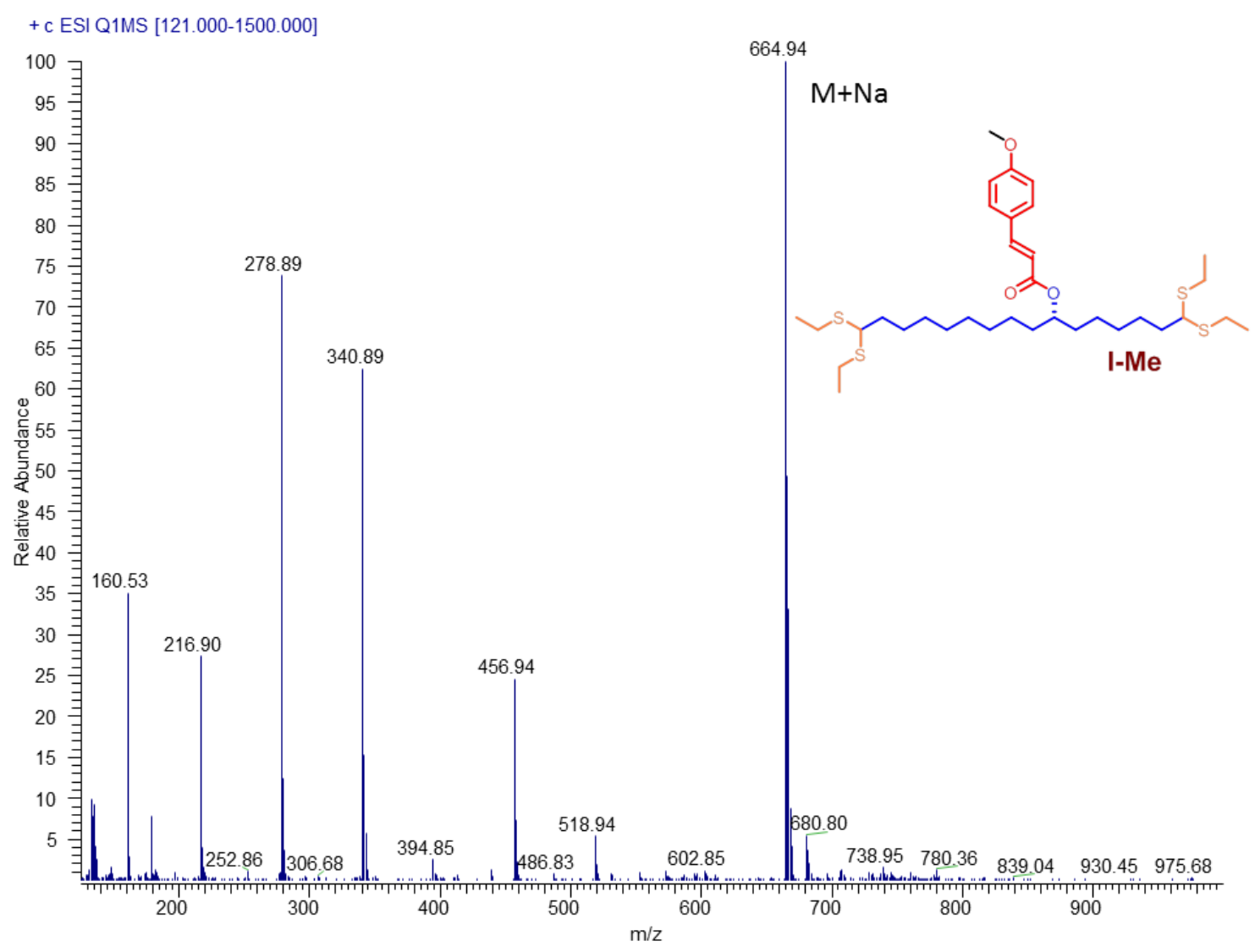

Fig. S17. Characterization of compound I-Me, MS/MS spectrum of compound I-Me. 


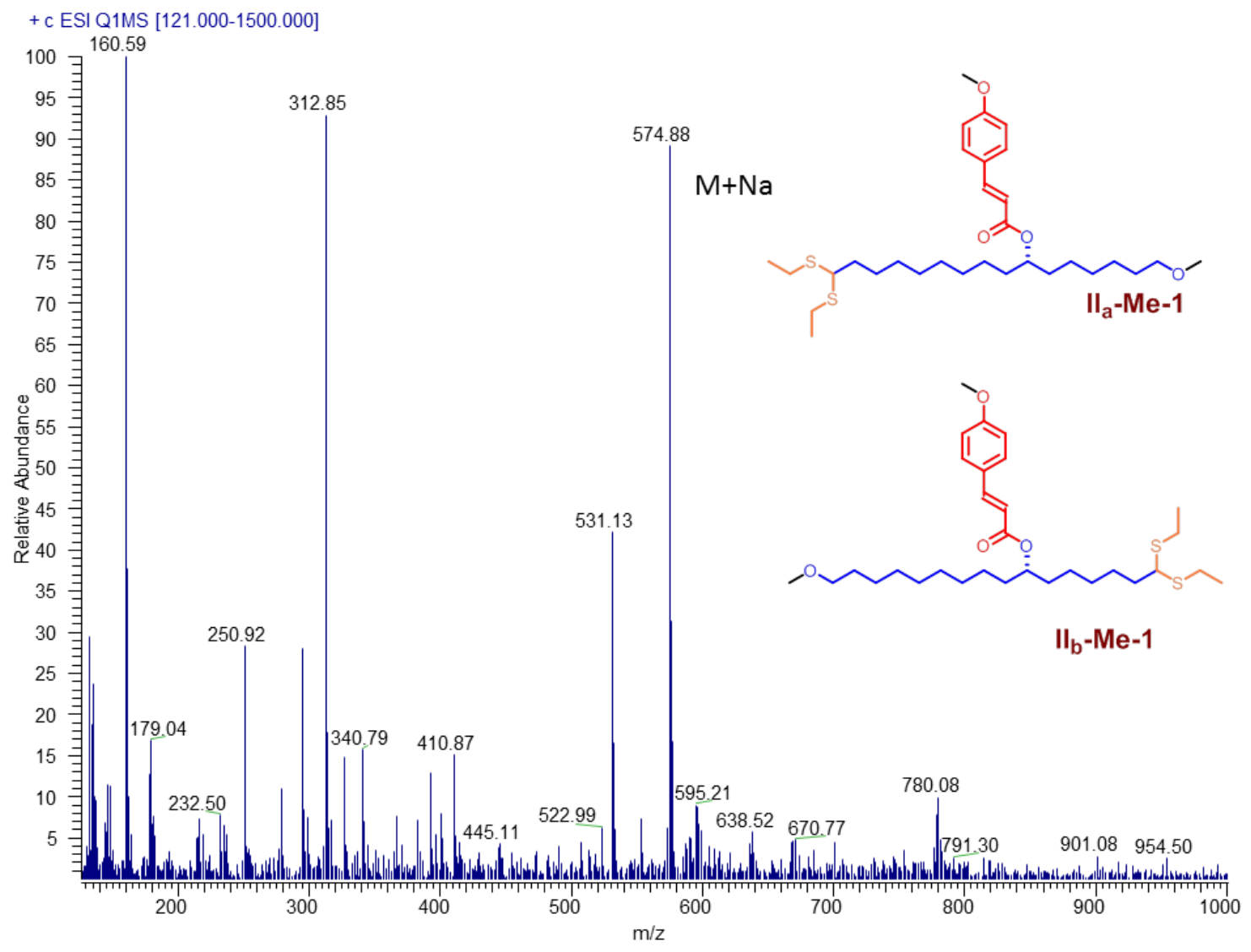

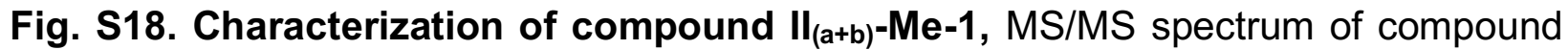
$\mathrm{II}_{(\mathrm{a}+\mathrm{b})}-\mathrm{Me}-1$. 


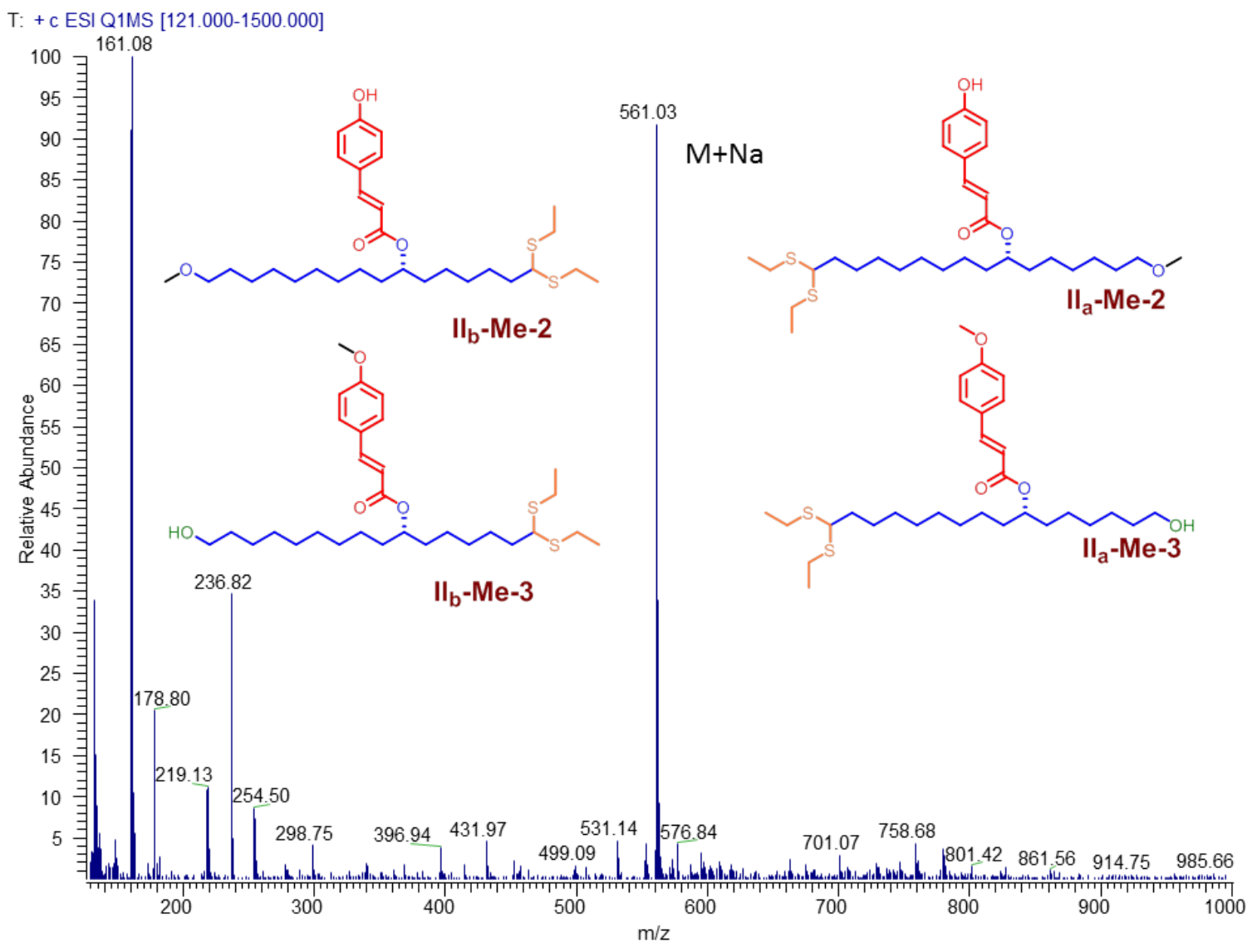

Fig. S19. Characterization of compound $\|_{(a+b)}-M e-2$ and $\|_{(a+b)}-M e-3, M S / M S$ spectrum of compound $\mathrm{II}_{(\mathrm{a}+\mathrm{b})}-\mathrm{Me}-2$ and $\mathrm{II}_{(\mathrm{a}+\mathrm{b})}-\mathrm{Me}-3$. 


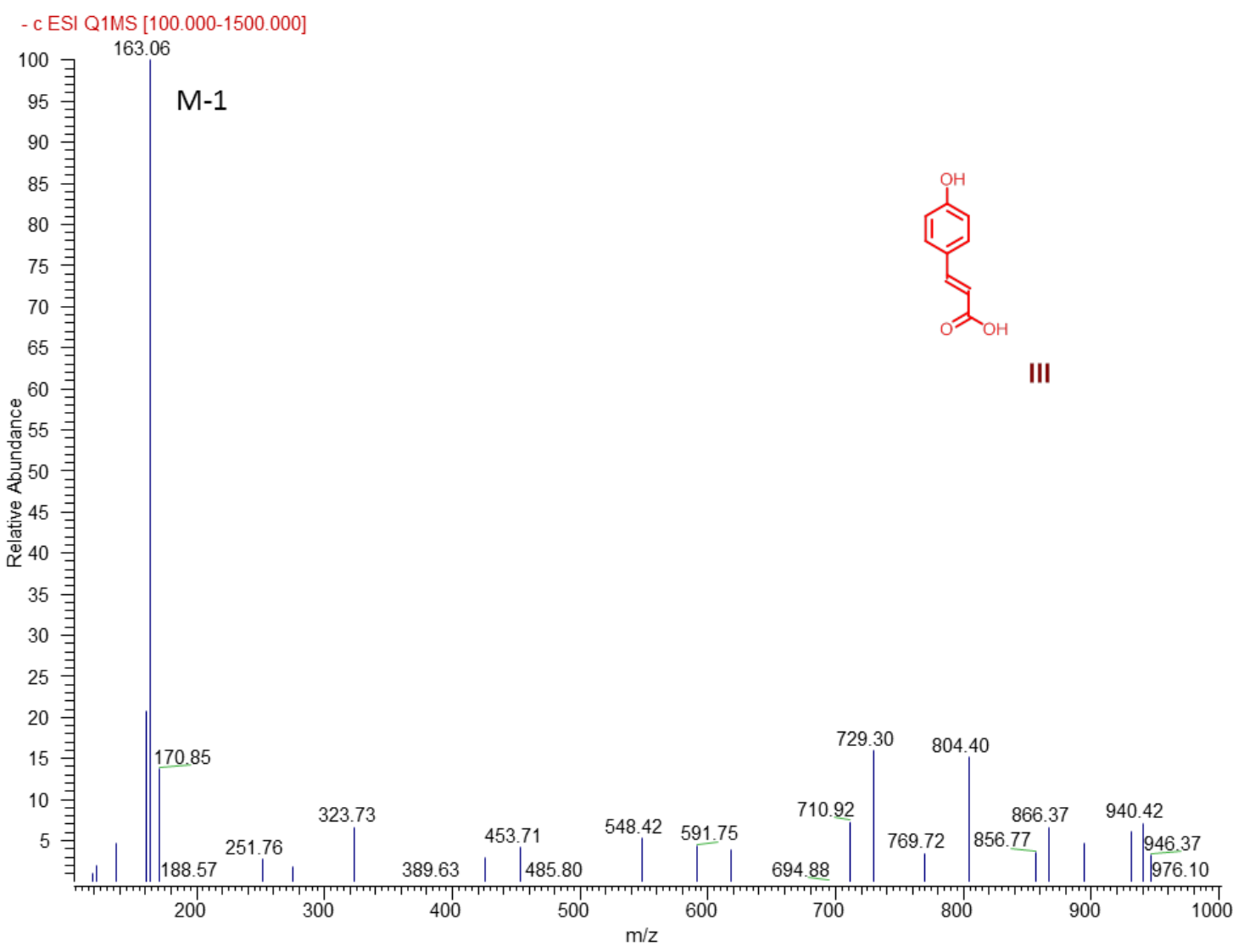

Fig. S20-A. MS/MS spectrum of compound III 


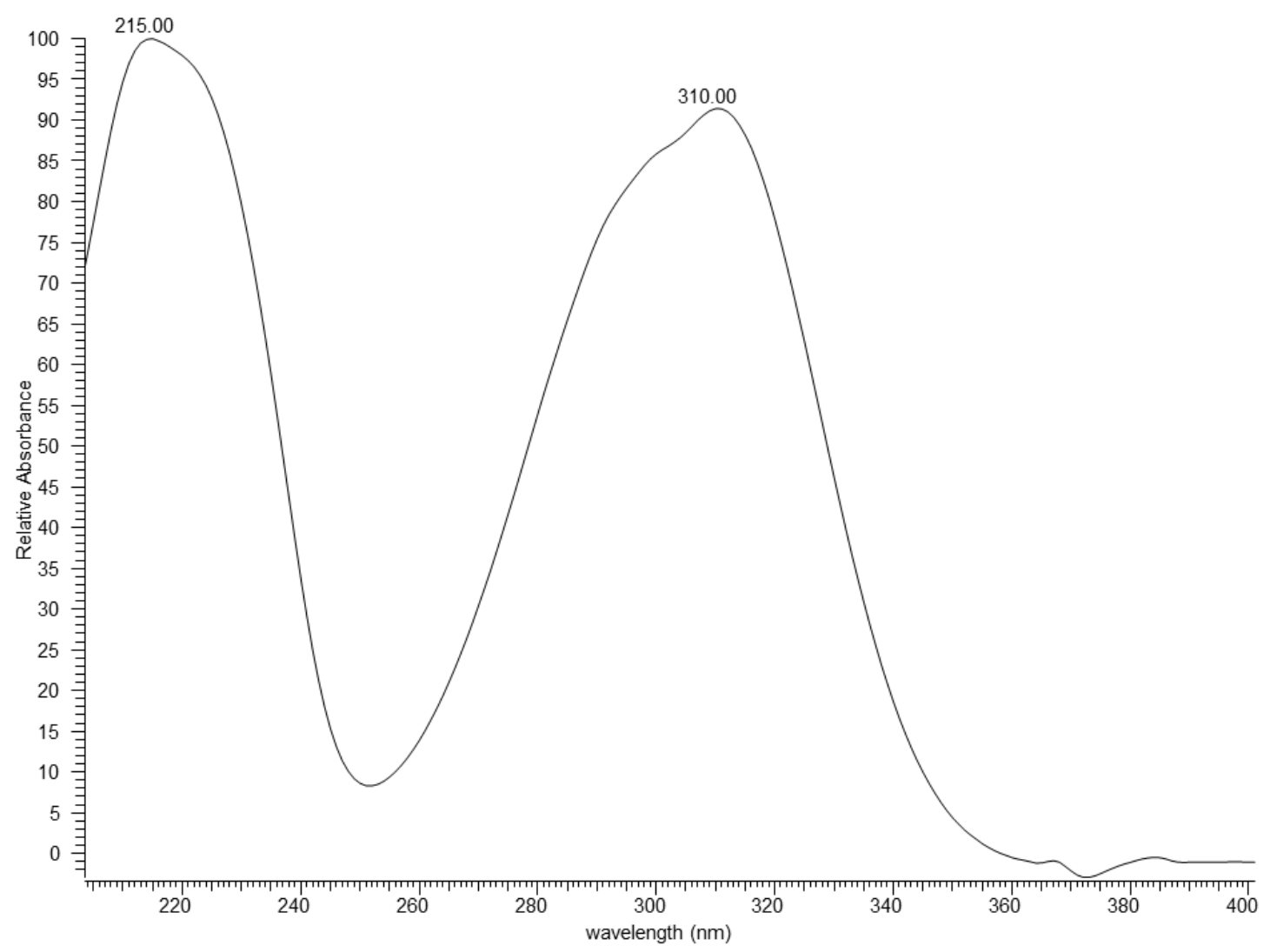

Fig. S20-B. UV spectrum of compound III, Compound III was confirmed as $p$ coumaric acid by comparing its retention time, UV and MS/MS spectra with that of the reference standard. 


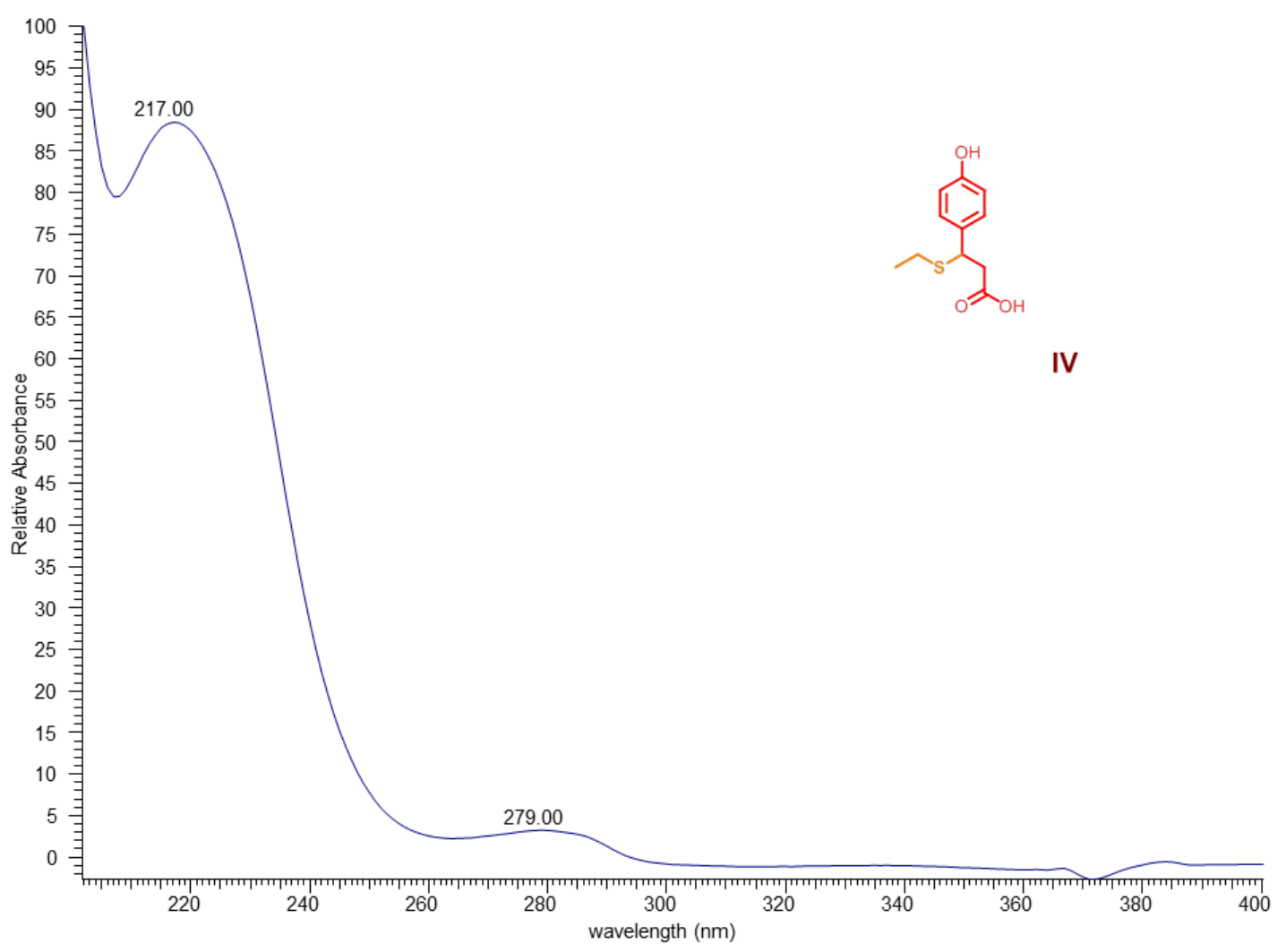

Fig. S21-A. Characterization of compound IV, UV spectrum of compound IV. 


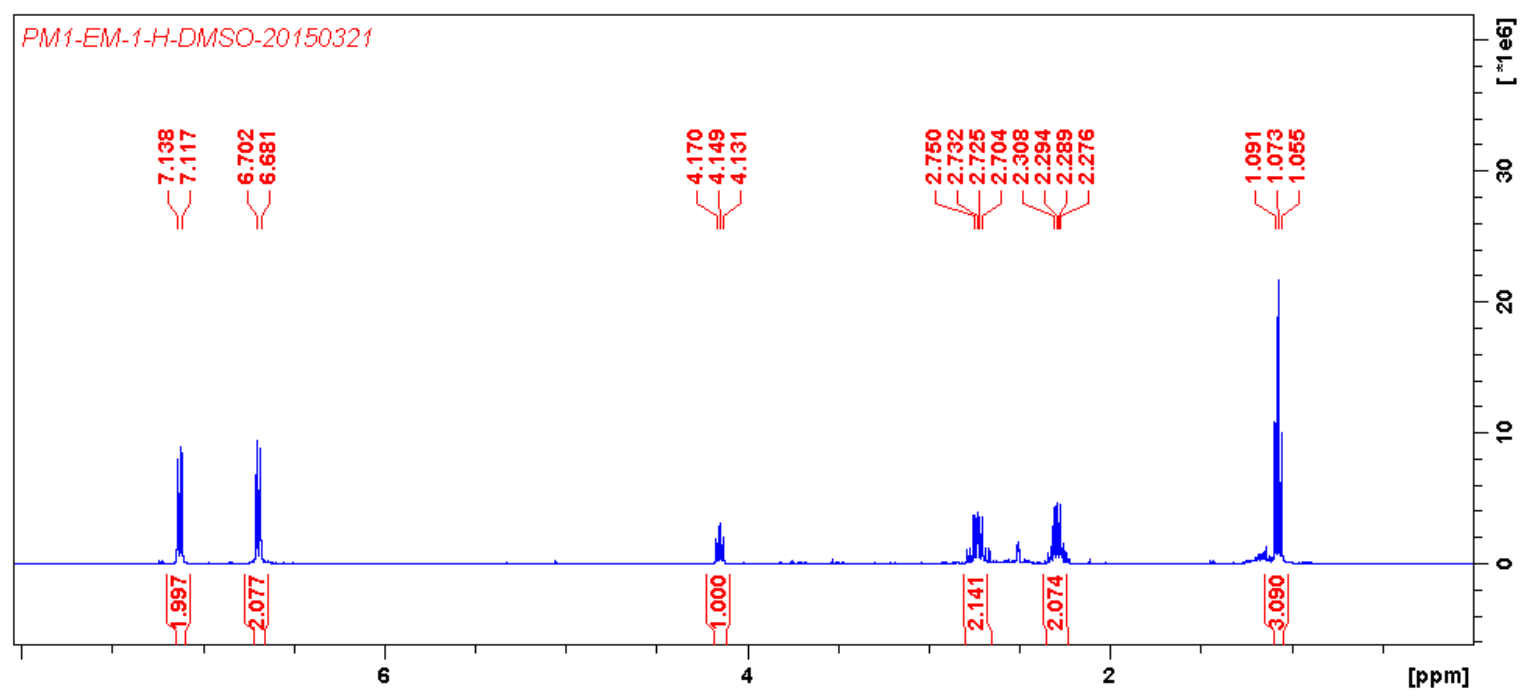

Fig. S21-B. Characterization of compound IV, ${ }^{1} \mathrm{H}$ NMR $\left(400 \mathrm{MHz}\right.$, DMSO- $\left.d_{6}\right)$ spectrum of compound IV. 


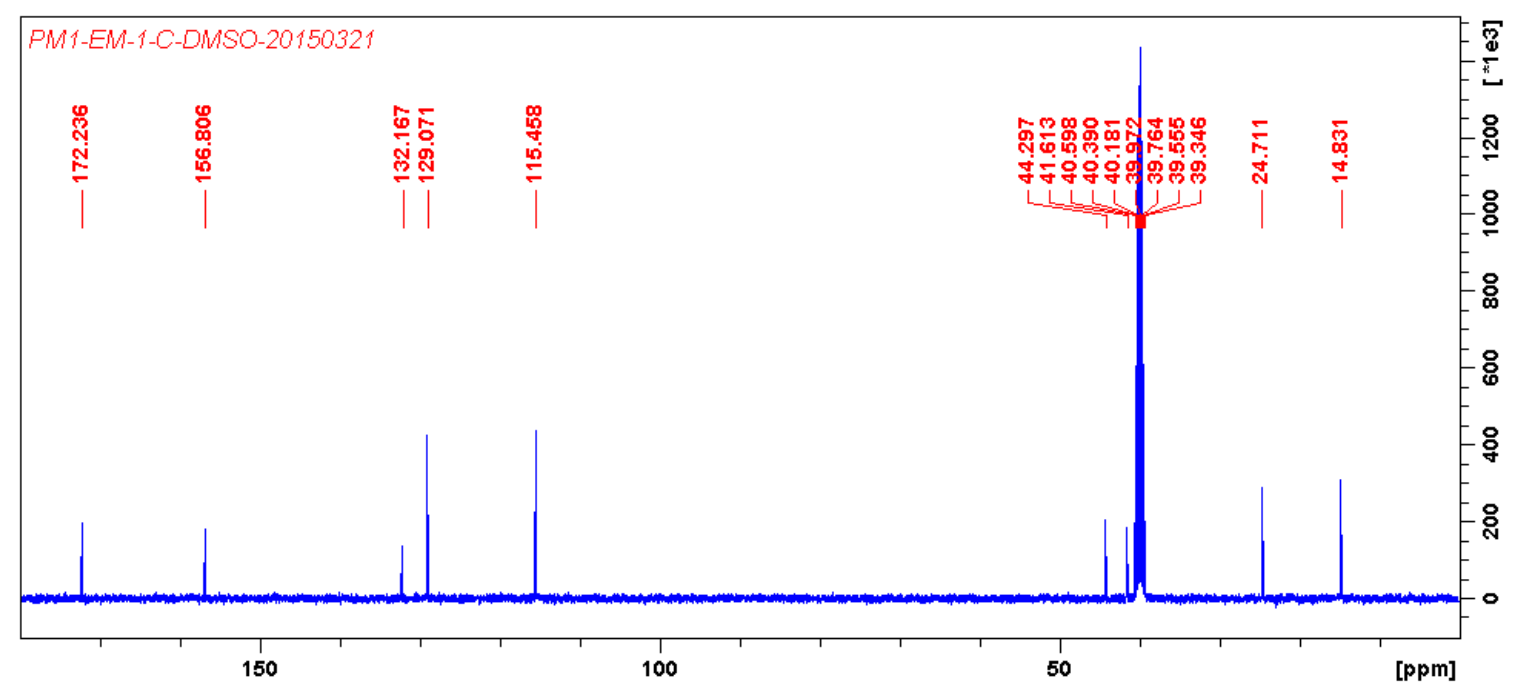

Fig. S21-C. Characterization of compound IV, ${ }^{13} \mathrm{C}$ NMR (100 MHz, DMSO- $\left.d_{6}\right)$ spectrum of compound IV. 


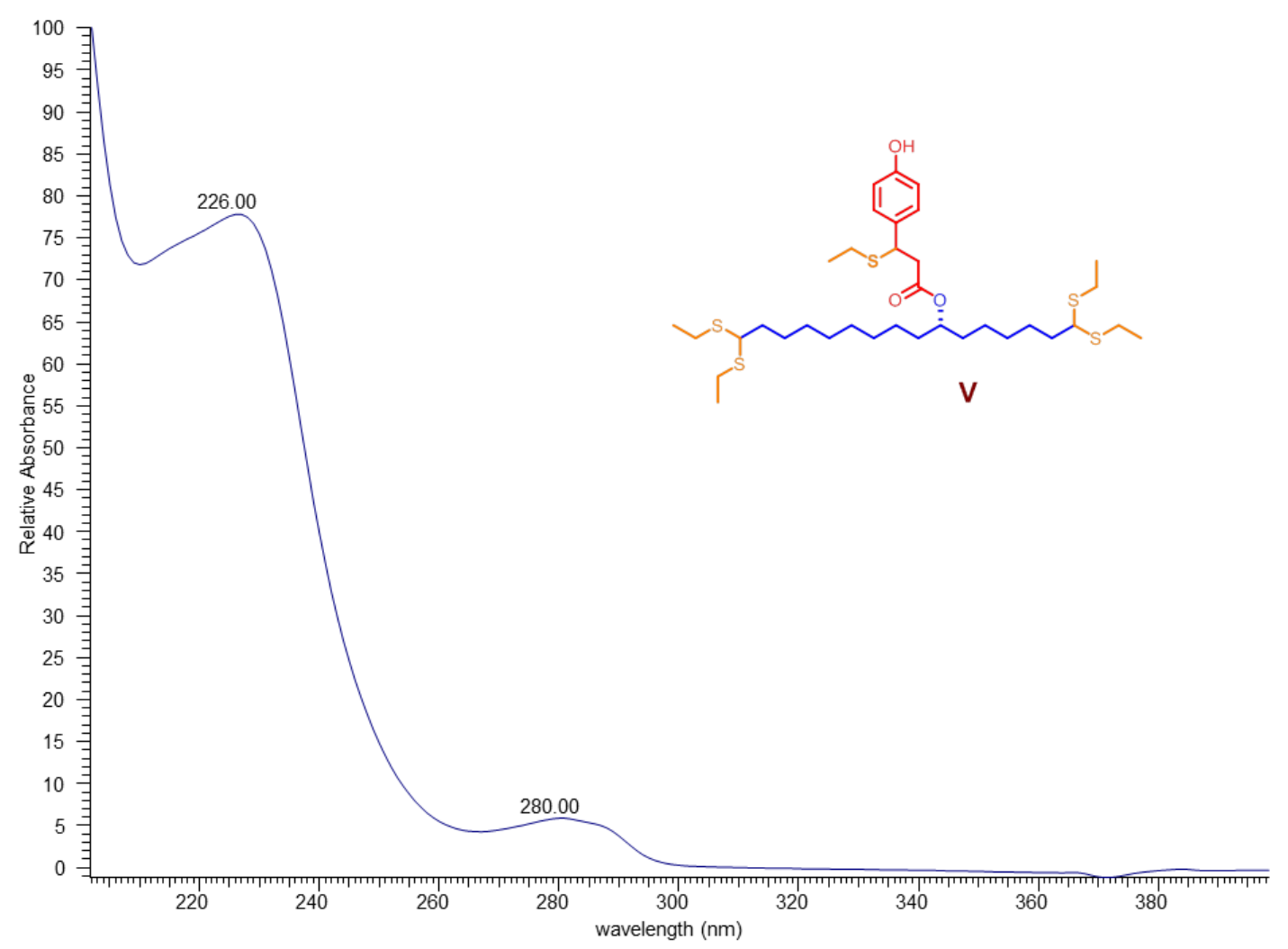

Fig. S22-A. Characterization of compound V, UV spectrum of compound V. 


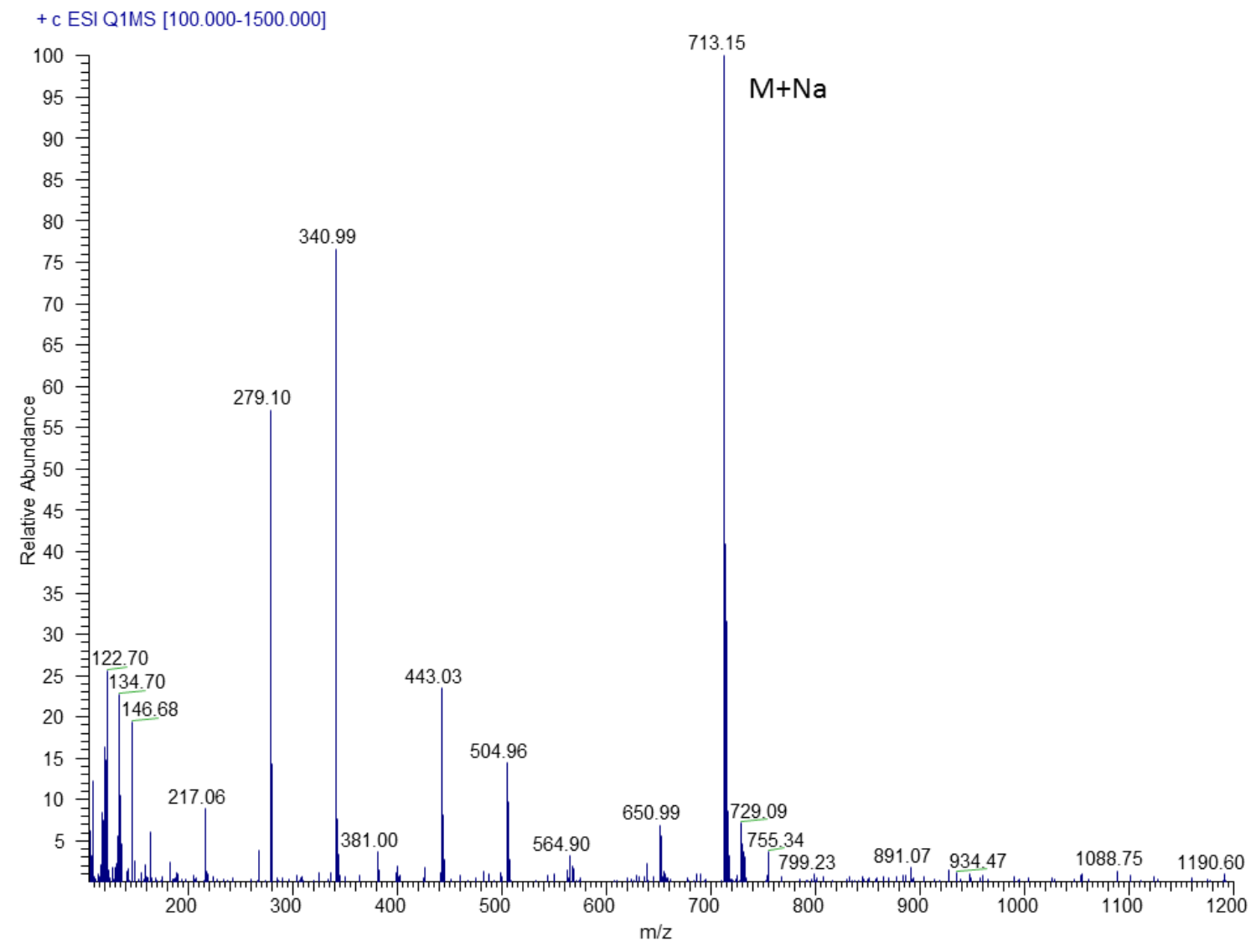

Fig. S22-B. Characterization of compound V, MS/MS spectrum of compound V. 


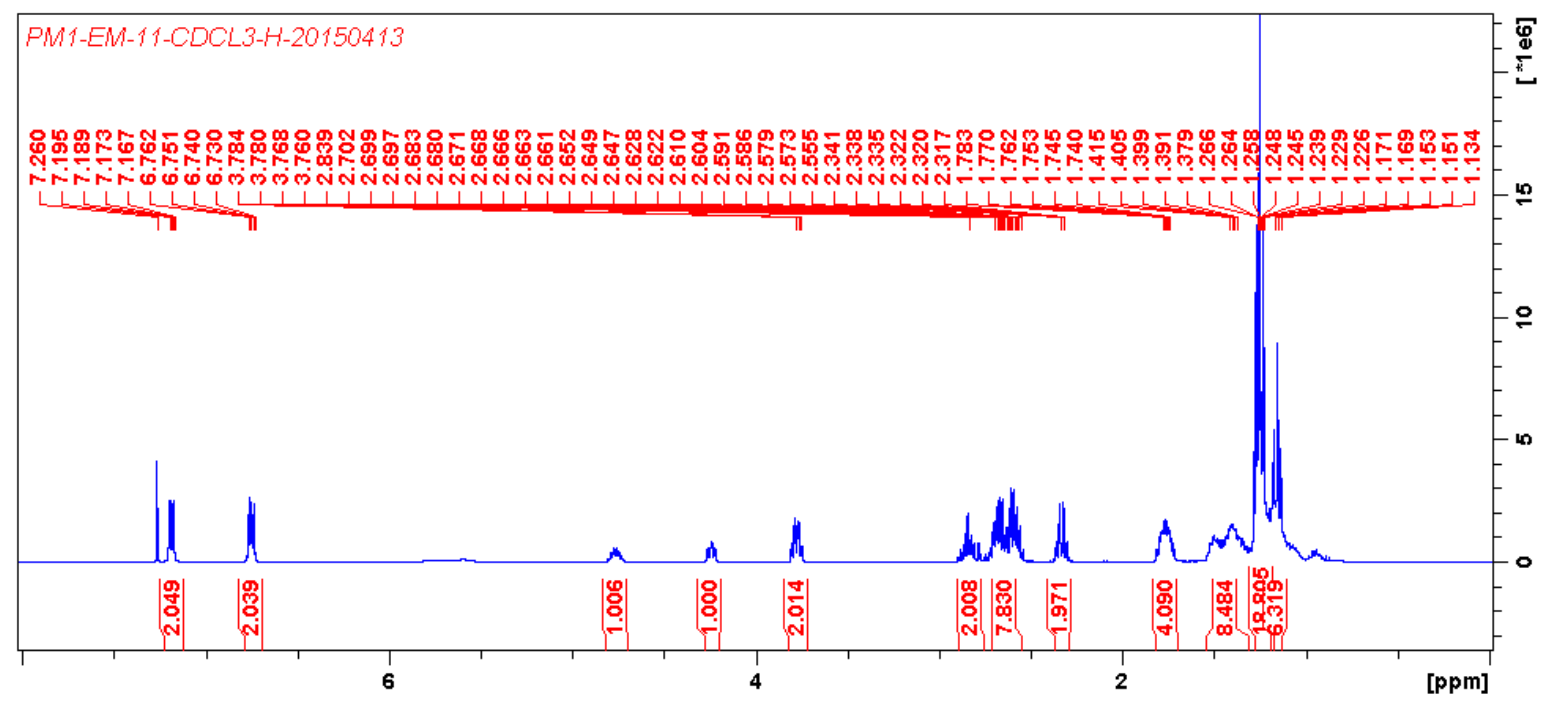

Fig. S22-C. Characterization of compound V, ${ }^{1} \mathrm{H}$ NMR $\left(400 \mathrm{MHz}, \mathrm{CDCl}_{3}\right)$ spectrum of compound $\mathbf{V}$. 


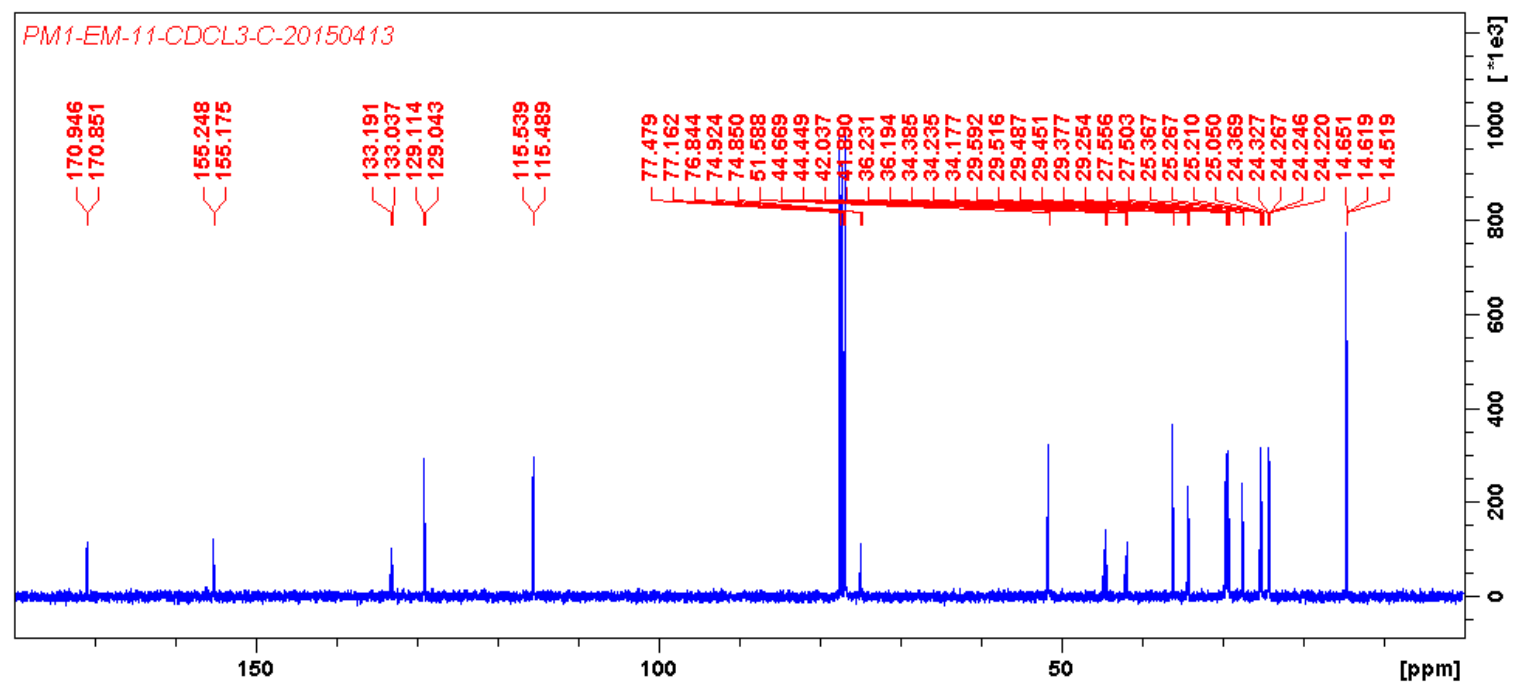

Fig. S22-D. Characterization of compound V, ${ }^{13} \mathrm{C}$ NMR $\left(100 \mathrm{MHz}, \mathrm{CDCl}_{3}\right)$ spectrum of compound $\mathbf{V}$. 


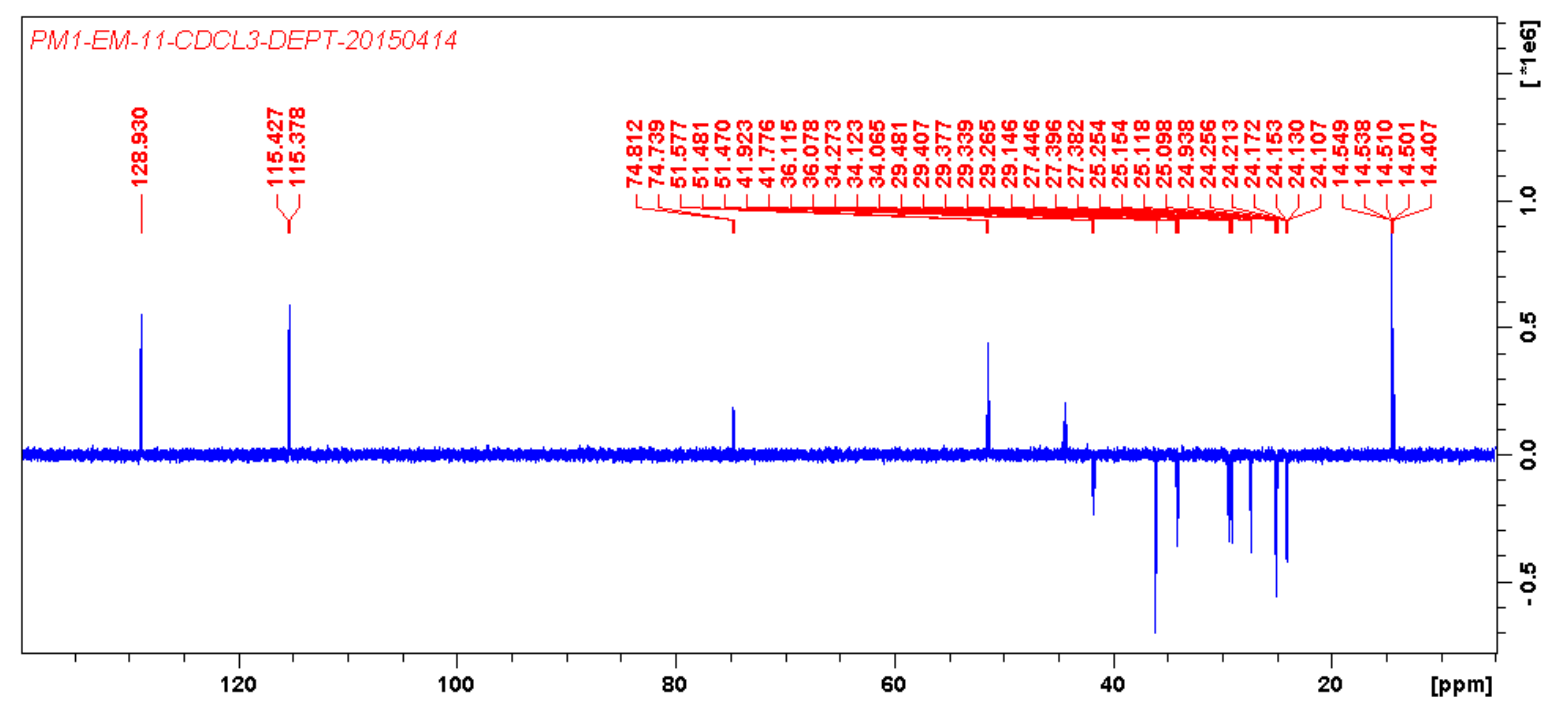

Fig. S22-E. Characterization of compound V, DEPT spectrum of compound V. 


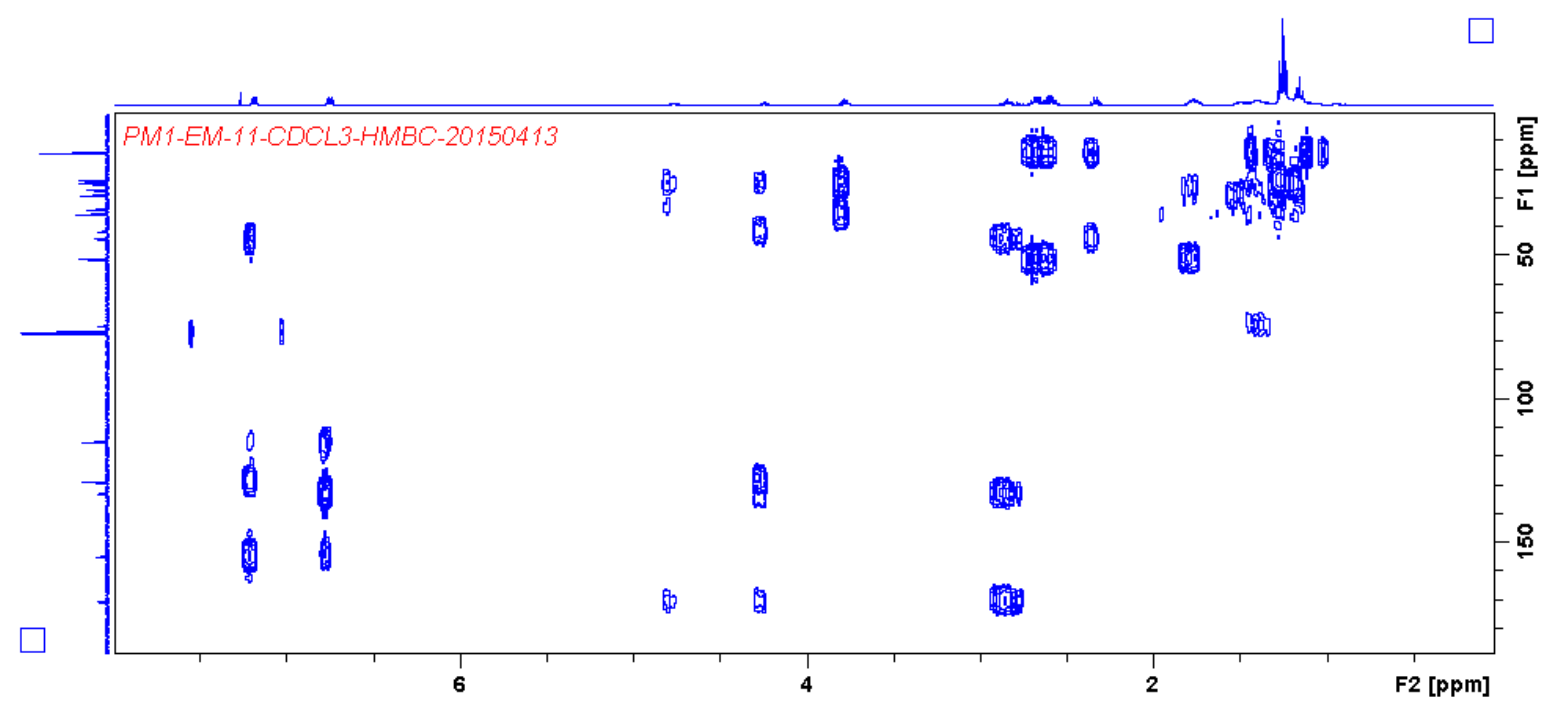

Fig. S22-F. Characterization of compound V, HMBC spectrum of compound V. 


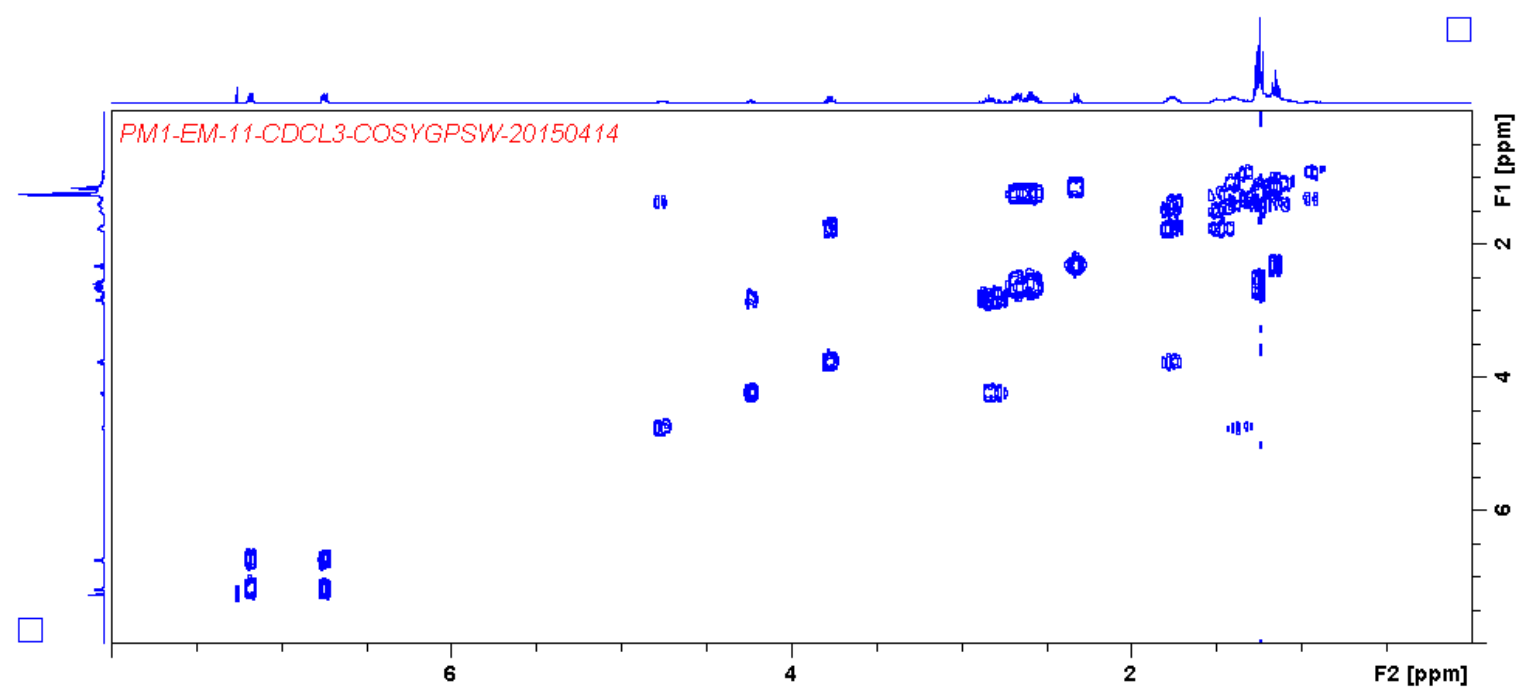

Fig. S22-G. Characterization of compound V, HH-COSY spectrum of compound $\mathbf{V}$. 


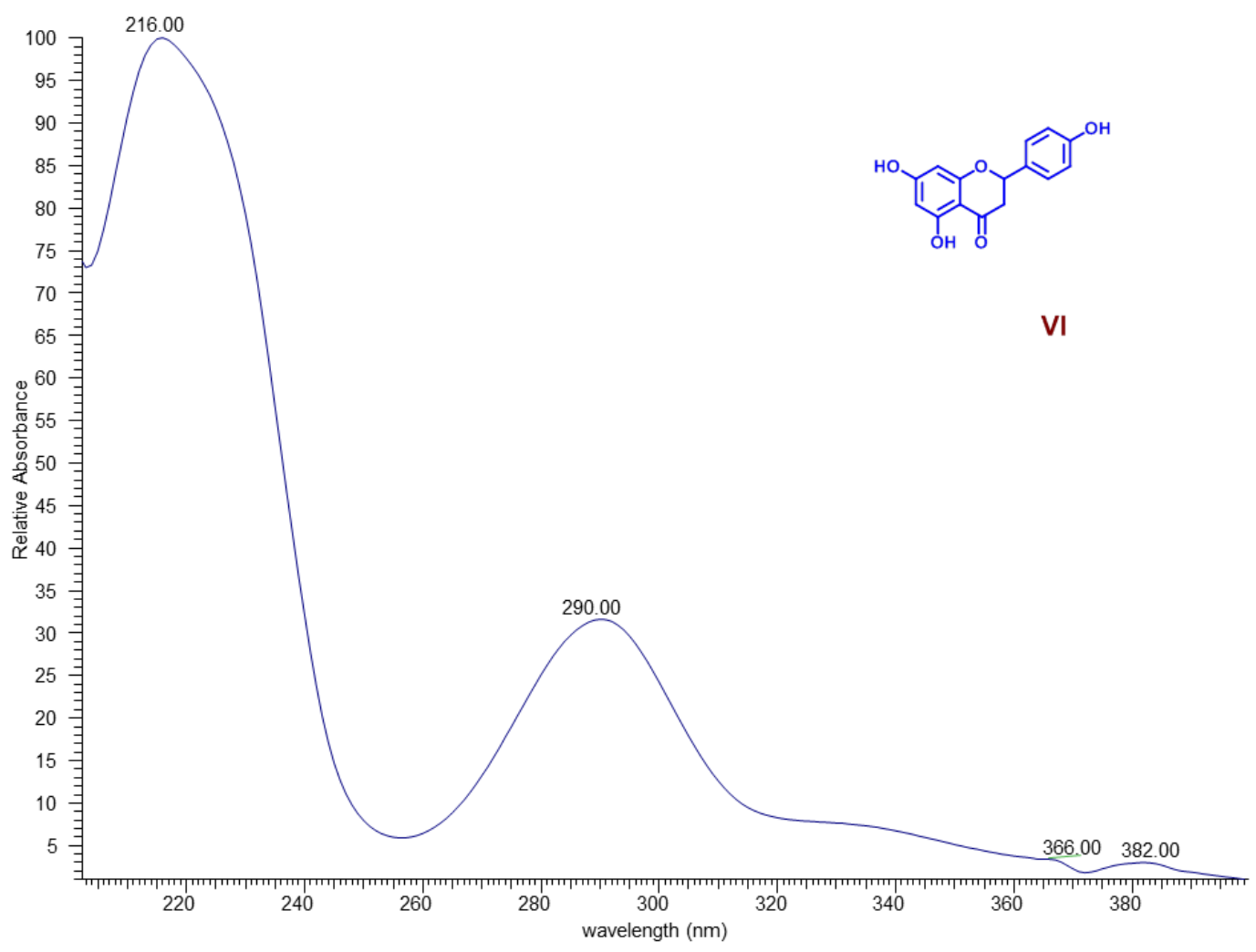

Fig. S23-A. UV spectrum of compound VI. 


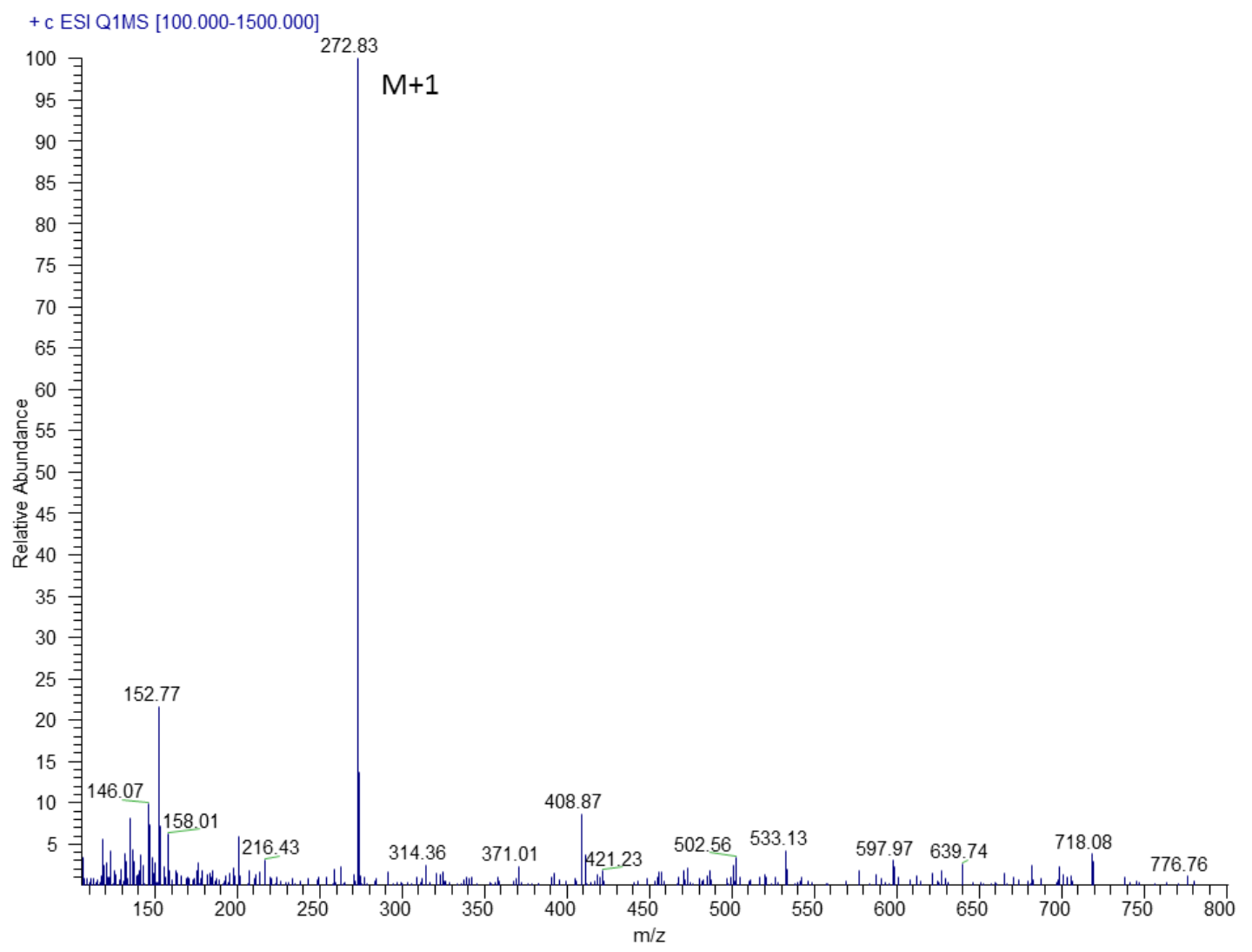

Fig. S23-B. MS/MS spectrum of compound VI, Compound VI was confirmed as naringenin by comparing its retention time, UV and MS/MS spectra with that of the reference standard. 


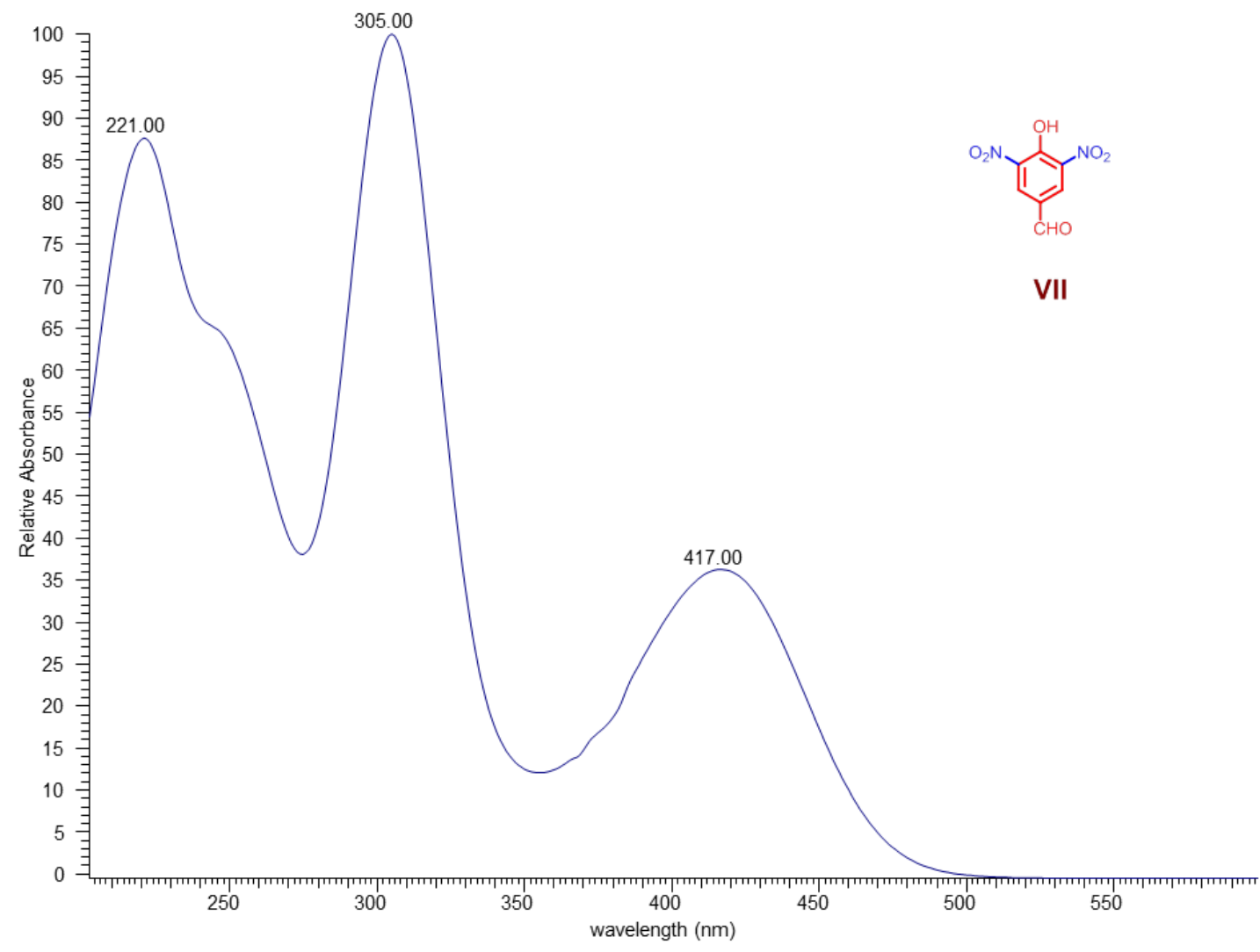

Fig. S24-A. Characterization of compound VII, UV spectrum of compound VII. 


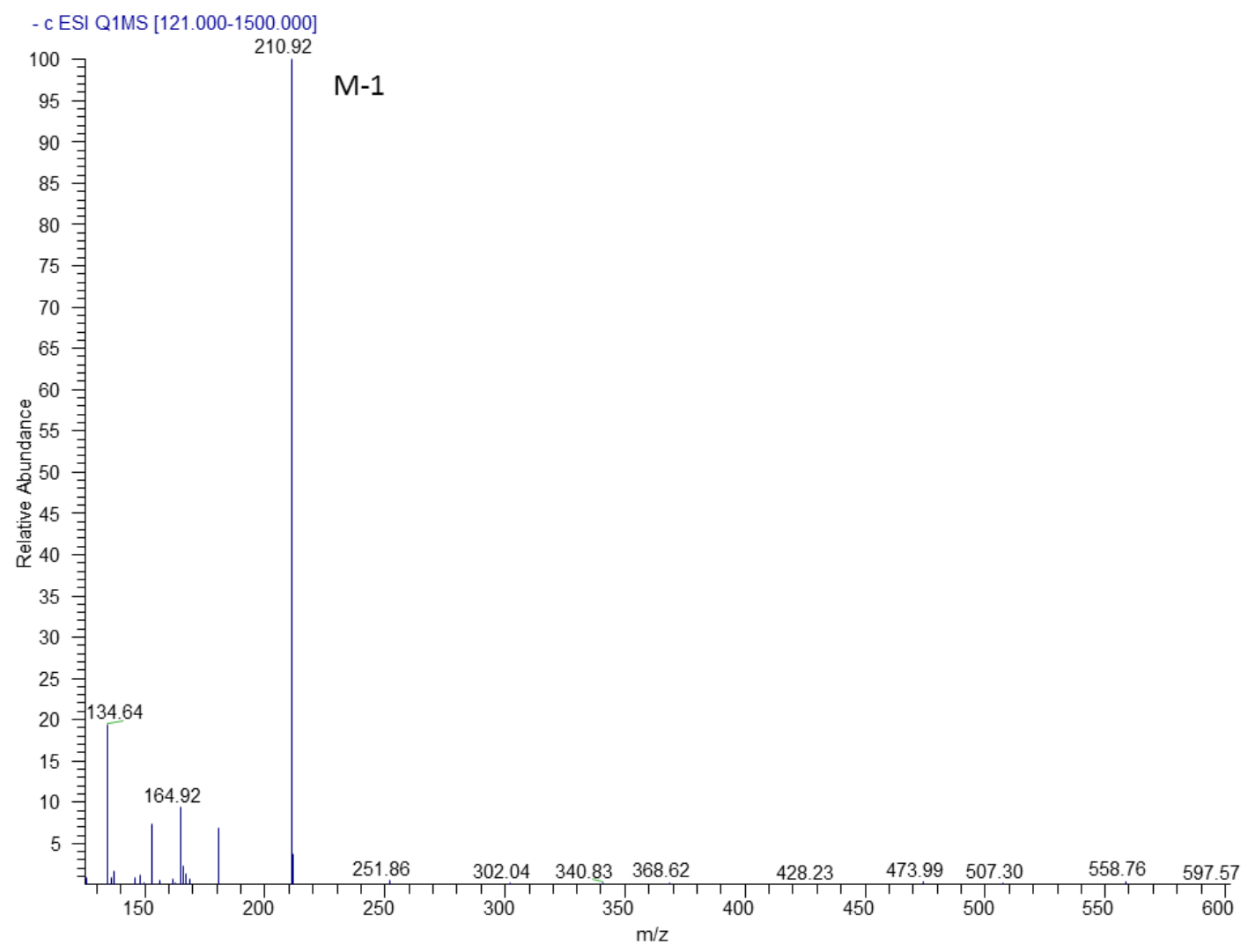

Fig. S24-B. Characterization of compound VII, MS/MS spectrum of compound VII. 


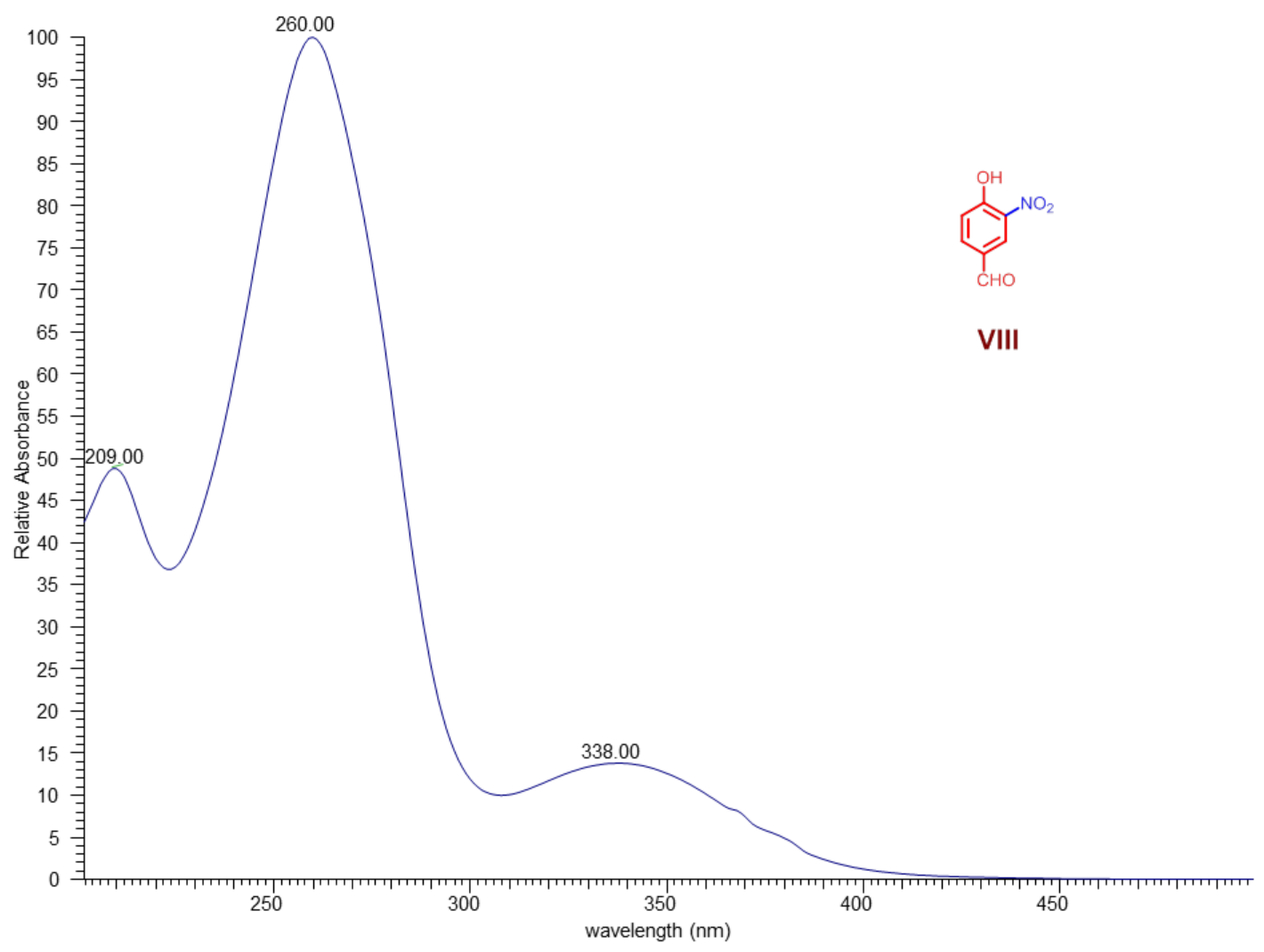

Fig. S25-A. Characterization of compound VIII, UV spectrum of compound VIII. 


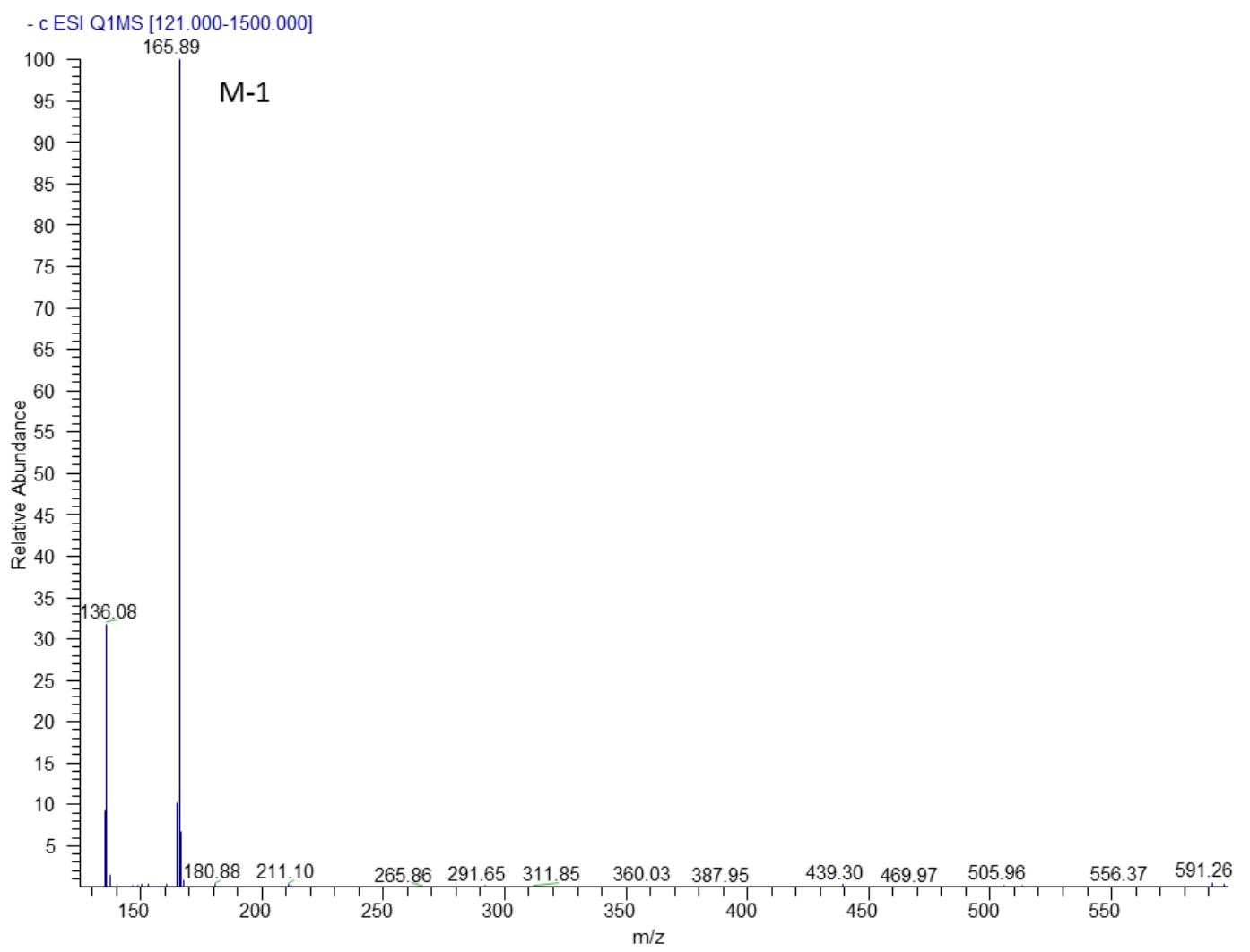

Fig. S25-B. Characterization of compound VIII, MS/MS spectrum of compound VIII. 


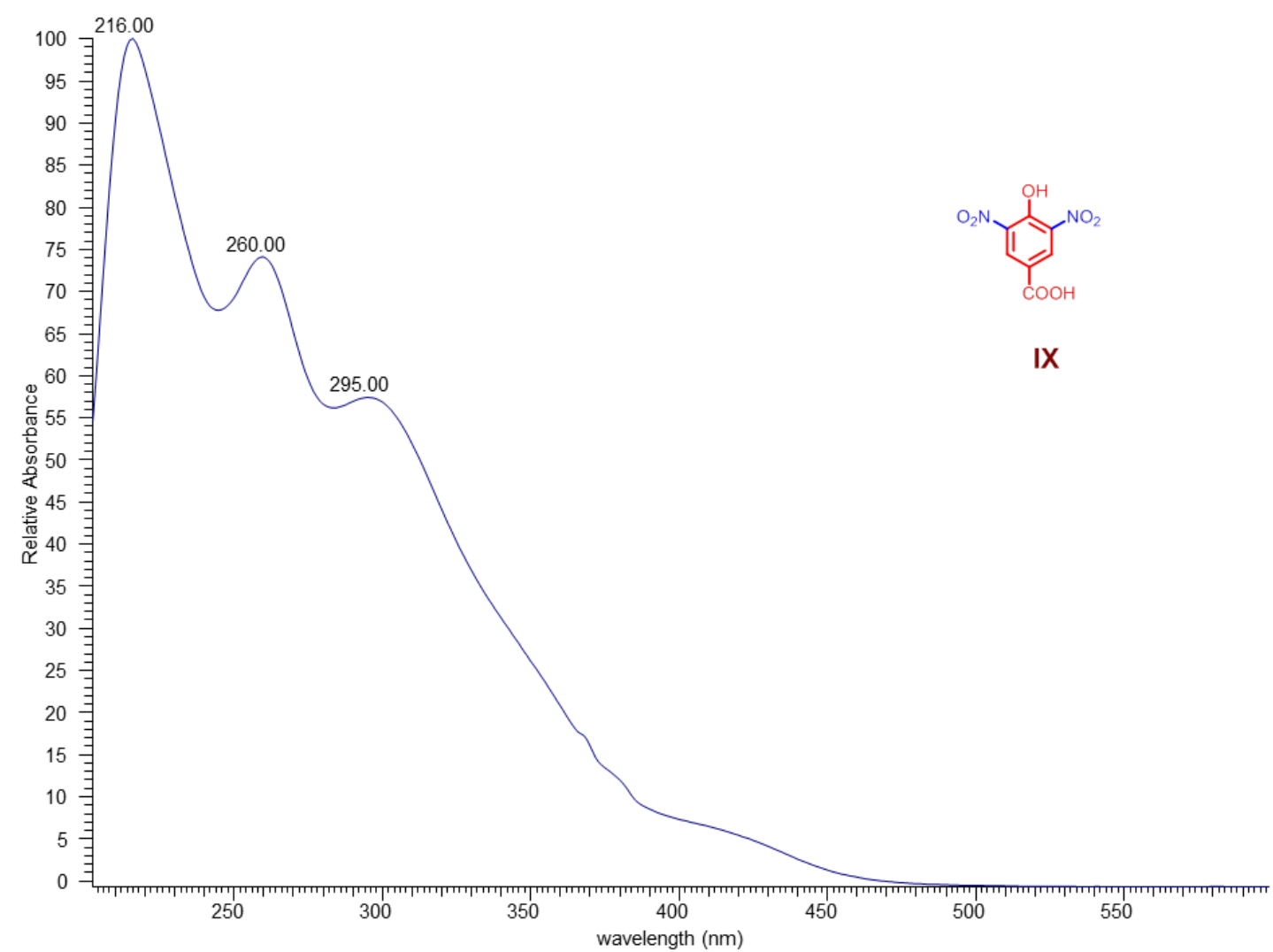

Fig. S26-A. Characterization of compound IX, UV spectrum of compound IX. 


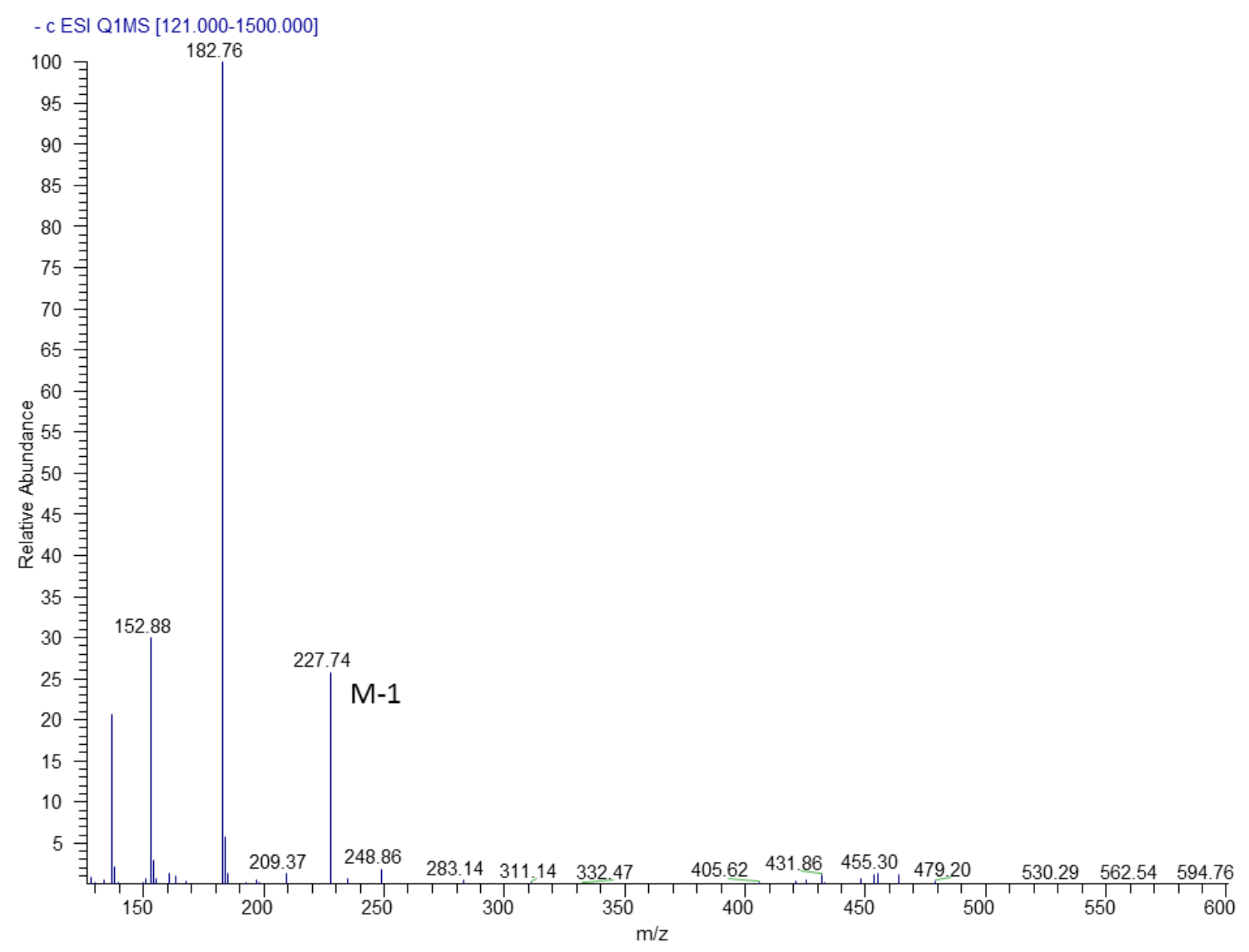

Fig. S26-B. Characterization of compound IX, MS/MS spectrum of compound IX. 


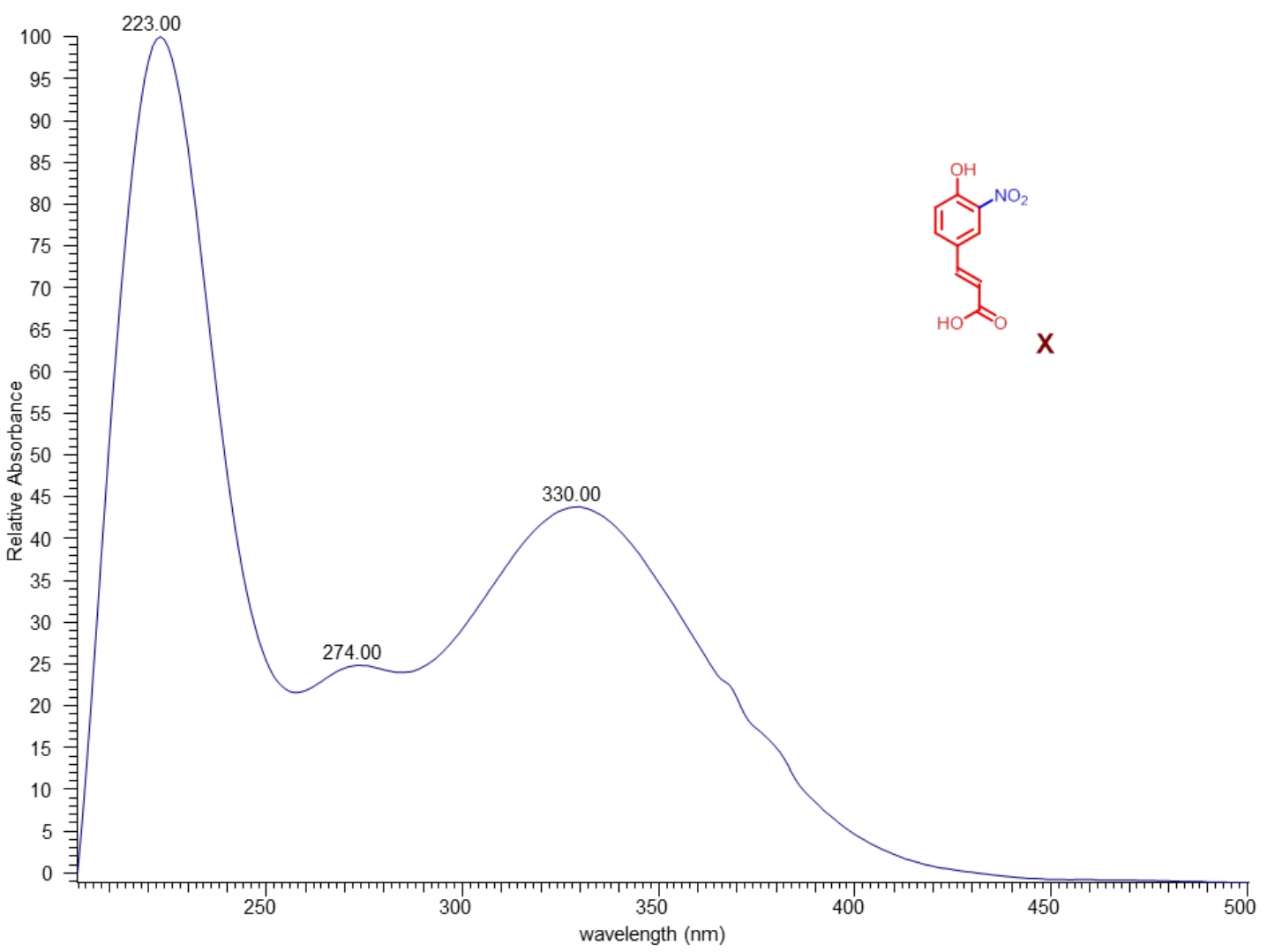

Fig. S27-A. Characterization of compound X, UV spectrum of compound X. 


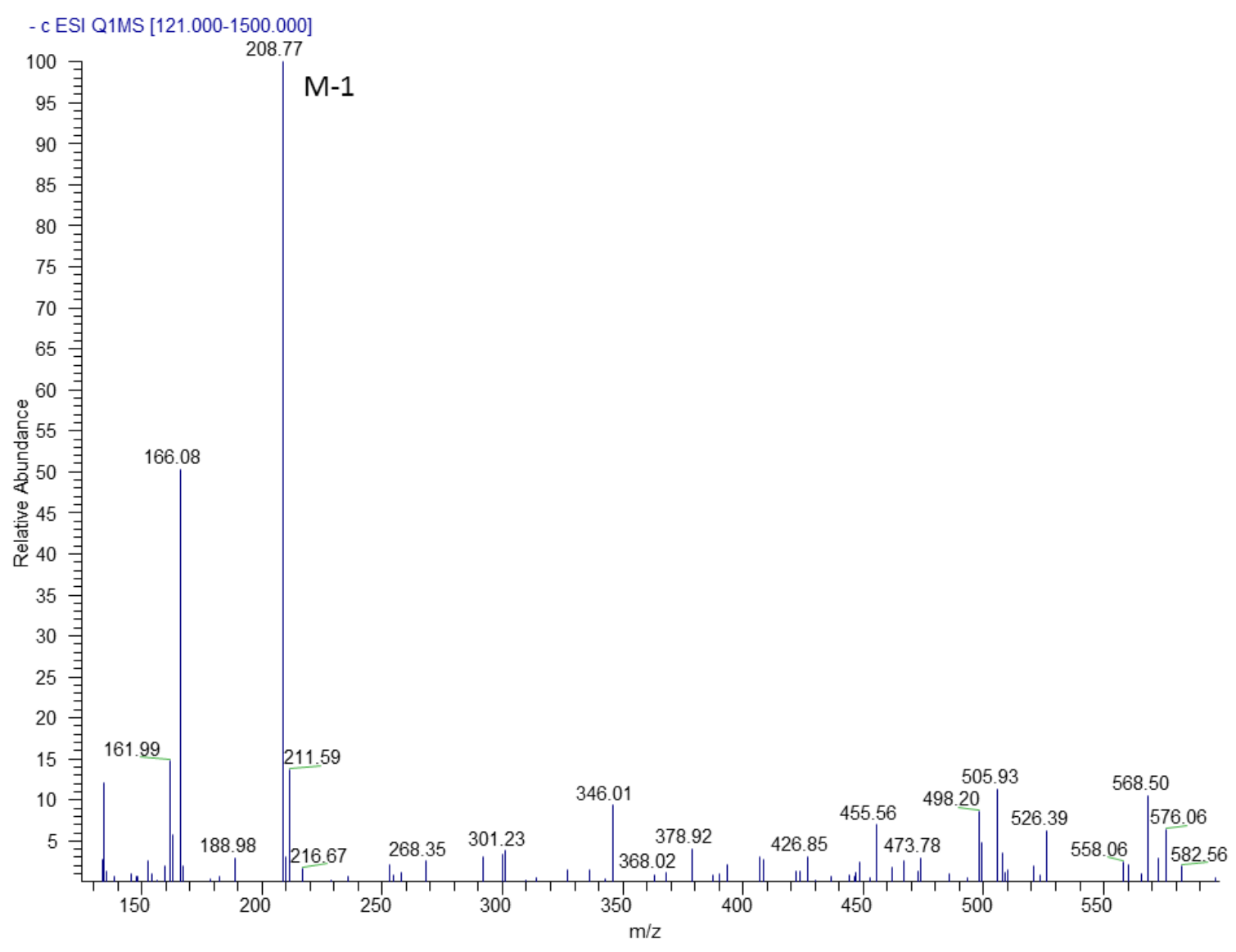

Fig. S27-B. Characterization of compound $\mathrm{X}, \mathrm{MS} / \mathrm{MS}$ spectrum of compound $\mathbf{X}$. 


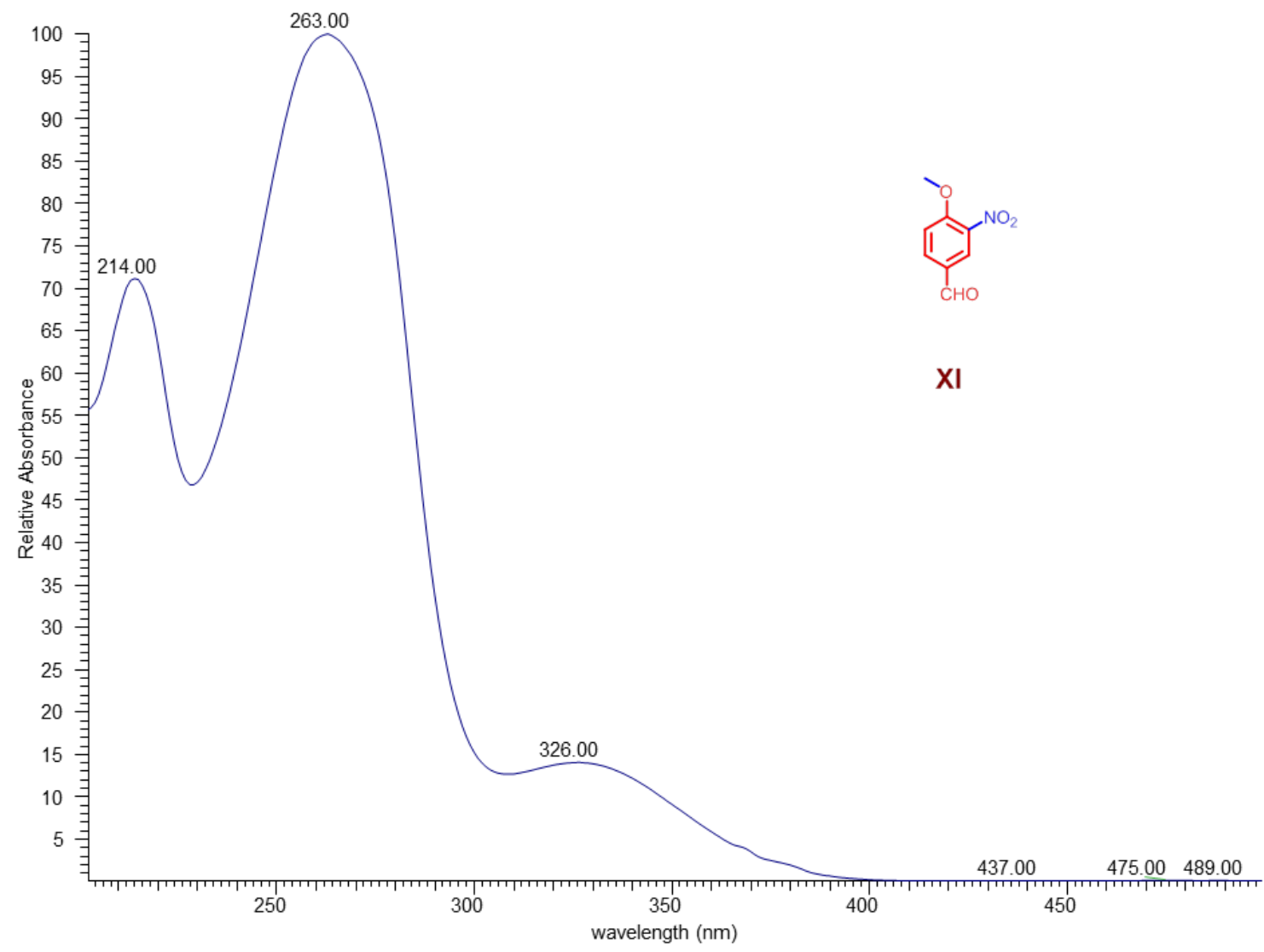

Fig. S28-A. Characterization of compound XI, UV spectrum of compound XI. 


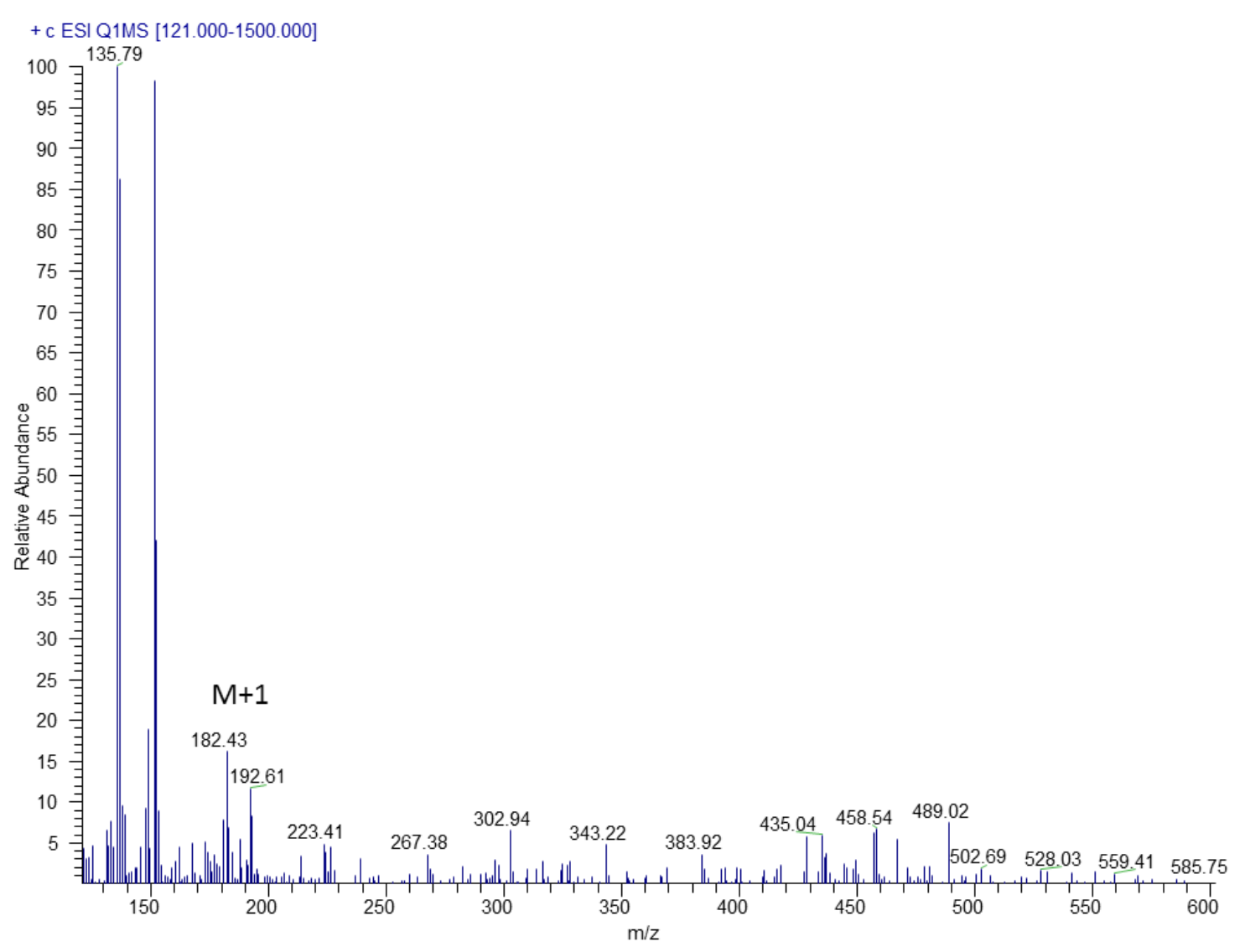

Fig. S28-B. Characterization of compound XI, MS/MS spectrum of compound XI. 


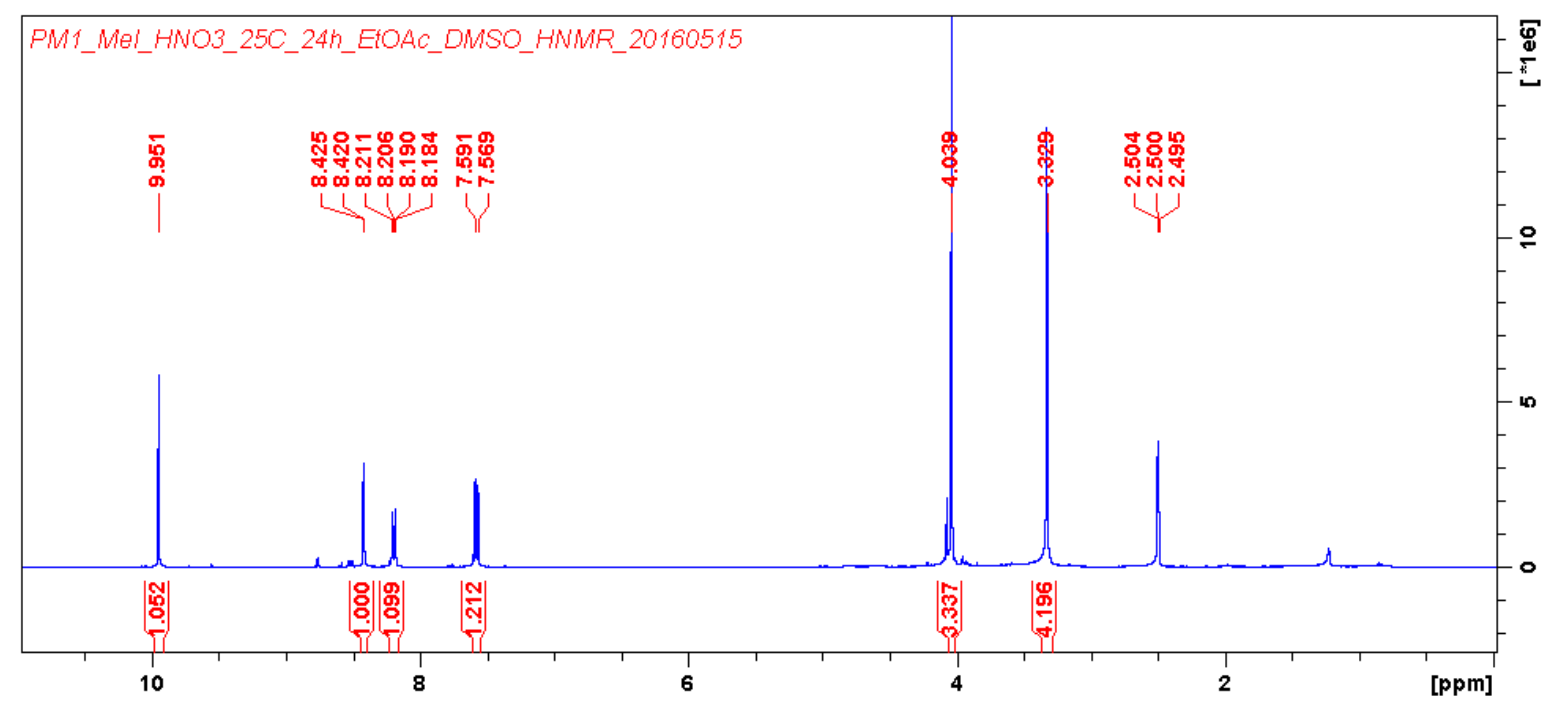

Fig. S28-C. Characterization of compound $\mathrm{XI},{ }^{1} \mathrm{H}$ NMR $\left(400 \mathrm{MHz}, \mathrm{CDCl}_{3}\right)$ spectrum of compound $\mathbf{X I}$. 


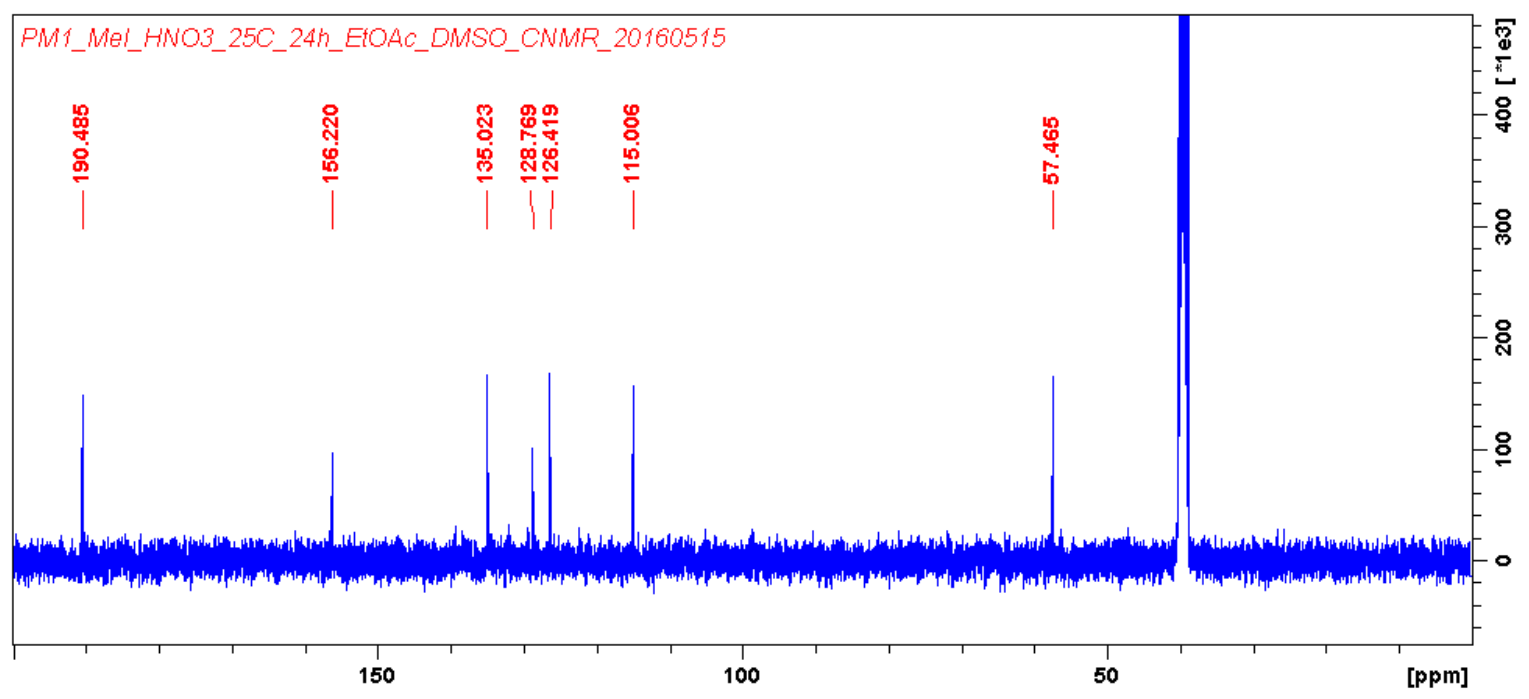

Fig. S28-D. Characterization of compound $\mathrm{XI},{ }^{13} \mathrm{C}$ NMR $\left(100 \mathrm{MHz}, \mathrm{CDCl}_{3}\right)$ spectrum of compound XI. 


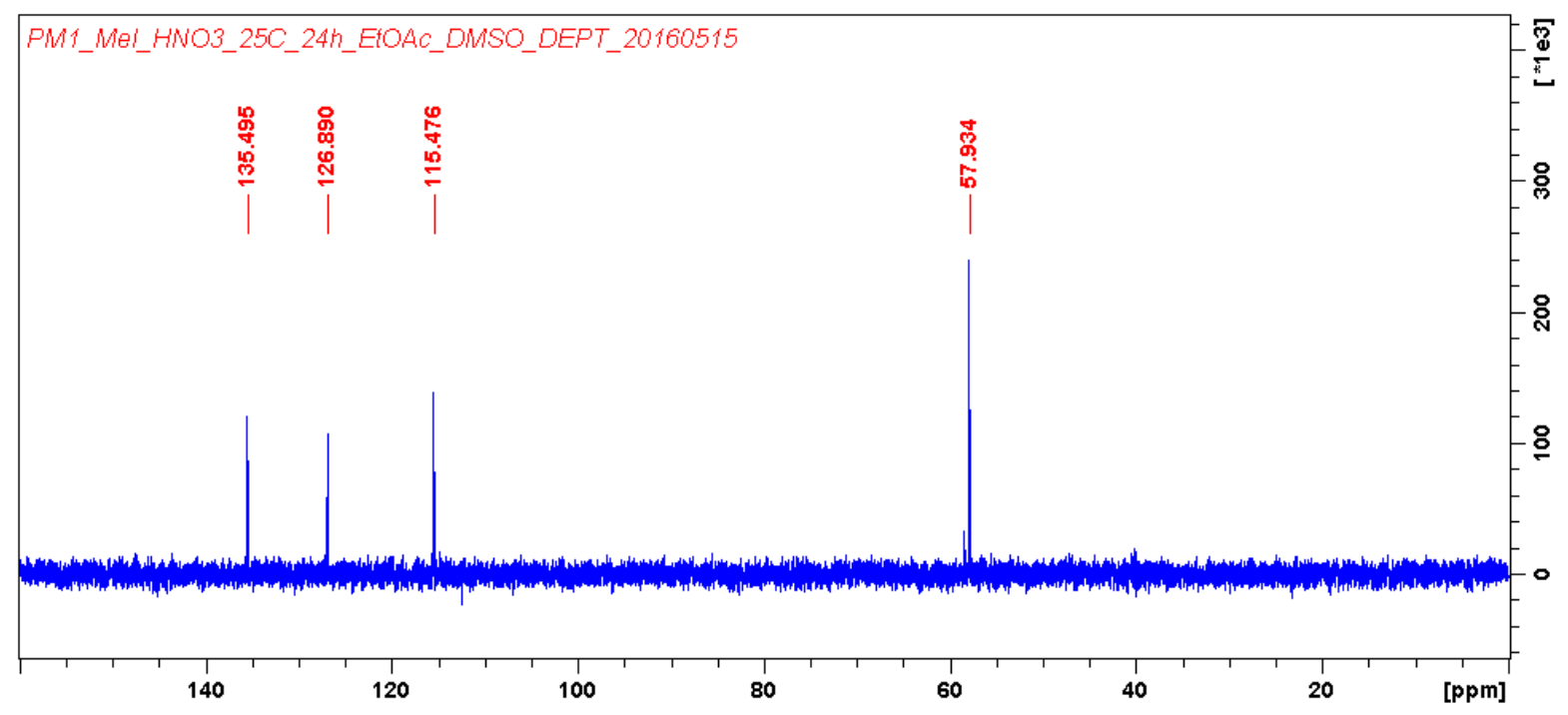

Fig. S28-E. Characterization of compound XI, DEPT spectrum of compound XI. 


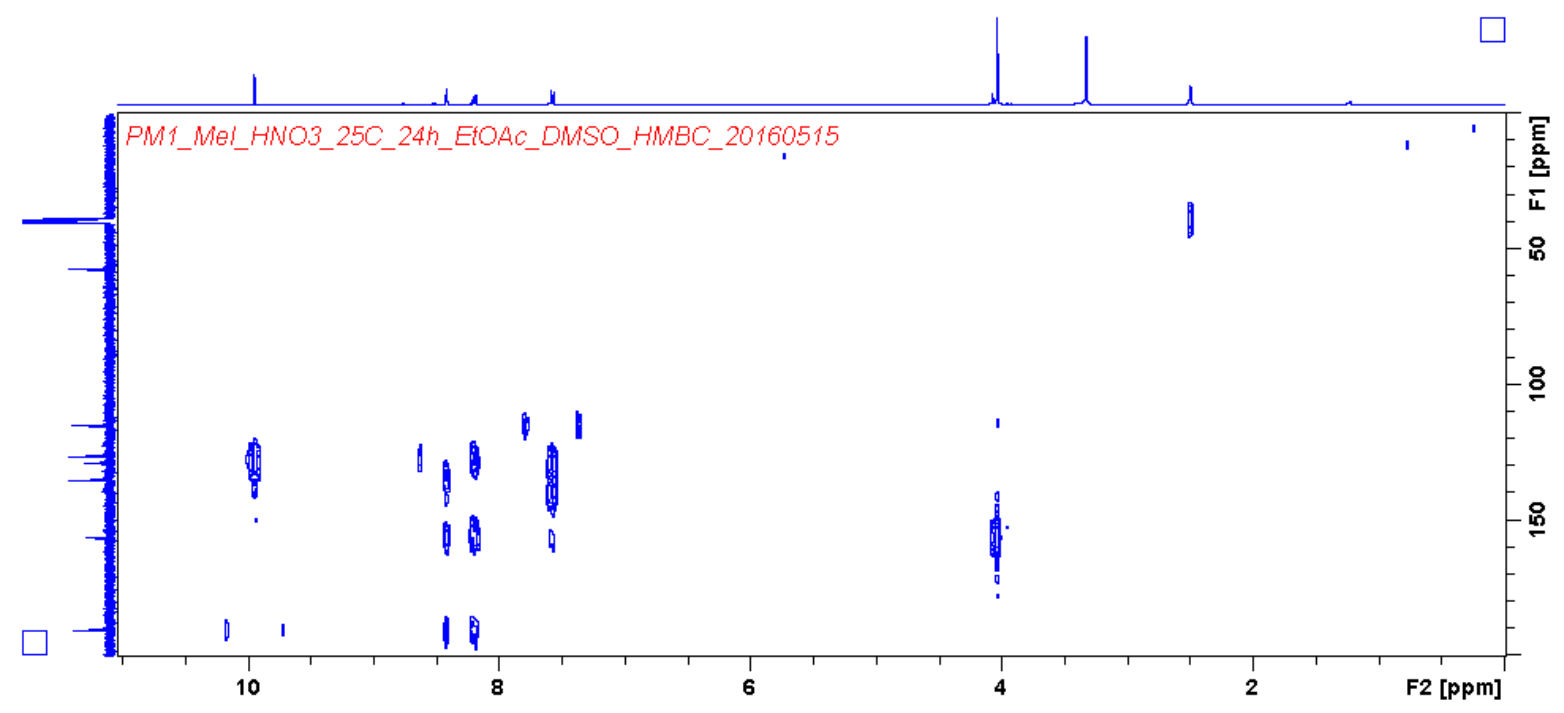

Fig. S28-F. Characterization of compound XI, HMBC spectrum of compound XI. 


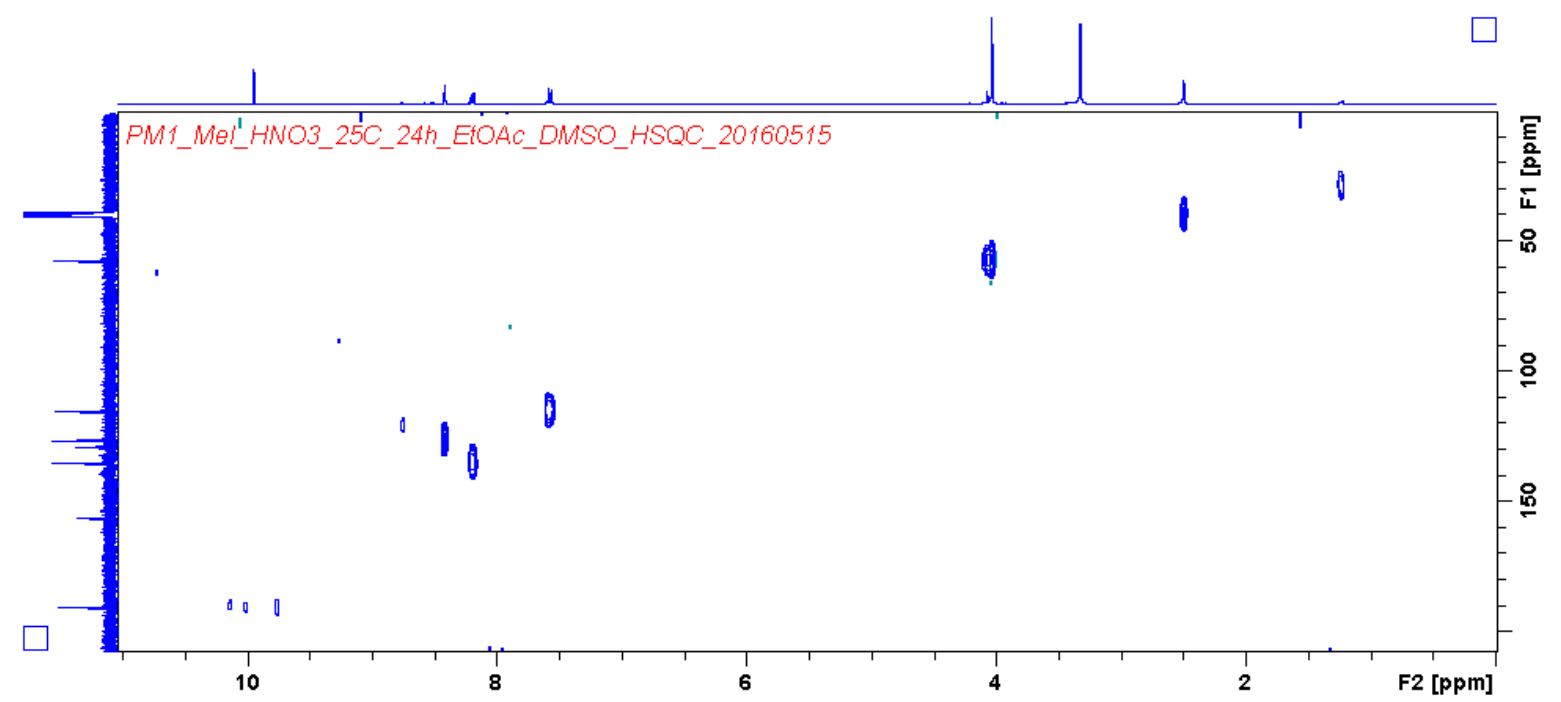

Fig. S28-G. Characterization of compound XI, HSQC spectrum of compound XI. 


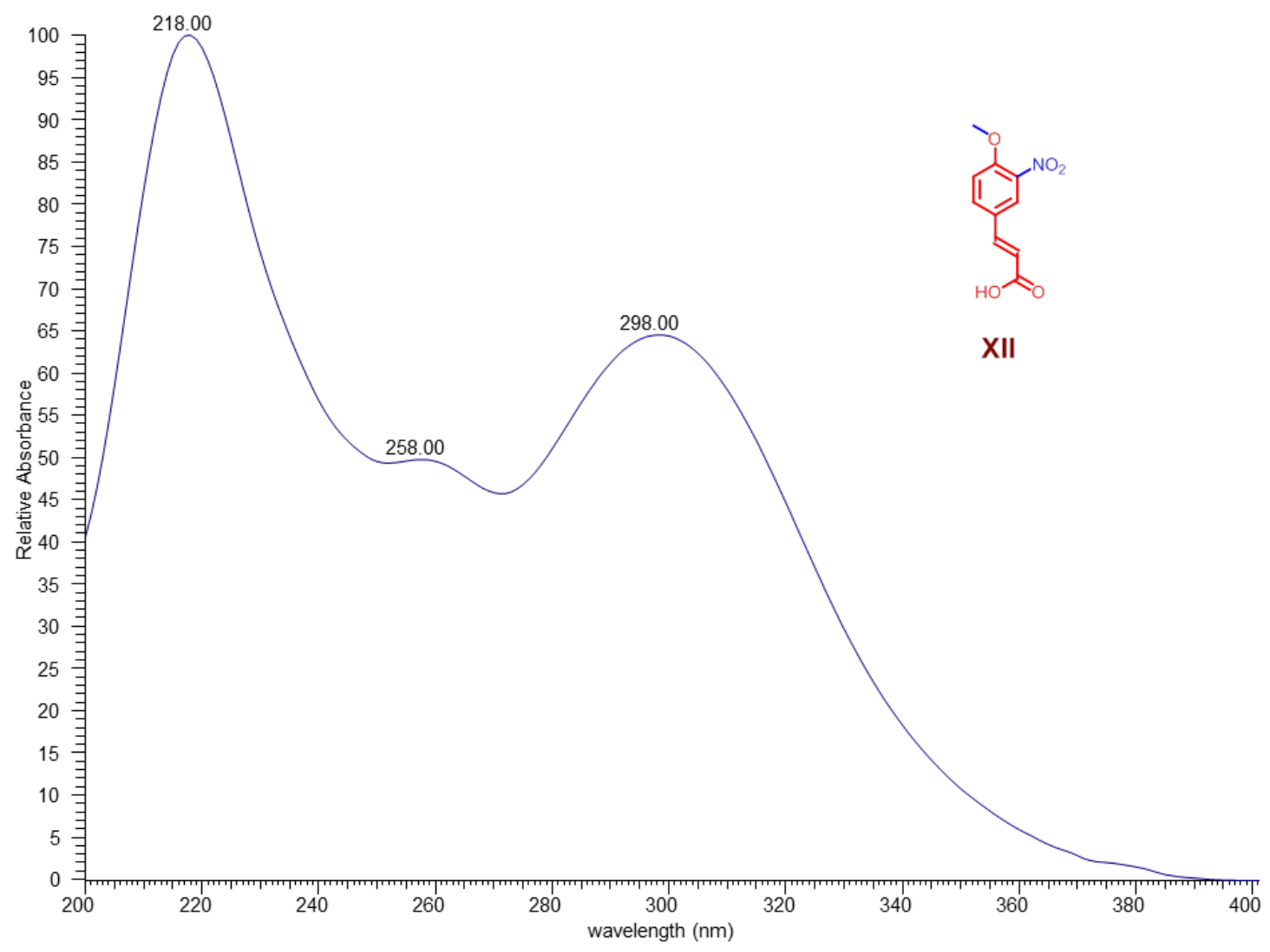

Fig. S29-A. Characterization of compound XII, UV spectrum of compound XII. 


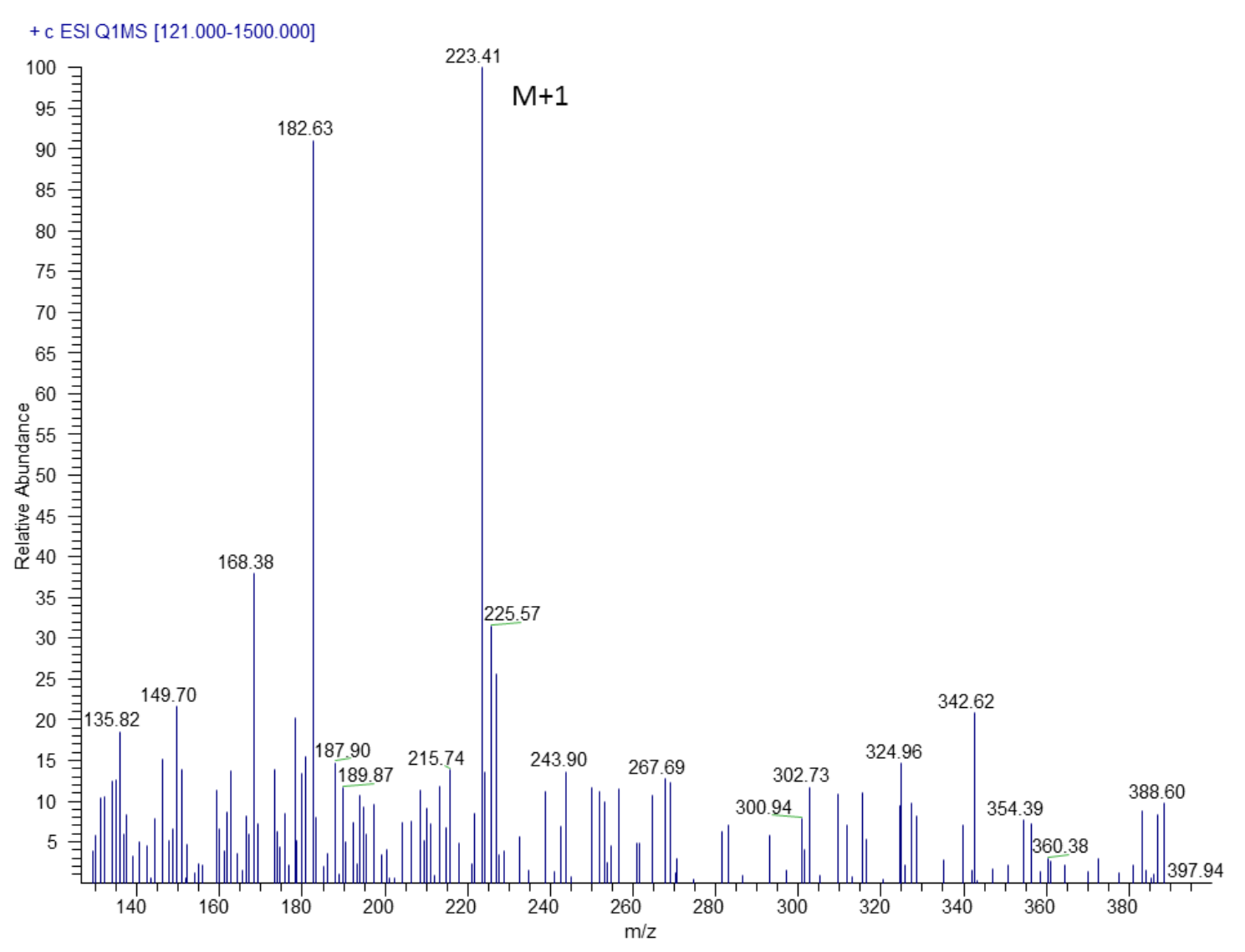

Fig. S29-B. Characterization of compound XII, MS/MS spectrum of compound XII. 


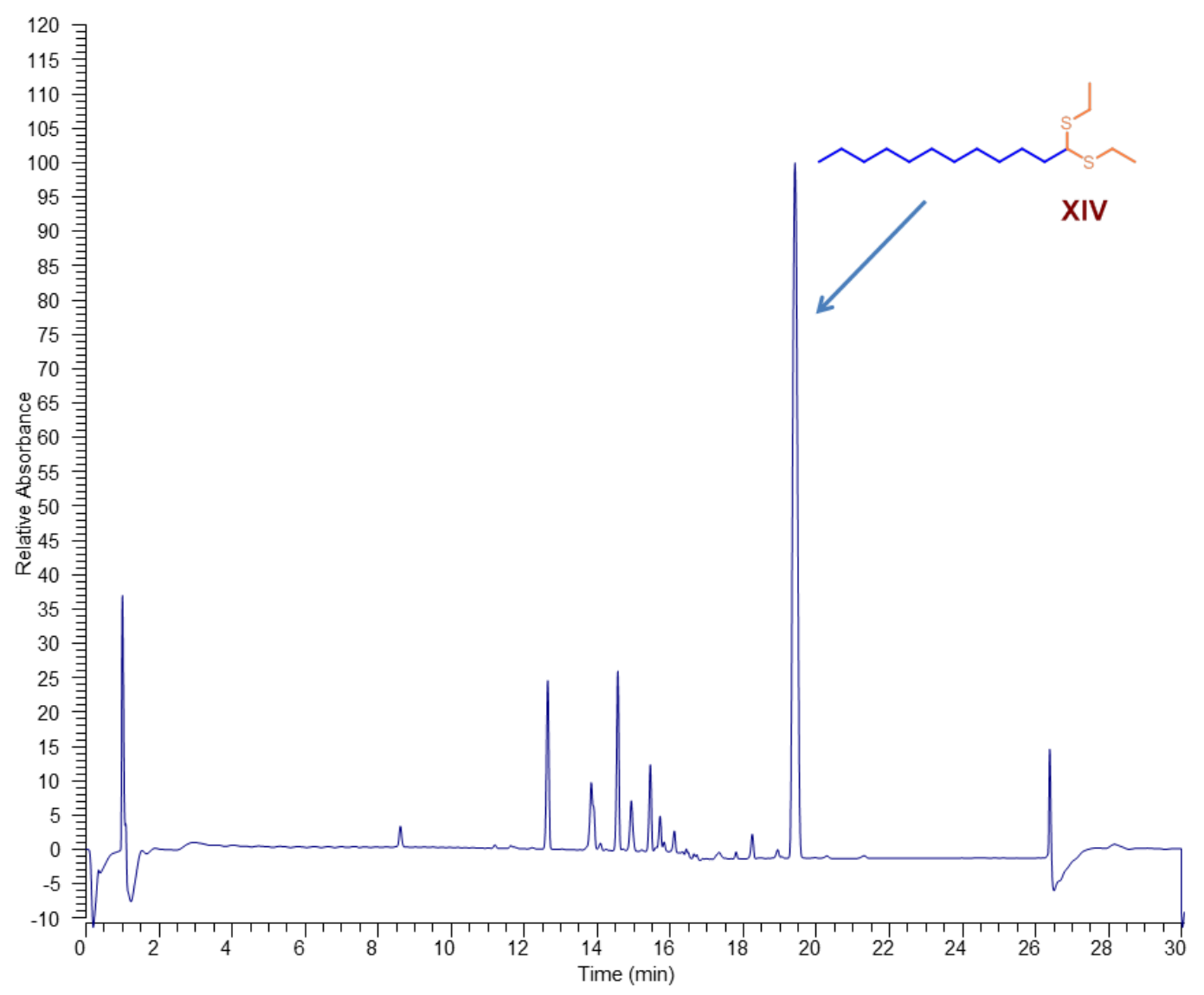

Fig. S30-A. Characterization of compound XIV, HPLC-UV (PDA) spectrum of compound XIV. 


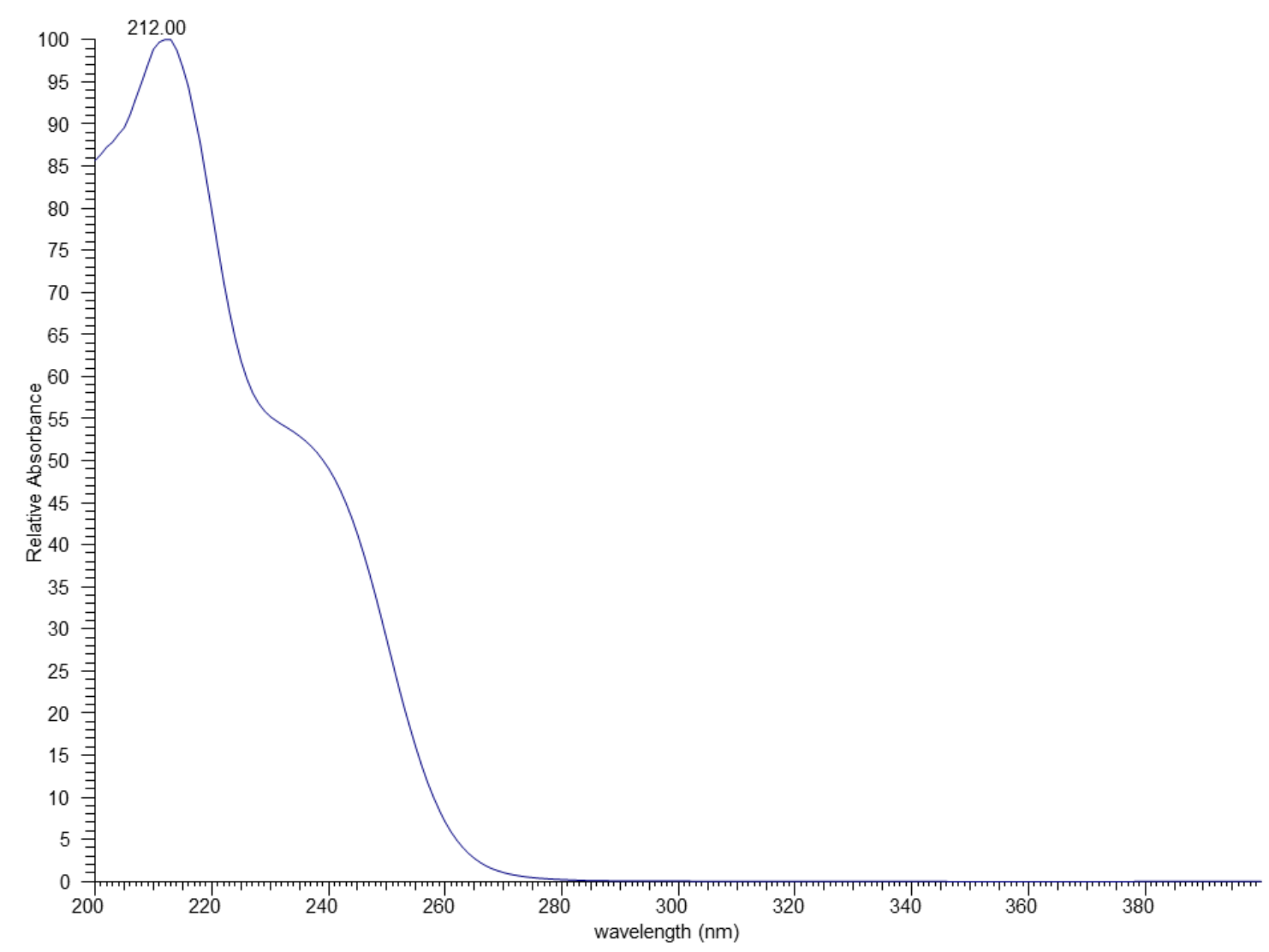

Fig. S30-B. Characterization of compound XIV, UV spectrum of compound XIV. 


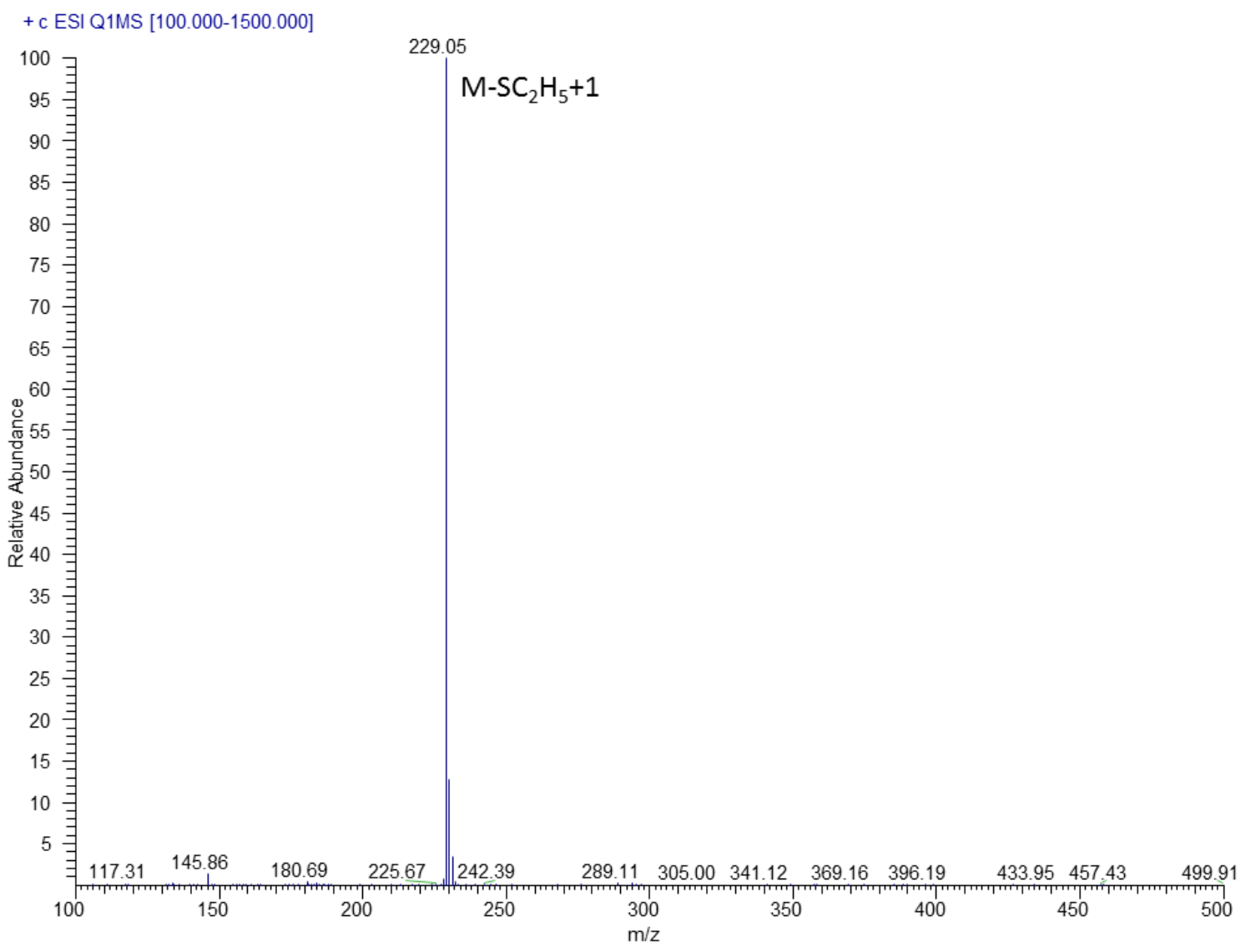

Fig. S30-C. Characterization of compound XIV, MS/MS spectrum of compound XIV. 


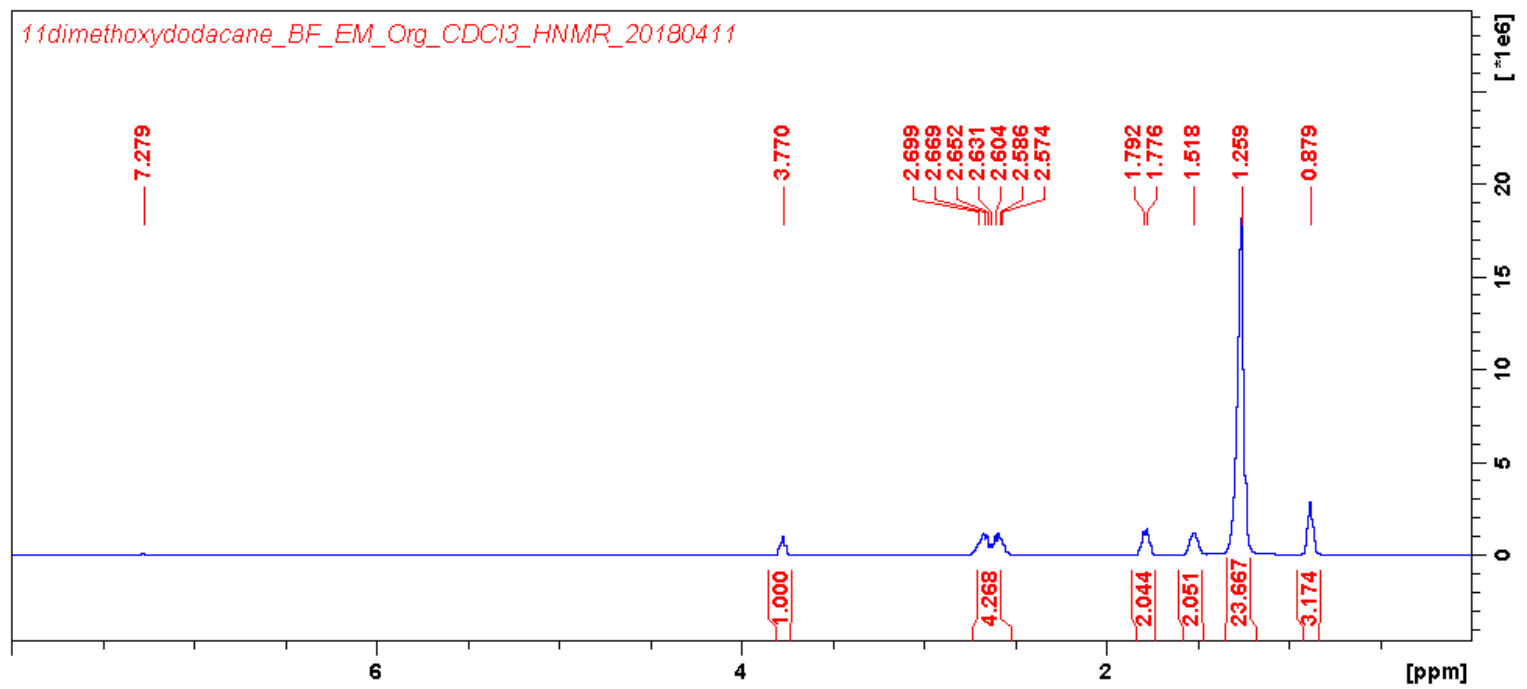

Fig. S30-D. Characterization of compound XIV, ${ }^{1} \mathrm{H} \mathrm{NMR}\left(400 \mathrm{MHz}, \mathrm{CDCl}_{3}\right)$ spectrum of compound XIV. 


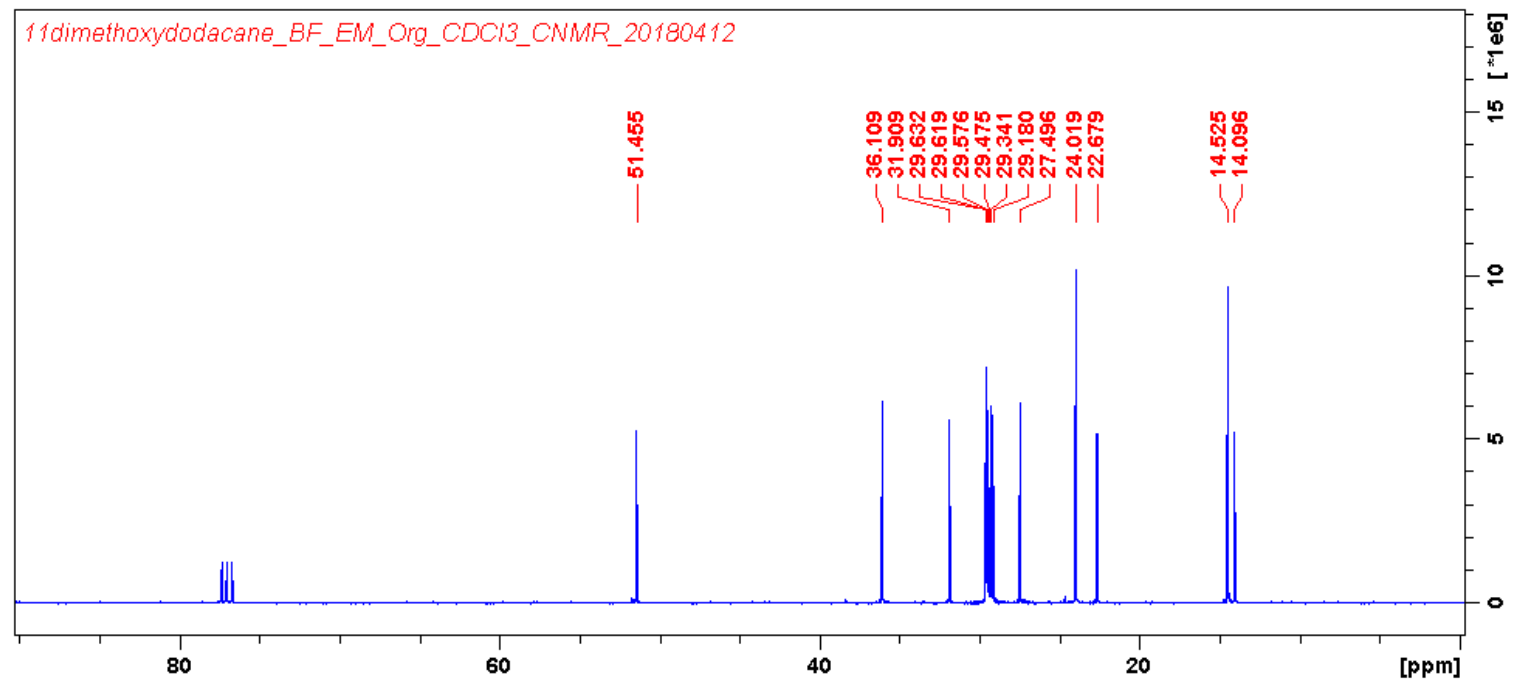

Fig. S30-E. Characterization of compound XIV, ${ }^{13} \mathrm{C} \mathrm{NMR}\left(100 \mathrm{MHz}, \mathrm{CDCl}_{3}\right)$ spectrum of compound XIV. 


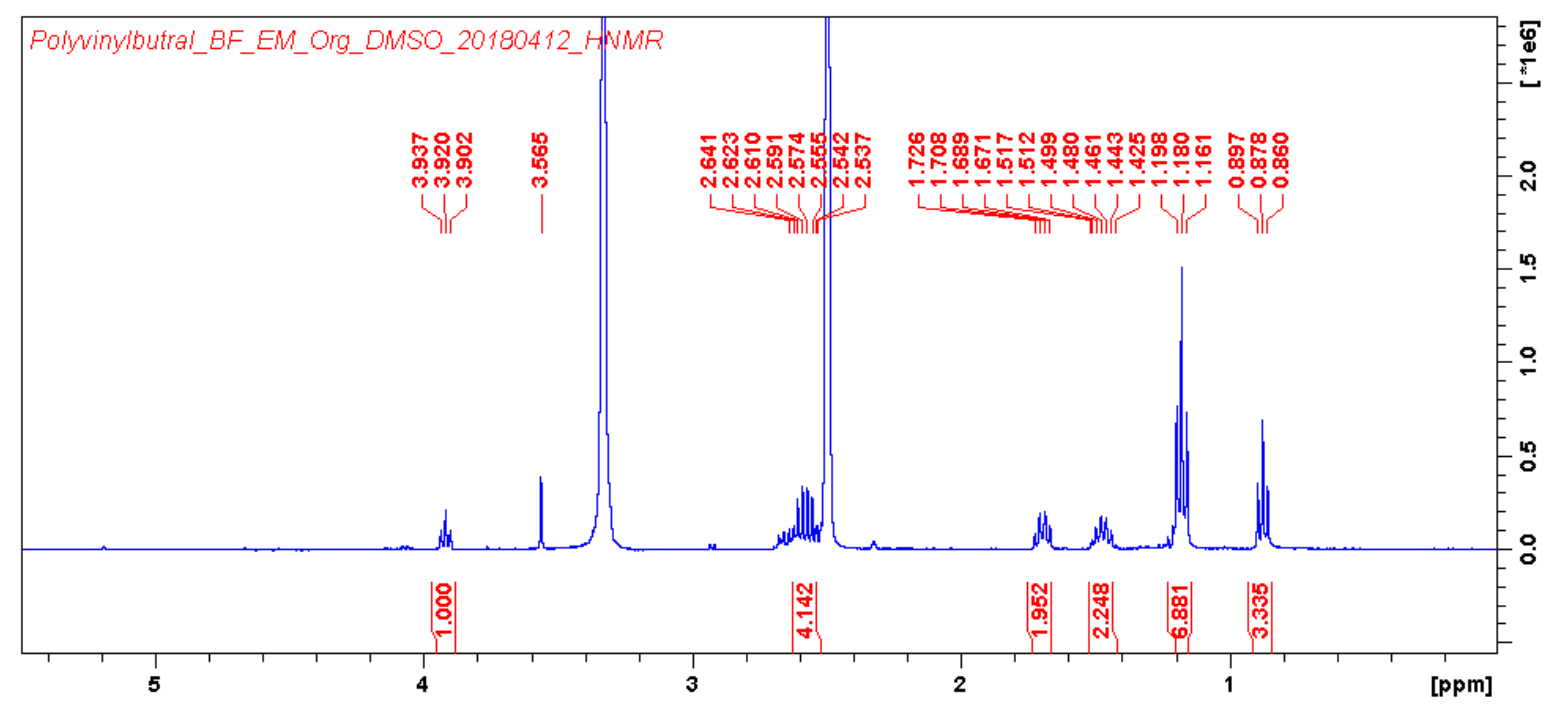

Fig. S31. Characterization of compound XV, ${ }^{1} \mathrm{H}$ NMR (400 MHz, DMSO- $\left.d_{6}\right)$ spectrum of compound XV. 


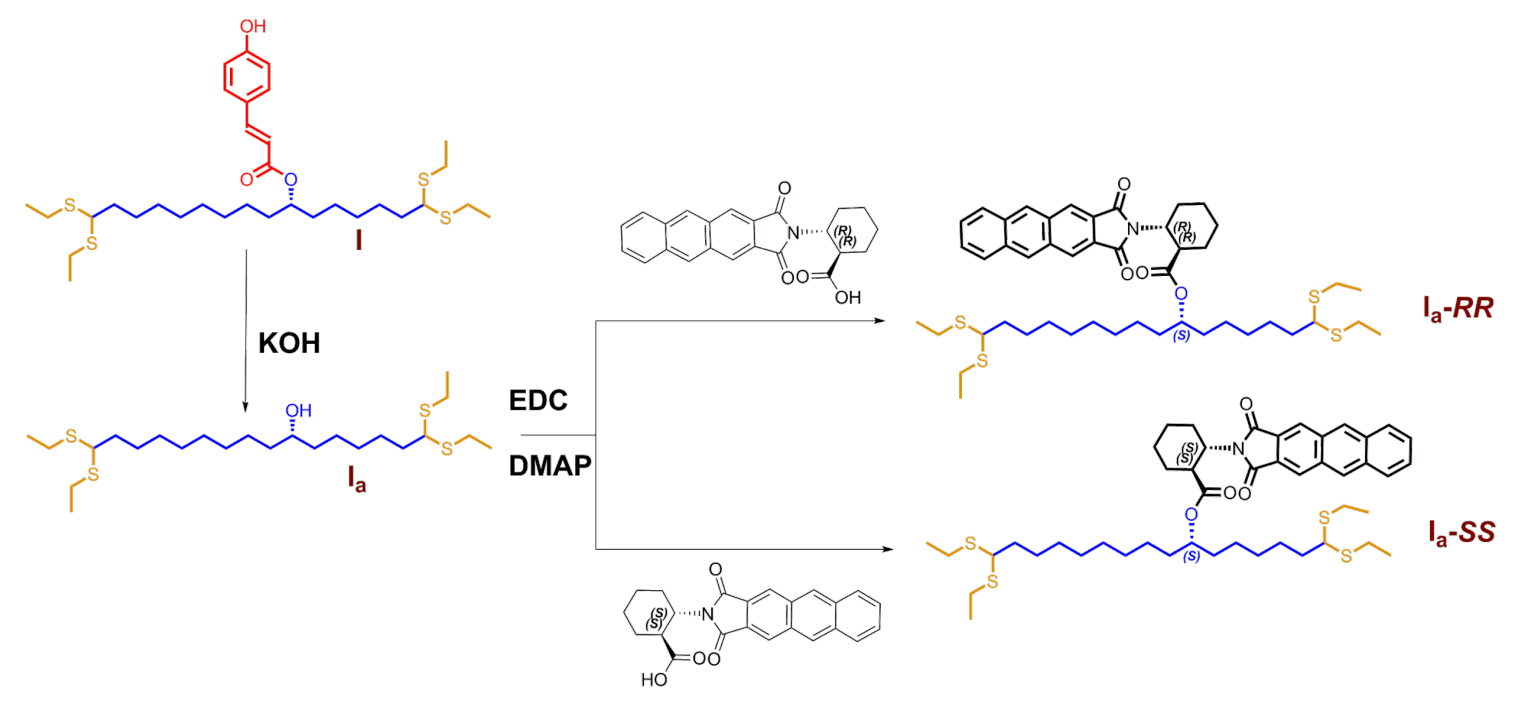

Fig. S32. Derivatization compound $l_{a}$ with (1R,2R)-(-)-2-(2,3anthracenedicarboximide) cyclohexane carboxylic acids and $(1 S, 2 S)-(+)-2-(2,3-$ anthracenedicarboximide) cyclohexane carboxylic acids. 


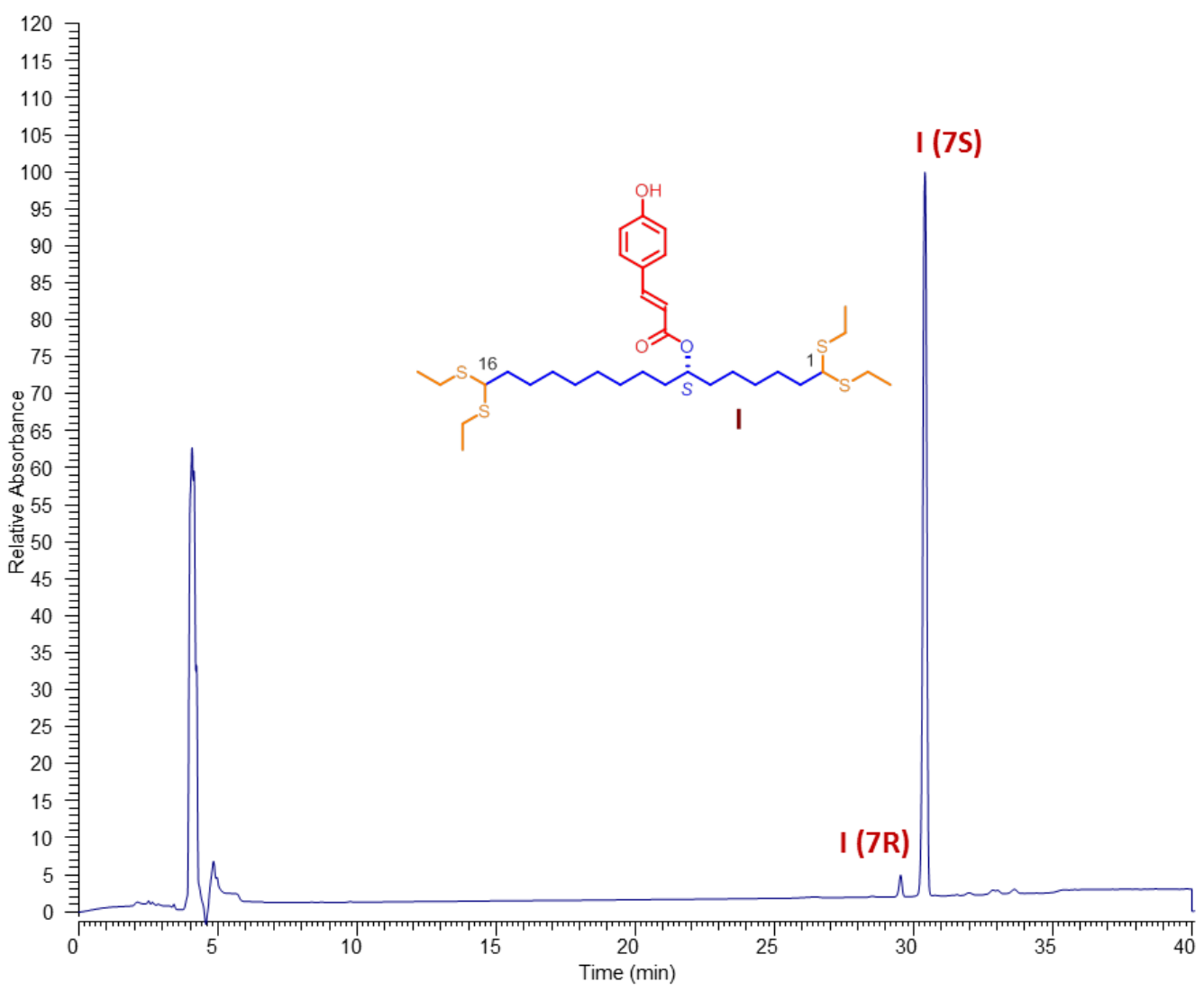

Fig. S33. HPLC-UV (PDA) chromatogram of enantiomeric resolution of I on a Lux $3 \mu$ Cellulose-4, $250 \times 4.6 \mathrm{~mm}$ chiral column. 


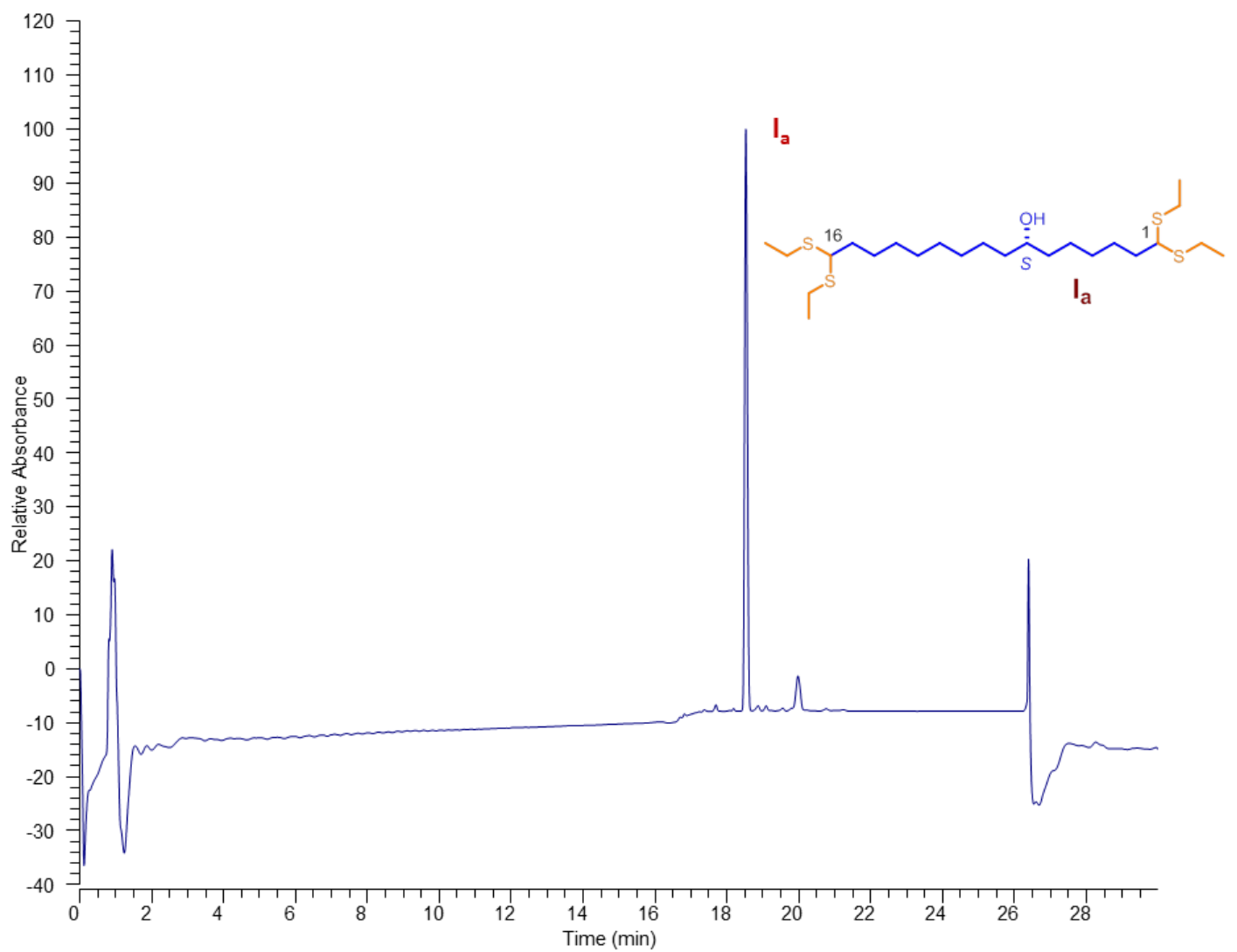

Fig. S34. HPLC-UV (PDA) chromatogram of compound Ia. 


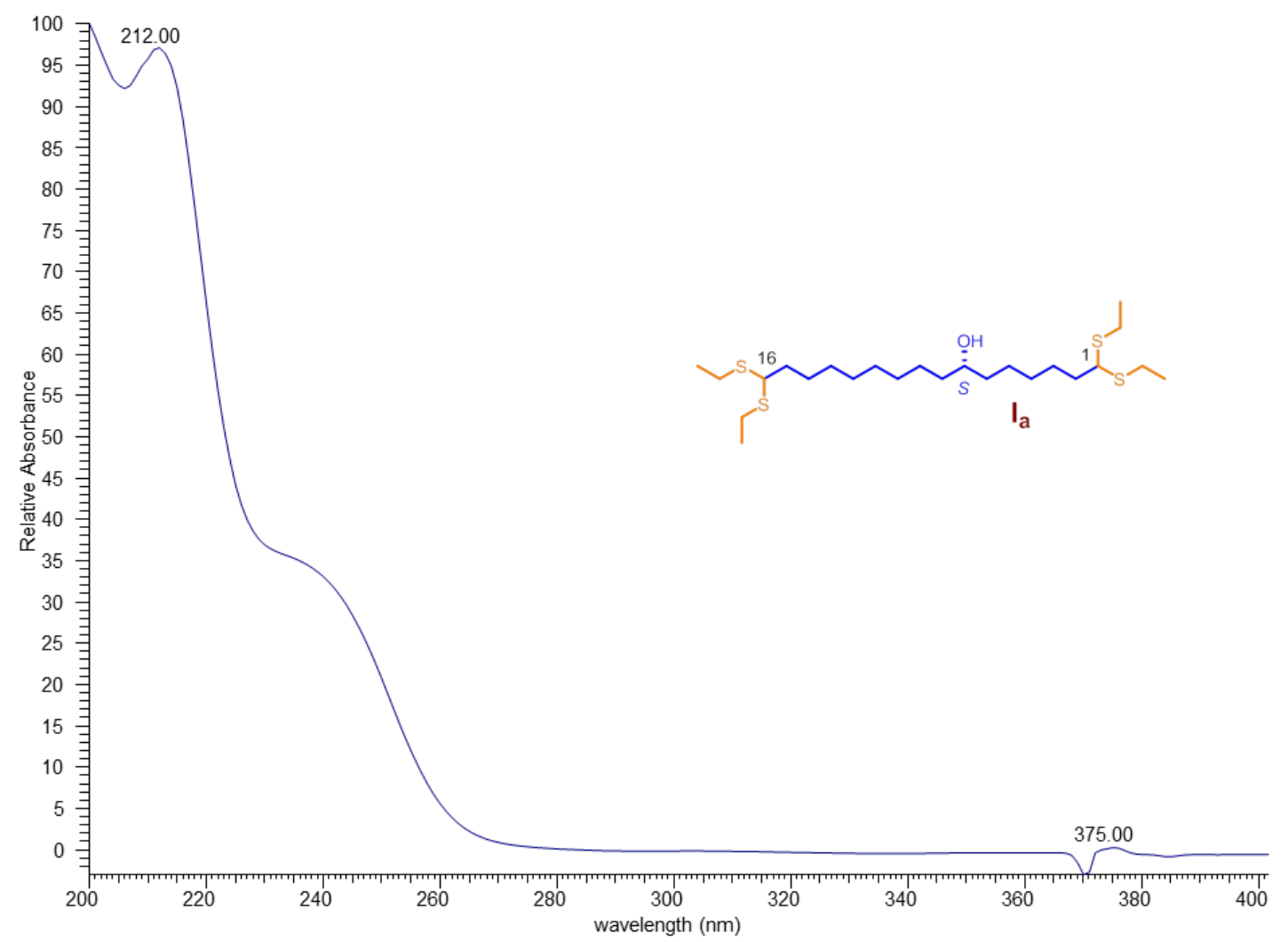

Fig. S35-A. Characterization of compound $I_{a}$, UV spectrum of compound $I_{a}$. 


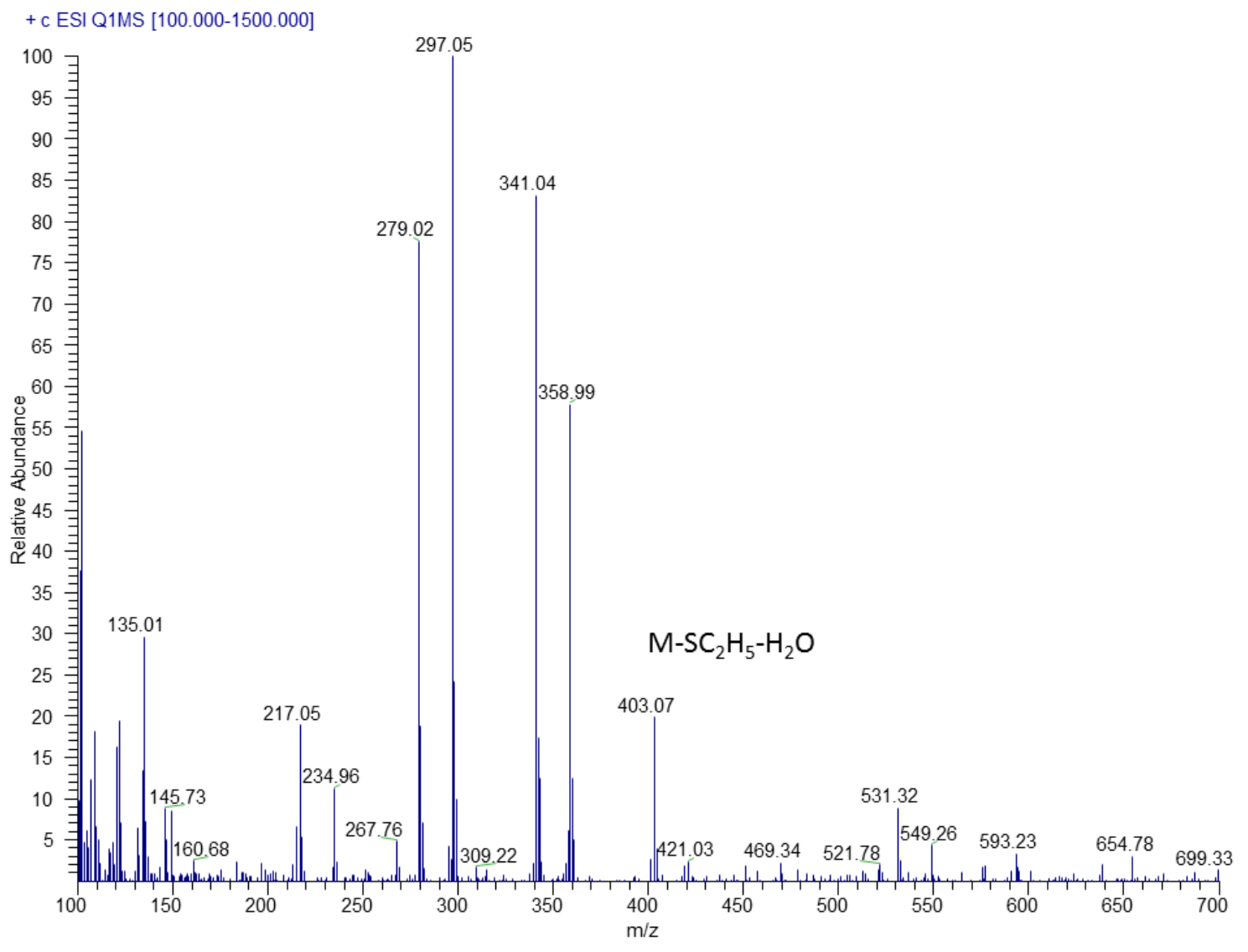

Fig. S35-B. Characterization of compound $I_{a}, M S / M S$ spectrum of compound $I_{a}$. 


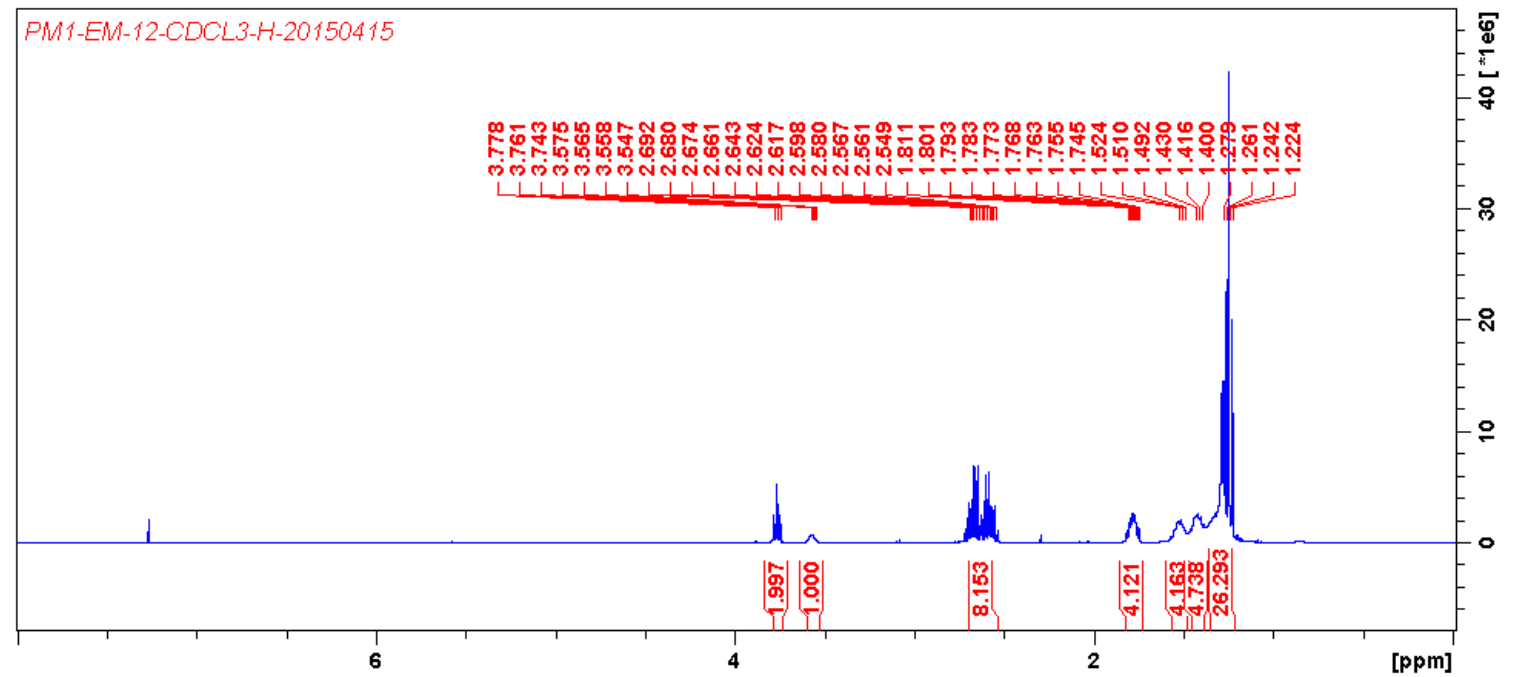

Fig. S35-C. Characterization of compound $\mathrm{I}_{\mathrm{a}},{ }^{1} \mathrm{H} \mathrm{NMR}\left(400 \mathrm{MHz}, \mathrm{CDCl}_{3}\right)$ spectrum of compound $\mathrm{I}_{\mathbf{a}}$. 


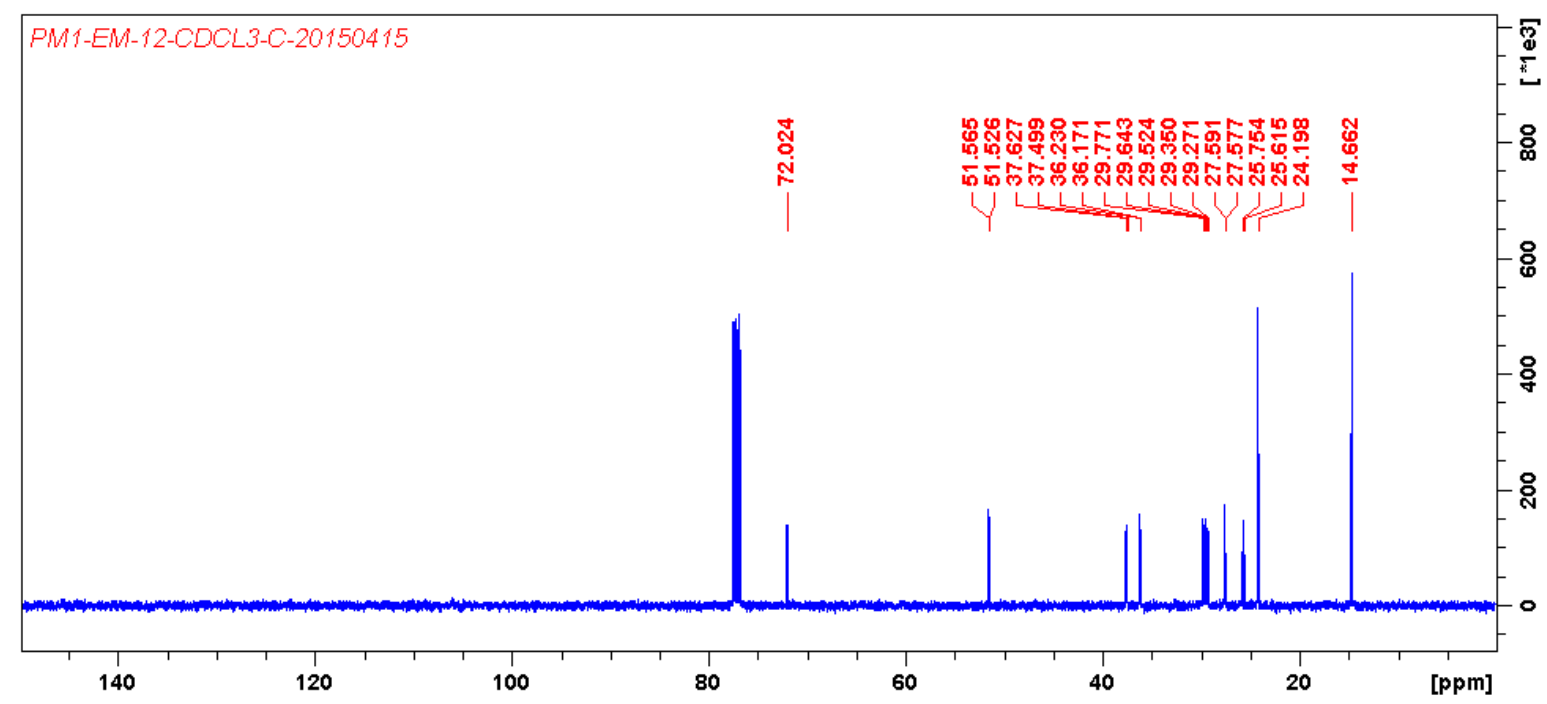

Fig. S35-D. Characterization of compound $\mathrm{I}_{\mathrm{a}},{ }^{13} \mathrm{C}$ NMR $\left(100 \mathrm{MHz}, \mathrm{CDCl}_{3}\right)$ spectrum of compound $\mathrm{I}_{\mathrm{a}}$. 


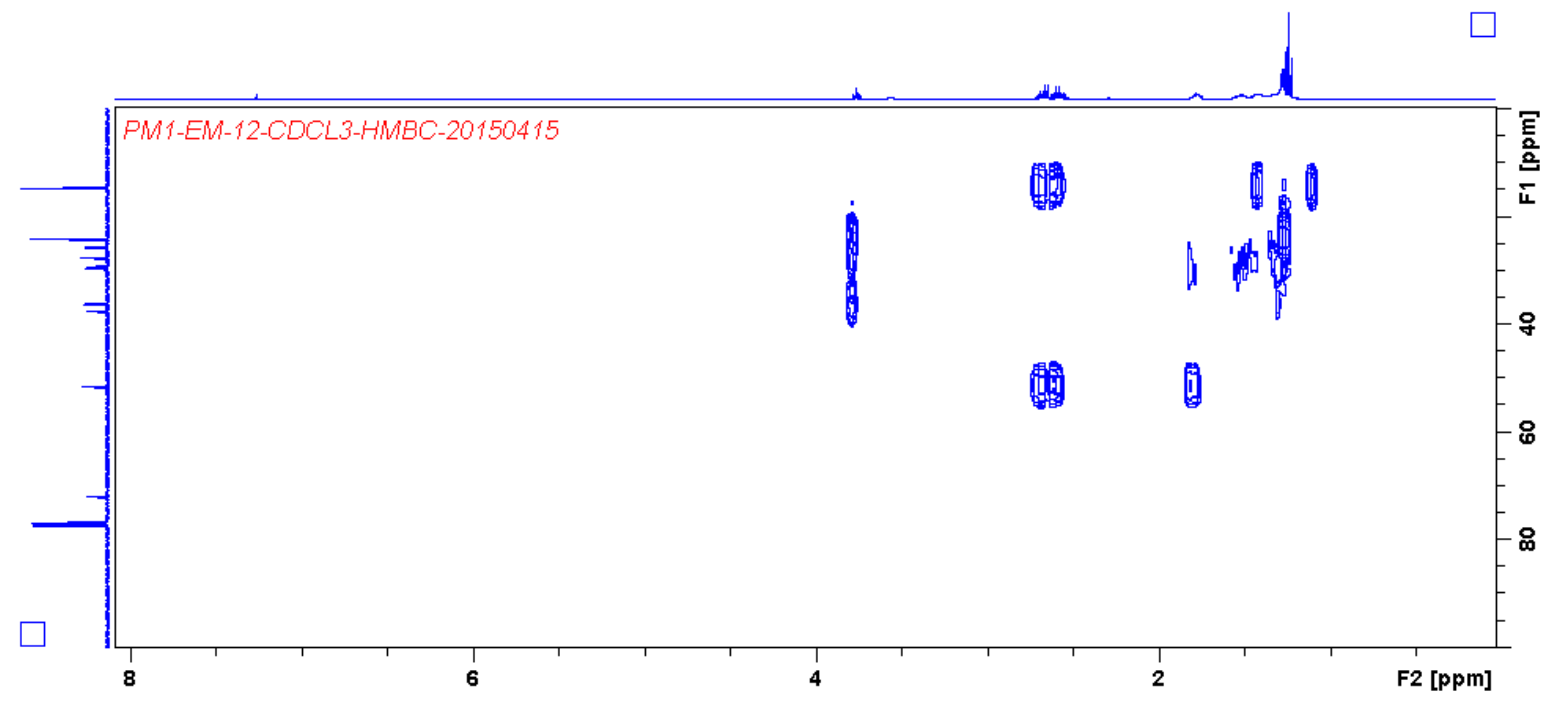

Fig. S35-E. Characterization of compound $\mathrm{l}_{\mathbf{a}}, \mathrm{HMBC}$ spectrum of compound $\mathrm{I}_{\mathbf{a}}$. 


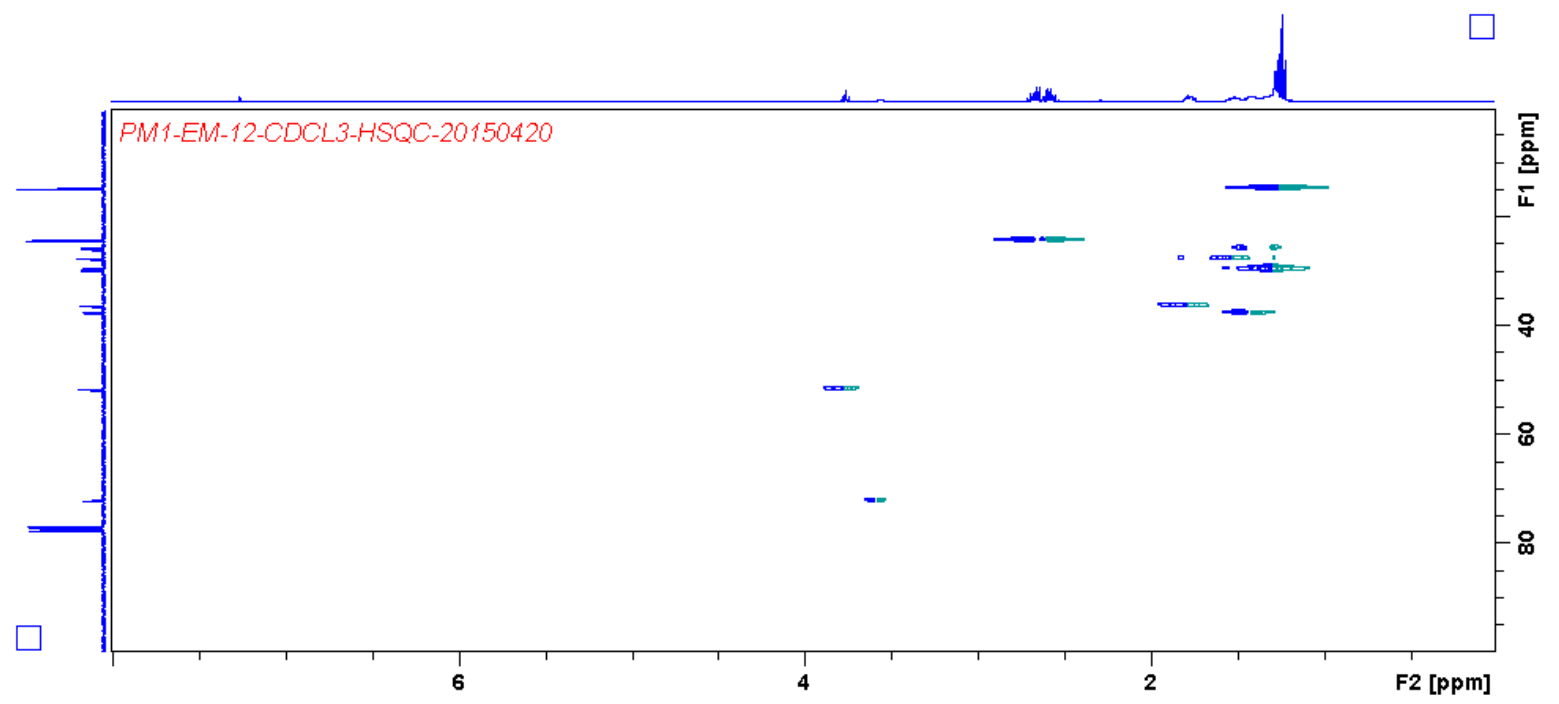

Fig. S35-F. Characterization of compound $I_{a}, H S Q C$ spectrum of compound $I_{a}$. 


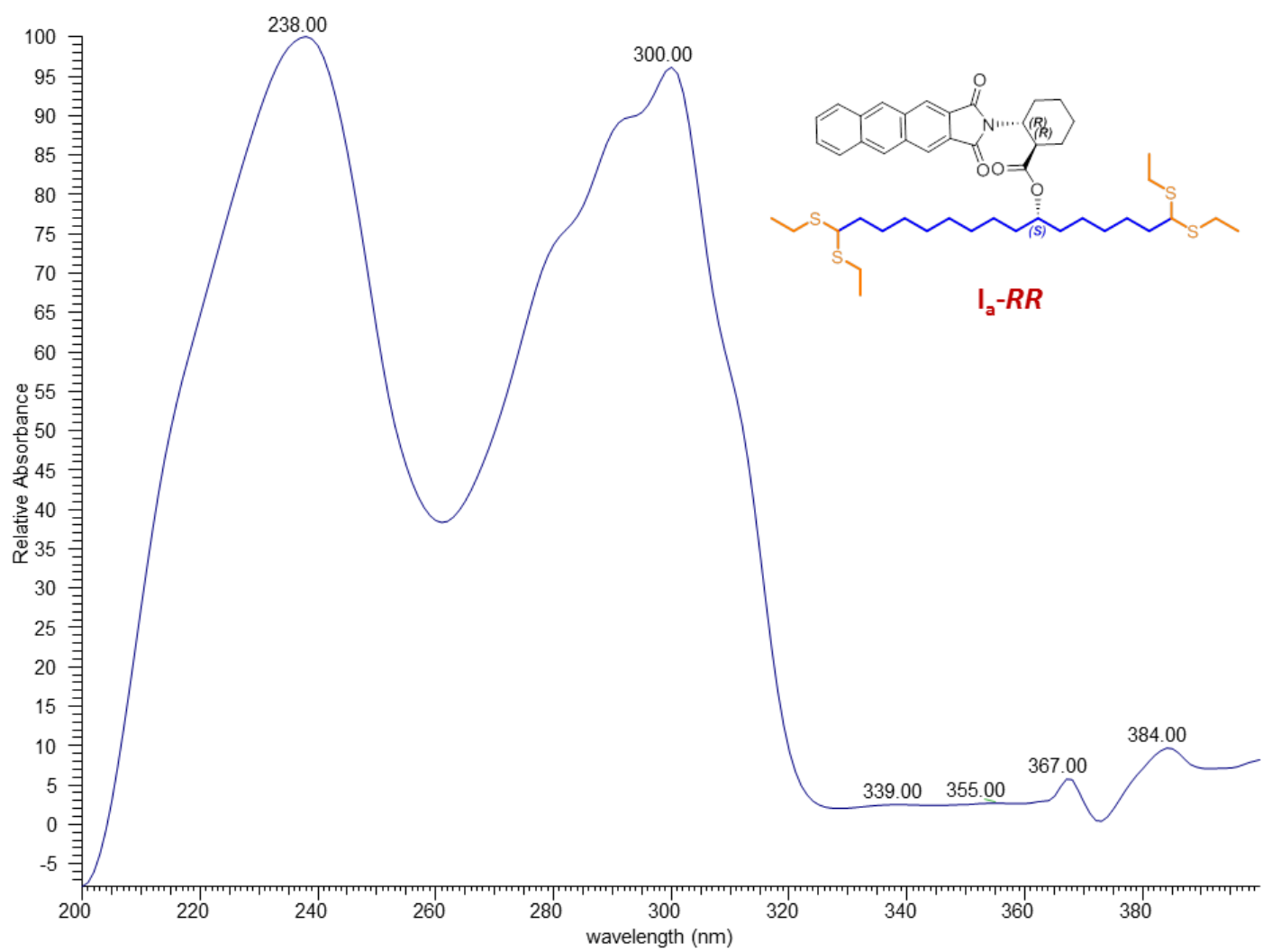

Fig. S36-A. Characterization of compound $\mathrm{I}_{\mathrm{a}}-R R$, UV spectrum of compound $\mathrm{I}_{\mathrm{a}}-\boldsymbol{R} R$. 


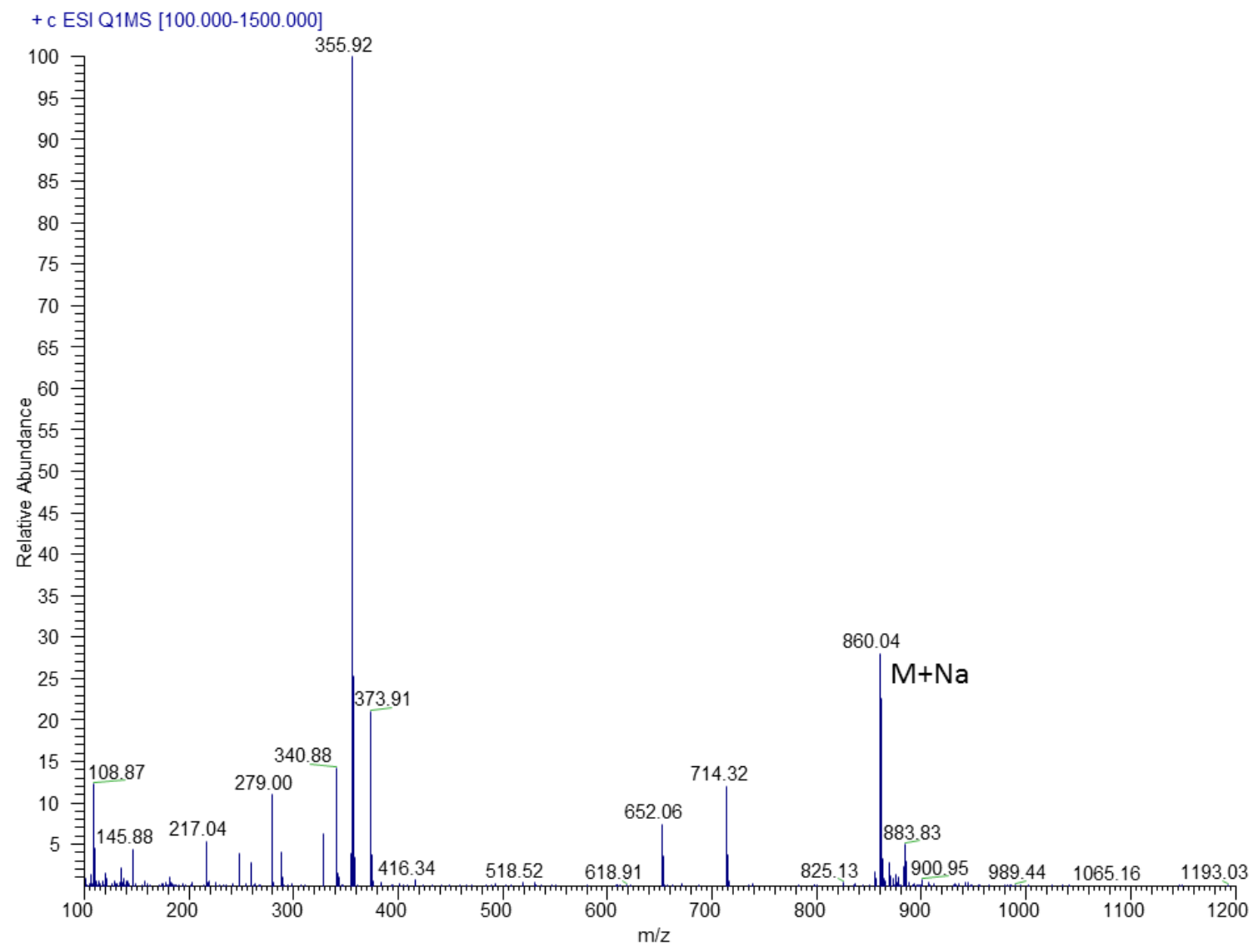

Fig. S36-B. Characterization of compound $\mathrm{I}_{\mathrm{a}}-\mathrm{RR}$, MS/MS spectrum of compound $\mathrm{I}_{\mathrm{a}}$ RR. 


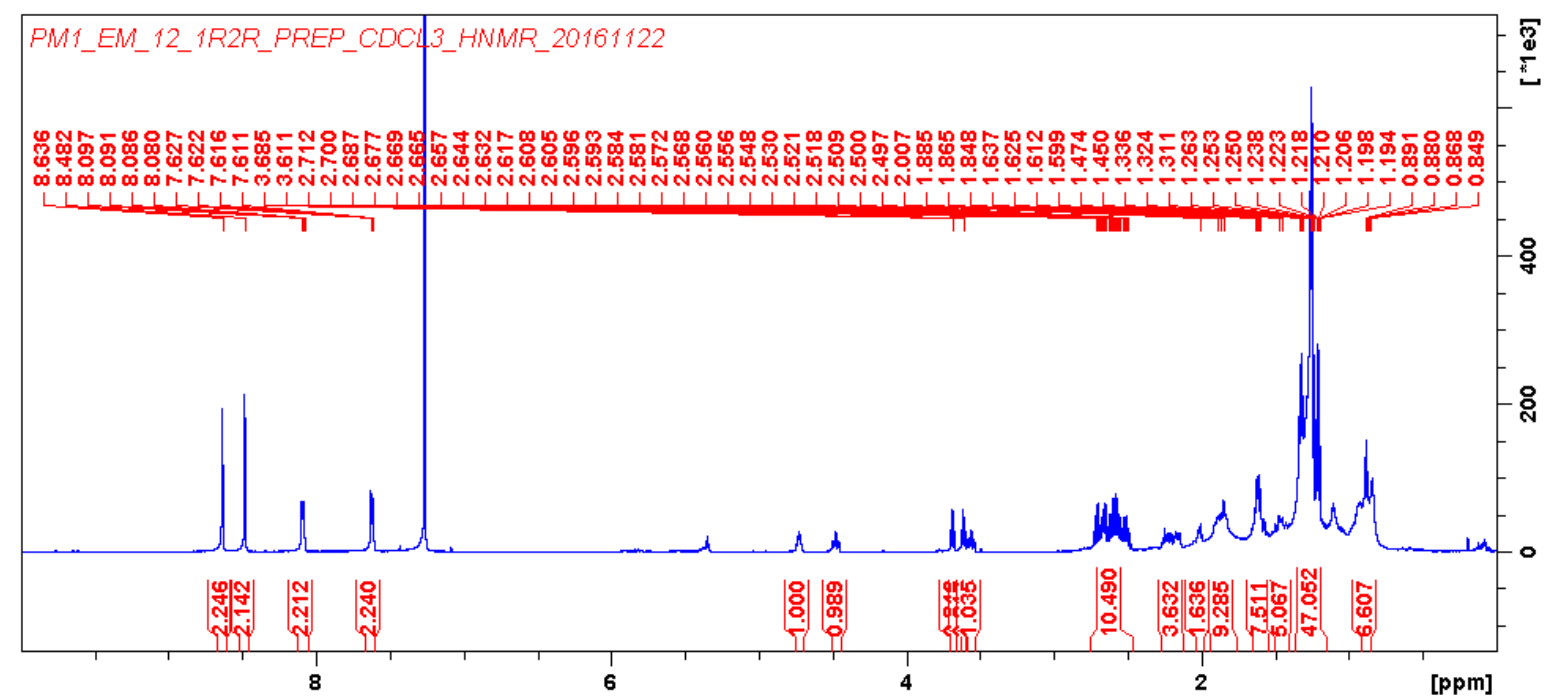

Fig. S36-C. Characterization of compound $\mathrm{I}_{\mathrm{a}}-\boldsymbol{R} \boldsymbol{R},{ }^{1} \mathrm{H} \mathrm{NMR}\left(600 \mathrm{MHz}, \mathrm{CDCl}_{3}\right)$ spectrum of compound $\mathrm{I}_{\mathrm{a}}-\boldsymbol{R} R$. 


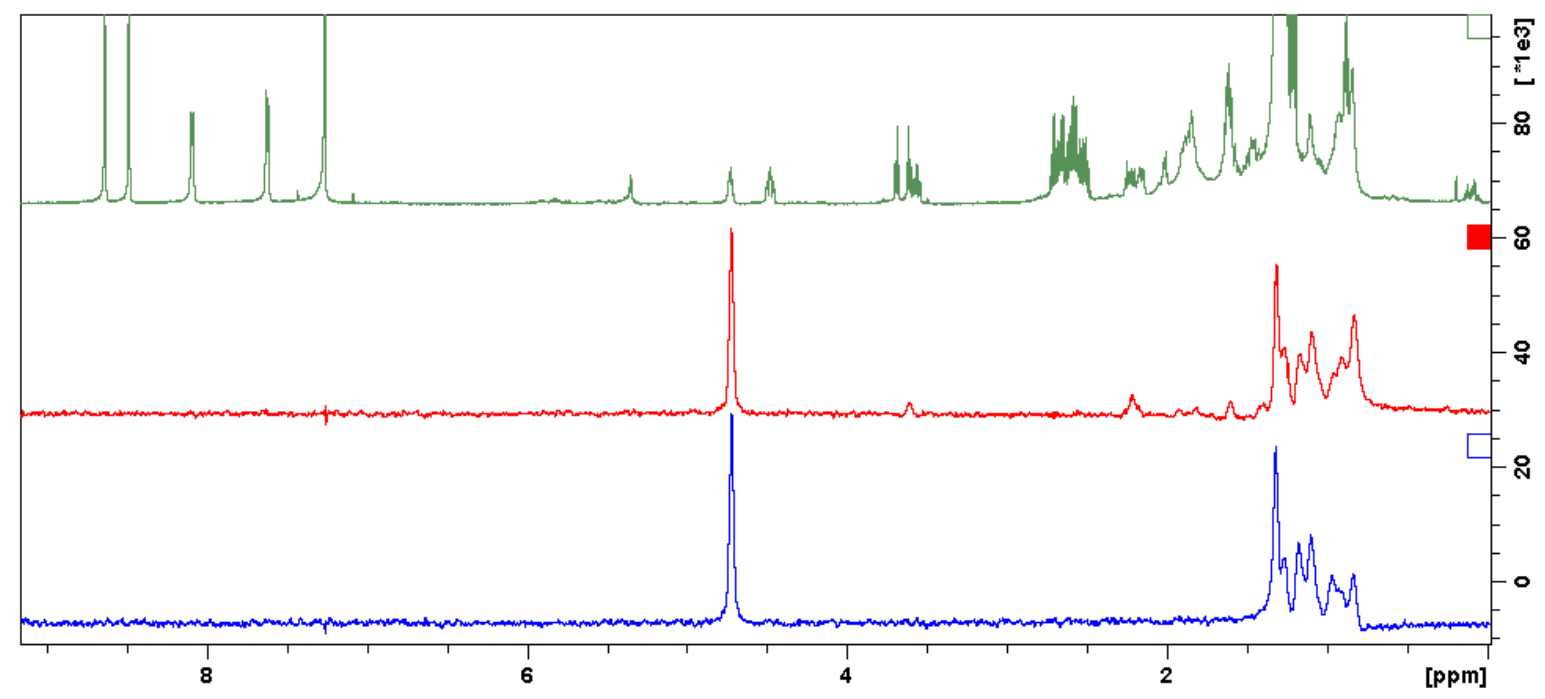

Fig. S36-D. Characterization of compound $\mathrm{I}_{\mathrm{a}}-\boldsymbol{R} \boldsymbol{R}$, Select $1 \mathrm{D}-\mathrm{TOCSY}(600 \mathrm{MHz}$, $\mathrm{CDCl}_{3}$ ) spectrum of compound $\mathbf{I}_{\mathbf{a}}-\boldsymbol{R} \boldsymbol{R}$. 


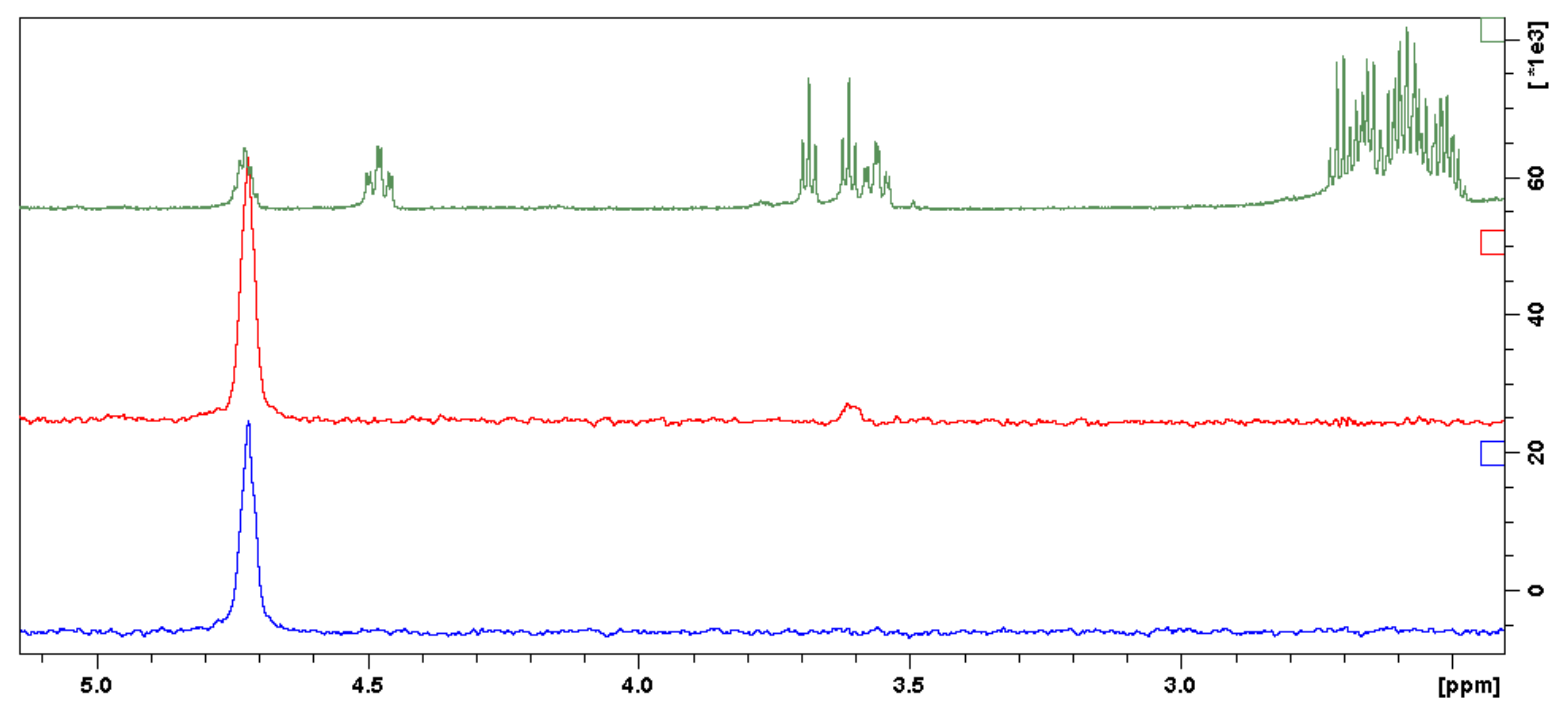

Fig. S36-E. Characterization of compound $\mathrm{I}_{\mathrm{a}}-\boldsymbol{R} R$, Enlarged select 1D-TOCSY (600 $\mathrm{MHz}, \mathrm{CDCl}_{3}$ ) spectrum of compound $\mathrm{I}_{\mathbf{a}}-\boldsymbol{R} R$. 


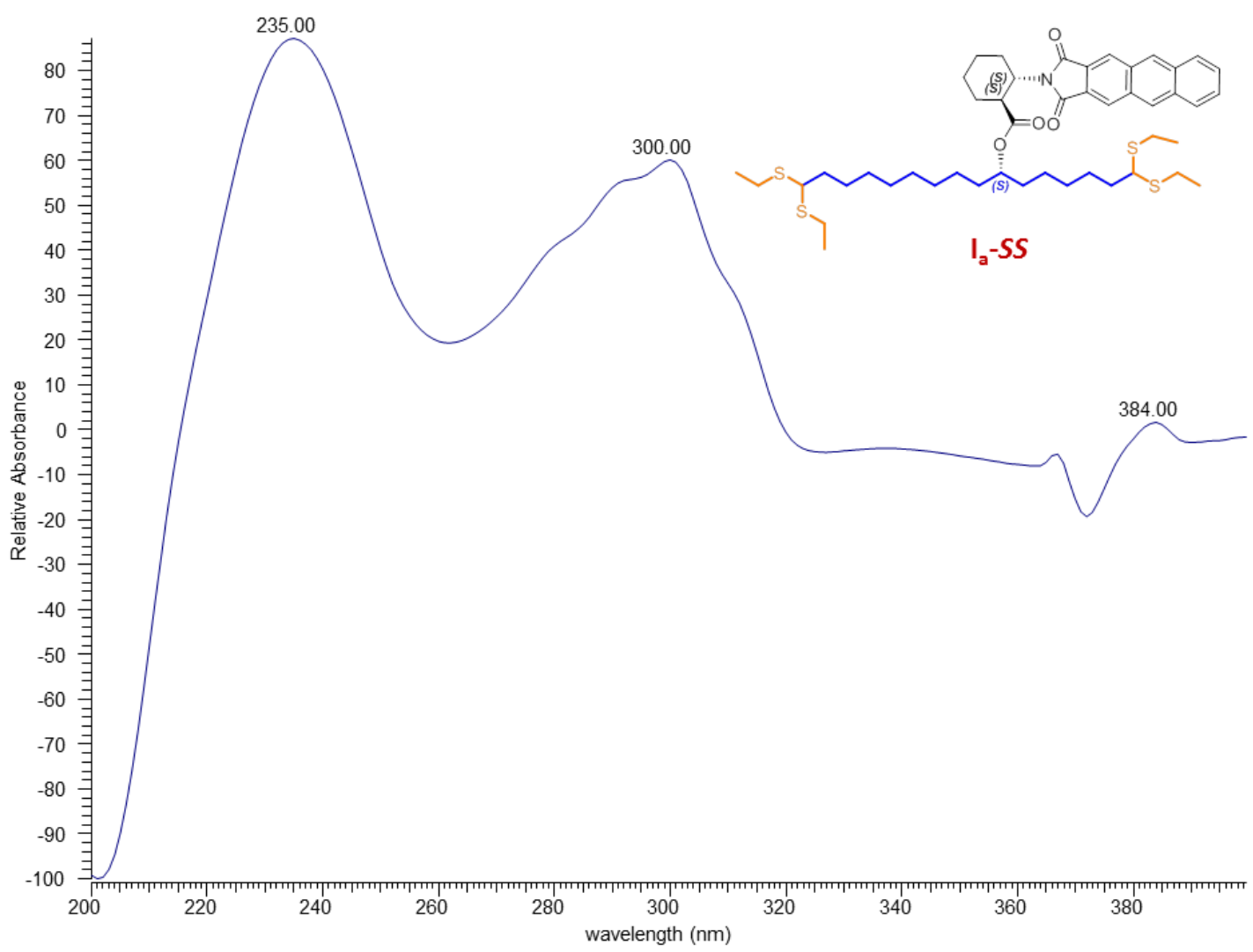

Fig. S37-A. Characterization of compound $\mathrm{I}_{\mathrm{a}}-\mathrm{SS}$, UV spectrum of compound $\mathrm{I}_{\mathrm{a}}-\mathrm{SS}$. 


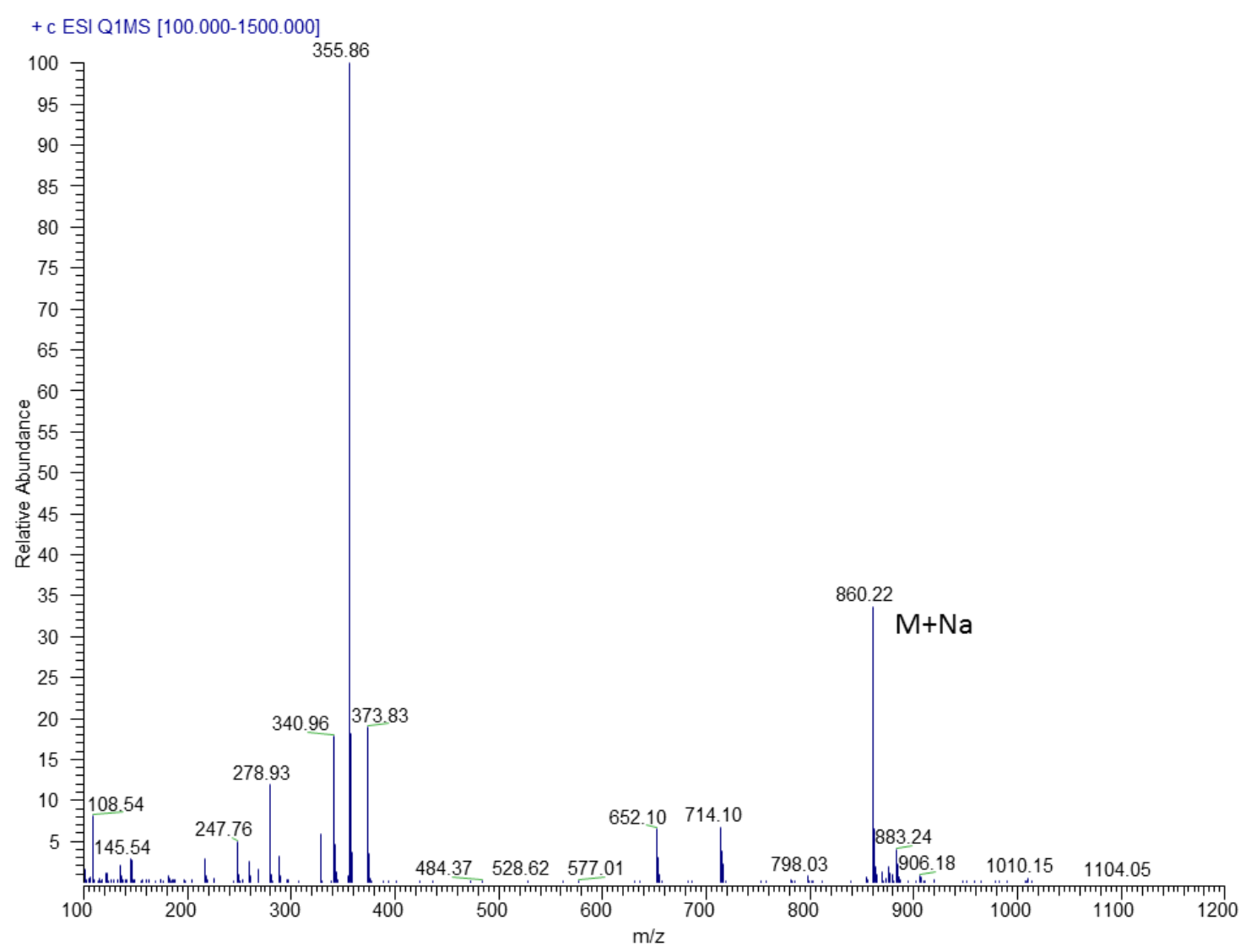

Fig. S37-B. Characterization of compound $\mathrm{I}_{\mathrm{a}}-\mathrm{SS}$, MS/MS spectrum of compound $\mathrm{I}_{\mathrm{a}}$ SS. 


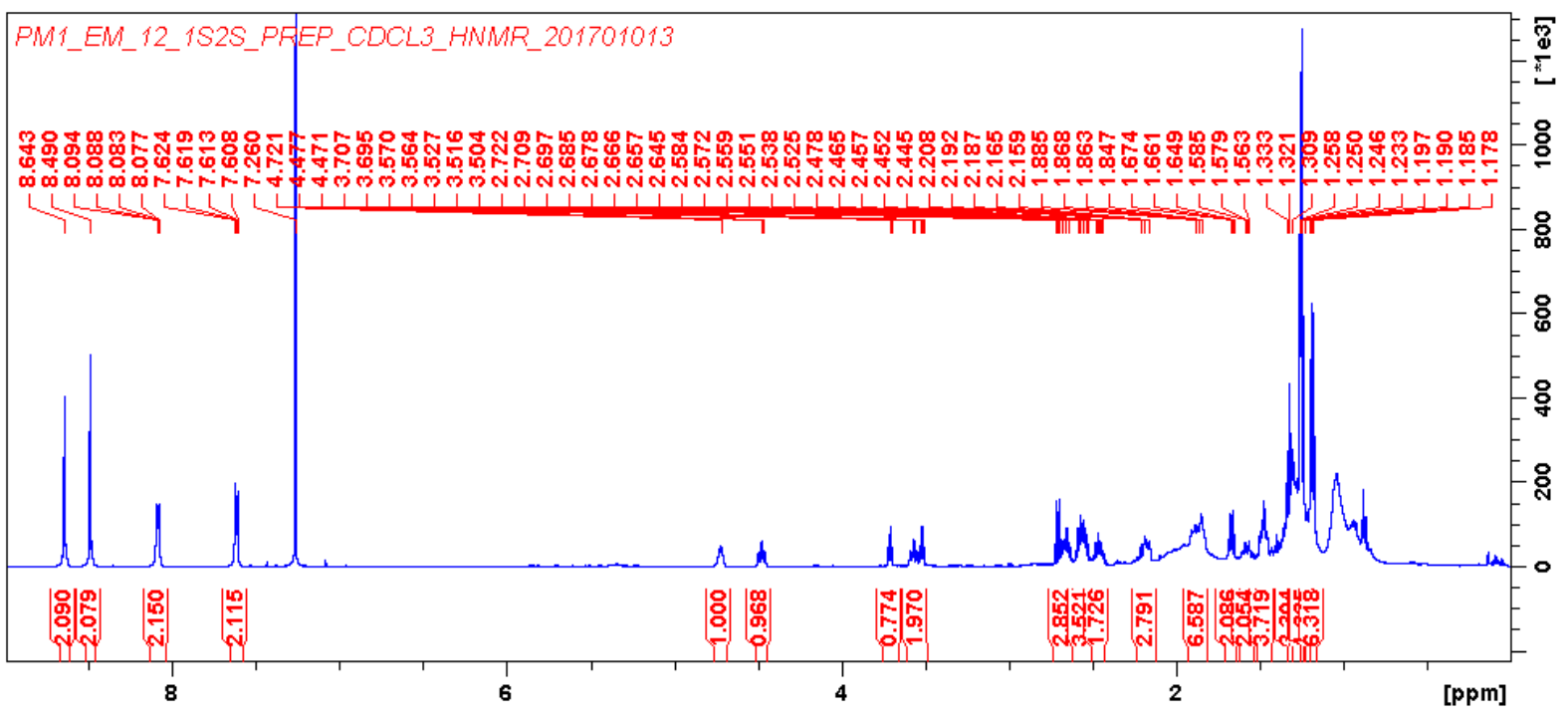

Fig. S37-C. Characterization of compound $\mathrm{I}_{\mathrm{a}}-\mathrm{SS},{ }^{1} \mathrm{H}$ NMR $\left(600 \mathrm{MHz}, \mathrm{CDCl}_{3}\right)$ spectrum of compound la-SS. 


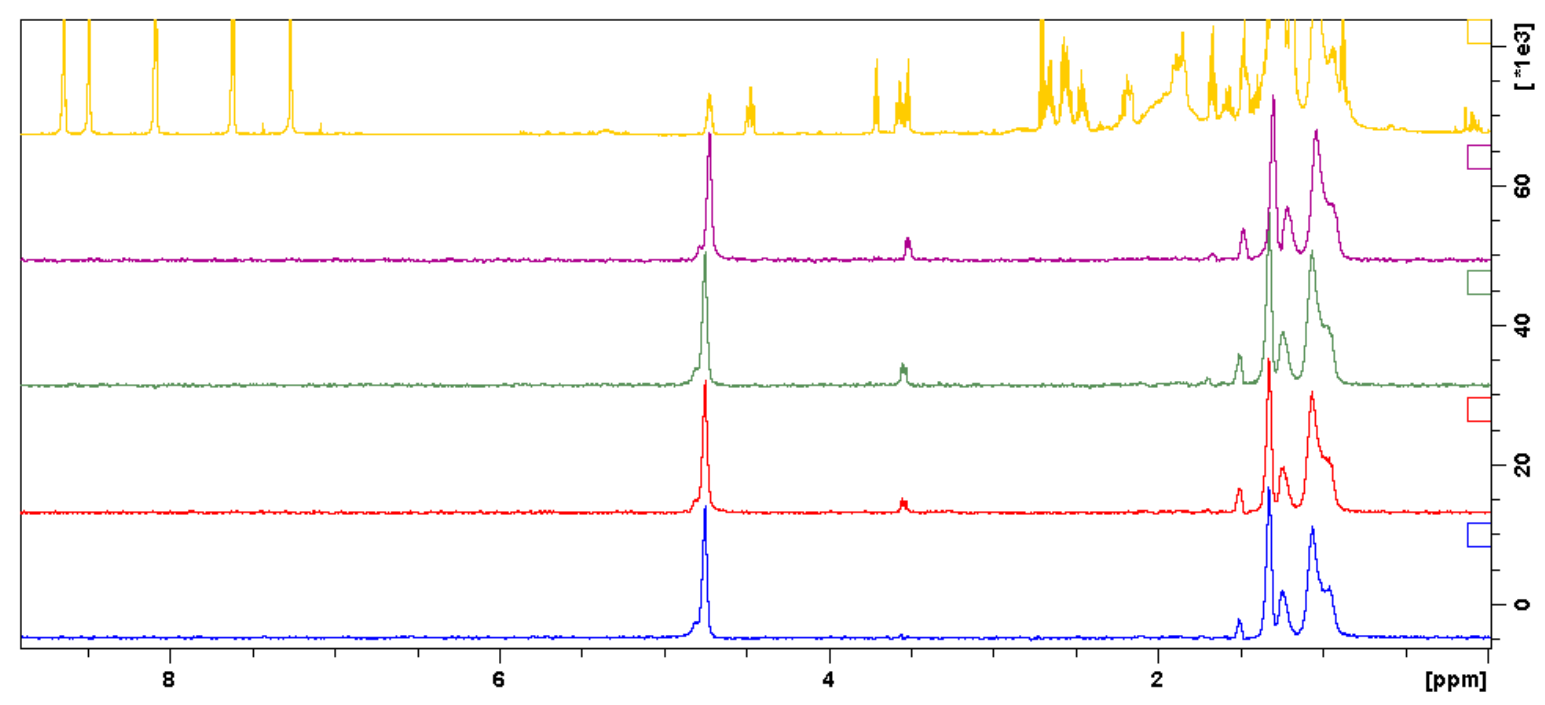

Fig. S37-D. Characterization of compound Ia-SS, Select 1D-TOCSY $(600 \mathrm{MHz}$, $\mathrm{CDCl}_{3}$ ) spectrum of compound $\mathrm{I}_{\mathbf{a}}-\mathrm{SS}$. 


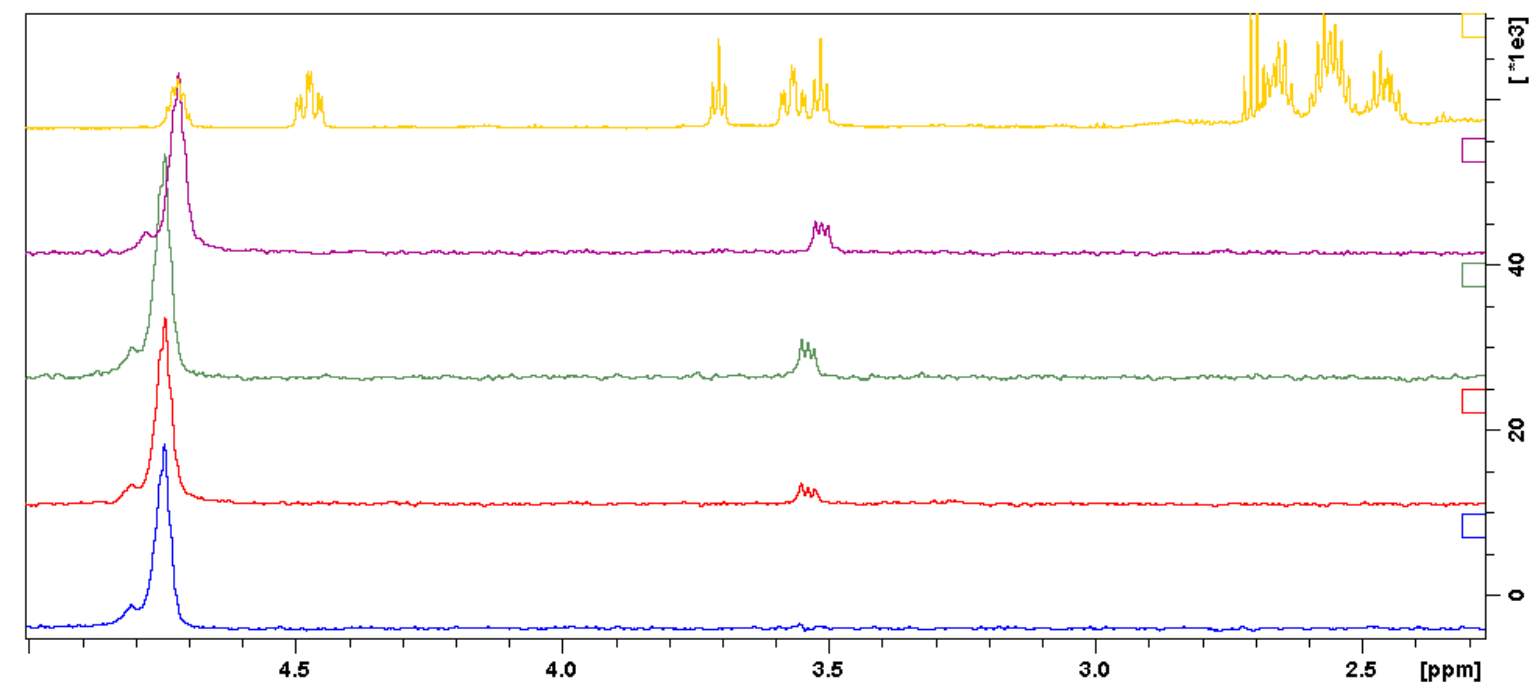

Fig. S37-E. Characterization of compound $\mathrm{l}_{\mathrm{a}}$-SS, Enlarged select 1D-TOCSY (600 $\mathrm{MHz}, \mathrm{CDCl}_{3}$ ) spectrum of compound $\mathrm{I}_{\mathrm{a}}-\mathrm{SS}$. 


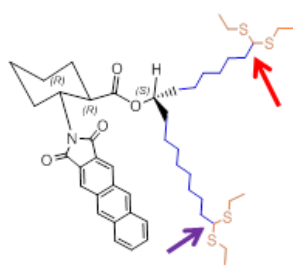

$\mathrm{I}_{\mathrm{a}}(S)-R R$

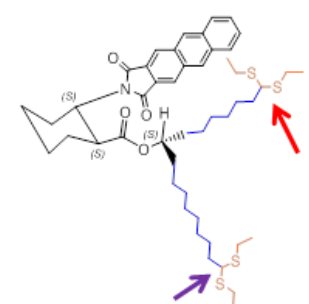

$\mathbf{I}_{\mathrm{a}}(S)-S S$

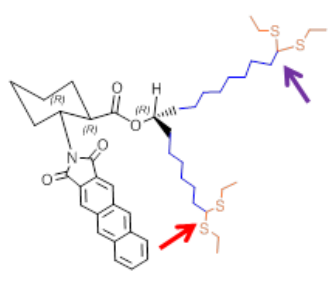

$\mathrm{I}_{\mathrm{a}}(R)-R R$

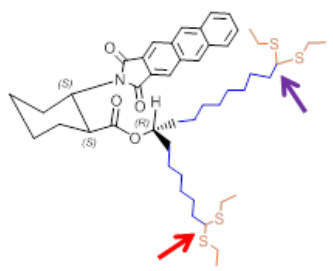

$\mathrm{I}_{\mathrm{a}}(R)-S S$

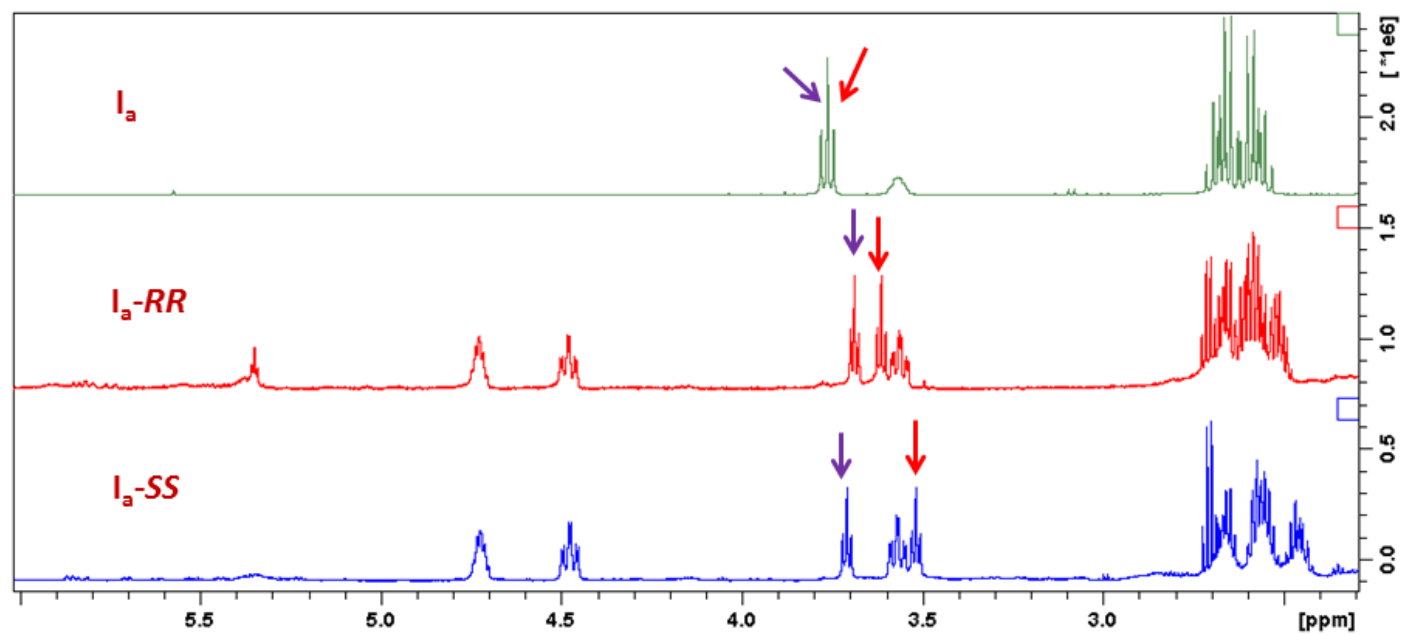

Fig. S38. Absolute configuration identification of compound $I_{a}$, Possible enantiomer derivatives of $\mathrm{I}_{\mathrm{a}}$ and enlarged select 1D-TOCSY $\left(600 \mathrm{MHz}, \mathrm{CDCl}_{3}\right)$ of compound $\mathrm{I}_{\mathrm{a}}-\boldsymbol{R} \boldsymbol{R}$, $\mathrm{I}_{\mathrm{a}}$-SS. 


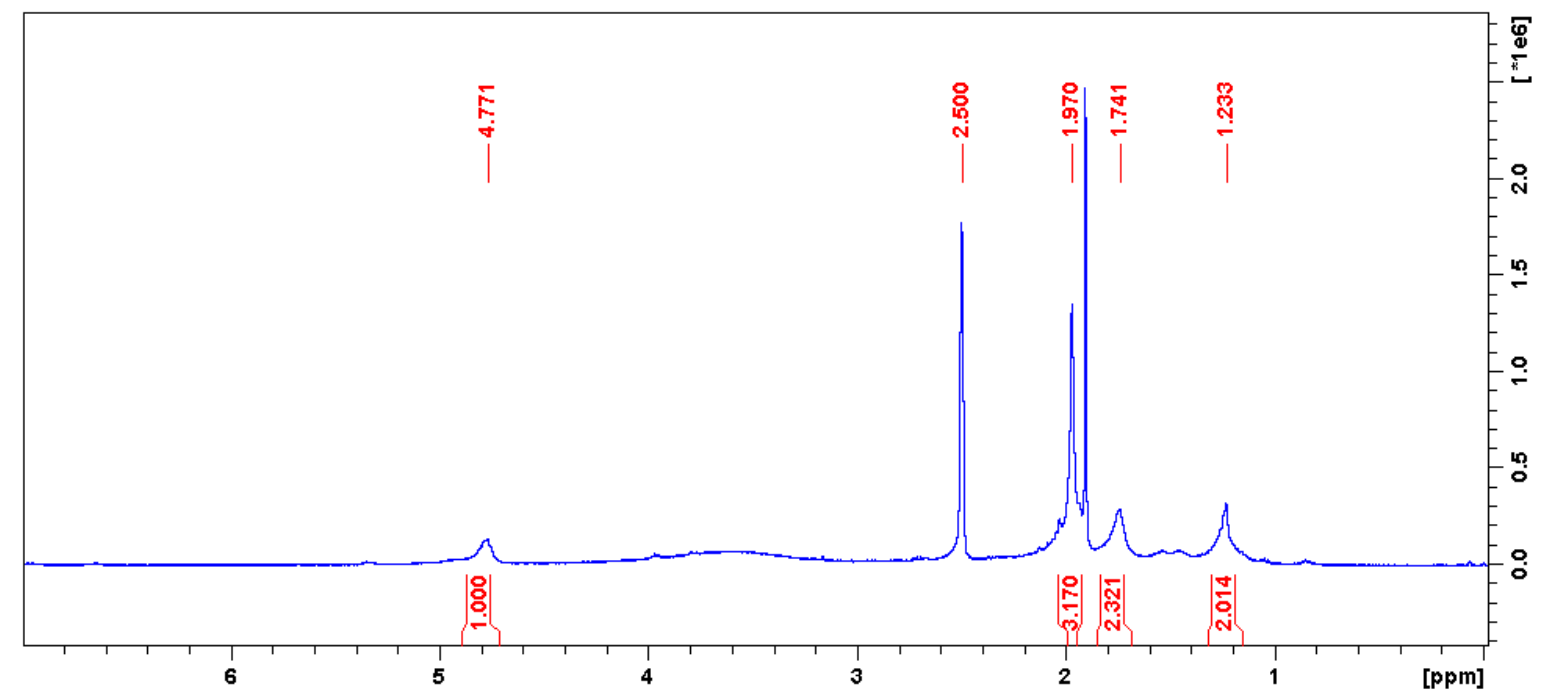

Fig. S39-A. Characterization of R-Ac, ${ }^{1} \mathrm{H}$ NMR (400 MHz, $\left.\mathrm{CDCl}_{3}\right)$ spectrum of R-Ac. 


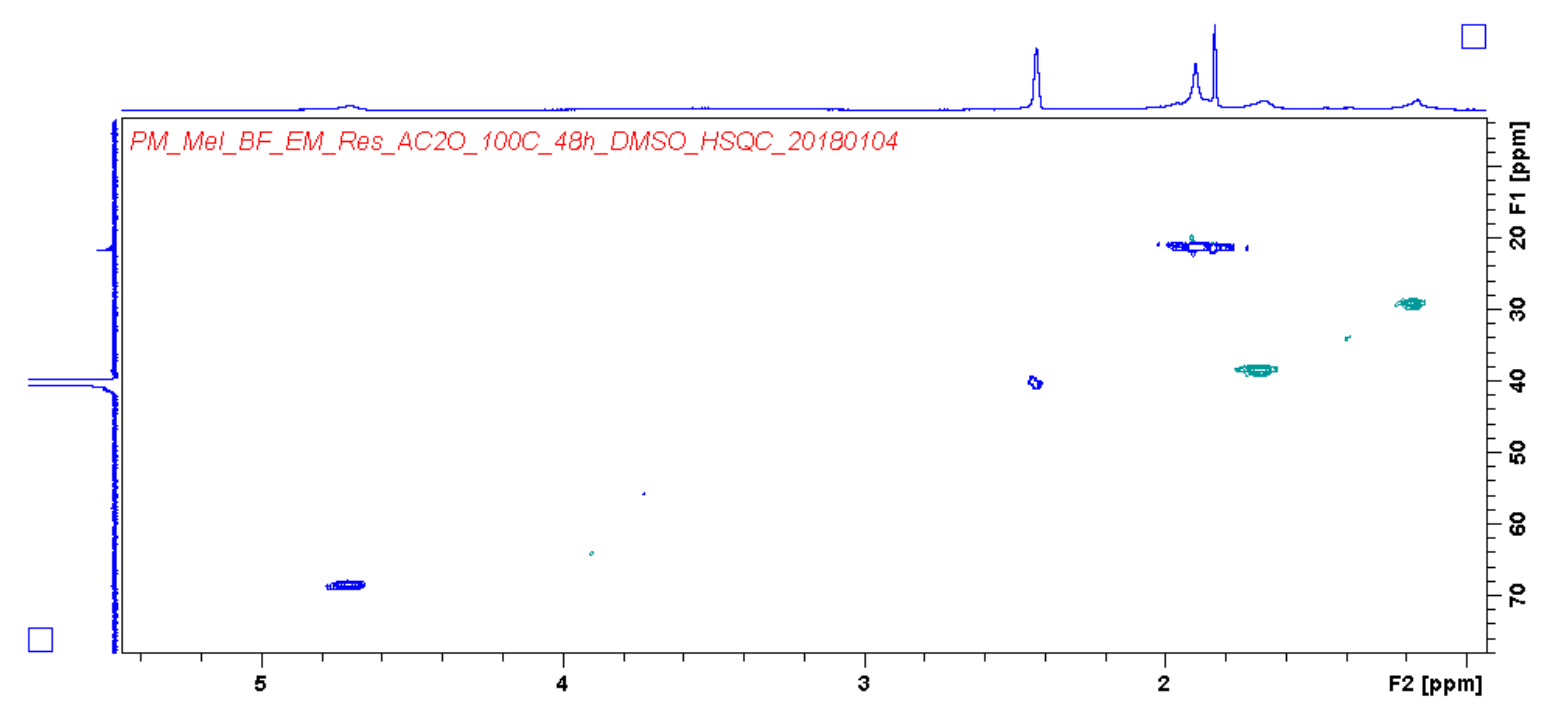

Fig. S39-B. Characterization of R-Ac, HSQC spectrum of R-Ac. 


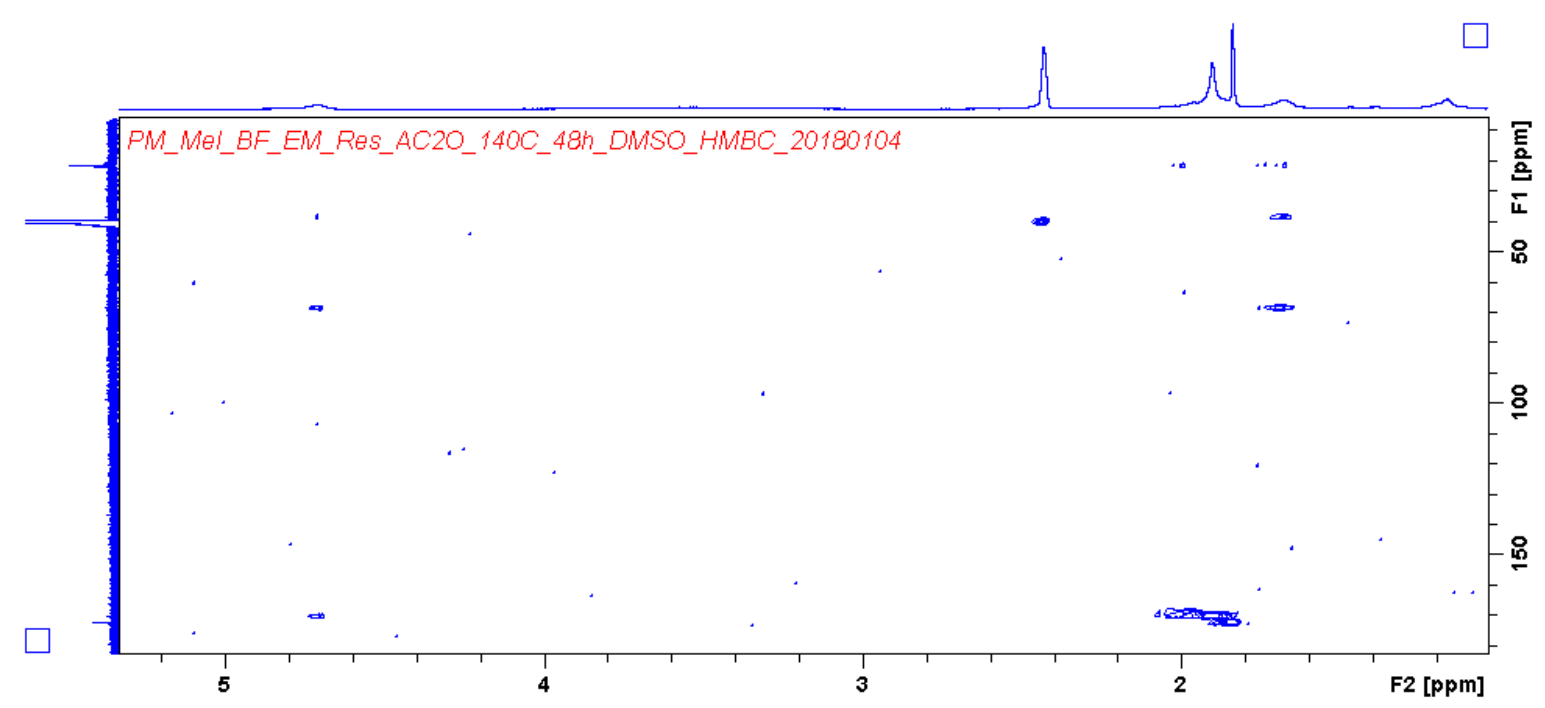

Fig. S39-C. Characterization of R-Ac, HMBC spectrum of R-Ac. 


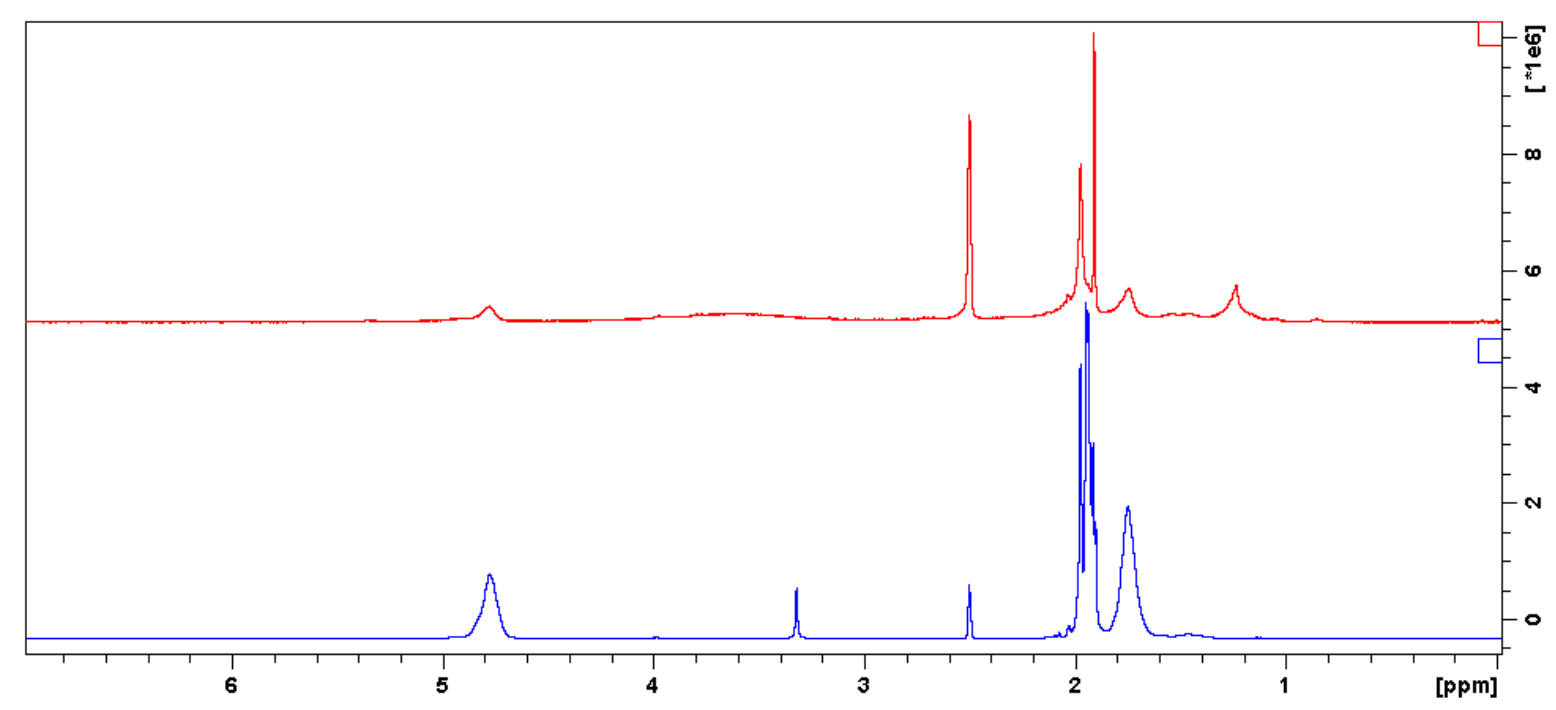

Fig. S39-D. Characterization of R-Ac, Comparison ${ }^{1} \mathrm{H}$ NMR $\left(400 \mathrm{MHz}, \mathrm{CDCl}_{3}\right)$ of R-Ac (red) and polyvinyl acetate (blue). 


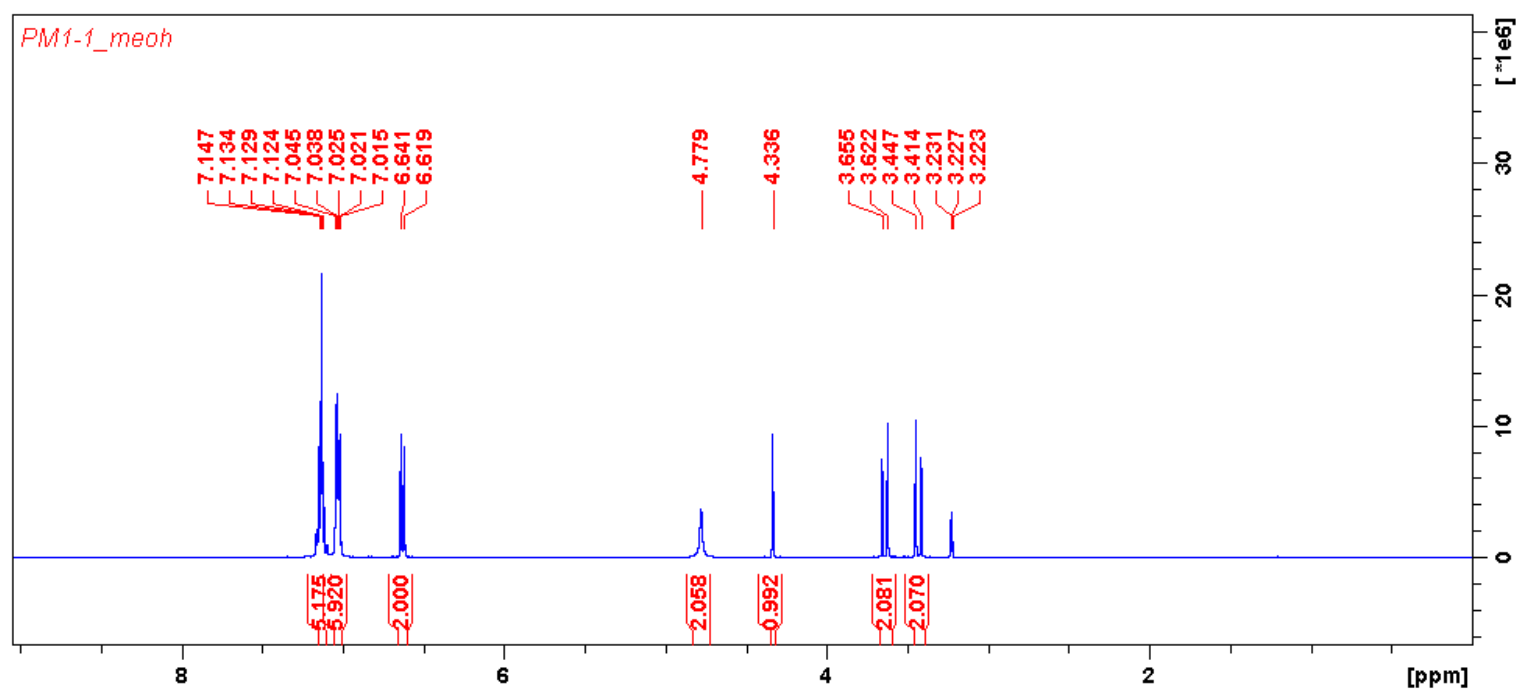

Fig. S40-A. Characterization of compound XVI, ${ }^{1} \mathrm{H}$ NMR (400 MHz, MeOD) spectrum of compound XVI. 


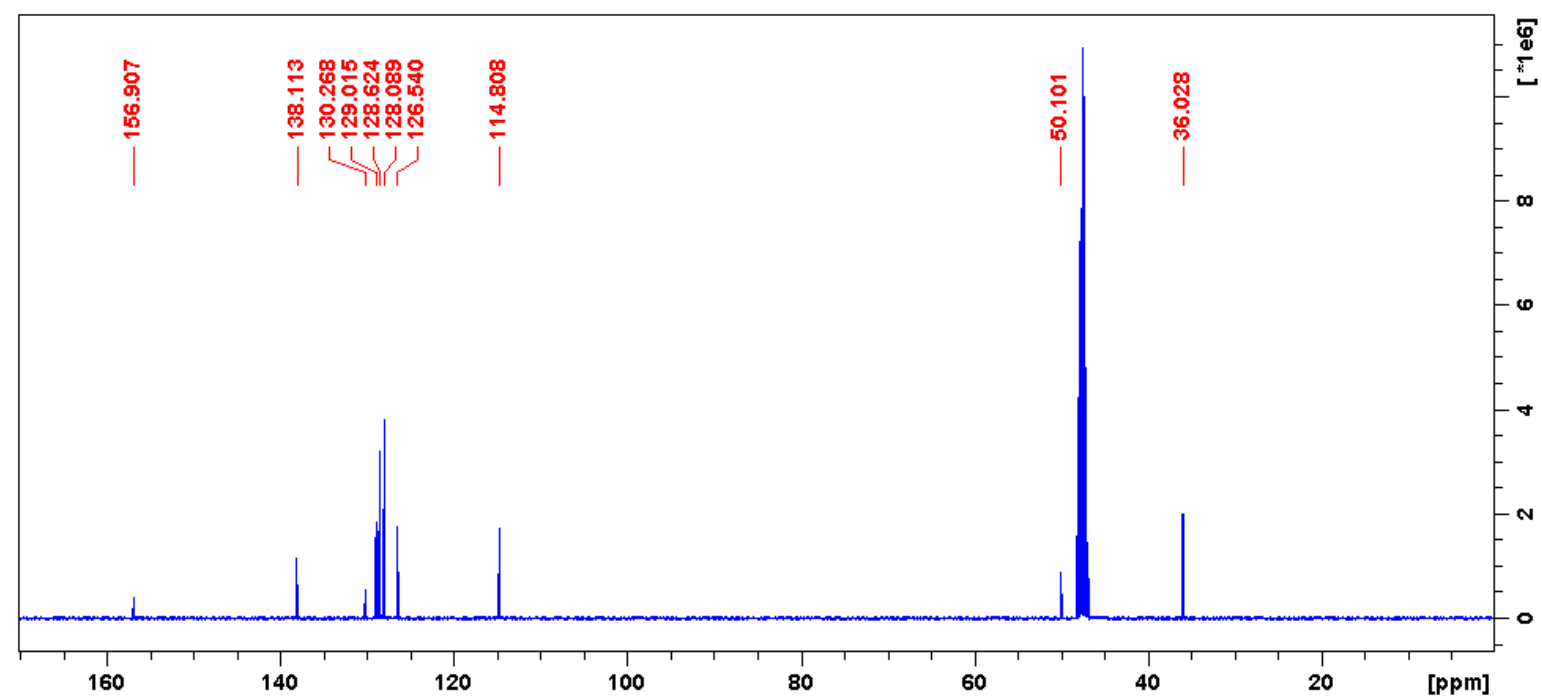

Fig. S40-B. Characterization of compound XVI, ${ }^{13} \mathrm{C}$ NMR $(100 \mathrm{MHz}, \mathrm{MeOD})$ spectrum of compound XVI. 


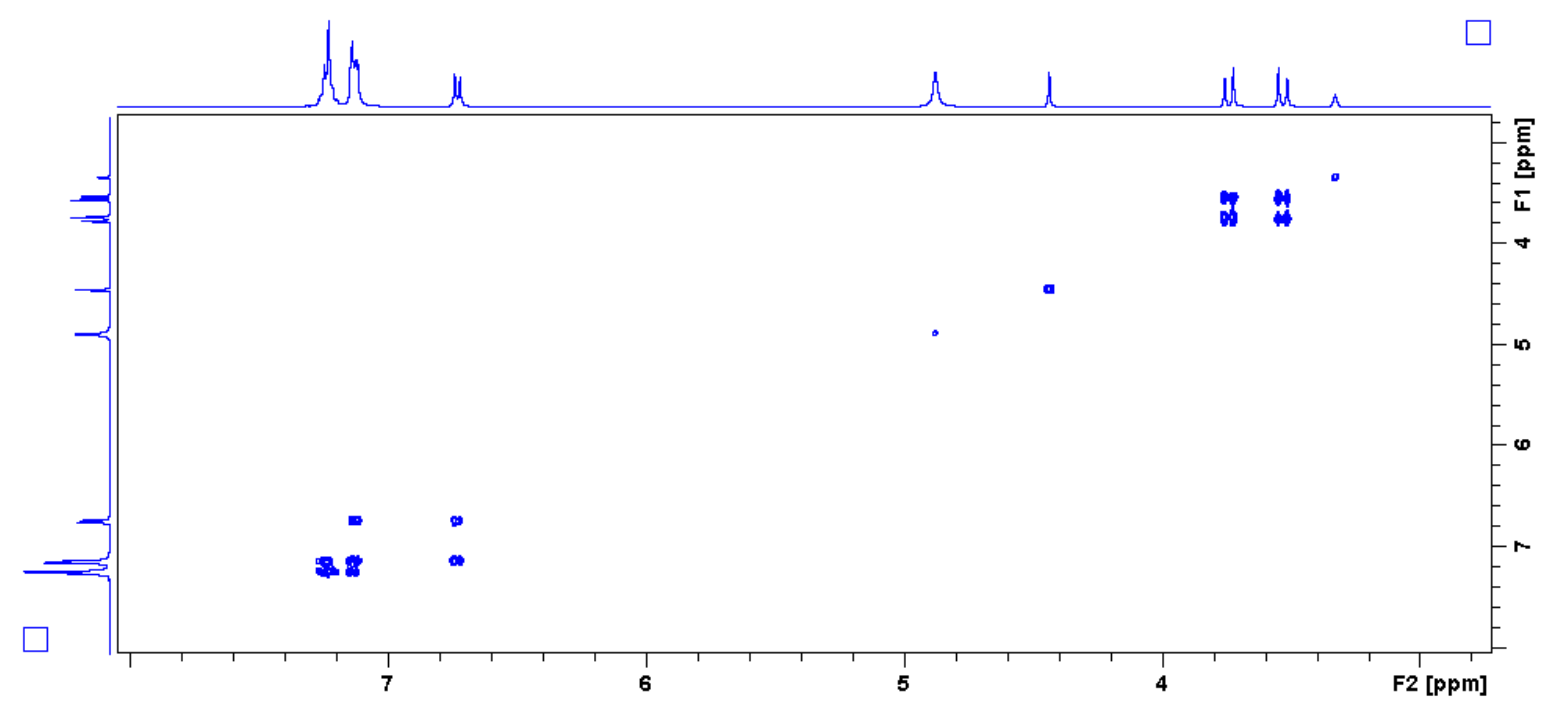

Fig. S40-C. Characterization of compound XVI, HH-COSY spectrum of compound $\mathbf{X V I}$. 


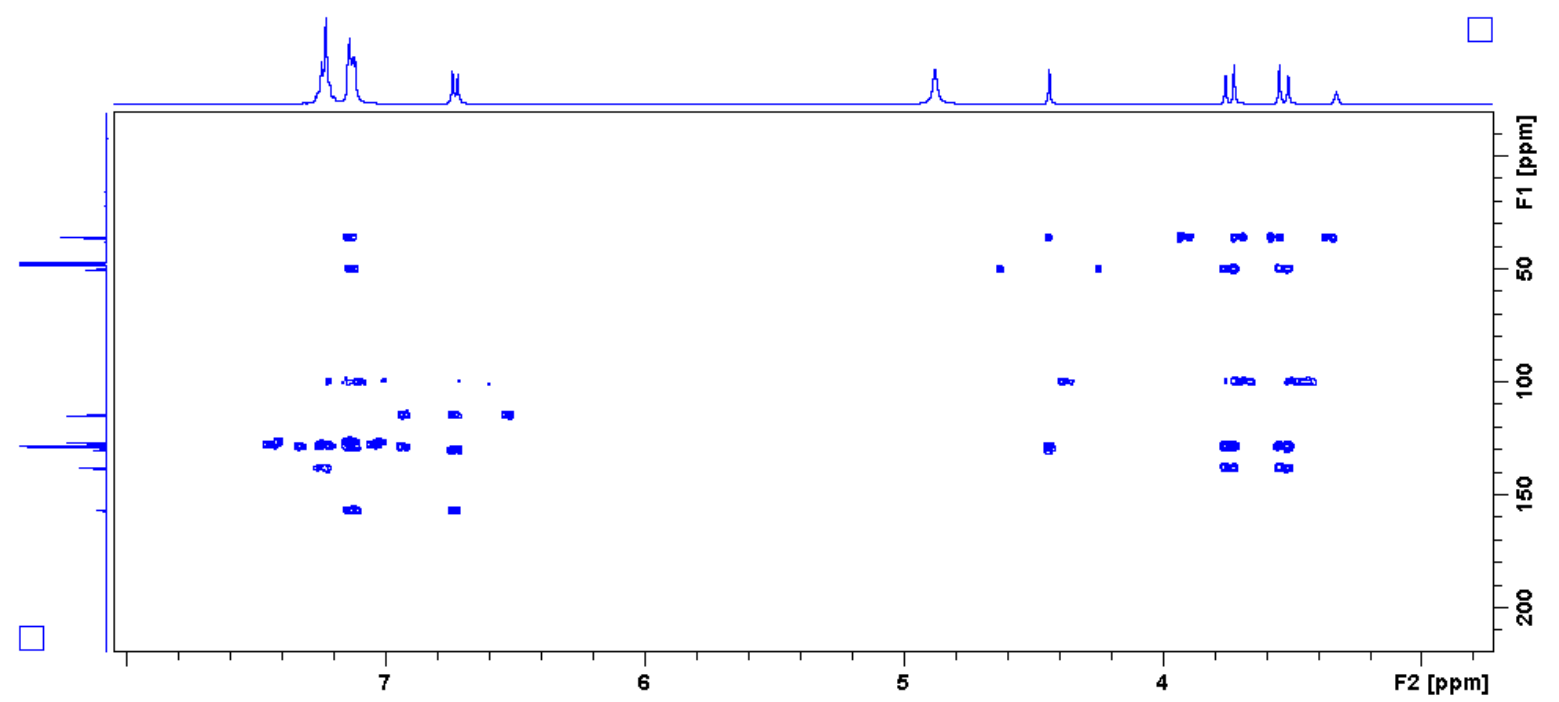

Fig. S40-D. Characterization of compound XVI, HMBC spectrum of compound XVI. 


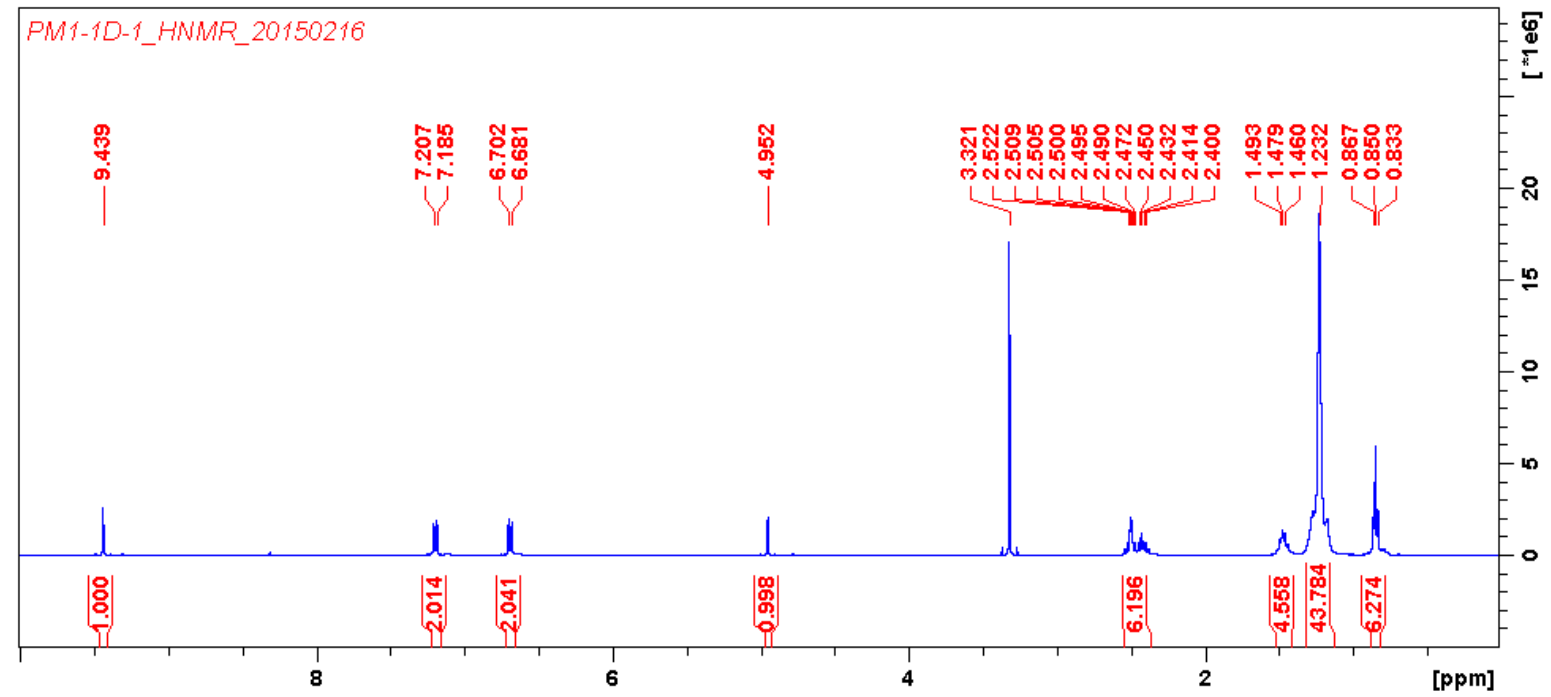

Fig. S41-A. Characterization of compound XVII, ${ }^{1} \mathrm{H}$ NMR $\left(400 \mathrm{MHz}, \mathrm{DMSO}-\mathrm{d}_{6}\right)$ spectrum of compound XVII. 


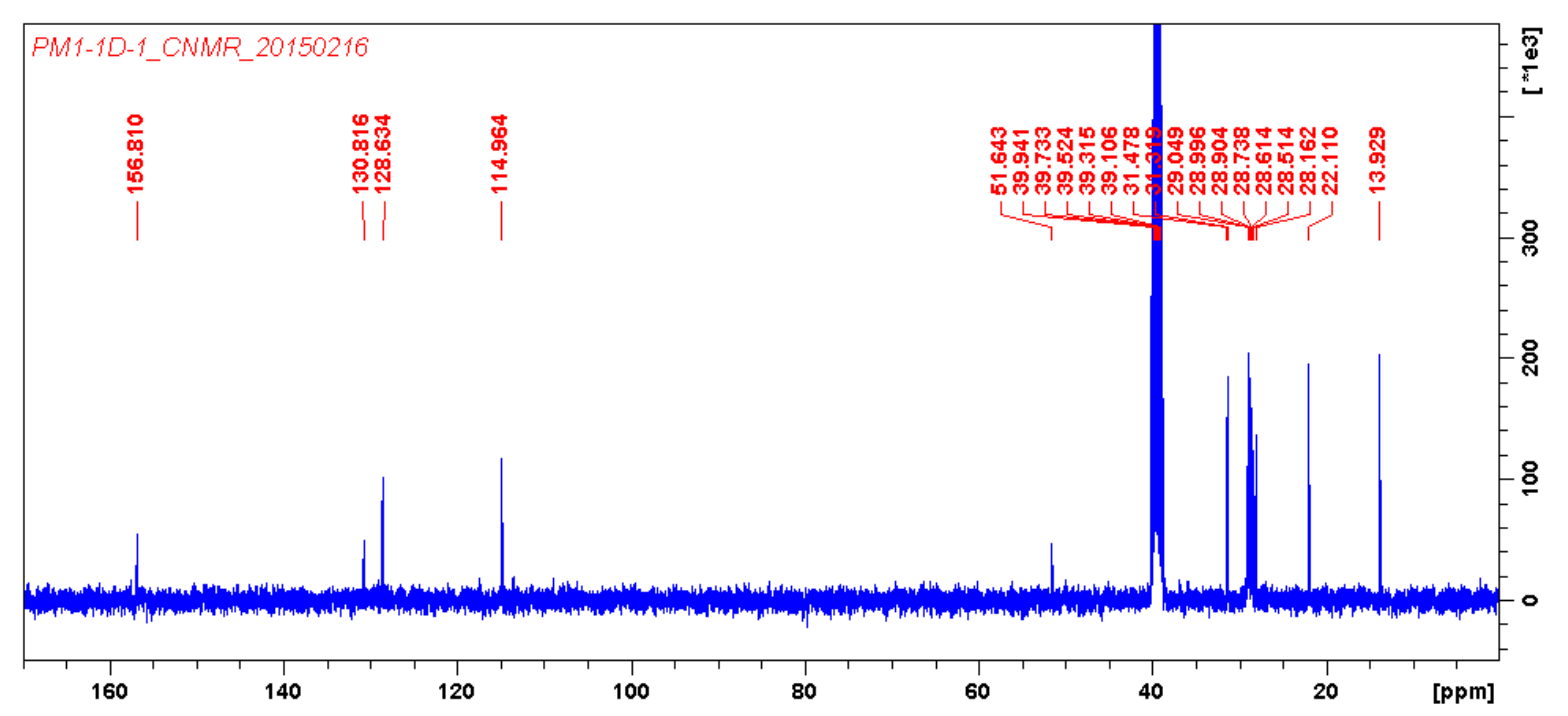

Fig. S41-B. Characterization of compound XVII, ${ }^{13} \mathrm{C}$ NMR (100 MHz, DMSO-d6) spectrum of compound XVII. 


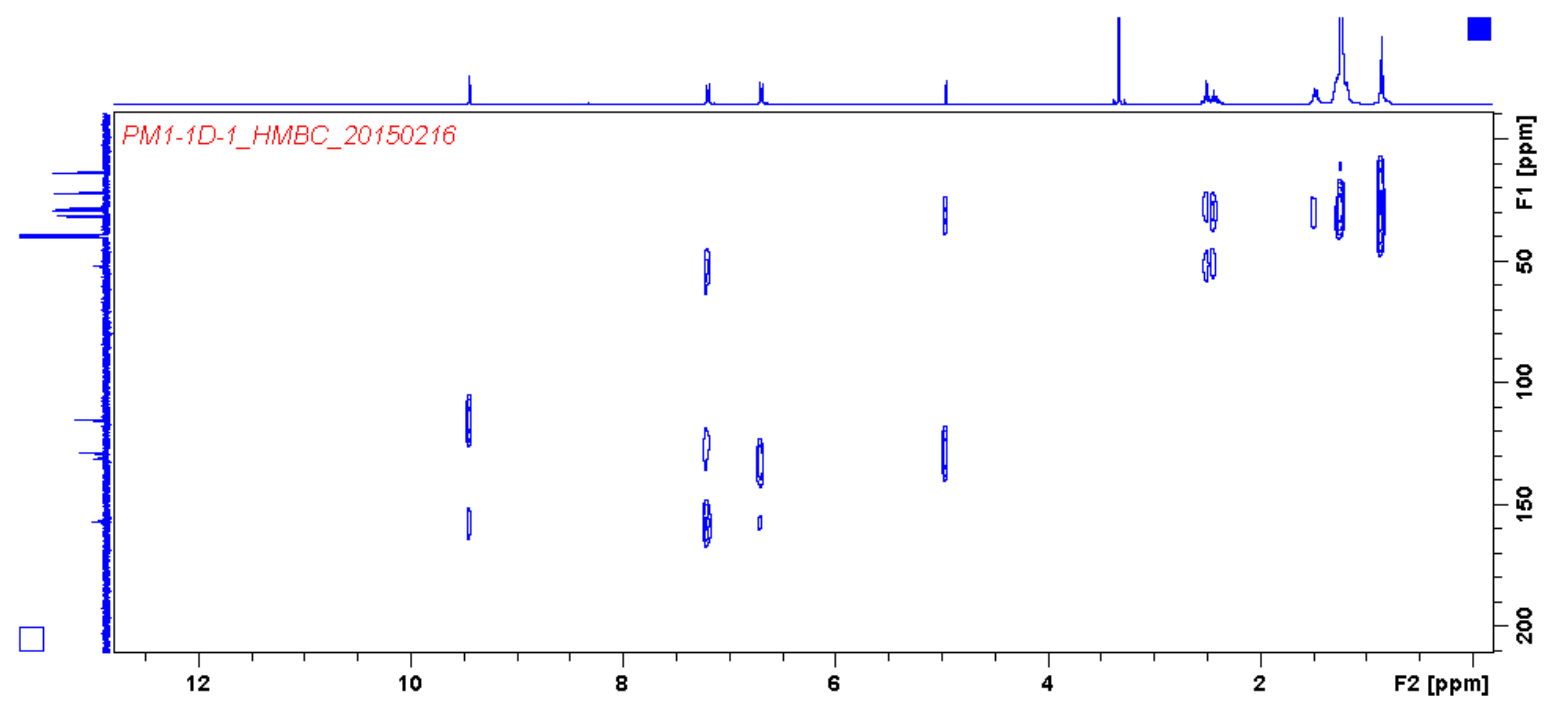

Fig. S41-C. Characterization of compound XVII, HMBC spectrum of compound XVII. 


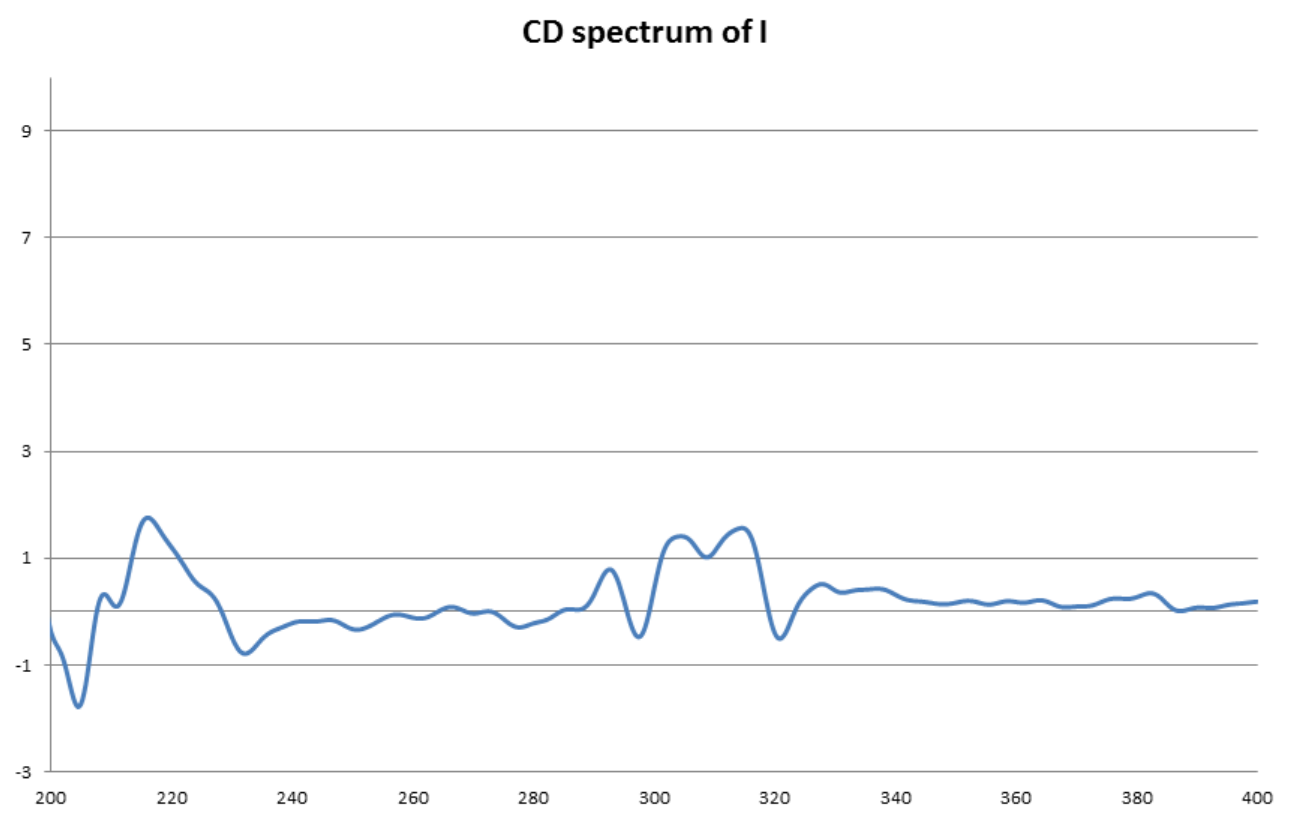

Fig. S42. CD spectrum of I. 


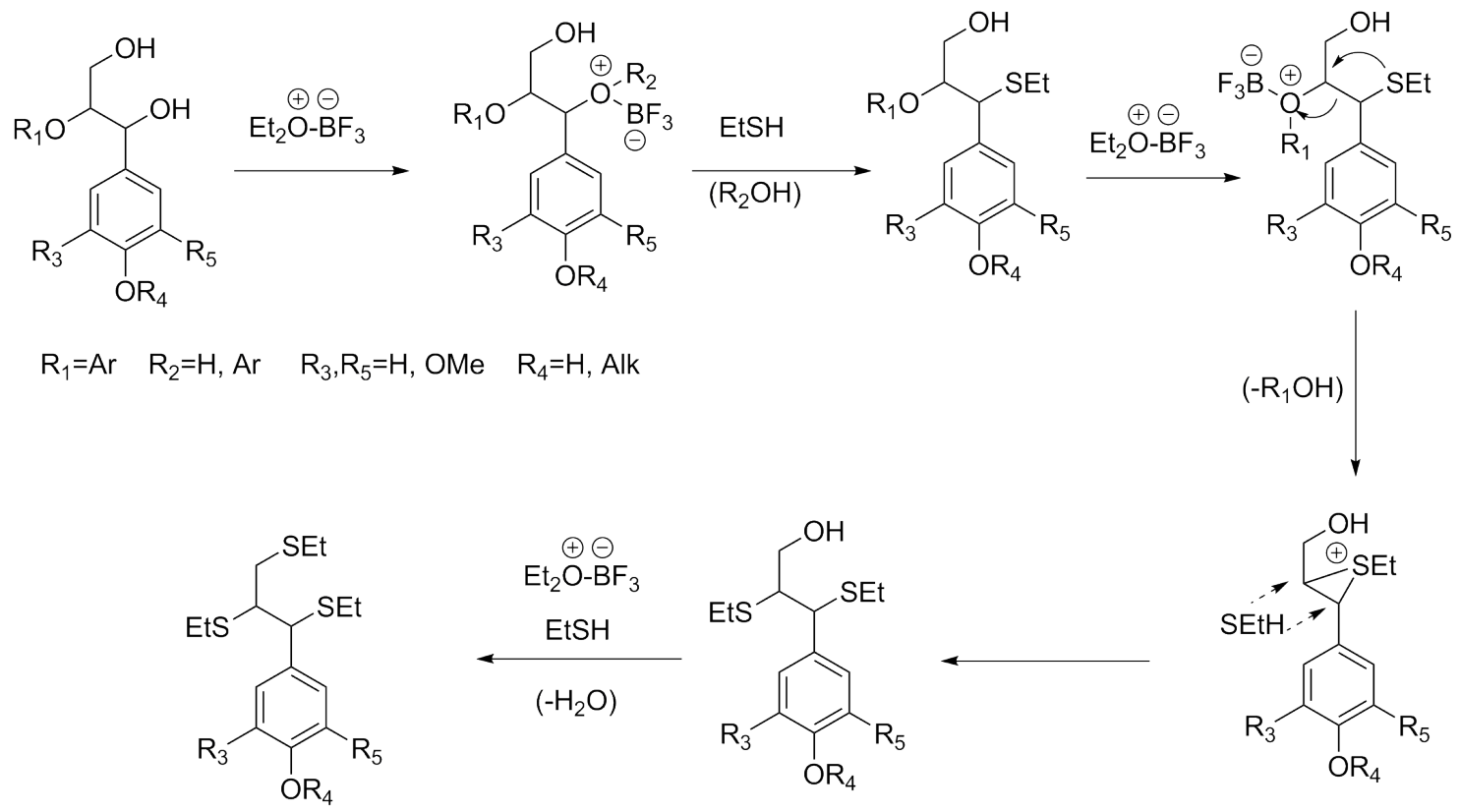

Fig. S43. The proposed mechanism ${ }^{10}$ of lignin thioacidolysis. 

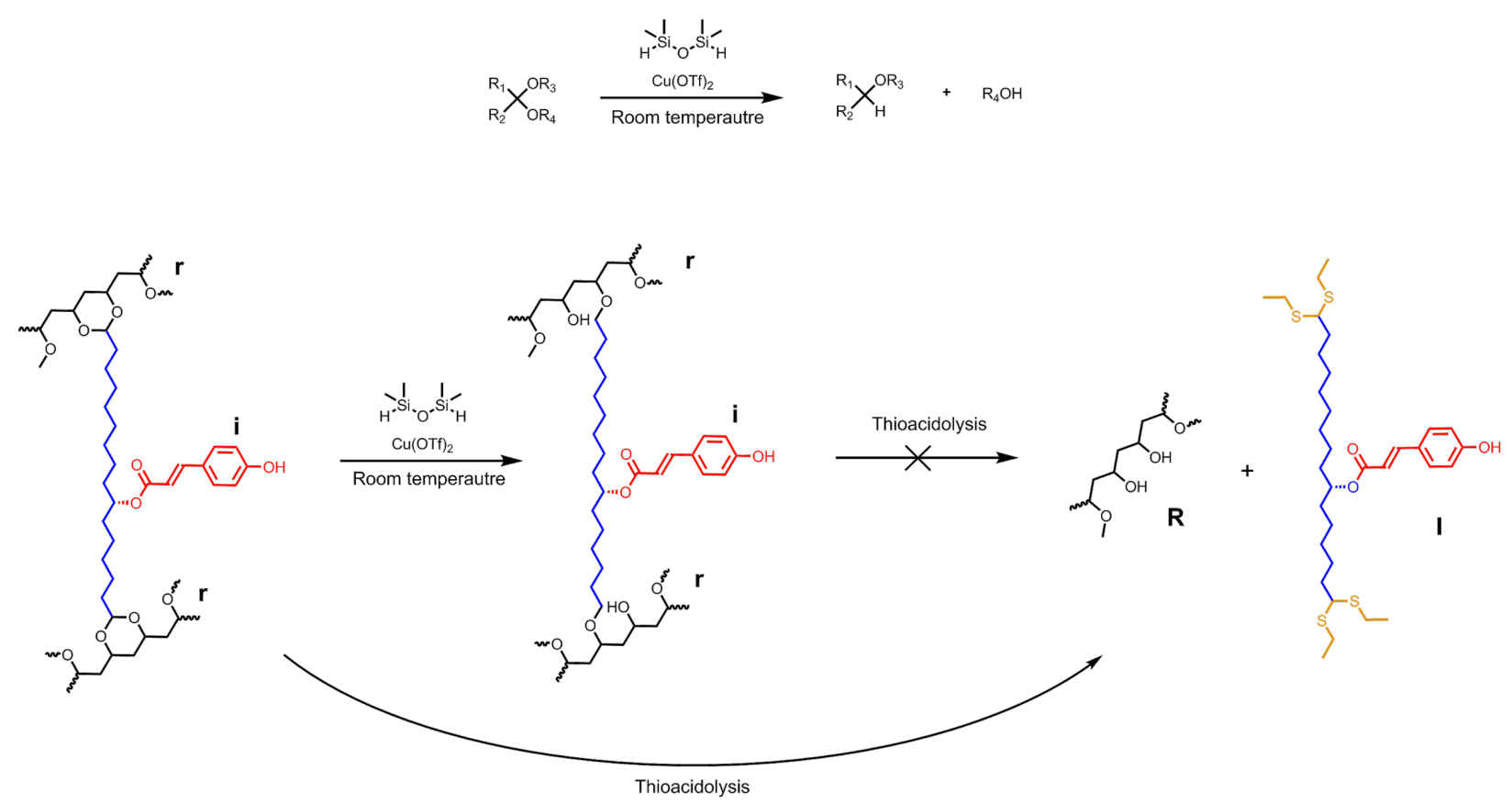

Fig. S44. Reduction of acetals to ethers with TMDS catalyzed by $\mathrm{Cu}(\mathrm{OTf}) 2^{25}$. Sporopollenin pretreated with $\mathrm{TMDS} / \mathrm{Cu}(\mathrm{OTf})_{2}$ becomes completely inert to thioacidolysis degradation. 
A Multi-CP

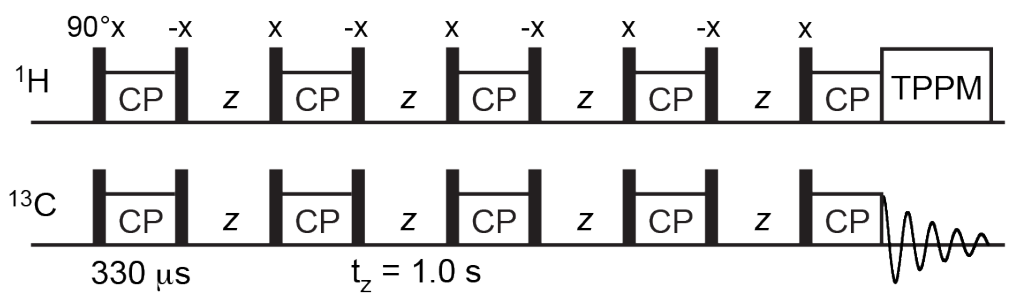

B Gated decoupling multi-CP

$13 \mathrm{kHz}$ MAS, $400 \mathrm{MHz}, 296 \mathrm{~K}$

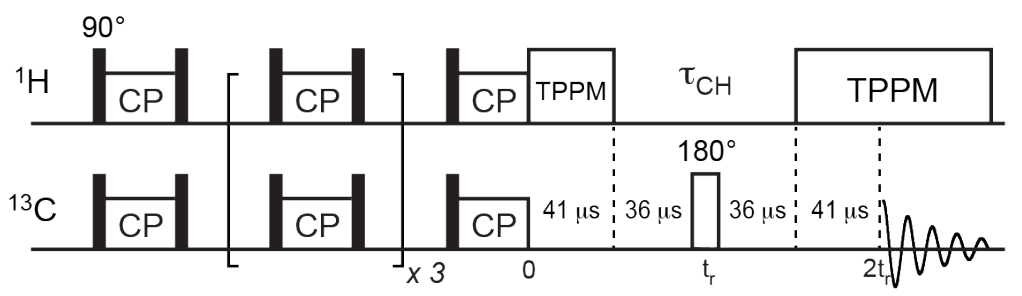

C $\mathrm{CH}_{2}$ selection

$6 \mathrm{kHz}$ MAS, $800 \mathrm{MHz}, 296 \mathrm{~K}$

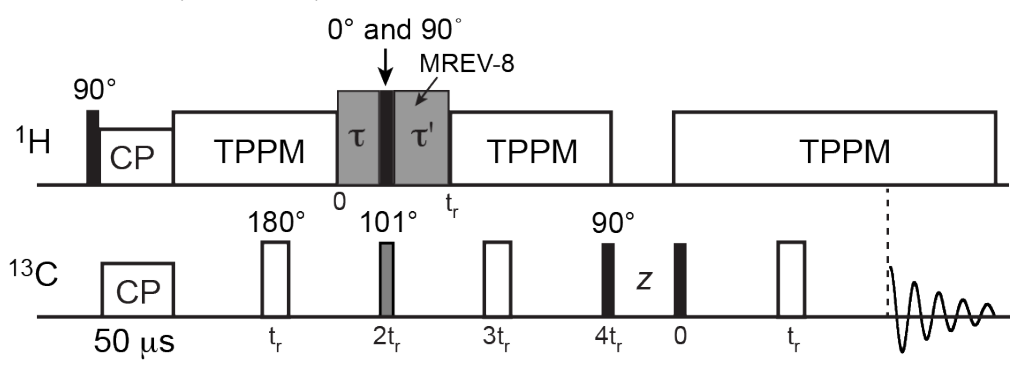

Fig. S45. ${ }^{13} \mathrm{C}$ SSNMR pulse sequences. A, Multi-CP sequence. Five CP periods alternated with ${ }^{1} \mathrm{H}$ spin-lattice relaxation periods $\left(\mathrm{t}_{\mathrm{z}}\right)$ to give quantitative ${ }^{13} \mathrm{C}$ spectra. The CP contact time was $330 \mu \mathrm{s}$ and the $t_{z}$ period was $1.0 \mathrm{~s}$. These values were optimized using the model tripeptide, formyl-MLF, by comparing its multi-CP spectrum with a quantitative direct polarization spectrum measured with a recycle delay of $35 \mathrm{~s}$. $B$, Gated-decoupling multi-CP sequence, where ${ }^{1} \mathrm{H}-{ }^{13} \mathrm{C}$ dipolar coupling during the window $t_{\mathrm{CH}}$ suppressed the signals of protonated carbons and selected the signals of quaternary carbons. $\mathbf{C}, \mathrm{CH}_{2}$ selection sequence. MREV-8 was used for ${ }^{1} \mathrm{H}$ homonuclear decoupling, and $t$ and t' were $35 \mu \mathrm{s}$ and $123 \mu \mathrm{s}$, respectively, which were optimized using L-Leucine as the model compound. 
A

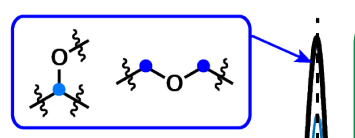

Residue (R) after thioacidolysis

Multi-CP spectrum

Deconvoluted peaks

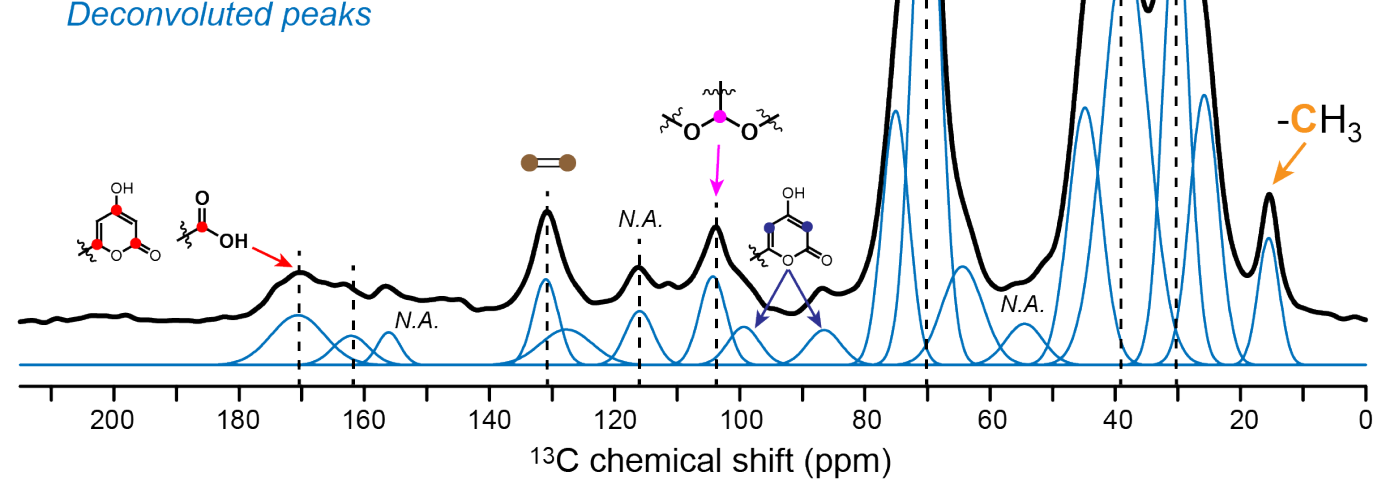

B

Fig. S46. ${ }^{13} \mathrm{C}$ solid-state NMR spectrum and proposed structure of residue (R) after thioacidolysis. A, Multi-CP spectrum of $\mathbf{R}$, measured on the $400 \mathrm{MHz}$ spectrometer at $296 \mathrm{~K}$ under $13 \mathrm{kHz}$ MAS. Spectral deconvolution gave the relative number of carbons for each peak. B, Proposed structure of $\mathbf{R}$. The functional group $\mathbf{R}^{\prime}$ is proposed to be glycerol $\left(\mathrm{C}_{3} \mathrm{H}_{8} \mathrm{O}_{3}\right)$ or glycerol like moiety, and some of these groups were removed and replaced with ethylsulfanyl groups during thioacidolysis. 
A Gated decoupling

Untreated sporopollenin

Multi-CP

Gated decoupled multi-CP

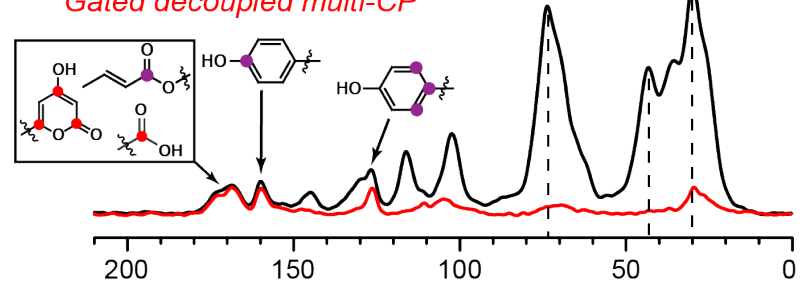

Residue (R) after thioacidolysis

Multi-CP

Gated decoupled multi-CP

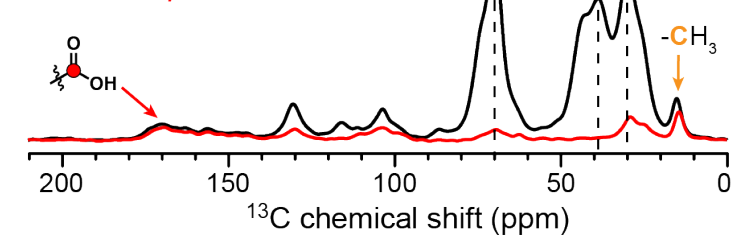

B $\mathrm{CH}_{2}$ selection

Untreated sporopollenin

$C P$

$\mathrm{CH}_{2}$ selected $\mathrm{CP}$

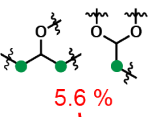

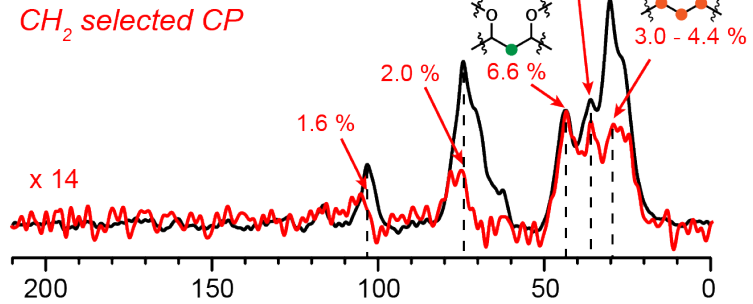

Leucine $\quad \mathrm{C} \delta\left(\mathrm{CH}_{3}\right)$

$\mathrm{CP}$
$\mathrm{CH}_{2}$ selected $\mathrm{CP}$

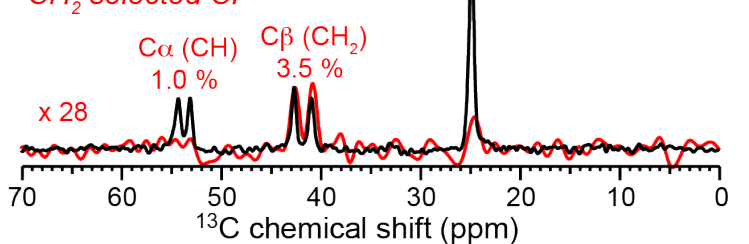

Fig. S47. Spectrally edited ${ }^{13} \mathrm{C}$ solid-state NMR spectra of sporopollenin and residue (R). A, Comparison between regular multi-CP and gated ${ }^{1} \mathrm{H}$-decoupled multiCP spectra. The latter suppresses the signals of protonated carbons. B, Comparison of regular single-CP spectrum and $\mathrm{CH}_{2}$-selected single-step $\mathrm{CP}$ spectrum. The non- $\mathrm{CH}_{2}$ signals are suppressed to $1-2 \%$ of its original intensity, as shown by the spectra of unlabeled L-Leucine. 


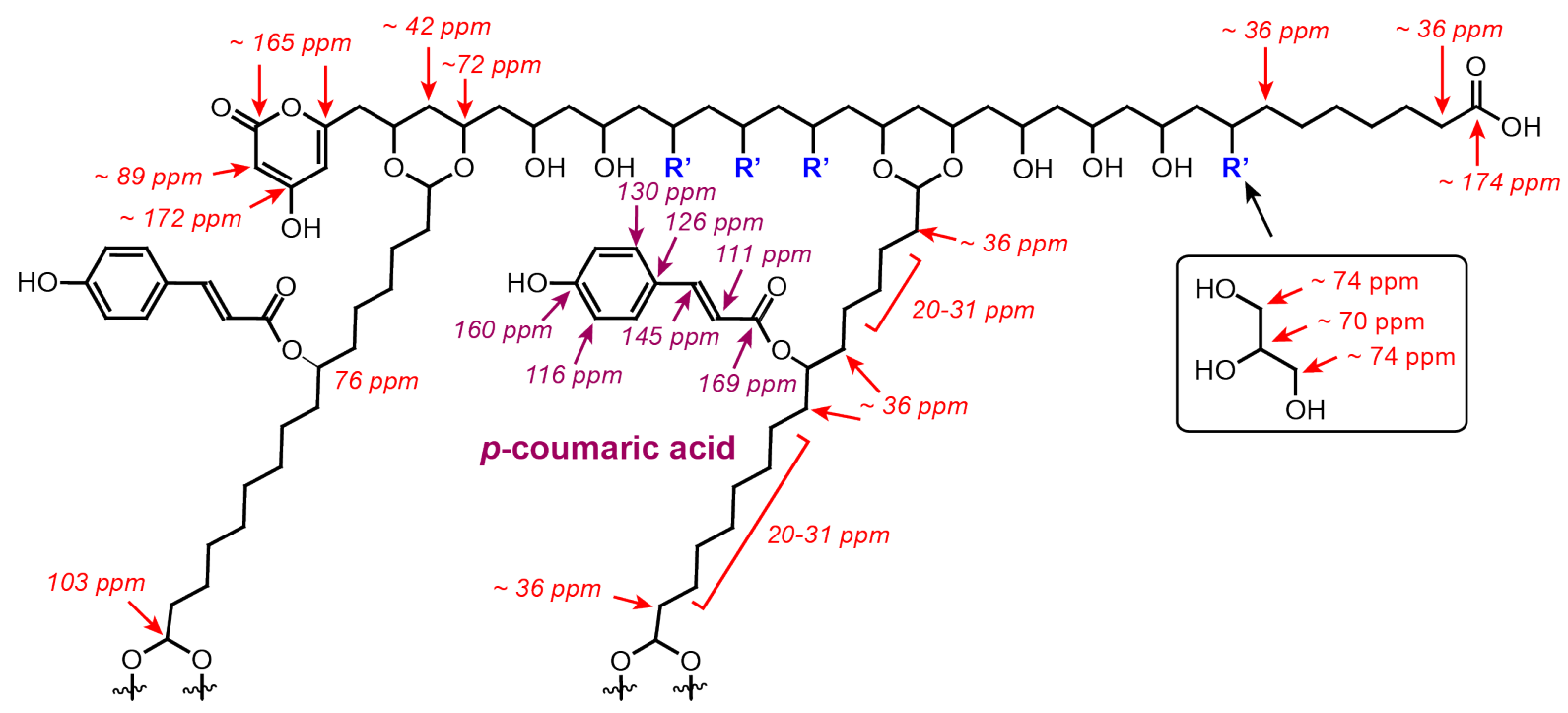

Fig. S48. Approximate ${ }^{13} \mathrm{C}$ chemical shifts obtained from ChemDraw and from measured spectra for the proposed structure of pine sporopollenin. For simplicity the second backbone is not shown. 


\section{Supplementary Tables}

Table S1. Conditions for ${ }^{13} \mathrm{C}$ multi-CP solid-state NMR experiments on untreated and treated sporopollenin samples.

\begin{tabular}{|c|c|c|c|c|}
\hline Sample & Amount & $\begin{array}{c}{ }^{1} \mathrm{H} \text { Larmor } \\
\text { frequency and } \\
\text { MAS }\end{array}$ & $\begin{array}{c}\text { Multi-CP } \\
\text { conditions }\end{array}$ & $\begin{array}{l}\text { Number of } \\
\text { scans }\end{array}$ \\
\hline untreated sporopollenin & $48 \mathrm{mg}$ & $400 \mathrm{MHz}$ & \multirow{2}{*}{$\begin{array}{l}\mathrm{t}_{\mathrm{z}}=4 \times 1 \mathrm{~s} \\
\text { total } \mathrm{CP} \text { contact } \\
\text { time }=0.33 \mathrm{~ms} \times 5\end{array}$} & 9,216 \\
\hline $\begin{array}{l}\text { Residue after } \\
\text { thioacidolysis }\end{array}$ & $52 \mathrm{mg}$ & $13 \mathrm{kHz}$ MAS & & 3,278 \\
\hline untreated sporopollenin & $17 \mathrm{mg}$ & \multirow{4}{*}{$\begin{array}{c}800 \mathrm{MHz} \\
14 \mathrm{kHz} \text { MAS }\end{array}$} & \multirow{4}{*}{$\begin{array}{l}\mathrm{t}_{\mathrm{z}}=4 \times 0.4 \mathrm{~s} \\
\text { total CP contact } \\
\text { time }=0.33 \mathrm{~ms} \times 5\end{array}$} & 9,728 \\
\hline $\begin{array}{l}\text { Residue after } \\
\text { thioacidolysis }\end{array}$ & $19 \mathrm{mg}$ & & & 20,480 \\
\hline $\mathrm{Cu}(\mathrm{OTf})_{2}$ treated & $22 \mathrm{mg}$ & & & 17,408 \\
\hline $\mathrm{NaBH}_{4}$ treated & $19 \mathrm{mg}$ & & & 22,528 \\
\hline
\end{tabular}


Table S2. Quantification of carbon numbers in untreated sporopollenin from ${ }^{13} \mathrm{C}$ solid-state NMR spectra. The ${ }^{13} \mathrm{C}$ chemical shifts, percent integrated intensity of each peak, ratio of centerband intensity to total intensity under $13 \mathrm{kHz}$ MAS on the $400 \mathrm{MHz}$ spectrometer, integrated intensities after correcting for sideband intensity loss, and the final relative carbon numbers, are shown. The intensity ratios of the multi-CP spectrum to the quantitative spectrum of formyl-MLF are also given and are used to calculate the relative carbon numbers. The intensity of the resolved $160-p p m$ peak $\left(^{*}\right)$ is taken to represent 2 carbons, which correspond to two sets of $p$-coumaric acids.

\begin{tabular}{|c|c|c|c|c|c|c|c|}
\hline $\begin{array}{c}{ }^{13} \mathrm{C} \\
\text { chemical } \\
\text { shifts } \\
\text { (ppm) }\end{array}$ & $\begin{array}{l}\text { Integrated } \\
\text { intensity } \\
(\%)\end{array}$ & $\begin{array}{l}\text { Centerband } \\
\text { / Total } \\
\text { intensity } \\
\text { ratio }\end{array}$ & $\begin{array}{l}\text { Multi-CP/ } \\
\text { quantitative } \\
\text { intensity } \\
\text { ratio }\end{array}$ & $\begin{array}{c}\text { Corrected } \\
\text { integrated } \\
\text { intensity } \\
(\%)\end{array}$ & $\begin{array}{l}\text { No. of } \\
\text { carbons }\end{array}$ & Assignment & $\begin{array}{l}\text { No. } \\
\text { carbons } \\
\text { per } \\
\text { group }\end{array}$ \\
\hline 173.0 & 1.33 & 0.90 & 0.80 & 1.85 & $1 \& 1$ & $\begin{array}{l}\text { Ester \& a- } \\
\text { pyrone }\end{array}$ & 5 \\
\hline 96.4 & 1.06 & 1.00 & 1.00 & 1.06 & 1 & a-pyrone & \\
\hline 87.5 & 1.18 & 1.00 & 1.00 & 1.18 & 1 & a-pyrone & \\
\hline 168.4 & 2.23 & 0.90 & 0.80 & 3.10 & $1 \& 2$ & $\begin{array}{l}\text { a-pyrone \& } \\
\text { p-coumaric }\end{array}$ & 18 \\
\hline $160.0^{*}$ & 1.50 & 0.90 & 0.75 & 2.22 & 2 & p-coumaric & \\
\hline 145.3 & 1.68 & 0.90 & 0.75 & 2.49 & 2 & p-coumaric & \\
\hline 130.0 & 3.05 & 0.87 & 0.75 & 4.67 & 4 & p-coumaric & \\
\hline 126.4 & 1.28 & 0.87 & 0.75 & 1.96 & 2 & p-coumaric & \\
\hline 116.5 & 3.13 & 0.89 & 0.75 & 4.69 & 4 & p-coumaric & \\
\hline 111.4 & 1.68 & 0.89 & 0.75 & 2.52 & 2 & p-coumaric & \\
\hline 102.8 & 5.30 & 1.00 & 1.00 & 5.30 & $4-5$ & Acetal & $4-5$ \\
\hline 74.3 & 8.61 & 1.00 & 1.00 & 8.61 & 8 & O-bearing & 26 \\
\hline 69.8 & 2.26 & 1.00 & 1.00 & 2.26 & 2 & & \\
\hline 71.0 & 16.58 & 1.00 & 1.00 & 16.58 & 15 & & \\
\hline 64.0 & 1.01 & 1.00 & 1.00 & 1.01 & 1 & & \\
\hline 43.8 & 13.23 & 1.00 & 1.00 & 13.23 & 12 & $\mathrm{C}-(\mathrm{C}-\mathrm{O})$ & 21 \\
\hline 36.4 & 9.97 & 1.00 & 1.00 & 9.97 & 9 & $\mathrm{C}-(\mathrm{C}-\mathrm{O})$ & \\
\hline 30.9 & 10.79 & 1.00 & 1.00 & 10.79 & 10 & $\mathrm{CH}_{2}$ & 21 \\
\hline 26.3 & 11.92 & 1.00 & 1.00 & 11.92 & 11 & & \\
\hline 153.6 & 0.80 & 0.90 & 0.75 & 1.19 & 1 & - & \\
\hline 53.2 & 1.47 & 1.00 & 1.00 & 1.47 & 1 & - & \\
\hline
\end{tabular}


Table S3. Comparison of the carbon numbers for each major functional group determined from ${ }^{13} \mathrm{C}$ solid-state NMR spectra and the carbon numbers in the proposed structure of pine sporopollenin.

\begin{tabular}{l|lll}
\hline $\begin{array}{l}{ }^{13} \mathrm{C} \quad \text { chemical } \\
\text { shift ranges }\end{array}$ & Functional groups & $\begin{array}{c}\text { Assigned No. of } \\
\text { carbons in } 2 \text { units }\end{array}$ & $\begin{array}{c}\text { No. of carbons in the } \\
\text { proposed structure }\end{array}$ \\
\hline $\begin{array}{l}173,168, \\
96-87 \mathrm{ppm}\end{array}$ & Ester \& a-pyrone & $5 \times 2=10$ & 12 \\
$168-111 \mathrm{ppm}$ & p-coumaric acid & $18 \times 2=36$ & 36 \\
$103 \mathrm{ppm}$ & Acetal & $4-5 \times 2=8-10$ & 8 \\
$74-63 \mathrm{ppm}$ & O-bearing & $26 \times 2=52$ & 54 \\
$44-36 \mathrm{ppm}$ & C-(CO) & $21 \times 2=42$ & 46 \\
$31-26 \mathrm{ppm}$ & Aliphatic $\mathrm{CH}_{2}$ & $21 \times 2=42$ & 44 \\
& Unassigned & $2 \times 2=4$ & 200 \\
\hline
\end{tabular}


Table S4. Quantification of carbon numbers in insoluble residue $(\mathbf{R})$ after thioacidolysis from ${ }^{13} \mathrm{C}$ NMR spectra. The ${ }^{13} \mathrm{C}$ chemical shifts, percent integrated intensity of each peak, ratio of centerband intensity to total intensity under $13 \mathrm{kHz}$ MAS on a $400 \mathrm{MHz}$ spectrometer, integrated intensities after correcting for sideband intensity loss, and the final relative carbon numbers, are shown. The intensity ratios of the multi-CP spectrum to the quantitative spectrum of formyl-MLF are also shown and are used to calculate the relative carbon numbers. The integrated intensities of the resolved 131-ppm and 128-ppm peaks $\left(^{*}\right)$ are taken to represent 2 carbons, which correspond to two sets of alkene groups.

\begin{tabular}{|c|c|c|c|c|c|c|c|}
\hline $\begin{array}{l}{ }^{13} \mathrm{C} \\
\text { chemical } \\
\text { shifts } \\
\text { (ppm) }\end{array}$ & $\begin{array}{l}\text { Integrated } \\
\text { intensity } \\
(\%)\end{array}$ & $\begin{array}{l}\text { Centerband } \\
\text { / Total } \\
\text { intensity } \\
\text { ratio }\end{array}$ & $\begin{array}{l}\text { Multi-CP/ } \\
\text { quantitative } \\
\text { intensity } \\
\text { ratio }\end{array}$ & $\begin{array}{c}\text { Corrected } \\
\text { integrated } \\
\text { intensity } \\
(\%)\end{array}$ & $\begin{array}{c}\text { No. of } \\
\text { carbons }\end{array}$ & Assignment & $\begin{array}{l}\text { No. } \\
\text { carbons } \\
\text { per } \\
\text { group }\end{array}$ \\
\hline 170.6 & 2.84 & 0.90 & 0.80 & 3.94 & $2-3$ & $\begin{array}{c}\text { Ester \& a- } \\
\text { pyrone }\end{array}$ & $5-6$ \\
\hline 162.1 & 1.12 & 0.90 & 0.80 & 1.56 & 1 & a-pyrone & \\
\hline 99.3 & 1.27 & 1.00 & 1.00 & 1.27 & 1 & a-pyrone & \\
\hline 86.5 & 1.25 & 1.00 & 1.00 & 1.25 & 1 & a-pyrone & \\
\hline $131^{*}$ & 2.29 & 0.87 & 0.75 & 3.51 & 2 & Alkene & 4 \\
\hline $127.7^{*}$ & 1.96 & 0.87 & 0.75 & 3.00 & 2 & Alkene & \\
\hline 104.2 & 2.51 & 1.00 & 1.00 & 2.51 & 2 & Acetal & 2 \\
\hline 75.1 & 7.2 & 1.00 & 1.00 & 7.20 & 5 & & \\
\hline 70.2 & 16.94 & 1.00 & 1.00 & 16.94 & 11 & O-bearing & 19 \\
\hline 64.4 & 4.29 & 1.00 & 1.00 & 4.29 & 3 & & \\
\hline 44.85 & 9.03 & 1.00 & 1.00 & 9.03 & 6 & $\mathrm{C}-(\mathrm{C}-\mathrm{O})$ & 19 \\
\hline 38.35 & 20.06 & 1.00 & 1.00 & 20.06 & 13 & $\mathrm{C}-(\mathrm{C}-\mathrm{O})$ & \\
\hline 30.3 & 12.78 & 1.00 & 1.00 & 12.78 & 9 & $\mathrm{CH}_{2}$ & 16 \\
\hline 25.8 & 8.26 & 1.00 & 1.00 & 8.26 & 5 & $\mathrm{CH}_{2}$ & \\
\hline 15.5 & 2.88 & 1.00 & 1.00 & 2.88 & 2 & $\mathrm{CH}_{3}$ & \\
\hline 156.1 & 0.79 & 0.90 & 0.75 & 1.17 & 1 & - & \\
\hline 146.5 & 1.26 & 0.90 & 0.75 & 1.87 & 1 & - & \\
\hline 116 & 1.64 & 0.89 & 0.75 & 2.46 & $1-2$ & - & \\
\hline 110.9 & 0.91 & 0.89 & 0.75 & 1.36 & 1 & - & \\
\hline 54.55 & 1.65 & 1.00 & 1.00 & 1.65 & 1 & - & \\
\hline
\end{tabular}


Table S5. Comparison of the carbon numbers for each major functional group determined from ${ }^{13} \mathrm{C}$ solid-state NMR spectra and the carbon numbers in the proposed residue $\mathbf{R}$ structure.

\begin{tabular}{l|lll}
\hline $\begin{array}{l}{ }^{13} \mathrm{C} \quad \text { chemical } \\
\text { shift ranges }\end{array}$ & Functional groups & $\begin{array}{l}\text { Assigned No. } \\
\text { carbons in } 2 \text { units }\end{array}$ & $\begin{array}{c}\text { of } \\
\text { the of carbons in } \\
\text { structure }\end{array}$ \\
\hline $\begin{array}{l}171,162, \\
99-86 \mathrm{ppm}\end{array}$ & Ester \& a-pyrone & $5-6 \times 2=10-12$ & 12 \\
$131,128 \mathrm{ppm}$ & Alkene & $4 \times 2=8$ & 8 \\
$104 \mathrm{ppm}$ & Acetal & $2 \times 2=4$ & 4 \\
$75-64 \mathrm{ppm}$ & O-bearing & $19 \times 2=38$ & 38 \\
$44-36 \mathrm{ppm}$ & C-(CO) & $19 \times 2=38$ & 38 \\
$31-26 \mathrm{ppm}$ & Aliphatic $\mathrm{CH}_{2}$ & $14 \times 2=28$ & 30 \\
$16 \mathrm{ppm}$ & Aliphatic $\mathrm{CH}_{3}$ & $2 \times 2=4$ & 4 \\
& Unassigned & $5-6 \times 2=10-12$ & 134 \\
\hline
\end{tabular}




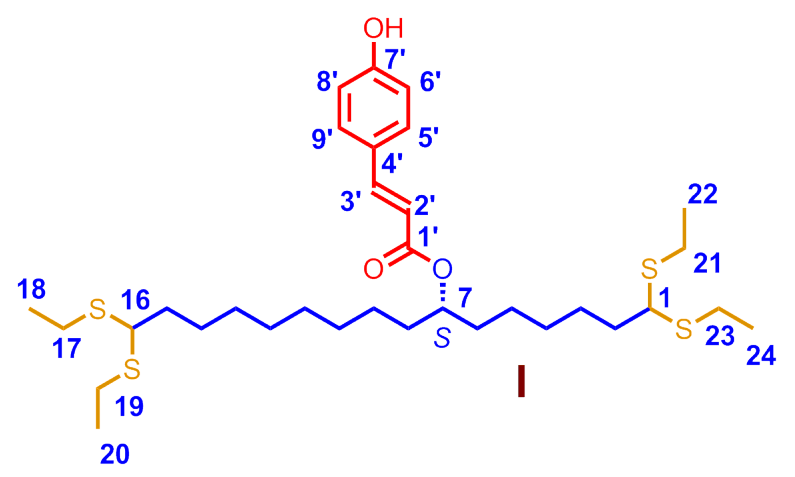

$\left.{ }^{1} \mathrm{H} \mathrm{NMR}\left(\mathrm{CDCl}_{3}, 400 \mathrm{MHz}\right), \delta 7.59(1 \mathrm{H}, \mathrm{d}, J=16.0 \mathrm{~Hz}, \mathrm{H}-3)^{\prime}\right), 7.42(2 \mathrm{H}, \mathrm{d}, J=8.4 \mathrm{~Hz}, \mathrm{H}-$ 5',9'), $6.82\left(2 \mathrm{H}, \mathrm{d}, J=8.4 \mathrm{~Hz}, \mathrm{H}-6^{\prime}, 8^{\prime}\right), 6.28\left(1 \mathrm{H}, \mathrm{d}, J=16.0 \mathrm{~Hz}, \mathrm{H}-2^{\prime}\right), 4.97(1 \mathrm{H}, \mathrm{t}, J=$ $5.6 \mathrm{~Hz}, \mathrm{H}-7), 3.74(2 \mathrm{H}, \mathrm{t}, \mathrm{J}=6.8 \mathrm{~Hz}, \mathrm{H}-1,16), 2.60(8 \mathrm{H}, \mathrm{m}, \mathrm{H}-17,19,21,23), 1.76(4 \mathrm{H}$, $\mathrm{m}, \mathrm{H}-2,15), 1.53(12 \mathrm{H}, \mathrm{m}, \mathrm{H}-3,5,6,8,9,14), 1.29(10 \mathrm{H}, \mathrm{m}, \mathrm{H}-4,10,11,12,13), 1.23$ $(12 \mathrm{H}, \mathrm{t}, J=7.2 \mathrm{~Hz}, \mathrm{H}-18,20,22,24)$.

${ }^{13} \mathrm{C} \mathrm{NMR}\left(\mathrm{CDCl}_{3}, 100 \mathrm{MHz}\right), \delta 167.2$ (C-1'), 157.4 (C-7'), 144.0 (C-3'), 129.9 (C-5', 9'), 127.5 (C-4'), 116.3 (C-2'), 115.8 (C-6', 8'), 74.2 (C-7), 51.4, 51.5 (C-1, 16), 36.0, 36.1 (C-2, 15), 34.2, 34.3 (C-6, 8), 29.1, 29.2, 29.4, 29.5, 29.6 (C-4, 10, 11, 12, 13), 27.4, 27.5 (C-3, 14), 25.2, 25.4 (C-5, 9), 24.1 (C-17, 19, 21, 23), 14.5 (C-18, 20, 22, 24). 

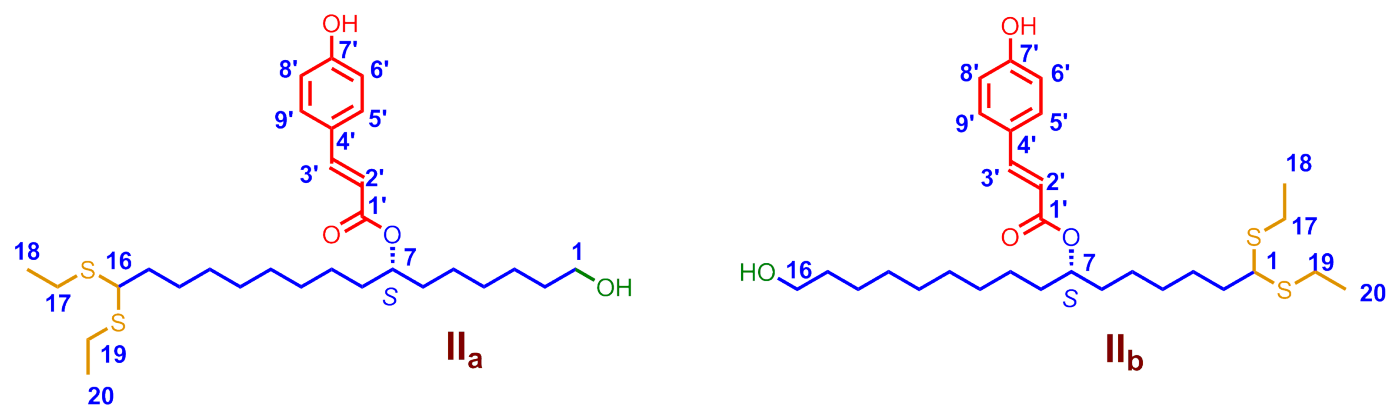

${ }^{1} \mathrm{H} \mathrm{NMR}\left(\mathrm{II}_{\mathrm{a}}, \mathrm{CDCl}_{3}, 400 \mathrm{MHz}\right), \delta 7.61(1 \mathrm{H}, \mathrm{d}, J=16.0 \mathrm{~Hz}, \mathrm{H}-3$ '), $7.43(2 \mathrm{H}, \mathrm{d}, J=8.0 \mathrm{~Hz}$, H-5', 9'), $6.84\left(2 \mathrm{H}, \mathrm{d}, J=8.0 \mathrm{~Hz}, \mathrm{H}-6^{\prime}, 8^{\prime}\right), 6.30\left(1 \mathrm{H}, \mathrm{d}, J=16.0 \mathrm{~Hz}, \mathrm{H}-2^{\prime}\right), 4.99(1 \mathrm{H}, \mathrm{t}, J=$ $5.6 \mathrm{~Hz}, \mathrm{H}-7), 3.76(1 \mathrm{H}, \mathrm{t}, J=6.8 \mathrm{~Hz}, \mathrm{H}-16), 3.63(2 \mathrm{H}, \mathrm{m}, \mathrm{H}-1), 2.63(4 \mathrm{H}, \mathrm{m}, \mathrm{H}-17,19)$, $1.78(2 \mathrm{H}, \mathrm{m}, \mathrm{H}-15), 1.56(10 \mathrm{H}, \mathrm{m}, \mathrm{H}-5,6,8,9,14), 1.31(14 \mathrm{H}, \mathrm{m}, \mathrm{H}-2,3,4,10,11,12$, 13), $1.25(6 \mathrm{H}, \mathrm{t}, J=7.2 \mathrm{~Hz}, \mathrm{H}-18,20)$.

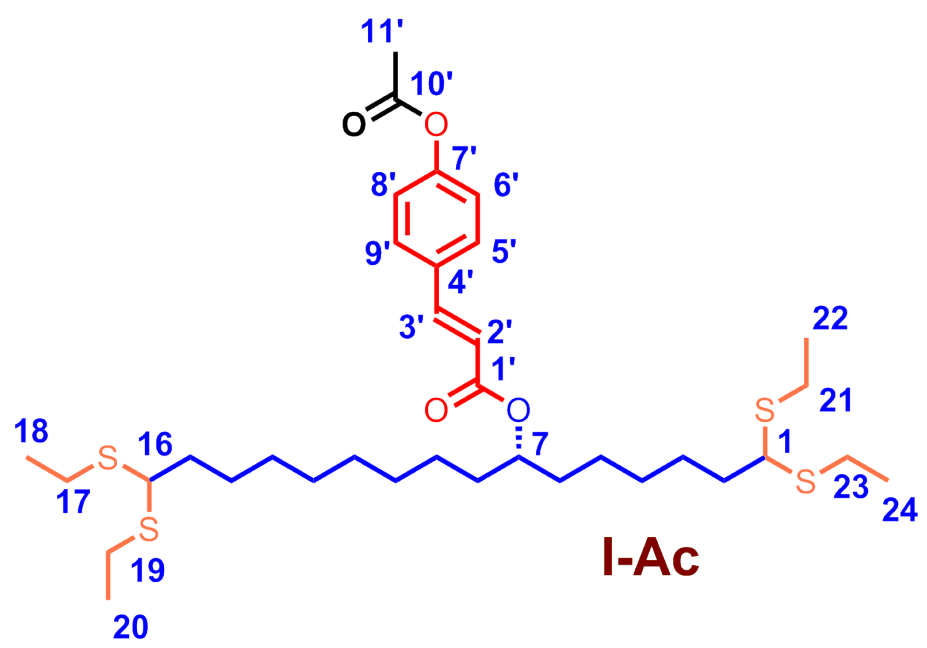

${ }^{1} \mathrm{H} \mathrm{NMR}\left(\mathrm{CDCl}_{3}, 400 \mathrm{MHz}\right), \delta 7.64(1 \mathrm{H}, \mathrm{d}, J=16.0 \mathrm{~Hz}, \mathrm{H}-3$ '), $7.54(2 \mathrm{H}, \mathrm{d}, J=8.4 \mathrm{~Hz}, \mathrm{H}-$ 5', 9'), $7.12\left(2 \mathrm{H}, \mathrm{d}, J=8.4 \mathrm{~Hz}, \mathrm{H}-6^{\prime}, 8^{\prime}\right), 6.38(1 \mathrm{H}, \mathrm{d}, J=16.0 \mathrm{~Hz}, \mathrm{H}-2$ '), $4.99(1 \mathrm{H}, \mathrm{m}, \mathrm{H}-$ 7), $3.76(2 \mathrm{H}, \mathrm{t}, J=6.8 \mathrm{~Hz}, \mathrm{H}-1,16), 2.61(8 \mathrm{H}, \mathrm{m}, \mathrm{H}-17,19,21,23), 2.31\left(3 \mathrm{H}, \mathrm{s}, \mathrm{H}-11^{\prime}\right)$, $1.77(4 \mathrm{H}, \mathrm{m}, \mathrm{H}-2,15), 1.55(12 \mathrm{H}, \mathrm{m}, \mathrm{H}-3,5,6,8,9,14), 1.26(10 \mathrm{H}, \mathrm{m}, \mathrm{H}-4,10,11,12$, 13), $1.23(12 \mathrm{H}, \mathrm{t}, \mathrm{J}=7.2 \mathrm{~Hz}, \mathrm{H}-18,20,22,24)$.

${ }^{13} \mathrm{C}$ NMR ( $\left.\mathrm{CDCl}_{3}, 100 \mathrm{MHz}\right), \delta 169.3$ (C-10'), 166.9 (C-1'), 152.1 (C-7'), 143.4 (C-3'), 132.4 (C-4'), 129.3 (C-5', 9'), 122.2 (C-6', 8'), 119.0 (C-2'), 74.6 (C-7), 51.6, 51.5 (C-1, 16), 36.3, 36.2 (C-2, 15), 34.4, 34.3 (C-6, 8), 29.2, 29.3, 29.5, 29.6, 29.7 (C-4, 10, 11, 12, 13), 27.6, 27.5 (C-3, 14), 25.5, 25.3 (C-5, 9), 24.2 (C-17, 19, 21, 23), 14.7 (C-18, 20, $22,24)$. 

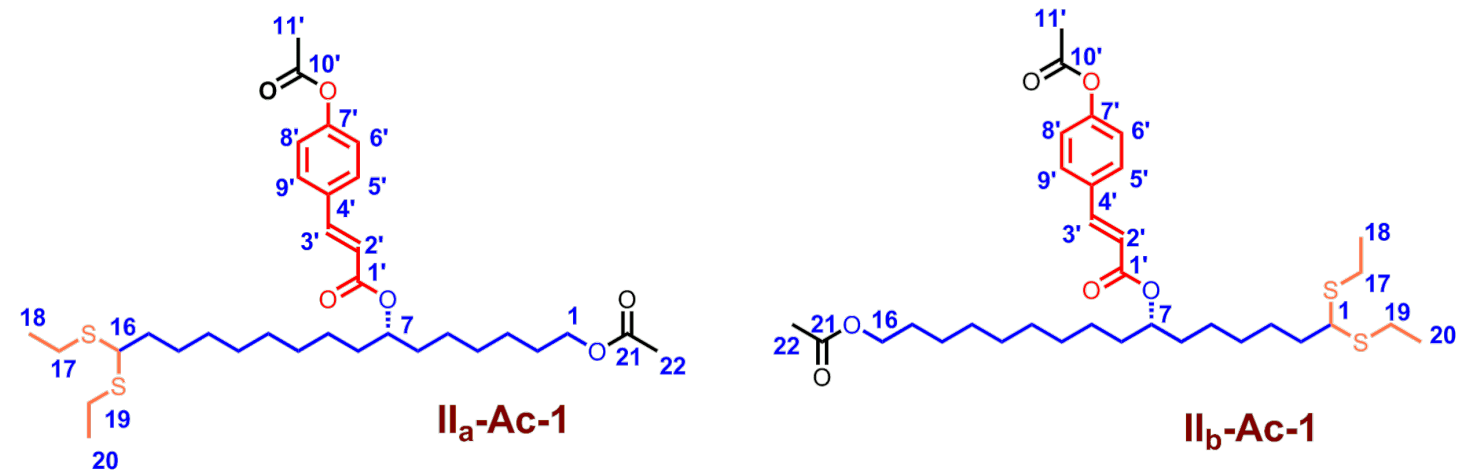

${ }^{1} \mathrm{H}$ NMR (Il $\left.\mathrm{a}-\mathrm{Ac}-1, \mathrm{CDCl}_{3}, 400 \mathrm{MHz}\right), \delta 7.65\left(1 \mathrm{H}, \mathrm{d}, J=16.0 \mathrm{~Hz}, \mathrm{H}-3^{\prime}\right), 7.55(2 \mathrm{H}, \mathrm{d}, J=$ $\left.8.4 \mathrm{~Hz}, \mathrm{H}-5^{\prime}, 9^{\prime}\right), 7.12\left(2 \mathrm{H}, \mathrm{d}, J=8.4 \mathrm{~Hz}, \mathrm{H}-6^{\prime}, 8^{\prime}\right), 6.39\left(1 \mathrm{H}, \mathrm{d}, J=16.0 \mathrm{~Hz}, \mathrm{H}-2^{\prime}\right), 5.00$ $(1 \mathrm{H}, \mathrm{t}, J=5.6 \mathrm{~Hz}, \mathrm{H}-7), 4.04(2 \mathrm{H}, \mathrm{t}, J=6.8 \mathrm{~Hz}, \mathrm{H}-1), 3.76(1 \mathrm{H}, \mathrm{t}, J=6.8 \mathrm{~Hz}, \mathrm{H}-16), 2.63$ $(4 \mathrm{H}, \mathrm{m}, \mathrm{H}-17,19), 2.31\left(3 \mathrm{H}, \mathrm{s}, \mathrm{H}-11^{\prime}\right), 2.03(3 \mathrm{H}, \mathrm{s}, \mathrm{H}-22), 1.78(2 \mathrm{H}, \mathrm{m}, \mathrm{H}-15), 1.55$ $(10 \mathrm{H}, \mathrm{m}, \mathrm{H}-5,6,8,9,14), 1.26(14 \mathrm{H}, \mathrm{m}, \mathrm{H}-2,3,4,10,11,12,13), 1.25(6 \mathrm{H}, \mathrm{t}, \mathrm{J}=7.2$ $\mathrm{Hz}, \mathrm{H}-18,20)$.

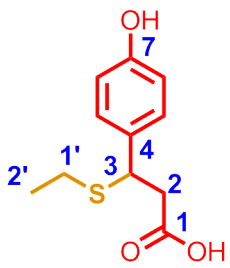

VII

${ }^{1} \mathrm{H}$ NMR $\left(\mathrm{CDCl}_{3}, 400 \mathrm{MHz}\right), \delta 7.13(2 \mathrm{H}, \mathrm{d}, J=8.4 \mathrm{~Hz}, \mathrm{H}-5,9), 6.69(2 \mathrm{H}, \mathrm{d}, J=8.4 \mathrm{~Hz}$, $\mathrm{H}-6,8), 4.14(1 \mathrm{H}, \mathrm{t}, J=7.2 \mathrm{~Hz}, \mathrm{H}-3), 2.73(2 \mathrm{H}, \mathrm{m}, \mathrm{H}-2), 2.29\left(2 \mathrm{H}, \mathrm{m}, \mathrm{H}-1^{\prime}\right), 1.07(3 \mathrm{H}, \mathrm{t}$, $\left.J=7.2 \mathrm{~Hz}, \mathrm{H}-2{ }^{\prime}\right)$.

${ }^{13} \mathrm{C} \mathrm{NMR}\left(\mathrm{CDCl}_{3}, 100 \mathrm{MHz}\right), \delta 172.2$ (C-1), 156.8 (C-7), 132.2 (C-4), 129.1 (C-5, 9), 115.5 (C-6, 8), 44.3 (C-2), 41.6 (C-3), 24.7 (C-1'), 14.8 (C-2'). 


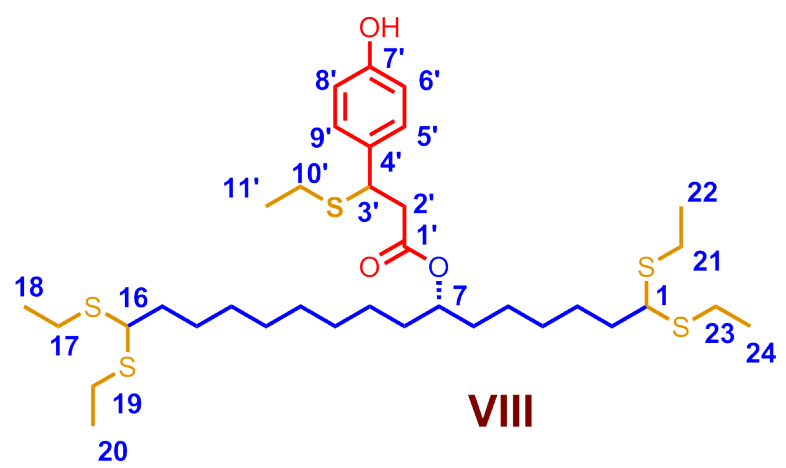

${ }^{1} \mathrm{H}$ NMR $\left(\mathrm{CDCl}_{3}, 400 \mathrm{MHz}\right), \delta 7.18(2 \mathrm{H}, \mathrm{d}, J=8.4 \mathrm{~Hz}, \mathrm{H}-5$ ', 9'), $6.75(2 \mathrm{H}, \mathrm{d}, J=8.4 \mathrm{~Hz}$, H-6', 8'), 4.76 (1H, m, H-7), 4.25 (1H, m, H-3'), $3.77(2 \mathrm{H}, \mathrm{t}, \mathrm{J}=6.8 \mathrm{~Hz}, \mathrm{H}-1,16), 2.84$ (2H, m, H-2'), 2.64 (8H, m, H-17, 19, 21, 23), 2.33 (2H, m, H-10'), 1.76 (4H, m, H-2,15), 1.54-1.31 (8H, m, H-3, 6, 8, 14), $1.26(14 \mathrm{H}, \mathrm{m}, \mathrm{H}-4,5,9,10,11,12,13), 1.25(12 \mathrm{H}, \mathrm{m}$, $\mathrm{H}-18,20,22,24), 1.15\left(3 \mathrm{H}, \mathrm{t}, \mathrm{J}=7.6 \mathrm{~Hz}, \mathrm{H}-11^{\prime}\right)$.

${ }^{13} \mathrm{C}$ NMR $\left(\mathrm{CDCl}_{3}, 100 \mathrm{MHz}\right), \delta 170.8,170.9$ (C-10'), 155.1, 155.2 (C-7'), 133.0, 133.2 (C-4'), 129.0, 129.1 (C-5', 9'), 115.4, 115.5 (C-6', 8'), 74.8, 74.9 (C-7), 51.5, 51.7 (C-1, 16), 44.7, 44.4 (C-2'), 42.0, 41.9 (C-3'), 36.2, 36.1 (C-2, 15), 34.4, 34.2, 34.1 (C-6, 8), 29.6, 29.5, 29.4, 29.4, 29.3, 29.2 (C-4, 10, 11, 12, 13), 27.6, 27.5 (C-3, 14), 25.4, 25.3, 25.2, 25.1 (C-5, 9), 24.4, 24.3, 24.3, 24.2, 24.2 (C-17, 19, 21, 23, 10'), 14.7, 14.6 (C-18, 20, 22, 24), 14.5 (C-11').

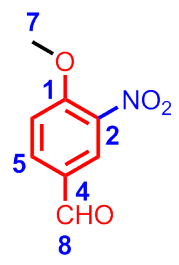

\section{XIV}

${ }^{1} \mathrm{H} \mathrm{NMR}\left(\mathrm{CDCl}_{3}, 400 \mathrm{MHz}\right), \delta 9.95(1 \mathrm{H}, \mathrm{s}, \mathrm{H}-8), 8.42(1 \mathrm{H}, \mathrm{d}, \mathrm{J}=2.0 \mathrm{~Hz}, \mathrm{H}-3), 8.20(1 \mathrm{H}$, dd, J = 8.8, 2.0 Hz, H-5), $7.58(1 \mathrm{H}, \mathrm{d}, J=8.8 \mathrm{~Hz}, \mathrm{H}-6), 4.04(3 \mathrm{H}, \mathrm{s}, \mathrm{H}-7)$.

${ }^{13} \mathrm{C}$ NMR (CDCl $\left.3,100 \mathrm{MHz}\right), \delta 190.5$ (C-8), 156.2 (C-1), 135.0 (C-2), 128.8 (C-5), 126.4 (C-3, 4), 115.0 (C-6), 57.5 (C-7). 


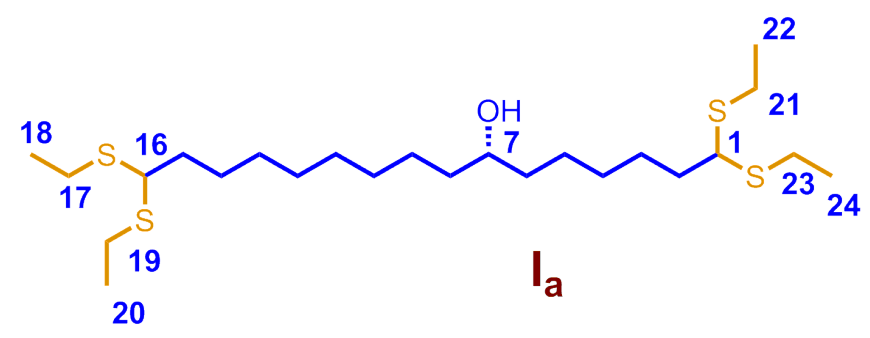

${ }^{1} \mathrm{H} \mathrm{NMR}\left(\mathrm{CDCl}_{3}, 400 \mathrm{MHz}\right), \delta 3.79(2 \mathrm{H}, \mathrm{t}, J=6.8 \mathrm{~Hz}, \mathrm{H}-1,16), 3.57(1 \mathrm{H}, \mathrm{m}, \mathrm{H}-7), 2.62$ $(8 \mathrm{H}, \mathrm{m}, \mathrm{H}-17,19,21,23), 1.78(4 \mathrm{H}, \mathrm{m}, \mathrm{H}-2,15), 1.52(4 \mathrm{H}, \mathrm{m}, \mathrm{H}-3,14), 1.42(4 \mathrm{H}, \mathrm{m}, \mathrm{H}-6$, 8), $1.26(14 \mathrm{H}, \mathrm{m}, \mathrm{H}-4,5,9,10,11,12,13), 1.24(12 \mathrm{H}, \mathrm{t}, \mathrm{J}=7.2 \mathrm{~Hz}, \mathrm{H}-18,20,22,24)$.

${ }^{13} \mathrm{C} \mathrm{NMR}\left(\mathrm{CDCl}_{3}, 100 \mathrm{MHz}\right), \delta 72.0$ (C-7), 51.6, 51.5 (C-1, 16), 37.5, 37.6 (C-2, 15), 36.3, 36.2 (C-6, 8), 29.8, 29.6, 29.5, 29.4, 29.3 (C-4, 10, 11, 12, 13), 27.6, 27.5 (C-3, 14), 25.8, 25.6 (C-5, 9), 24.2 (C-17, 19, 21, 23), 14.77 (C-18, 20, 22, 24).

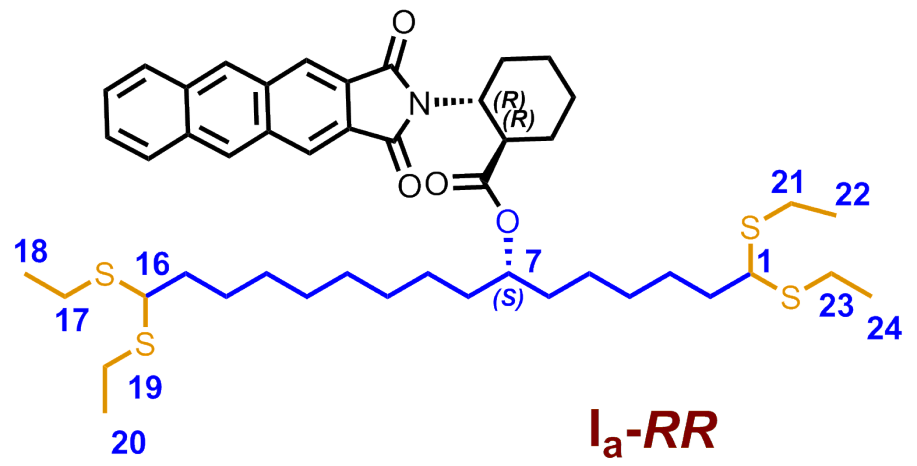

${ }^{1} \mathrm{H} \mathrm{NMR}\left(\mathrm{CDCl}_{3}, 600 \mathrm{MHz}\right), \delta 3.73(1 \mathrm{H}, \mathrm{t}, J=7.2 \mathrm{~Hz}, \mathrm{H}-7), 3.69(1 \mathrm{H}, \mathrm{t}, J=6.6 \mathrm{~Hz}, \mathrm{H}-$ 16), $3.61(1 \mathrm{H}, \mathrm{t}, J=6.6 \mathrm{~Hz}, \mathrm{H}-1), 2.62(8 \mathrm{H}, \mathrm{m}, \mathrm{H}-17,19,21,23), 1.86(4 \mathrm{H}, \mathrm{m}, \mathrm{H}-2,15)$, $1.62(4 \mathrm{H}, \mathrm{m}, \mathrm{H}-3,14), 1.33(4 \mathrm{H}, \mathrm{m}, \mathrm{H}-6,8), 1.27(14 \mathrm{H}, \mathrm{m}, \mathrm{H}-4,5,9,10,11,12,13)$, $1.21(6 \mathrm{H}, \mathrm{t}, J=7.8 \mathrm{~Hz}, \mathrm{H}-18,20), 1.20(6 \mathrm{H}, \mathrm{t}, J=7.8 \mathrm{~Hz}, \mathrm{H}-22,24)$. 


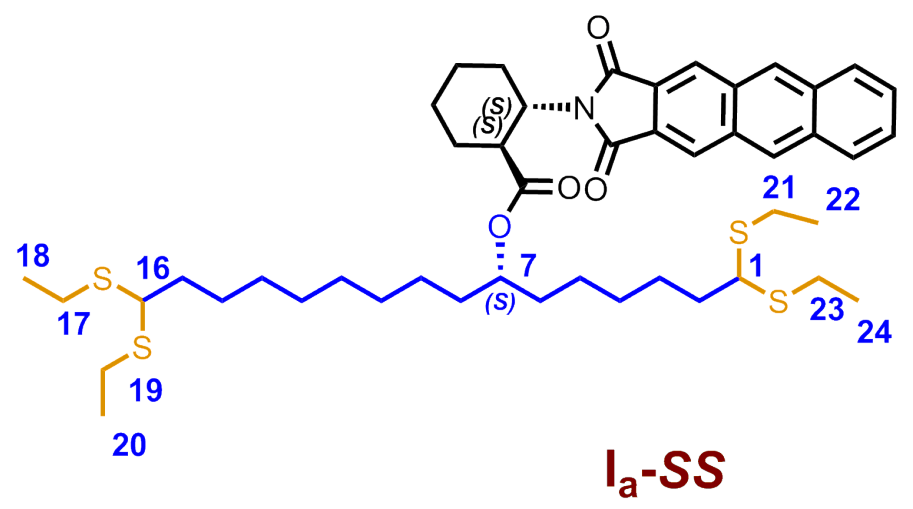

${ }^{1} \mathrm{H}$ NMR $\left(\mathrm{CDCl}_{3}, 600 \mathrm{MHz}\right), \delta 3.72(1 \mathrm{H}, \mathrm{t}, J=6.6 \mathrm{~Hz}, \mathrm{H}-7), 3.71(1 \mathrm{H}, \mathrm{t}, J=7.2 \mathrm{~Hz}, \mathrm{H}-$ 16), $3.52(1 \mathrm{H}, \mathrm{t}, J=7.2 \mathrm{~Hz}, \mathrm{H}-1), 2.56(8 \mathrm{H}, \mathrm{m}, \mathrm{H}-17,19,21,23), 1.87(4 \mathrm{H}, \mathrm{m}, \mathrm{H}-2,15)$, $1.67(4 \mathrm{H}, \mathrm{m}, \mathrm{H}-3,14), 1.47(4 \mathrm{H}, \mathrm{m}, \mathrm{H}-6,8), 1.25(14 \mathrm{H}, \mathrm{m}, \mathrm{H}-4,5,9,10,11,12,13)$, $1.19(6 \mathrm{H}, \mathrm{t}, \mathrm{J}=7.2 \mathrm{~Hz}, \mathrm{H}-18,20), 1.18(6 \mathrm{H}, \mathrm{t}, \mathrm{J}=7.2 \mathrm{~Hz}, \mathrm{H}-22,24)$. 


\section{Supplementary References}

1. Shaw, G. \& Yeadon, A. Chemical studies on the constitution of some pollen and spore membranes. J. Chem. Soc. Perkin 11, 16-22 (1966).

2. Schulze Osthoff, K. \& Wiermann, R. Phenols as Integrated Compounds of Sporopollenin from Pinus Pollen. J. Plant Physiol. 131, 5-15 (1987).

3. Wehling, K., Niester, C., Boon, J. J., Willemse, M. T. \& Wiermann, R. p-Coumaric acid - a monomer in the sporopollenin skeleton. Planta 179, 376-380 (1989).

4. Gubatz, S., Rittscher, M., Meuter, A., Nagler, A. \& Wiermann, R. Tracer Experiments on Sporopollenin Biosynthesis. Grana 32, 12-17 (1993).

5. Meuter-Gerhards, A., Riegert, S. \& Wiermann, R. Studies on Sporopollenin Biosynthesis in Cucurbita maxima (DUCH.) - II. The Involvement of Aliphatic Metabolism. J. Plant Physiol. 154, 431-436 (1999).

6. Couderchet, M., Schmalfuß, J. \& Böger, P. Incorporation of Oleic Acid into Sporopollenin and Its Inhibition by the Chloroacetamide Herbicide Metazachlor. Pestic. Biochem. Physiol. 55, 189-199 (1996).

7. Ahlers, F., Thom, I., Lambert, J., Kuckuk, R. \& Rolf Wiermann. 1H NMR analysis of sporopollenin from Typha Angustifolia. Phytochemistry 50, 1095-1098 (1999).

8. Ahlers, F., Lambert, J. \& Wiermann, R. Acetylation and silylation of piperidine solubilized sporopollenin from pollen of Typha angustifolia L. Z. Naturforsch. C 58, 807-811 (2003).

9. Kettley, S. J. Novel derivatives of sporopollenin for potential applications in solid phase organic synthesis and drug delivery. (2001).

10. Rolando, C., Monties, B. \& Lapierre, C. Thioacidolysis. in Methods in Lignin Chemistry 334-349 (Springer, Berlin, Heidelberg, 1992).

11. Sawamura, K., Tobimatsu, Y., Kamitakahara, H. \& Takano, T. Lignin Functionalization through Chemical Demethylation: Preparation and Tannin-Like Properties of Demethylated 
Guaiacyl-Type Synthetic Lignins. ACS Sustainable Chemistry \& Engineering 5, 5424-5431 (2017).

12. Thompson, R. S., Jacques, D., Haslam, E. \& Tanner, R. J. N. Plant proanthocyanidins. Part I. Introduction; the isolation, structure, and distribution in nature of plant procyanidins. $J$. Chem. Soc. Perkin 1 0, 1387-1399 (1972).

13. Osman, S. F., Irwin, P., Fett, W. F., O’Connor, J. V. \& Parris, N. Preparation, isolation, and characterization of cutin monomers and oligomers from tomato peels. J. Agric. Food Chem. 47, 799-802 (1999).

14. Lu, F. \& Ralph, J. Non-degradative dissolution and acetylation of ball-milled plant cell walls: high-resolution solution-state NMR. Plant J. 35, 535-544 (2003).

15. Rasouli, M., Ostovar-Ravari, A. \& Shokri-Afra, H. Characterization and improvement of phenol-sulfuric acid microassay for glucose-based glycogen. Eur. Rev. Med. Pharmacol. Sci. 18, 2020-2024 (2014).

16. Zhang, Y.-J., Dayoub, W., Chen, G.-R. \& Lemaire, M. TMDS as a Dual-Purpose Reductant in the Regioselective Ring Cleavage of Hexopyranosyl Acetals to Ethers. Eur. J. Org. Chem. 2012, 1960-1966 (2012).

17. Ohtaki, T., Akasaka, K., Kabuto, C. \& Ohrui, H. Chiral discrimination of secondary alcohols by both 1H-NMR and HPLC after labeling with a chiral derivatization reagent, 2-(2, 3anthracenedicarboximide) cyclohexane carboxylic acid. Chirality 17, (2005).

18. Johnson, R. L. \& Schmidt-Rohr, K. Quantitative solid-state 13C NMR with signal enhancement by multiple cross polarization. J. Magn. Reson. 239, 44-49 (2014).

19. Mao, J. D. \& Schmidt-Rohr, K. Accurate quantification of aromaticity and nonprotonated aromatic carbon fraction in natural organic matter by $13 \mathrm{C}$ solid-state nuclear magnetic resonance. Environ. Sci. Technol. 38, 2680-2684 (2004).

20. Guilford, W. J., Schneider, D. M., Labovitz, J. \& Opella, S. J. High resolution solid state C NMR spectroscopy of sporopollenins from different plant taxa. Plant Physiol. 86, 134-136 
(1988).

21. Mao, J.-D. \& Schmidt-Rohr, K. Methylene spectral editing in solid-state 13C NMR by threespin coherence selection. J. Magn. Reson. 176, 1-6 (2005).

22. Shibuya, T., Funamizu, M. \& Kitahara, Y. Novel p-coumaric acid esters from Pinus densiflora pollen. Phytochemistry 17, 979-981 (1978).

23. Tian, S. et al. Isolation and identification of oligomers from partial degradation of lime fruit cutin. J. Agric. Food Chem. 56, 10318-10325 (2008).

24. Massiot, D. et al. Modelling one- and two-dimensional solid-state NMR spectra. Magn. Reson. Chem. 40, 70-76 (2001).

25. Zhang, Y.-J., Dayoub, W., Chen, G.-R. \& Lemaire, M. Environmentally benign metal triflatecatalyzed reductive cleavage of the C-O bond of acetals to ethers. Green Chem. 13, 2737 (2011). 